DOE/CS/ 20026-01 Vol. 4

Dr.2041 Vol. 4 of 4 Volumes

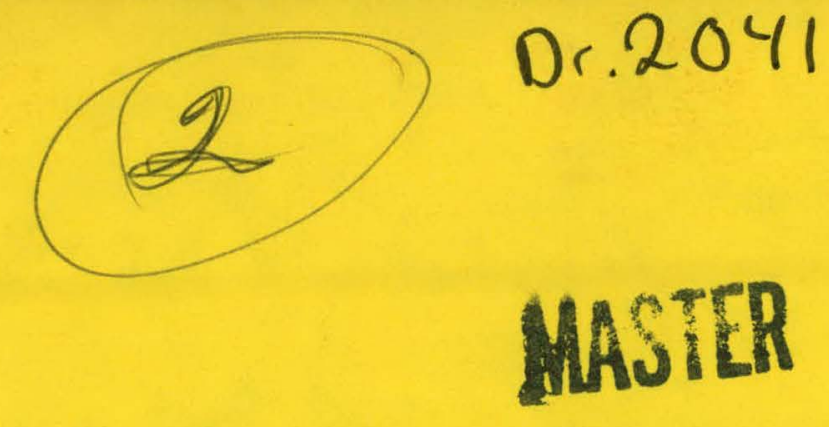

\title{
Systems Analysis for the Development of Small Resource Recovery Systems
}

System Performance Data

Final Report

October 1980

\section{Prepared for:}

\section{U.S. Department of Energy}

Assistant Secretary for Conservation and Solar Energy

Office of Buildings and Community Systems Under Contract No. AC01-77CS 20026 


\section{DISCLAIMER}

This report was prepared as an account of work sponsored by an agency of the United States Government. Neither the United States Government nor any agency Thereof, nor any of their employees, makes any warranty, express or implied, or assumes any legal liability or responsibility for the accuracy, completeness, or usefulness of any information, apparatus, product, or process disclosed, or represents that its use would not infringe privately owned rights. Reference herein to any specific commercial product, process, or service by trade name, trademark, manufacturer, or otherwise does not necessarily constitute or imply its endorsement, recommendation, or favoring by the United States Government or any agency thereof. The views and opinions of authors expressed herein do not necessarily state or reflect those of the United States Government or any agency thereof. 


\section{DISCLAIMER}

Portions of this document may be illegible in electronic image products. Images are produced from the best available original document. 


\section{NOTICE}

This report ivas prepored as an account of work sf onsored by the United States Government. Neither the United States nor the United States Dupartment of Energy. nor sny of their wnoloy ses, mukes any warrarity, xprizs or implied, or saumes any lo jal liablitity or responsibility for the sccuracy, completeness, $c$; vsafulness of any information, spparatus. product, or process dis, osed, or rupresents that its usa would not infringe privately owned i iches. Reference hertin to any specific commercial product, prorses, or service by trade nane, mark, manu factur'yr, or otherwise, does not necessarily constixute or irnply its endorsement, recommon,decion. or favoring by the United Stares Government or any egency $t$ t, grsof. The views and opinions of authore expreused herein do nox ne essarily state or reflece those of the United States Government if any agency thereot.

Copies of these materials may ise obtained from:

U.S. Departwent of Exurgy

Technfcal Informatior Center

P.0. Box 62

Oak RIdge, Tennessee 378.30 


\section{Systems Analysis for the Development of Small Resource Recovery Systems}

\section{System Performance Data}

Final Report

October 1980

Prepared by:

Mr. Phillip G. Crnkovich and

Mr. Arthur J. Helmstetter

Systems Technology Corporation

Xenia, Ohio 45385

Under Contract No. AC01-77CS 20026

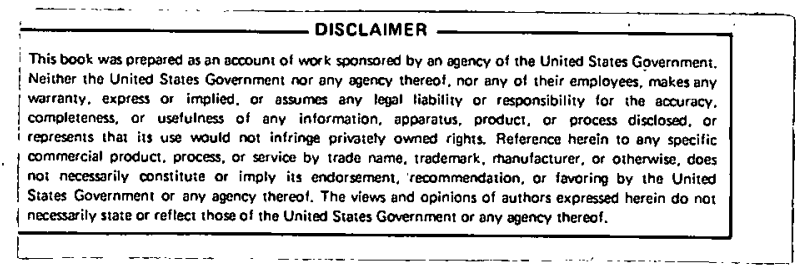

Prepared for:

\section{U.S. Department of Energy}

Assistant Secretary for Conservation and Solar Energy

Office of Buildings and Community Systems

Washington D.C. 20585 


\section{ABSTRACT}

In response to the increasing need for small-scale solid waste processing. facilities, the U.S. Department of Energy (DOE) contracted with Systems Technology Corporation (SYSTECH) to identify the technologies that should be developed to make such facilities attractive to and viable for small municipalities with solid waste between 50 and 250 tons per day (TPD). In addition to identify.ing candidate technologies, SYSTECH applied a set of criteria to them to determine those that could best satisfy the existing market conditions. The criteria included costs of the alternative landfill disposal, material and energy prices, developmental status of the technology, . and environmental impact of the systems. The system types studied included those with mechanical separation, thermal and thermochemical energy recovery, and bioconversion processes. For these studies, the performance of each system was simulated by a mathematical model.. After the systems were evaluated, the most promising were analyzed to determine which components and operating parameters had the greatest impact on system viability. Accordingly, the research and development (R\&D) needs to advance the state-of-the-art for small-scale solid waste processing facilities were identified.

The study results are documented in four volumes: (1) Executive Summary, (2). Description of Solid. Waste Modular Simulator, (3) Research and Development Needs, and (4) System Performance Data. 
Abstract . . . . . . . . . . . . . . . . . . . 1

Figures .............................. iv

1. Introduction ..................... 1

2. Thermal Processing Systems ............... 3

Excess-air incineration ............ 3

Refractory-1ined incinerators . . ...... 3

Waterwall incinerator ............. 4

Rotary-kiln incinerator . ........... 4

Multiple-hearth incinerator . . . . ..... 10

Fluidized-bed incinerator . . . . . . . . 13

Suspension-fired cyclonic . . . . . . . . : 15

Starved-air incineration/gasification . . . . . . . 17

Modular incinerators . . . . . . . . . . 17

Rotary kiln . . . . . . . . . . . . . 23

Packed bed ................. 26

Fluidized bed .................. . 34

Horizontal auger . . . . . . . . . . . . . . 39

Pyrolysis (indirect heating) ............ 42

Travelling grate ................ 42

Rotary kiln ................. 46

Packed bed ............... 50

Fluidized bed ............... 54

Horizontal auger .............. 56

Plasma arc .................. 60

3. Mechanical Processing Systems . . . . . . . . . . 63

Coarse refuse derived fuel ............. 63

Materials separation .............. 65

Dust refuse derived fuel . . . . . . . . . . . 78

Densified refuse derived fuel ............. 80

Fine refuse derived fuel .. . . . . . . . . . . 84

4. Mechanical Processing Components . . . . . . . . . 87

Receiving module .................. 87

Tipping floor'................ 87

The conveyor bottom pit ............. 89

The crane/push pit .............. 89

The crane pit . . . . . . . . . . . 92

The bulldozer pit . . . . . . . . . . . 92 
CONTENTS (continued)

Primary size reduction module . . . . . . . . . . 95

The horizontal axis hammermill . . . . . . . . 95

The vertical axis hammermill .. . . . . . . 97

The flail mill . . . . . . . . . . . . . 101

The shear shredder .............. 101

Combustible separation module . . . . . . . . . . 104

Air classifiers . . . . . . . . . . . . 104

The dual vortex air classifier . . . . . . 105

Air density separator . . . . . . . . . 105

The vibrolutriator air classifier . . . . . . 105

Rotary drum air classifier . . . . . . . . 109

Rotary screen.................. 109

Refuse derived fuel preparation module . . . . . . . 109

Fine rotating screen .............. 111

Magnet . . . . . . . . . ........ 111

Secondary size reduction . . . . . . . . . . 114

Fuel densification . . . . . . . . . . . . . . . 114

Pelletizers.................. 117

Cubetter ................... 117

Briquetter . . . . . . . . . . . . . . . 117

Fuel storage module . . . . . . . . . . . . 120

The live center bin . . . . . . . . . . . . 120

Covered pile................. 122

The silo.................. 122

The transfer trailer ............ 125

Ferrous separation ............... 125

Multistage magnet............... 125

Drum magnet .................. 125

Building and facilities . . . . . . . . . . . 129

5. Biological Processing . . . . . . . . . . . . 130

Introduction .................. 130

Pretreatment processes . . . . . . . . . . . 130

Mechanical size reduction and separation . . . . 130

Enzymatic hydrolysis of cellulose to glucose . . 130

Acid hydrolysis of cellulose to glucose . . . . 132

Principle methods of bioconversion of MSW . . . . . 134

Aerobic bioconversion . . . . . . . . . . 134

Conversion to ethanol . . . . . . . . . . 138

Anaerobic bioconversion . . . . . ... . . 138

Landfill gas recovery . . . . . . . . . . 138

Anaerobic digesters . . . . . . . . . . . . . 139

Annelidic (earthworms) processing of MSW . . . . 140

References . . . . . . . . . . . . . . . . . . . . . 144 


\section{FIGURES}

Number

Page

1 Waterwall incinerator .................. 5

$20^{\prime}$ Conner energy recovery unit . . . . . . . . . . . . . 7

3 Watson energy systems process schematic . . . . . . . . . 8

4 Envirotech process flow diagram . . . . . . . . . . . . 11

5 Envirotech multiple hearth furnace . . . . . . . . . . . 12

6 Thermal Processes, Inc., process diagram . . . . . . . . . . 14

7 Ecologenics process flow schematic . . . . . . . . . . 16

8 Modular incinerator schematic . . . . . . . . . . . . 19

9 Wright-Malta process schematic . . . . . . . . . . . 24

10 Andco-Torrax process schematic . . . . . . . . . . . . . . 27

11 Simplex process schematic . . . . . . . . . . . . . 29

12 Tech Air process diagram . . . . . . . . . . . . . . . 31

13 Century Research process schematic . . . . . . . . . . 33

14 Stanford University/Combustion Power process schematic . . . . . 35

15 Thermonetics gasification system . . . . . . . . . . . . 38

16 Scientific Energy Engineering incineration system configuration. . . . . . . . . . . . . . . . . . 40

17 Scientific Energy Engineering process flow diagram . . . . . . 41

18 Wallace-Atkins process diagram ................. . . . 44

19 Pan American Resources energy conversion process schematic . . . 47

20 Pyro Sol process diagram . . . . . . . . . . . . . . . . . 49 


\section{FIGURES (continued)}

Number

Page

21 Leas Brothers energy converter schematic . . . . . . . . . 51

22 Environomics blue water gasifier . . . . . . . . . . 53

23 Teknekron process schematic . . . . . . . . . . . 55

24 Enterprise Company process diagram . . . . . . . . . . . . 57

25 Redker-Young process diagram . . . . . . . . . . . . 59

26 Resource Recovery plasma refuse converter schematic . . . . . . 61

27 AENCO system . . . . . . . . . . . . . . . . . . . . . 64

28 Cecchini-Sorain process schematic . . . . . . . . . . 66

29 Flakt, Inc., materials recovery process . . . . . . . . . . 77

30 Combustion Equipment Associates process schematic . . . . . . . 79

31 Lehigh Forming process diagram . . . . . . . . . . . . . 81

32 Vista Chemical and Fiber product process diagram . . . . . . . 83

33 Waste Control Science process schematic . . . . . . . . 85

34 Tipping floor schematic and operational data . . . . . . . 88

35 Conveyor pit schematic and operational data . . . . . . . . 90

36 Crane/push pit schematic and operational data . . . . . . . 91

37 Crane pit schematic and operational data . . . . . . . . . 93

38 Dozer pit schematic and operational data . . . . . . . . . 94

39 Horizontal hammermill schematic and operational data . . . . . 96

40 Post rotary screen horizontal hammermill operational data . . . 98

41 Vertical hammermill schematic and operational data . . . . . . 99

42 Post rotary screen vertical hammermill operational data . . . 100 
FIGURES (continued)

Number

Page

43 Flail mill schematic and operational data . . . . . . . . . 102

44 Shear shredder schematic and operational data . . . . . . . . 103

45 Dual vortex air classifier schematic and operational data . . . 106

46 Air density separator schematic and operational data . . . . . 107

47 Vibrolutriator schematic and operational data . . . . . . . 108

48 Coarse rotary screen schematic and operational data . . . . . . 110

49 Fine rotary screen schematic and operational data . . ... . . . 112

50 Tramp metal magnet schematic and operational data . . . . . . . 113

51 Secondary horizontal hammermill operational data . . . . . . . 115

52 Secondary vertical hammermill operational data . . . . . . . . 116

53 Pelletizer schematic and operational data . . . . . . . . . 118

.54 Cubetter schematic and operational data . . . . . . . . . . 119

55 Live center bin schematic and operational data . . . . . . . . 121

56 Atlas bin schematic and operational data. . . . . . . . . . 123

57 Bunker schematic and operational data . . . . . . . . . . 124

58 Transfer trailer schematic and operational data . . . . . . . 126

59 Multistage magnet schematic and operational data .. . . . . . . 127

60 Drum magnet schematic and operational data . . . . . . . . . . . 128

61 Biological processing systems . . . . . . . . . . . . 131

62 Enzyme hydrolysis process schematic . . . . . . . . . . . 133

63 Fairfield-Hardy digester process flow . . . . . . . . . . 136

64 Geochemical/Eweson digester schematic . . . . . . . . . . . 137

65 Anaerobic digestion process flow diagram . . . . . . . . . . 141 


\section{ACKNOWLEDGMENTS}

This program was performed under Department of Energy Contract No. EC-77-03-1478, "Smal1-Scale Resource Recovery System Analysis."

The DOE project officer was Charlotte Rines of the Office of Conservation and Solar Applications, Washington, D.C.

Data on equipment cost and performance were supplied by industry vendors, and market information was provided by national associations and material purchasers. The contributions of these groups are greatly appreciated. The contribution of Rick Haverland and other staff members involved in this project is acknowledged.

Systems Technology Corporation would like to express its gratitude to the above and all others associated with this evaluation. 


\title{
SECTION 1
}

\author{
INTRODUCTION
}

As part of the analysis of the current small-scale resource recovery technology, the resource recovery systems representative of each type of known technology was researched to acquire performance data for systems in the 50to 250-tons per day (TPD) range. Wherever the vendor data were for systems beyond this range, they were reasonably extrapolated. Intended primarily as a reference document, this volume describes the systems researched and presents their performance data. These data served as the input to the Solid Waste Modular Simulator (SWIMS) computer program in the various analyses to identify the research and development (R\&D) needs for the advancement of small-scale resource recovery systems. The system analyses, the computer simulation, and the identified research needs are presented in separate volumes.

The resource recovery systems investigated were divided into three categories: (1) thermal processing, (2) mechanical separation, and (3) biological processing. The thermal processing systems, in turn, were grouped under three incinerator types: excess-air combustion, starved-air combustion, and pyrolysis. Of these types, the excess-air incinerators have had the longest application in the United States and include refractory-lined incinerators, rotary-kiln incinerators, waterwall incinerators, and multiple-hearth furnaces. Much data are available on the operation of these systems in the throughput range of 250 TPD and above. Starved-air modular incinerators have been applied extensively at throughput rates of 20 to $100 \mathrm{TPD}$. The systems with the least available data are pyrolysis systems that "bake" the waste-in an inert atmosphere and generate a combustible gas which can be either combusted on site or sold as fuel. Various types of equipment (kilns, grates, fluidized beds, etc.) can be used in each of the three incinerator types since the main difference between the types is simply the amount of oxygen supplied. All three types may also incorporate mechanical processing equipment to improve the fuel quality of the waste before thermal processing.

Mechanical processing systems also are used to separate che waste stream into marketable products such as fuel, glass, aluminum, and ferrous metals. The operational efficiency of these systems depends on the size and density of the waste stream components. Most mechanical processing systems have equipment components to perform the following functions: receiving, reducing size, separating combustible materials, recovering ferrous, storing fuel, densifying fuel, and preparing fuel. Facilities currently using these types of equipment for resource recovery are located in Ames, Iowa; Chicago, Illinois; Milwaukee, Wisconsin; New Orleans, Louisiana; Baltimore County, Maryland; and Lane County, Oregon. 
Biological processes researched in this study include composting, anaerobic digestion, enzyme and acid hydrolysis, gas reclamation from landfills, and worm farming. In these processes, the organic materials in the waste stream are transformed into a form that has a market value. This organic fraction is separated from the remaining waste components by mechanical separation either before or after the biological process.

The information presented to characterize the resource recovery systems includes qualitative and quantitative data. The qualitative information includes system or component descriptions, degree of the equipment development, and equipment uncertainties requiring resolution. The quantitative information for the systems or components includes the following:

1. Throughput capacity.

2. Total capital cost.

3. Electric consumption per machine hour or per ton processed.

4. Maintenance/labor requirements per machine hour or per ton processed.

5. Operator labor requirement per machine hour or per ton processed.

6. Maintenance supply requirement per machine hour or per ton processed.

7. Separation efficiency (\%).

8. Thermal efficiency (\%), if applicable.

The unique systems included in this study are referred to by the manufacturer's name, rather than by a generic system type, to facilitate their identification. The inclusion or exclusion of specific systems does not reflect the relative viability of the systems studied. The Department of Energy has no formal opinions concerning the operational viability of any of. the systems considered or the accuracy of the data representing their performance. Since the information in this report was intended as a basis for a generalized system analysis, it should not be used to determine the viability of any system in a specific application. 


\section{SECTION 2}

THERMAL PROCESSING SYSTEMS

\section{EXCESS-AIR INCINERATION}

Refractory-1ined Incinerators (Clear Air, Inc.)

System Description--

The refractory-lined incinerator, in various forms, has been used for the volumetric reduction of solid waste for many years. Only recently have heat recovery units been added for the production of steam.

A refractory-1ined incinerator consists of a refractory-1ined combustion vessel that is usually square or rectangular. The material to be burned is fed into the incinerator through a charging chute usually located above the furnace. The material then drops onto a series of grates which slowly agitate and move the material through the furnace. There are numerous types of grates that are available such as rocking, reciprocating, and traveling grates, just to name a few. The resultant ash is discharged into an ash removal pit and subsequently removed while an air seal is maintained.

Experience--

Refractory-lined incinerators have been used for many years for the size reduction of solid waste. Many of these facilities have been closed due to the cost of modification to meet current air pollution codes. More recent installations are equipped with heat recovery units (usually a waste heat boiler).

Cost--

The estimated capital cost of a 150-TPD, refractory-1ined incinerator is $\$ 3,859,000$. The calculated net cost (with heat recovery) is $\$ 17.86$ per ton.

Research Needs--

1. Obtain detailed information to permit an in-depth cost and revenue analysis to verify cost projections.

2. Develop a method to minimize emissions without requiring a costly control device. 
Waterwall Incinerator (European Technology)

System Description--

A waterwall incinerator is, in essence, a water tube boiler designed specifically to burn raw solid waste. The heat produced by the combustion of the solid waste is transferred by radiant and convective heat transfer modes to the water filled boiler tubes thus producing steam and/or hot water for sale.

A waterwall incinerator consists of a tall, rectangular ashaped combustion chamber that is formed by boiler tubes on the top and sides. Due to the characteristics of firing solid waste, some tubes are covered with refractory to reduce erosion and corrosion, especially in the lower sections of the vessel. The bottom of the incinerator is formed by the grates which move the material through the combustion chamber (see Figure 1).

The raw solid waste is usually introduced into the incinerator through a plug flow chute. The material in the chute provides the needed air seal to limit the amount of combustion air entering the incinerator. When the waste leaves the chute, it is deposited on the grates where it is burned. Several types of grate arrangements are used, depending upon the manufacturer, to move the material through the incinerator. The ash is then deposited in the ash pit for removal.

The type of air pollution control devices used to control emissions depends on local regulations and the exit conditions of the flue gas.

Experience--

Waterwall incinerators have been used successfully in Europe for over 20 years. A number of waterwall incinerators have been built in the United States, but many of them have had serious boiler tube corrosion problems, especially in superheated sections.

Cost--

The estimated capital cost of a 200-TPD facility is $\$ 10,500,000$. The calculated net cost is $\$ 17.80$ per ton.

Research Needs--

1. Evaluation and testing of material resistant to boiler tube corrosion and erosion.

2. Obtain detailed information to permit an in-depth cost and revenue analysis to verify cost projections.

Rotary-Kiln Incinerator ( $0^{\prime}$ Conner)

System Description--

The rotary kiln incinerator is a combination of a rotary kiln and a waterwall incinerator--the first section is a water-cooled, rotary combustor while the second section is similar to a waterwall incinerator. The heat 


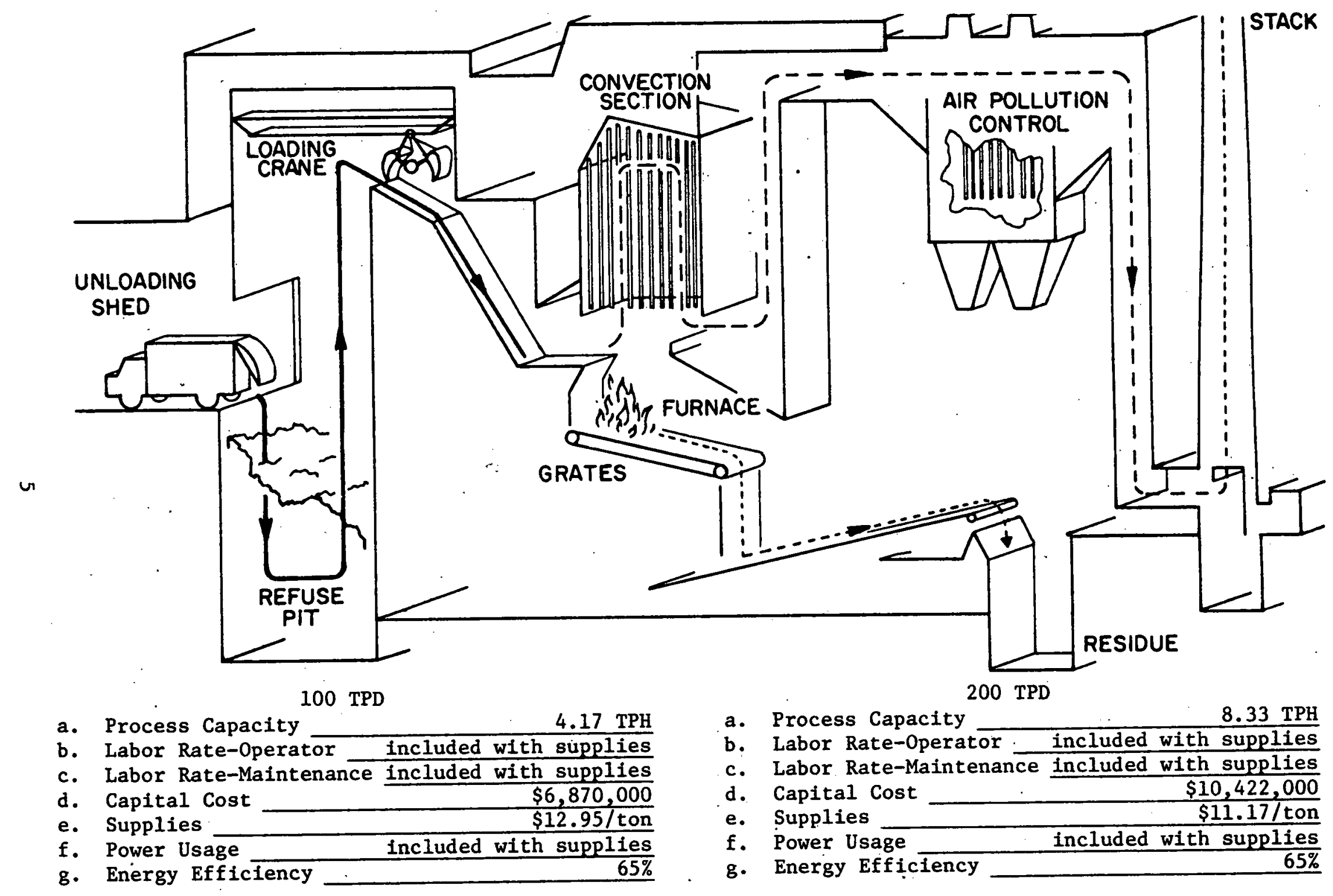

Figure 1. Waterwall incinerator. 
produced by the combustion of the waste material is transferred to the water filled boiler tubes by radiant and convective heat transfer modes, thus producing saleable steam and/or hot water (see Figure 2).

Raw solid wastes are fed into the system through a charging chute which, when filled, forms an air lock. A ram at the bottom of the charging chute pushes the material into the rotary combustor which is the primary combustion zone. It is water cooled to control the combustion temperature, thus reducing $\mathrm{HC}$ corrosion and $\mathrm{NO}_{\mathrm{x}}$ generation. The ash from the primary combustion zone falls through the holes in the rotary combustor to the ash pit below. Material discharged from the combustor falls onto a second horizontal grate in the waterwall section of the unit. The remaining ash is discharged into the second ash pit.

An electrostatic precipitator is used for air pollution control.

\section{Experience--}

This unit has been used to burn bagasse and waste paper in the Far East. Several successful test burns of Japanese refuse were made on the pilot plant located in Japan. Currently, a 150-TPD facility is being designed for Gallatin, Tennessee. It is expected to be completed in 1981.

\section{Cost--}

The estimated capital cost of a 150-TPD unit is $\$ 3,660,000$. The calculated net disposal cost is $\$ 8.03$ per ton.

Research Needs--

1. Evaluation and testing of material resistant to corrosion and erosion for the boiler tubes and rotary combustor.

2. Obtain detailed information to permit a detailed cost and revenue analysis to verify cost projections and the systems performance.

3. Determine expected useful life.

\section{Rotary-Kiln Incinerator (Watson Energy Systems)}

\section{System Description--}

The Watson Energy System (Figure 3) is a starved-air, rotary-kiln incinerator which gasifies the refuse in the first third of the kiln and burns the evolved gases in the remaining two thirds of the kiln. The waste and gases both flow down the kiln in the same direction--from the feed end to the discharge end.

Incoming refuse trucks tip their loads on either side of the pit, and a pair of traversing augers are used to move the material to a conveyor in the center of the pit. The pit conveyor transfers the raw refuse to a second conveyor which carries the material to a cleaning screen. After screening, the material goes to a picking line where the pickers remove any salvageable materials. 


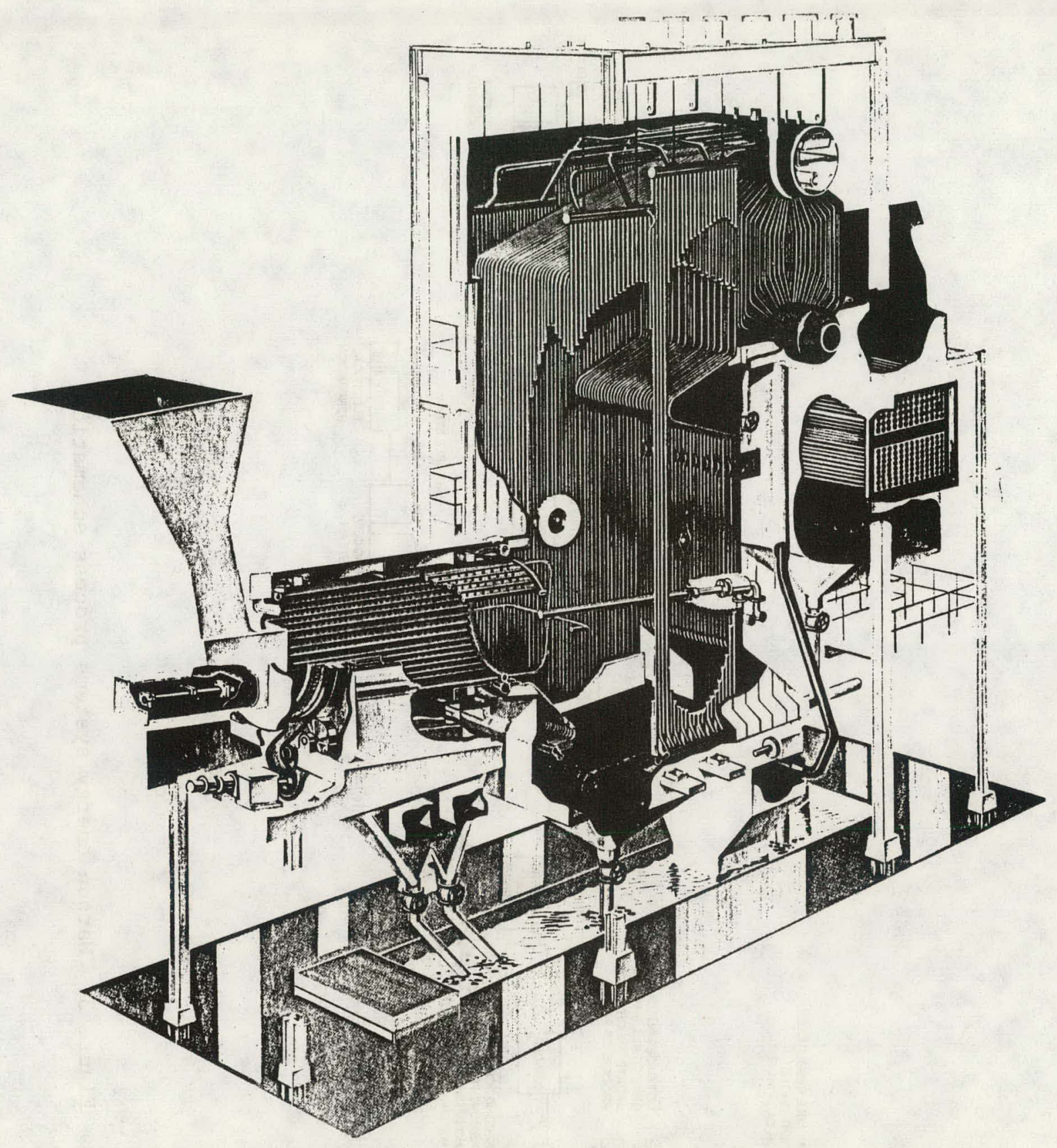

150 TPD
a. Process Capacity
$6.25 \mathrm{TPH}$
b. Labor Rate-Operator
$0.457 \mathrm{MH} /$ ton
c. Labor Rate-Maintenance included with supplies
d. Capital Cost $\$ \$ 3,660,000$
e. Supplies $\$ 2.67 /$ ton
f. Power Usage
g. Energy Efficiency $70.9 \%$

Figure 2. O'Conner energy recovery unit. 
THE PERCENT OF AVAILABLE RESOURCES SALVAGED IS DEPENDENT ON THE

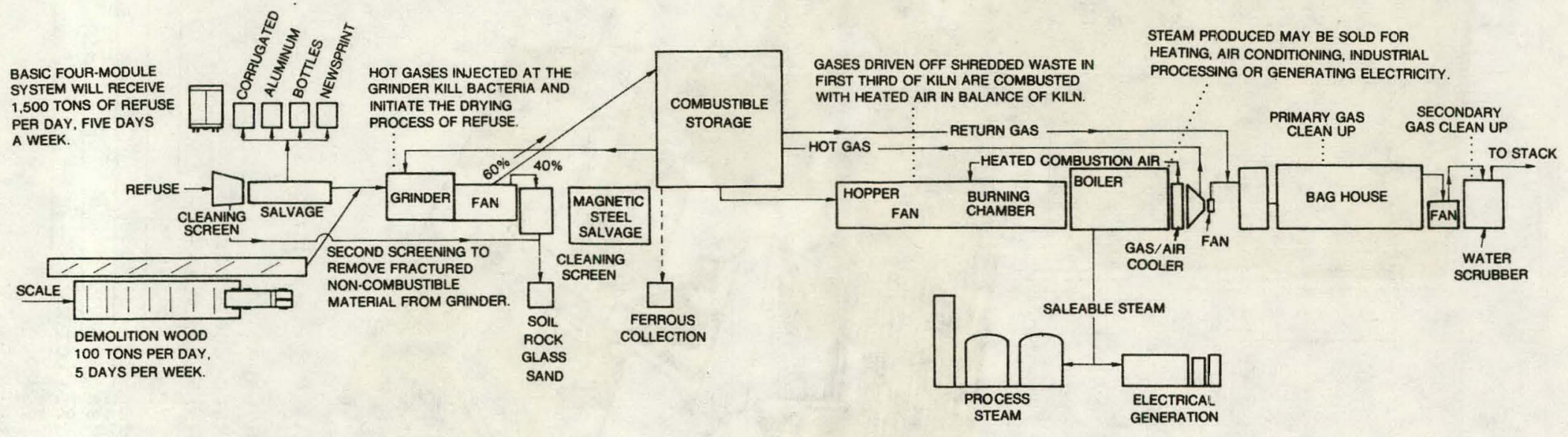

Figure 3. Watson energy systems process schematic. 
This material and the hot gases from the product gas cooler are introduced into the shredder which reduces the size of the material. The hot gases in the shredder dry the material and reduce the possibility of a shredder explosion by providing an inert atmosphere. At the discharge of the shredder, there is a small settling chamber to achieve material separation. The light fraction is pneumatically conveyed to the combustible storage bin, and the heavy fraction is screened a second time removing the ferrous metals with a magnetic separator.

This material and hot flue gases are introduced into the rotary kiln. In the first third of the rotary kiln, the material is partially burned and gasified. In the remaining two thirds of the kiln, the evolved gases are burned.

The hot flue gases from the kiln are passed through a waste heat bofler to produce steam. Next, the gases are directed to a water heater and a gas/ air cooler which preheats the combustion air for the kiln.

With the assist of a fan, the flue gases pass through a gas water cooler and a bag house to remove any particulate matter. A second fan pushes the air through a water scrubber before this air is discharged into the atmosphere.

Experience--

Watson Energy Systems has designed a four-module unit capable of processing 1600 to 2000 TPD. The design of this unit was verified in several small-scale test burns.

A permit has been obtained from the Alr Pollution Control District of Southern California to build a plant in Wilmington (City of Los Angeles), California.

Cost--

Watson Energy Systems estimates that this system (2000 TPD) with private financing would be economical with a tipping fee of $\$ 5.00 /$ ton and steam sold at $\$ 2.50 / 1000 \mathrm{lb}$. They did not supply any detailed information to confirm their cost calculations.

They have indicated that they would consider designing a small system for a given application.

\section{Research Needs--}

1. The reliability of the augers and screws in the raw refuse storage needs to be demonstrated.

2. The experience with high temperature kilns to date has been poor, and further testing will be required.

3. Erosion and fouling of the baler could be severe and should be specifically addressed. 


\section{Multiple-Hearth Incinerator (Envirotech, BSP Division)}

System Description--

The BSP Division of Envirotech, Davis, California, has designed a multiple-hearth furnace (Figures 4 and 5) capable of converting a mixture of refuse derived fuel (RDF) and sewage sludge into a low-Btu fuel gas. This process would use one part RDF to two parts municipal sewage sludge. Multiplehearth furnaces have been successfully used for the incineration of sludge as well as other carbonaceous waste materials including wood chips, bark, sawdust, peach pits, walnut shells, etc.

The multiple-hearth furnace requires a shredded and magnetically separated feedstock which can be mixed easily with sewage sludge. Incoming refuse is first passed through a rotary screen. The undersize material is magnetically separated and landfilled. The oversize material is shredded, magnetically separated, and passed over a disc screen before being recycled back to the shredder for further size reduction. The material passing through the disc screen is conveyed to a storage system.

A multiple-hearth furnace is a cylindrical, refractory-lined vessel that is vertically divided into several sections or hearths. In the center of the cylindrical shell is a vertical rotary shaft with radial arms. The teeth on the radial arms move the material in a spiral path across each hearth. As the arm travels across each hearth, the material is constantly agitated by the teeth. This exposes new surfaces of the material to the reaction and moves it toward the drop holes through which it falls to the next lower hearth. The drop holes are staggered so the material must travel across a width of the hearth before it can fall to the next lower hearth. This assures maximum retention time in the furnace which can also be controlled by adjusting the speed of the arms that are driven by a variable-speed drive.

The central shaft and the radial arms are cooled by air which is introduced through the base of the central shaft. The heated air, which exits at the top of the furnace, is piped to the bottom of the furnace where it serves as preheated combustion air. The partial combustion of the reaction gases sustains the process without the use of supplementary fuel. The rising air absorbs heat from the reaction in the lower hearth, and it rises into the upper hearth. Its sensible heat is transferred into the shredded material entering the unit. This heating drives a pyrolysis reaction in the lower hearth at temperatures up to $1400^{\circ} \mathrm{F}$ and later drys the material in the upper hearth. The pyrolysis gas exits at the top of the hearth at about $800-900^{\circ} \mathrm{F}$ and is piped to a gas combustor.

This low-Btu fuel gas is then burned in a boiler to produce steam. The ratio of $\mathrm{RDF}$ to sludge has a great impact on the efficiency of this system. As the amount of sludge is decreased, the efficiency will increase due to the lower moisture content of the combined feedstock. 
REFUSE PROCESS PLANT

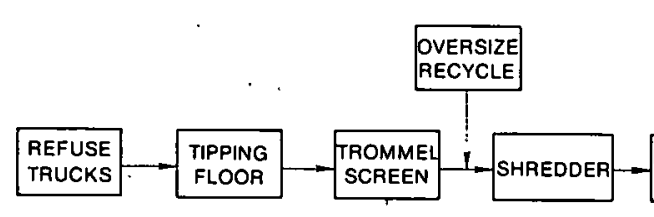

$\longrightarrow-\begin{aligned} & \text { FERROUS } \\ & \text { MAGNET }\end{aligned}-\left\{\begin{array}{l}\text { FERROUS } \\ \text { STORAGE }\end{array}\right.$

$\frac{1}{\text { REJECTS }}$

TOO
LANDFILL
STEAM PRODUCTION PLANT

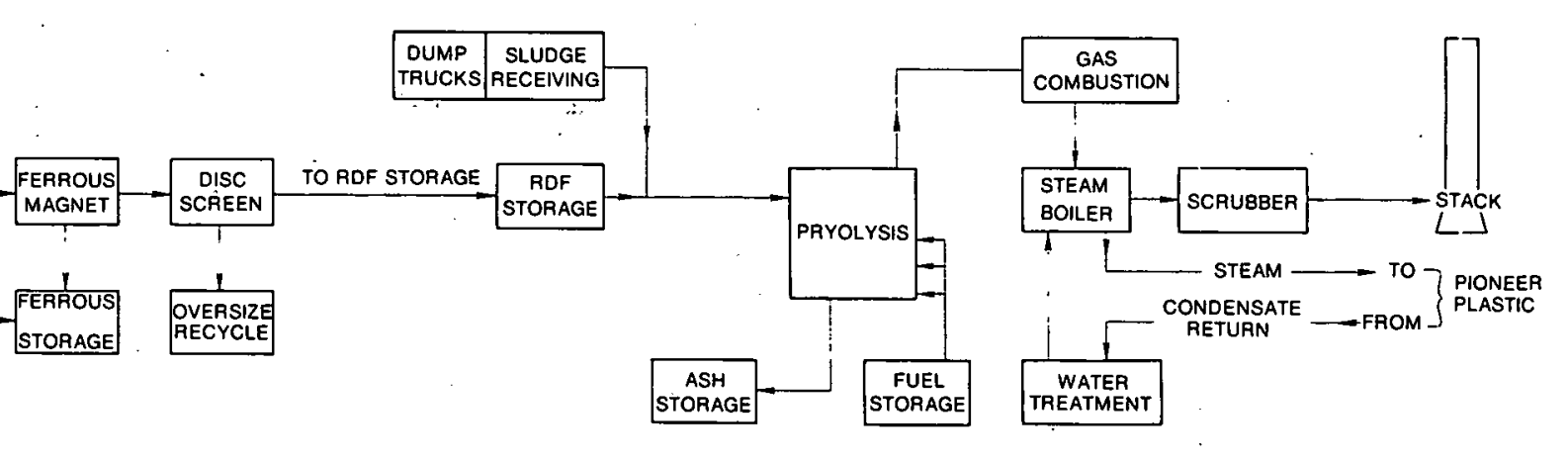

$250 \mathrm{TPD}$

a. Process Capacity

$10.42 \mathrm{TPH}$

b. Labor Rate-Operator $0.54 \mathrm{MH} /$ ton

c. Labor Rate-Maintenance \$4.93/ton

d. Capital Cost $\$ \$ 9,000,000$

e. Supplies

f. Power Usage

$-=$

g. Energy Efficiency

$36 \mathrm{kw}-\mathrm{hr} / \mathrm{ton}$

$45 \%$

Figure 4. Envirotech process flow diagram. 


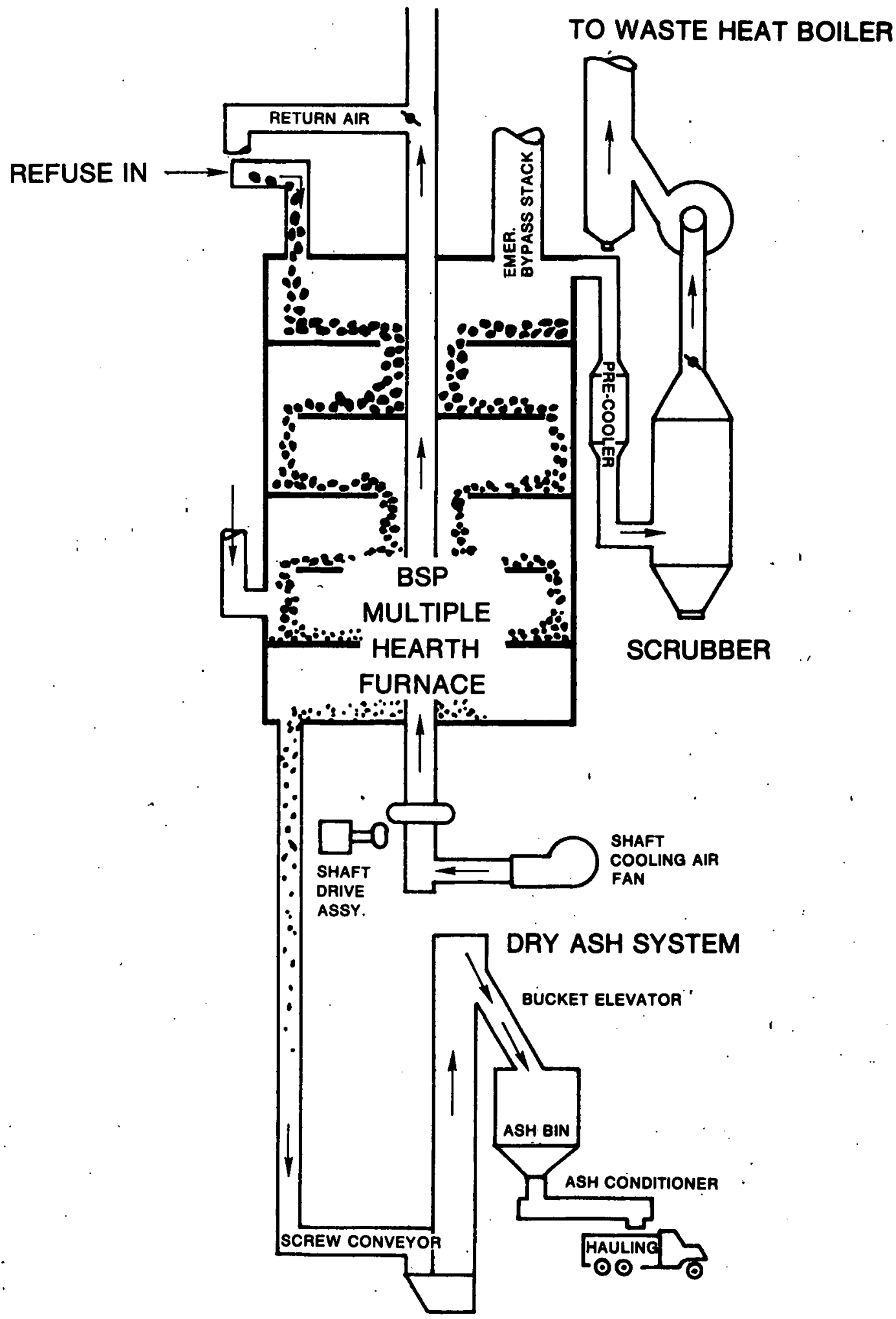

Figure 5. Envirotech multiple-hearth furnace. 


\section{Experience-r}

Envirotech has conducted tests at feed rates of. up to 5 tons of municipal solid waste (MSW) per hour. Currently a system is Deing designed to be capable of processing 1500 TPD.

Cost--

Envirotech estimates the capital cost of a 250-TPD facility would be approximately $\$ 9,000,000$. The net disposal cost was calculated to be $\$ 22.54$ per ton.

Research Needs--

1. Investigate possible methods to reduce the cost of processing for this system.

2. Conduct tests to determine the operating parameters at various refuse-to-sludge ratios.

3. Obtain additional technical and economic information for a more detailed evaluation of the system.

Fluidized-Bed Incinerator (Thermal Processes, Incorporated)

System Description--

Thermal Processes, Incorporated (TPI), of La Grange,. Illinois, has developed a fluidized-bed combustor (Figure 6) that can dispose of shredded municipal solid waste and produce a hot flue gas. This hot flue gas can then be passed through a waste heat boiler to produce saleable steam.

Incoming solid waste is shredded to a nominal 4-inch particle size and then magnetically separated. The material size is limited by the feed system rather than the combustor. Material is introduced into the side of the fluidized-bed combustor (a tall, rectangular, refractory-1ined box) by means of a stoker type feeder. The combustor-bed media (usually sand) is fluidized by air injected through orifices located in the bottom of the reactor. The turbulent action of the bed encourages complete combustion of the material.

The combustor consists of several factory assembled modules. The hot flue gases exiting from the top of the combustor can then be passed through a waste heat boiler to produce process steam, hot water, or heated air. Some pollution control equipment will be required, depending upon the particulate loading.

Inerts are removed from the bottom of the vessel through one or more hoppers to permit recycling of the bed material and removal of noncombustible debris on an intermittent basis. TPI expects that rocks, grit, metal, etc., will gravitate to the bottom of the sand-filled hopper for easy removal.

Experience--

TPI was formed in June 1977, and has constructed a pilot plant in Denver, Colorado. Presently they are designing a full-scale system which they expect 
75 TPD

a. Process Capacity

$3.125 \mathrm{TPH}$

b. Labor Rate-Operator $0.32 \mathrm{MH} /$ ton

c. Labor Rate-Maintenance

d. Capital Cost $\overline{\$ 810,000}$

TIP FLOOR

e. Supp1ies

f. Power Usage

g. Energy Efficiency $83 \mathrm{kw}-\mathrm{hr} / \mathrm{ton}$

$70 \%$

200 TPD

a. Process Capacity $\quad 8.33 \mathrm{TPH}$

b. Labor Rate-Operator $0.12 \mathrm{MH} /$ ton

c. Labor Rate-Maintenance

d. Capital Cost

e. Supplies

f. Power Usage

$\$ 2,025,000$

g. Energy Efficiency $80 \mathrm{kw}-\mathrm{hr} / \mathrm{ton}$

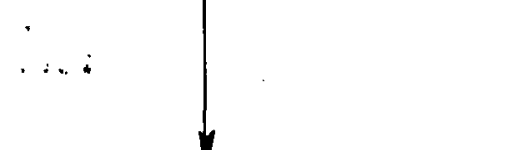
$70 \%$

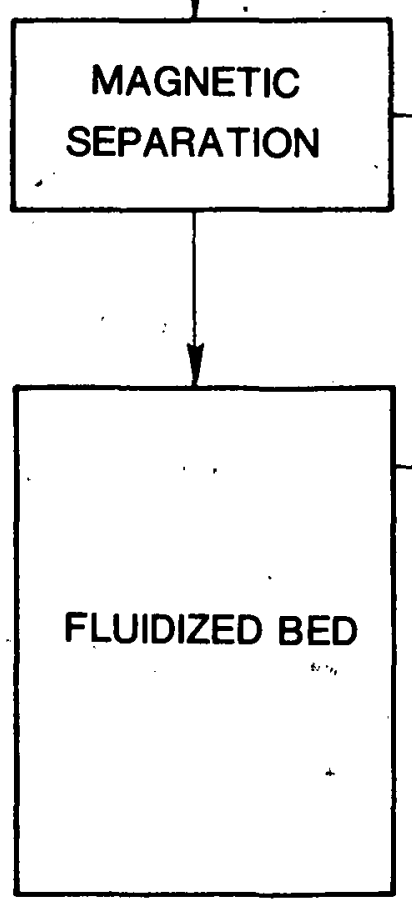

\section{FERROUS}

\section{SALE}

3

HOT

FLUE

GAS

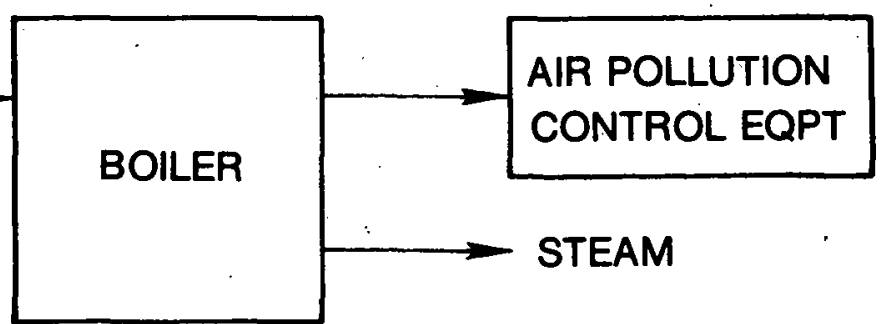

Figure 6. Therma1 Processes, Inc., process diagram. 
to be operational within the next 6 to 9 months, Prior to the formation of TPI, several members of the firm had experience with fluidized combustion.

Cost--

The estimated cost of the fluidized-bed combustion system. is $\$ 810,000$ and $\$ 2,024,000$ for the 75- and 200-TPD sizes, respectively. These costs include a 35 percent allowance for erection and installation costs. The cost of the front-end processing system and the building was not specified by the vendor and, therefore, has been estimated by using the standard modules in. the SWIMS computer model. The calculated net disposal cost is $\$ 8.4 \%$ per ton and $\$ 1.55$ per ton for the 75- and 200-TPD systems, respectively.<smiles>C1CCCCC1</smiles>

Research Needs--

1. Quantification of the combustion process including air requirements (combustion and fluidizing), details of the bed media system recycling, and particulate entrainment.

2. Analyzation of the reliability and maintainability of the feed systems and inert removal systems.

3. Determination of tendency of the fluidized bed to plug.

4. Develop firm cost estimate for system operation.

\section{Suspension-Fired Cyclonic (Ecologenics Corporation)}

\section{System Description--}

The Ecologenics system uses a slagging cyclonic burner to burn an RDF fuel product. The prototype of this system has been built and tested at a facility'in Red Lion, Pennsylvania.

This system consists of two modules: (1) a front end to prepare RDF and (2) a proprietary combustion chamber to burn RDF.

The front-end system is shown in Figure 7. The incoming material is run through a trommel with 3/4-in. holes and produces an undersize (less than 3/4 in.) and an oversize (greater than $3 / 4$ in.) fraction. The oversize is magnetically. separated to remove saleable magnetic materials.

After primary shredding, the trommel oversize is air classified and magnetically separated. The heavy fraction from the primary air classifier and the nonmagnetic from the trommel oversize are conveyed to the secondary air classifier. The heavy fraction is either landfilled or used for metal/ glass reclamation.

The light fractions from both primary and secondary air classifiers are shredded in a secondary shredder. The system stores the mâterial in a Harvestore Silo (used for hay and straw), manufactured by A. 0. Smith, Inc.

The RDF is burned in a proprietary, refractory-lined, vertical-shaft combustion chamber. The RDF enters the combustion chamber tangentially near 
200 TPD

a. Process Capacity

babor Rate-Operator $0.33 \mathrm{TPH}$

c. Labor Rate-Maintenance $0.57 \mathrm{MH} / \mathrm{ton}$

d. Capital Cost. __ $\$ \$ 4,218,000$

e. Supplies

$\$ 1.20 /$ ton

f. Power Usage

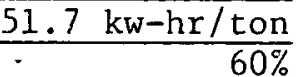

g. Energy Efficiency $60 \%$

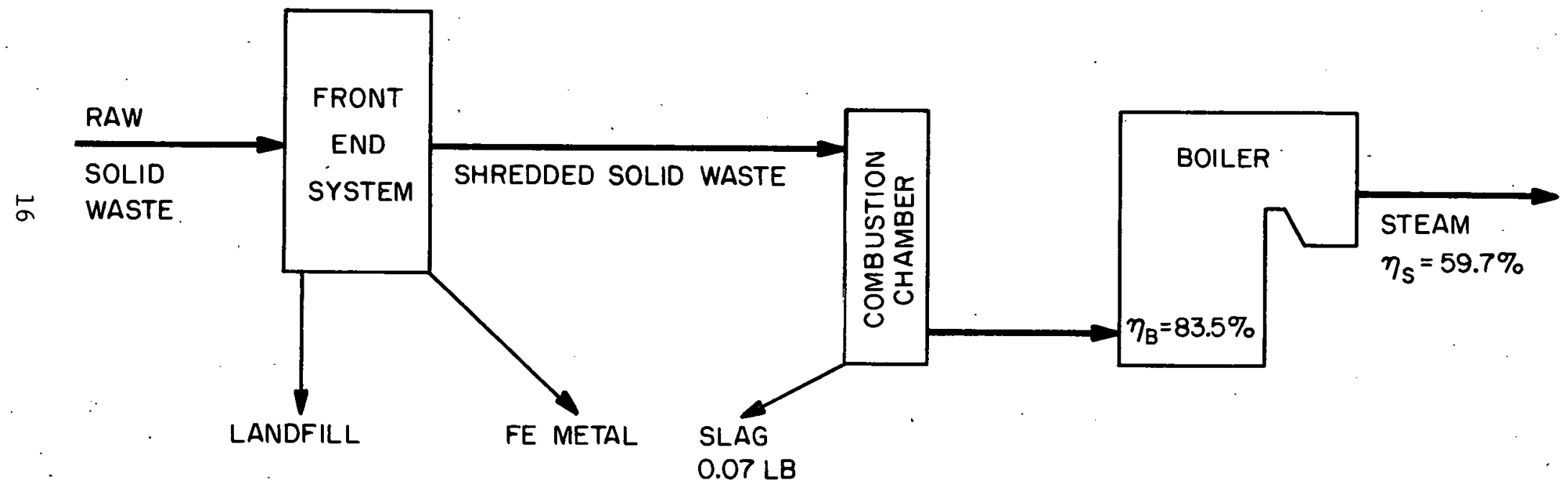

Figure 7. Ecologenics process flow schematic. 
the top which creates a vortex as the material falls. The residence time in the combustion chamber is approximately 2 seconds and requires roughly 20 to 25 percent excess air. A balanced-draft system is used to regulate combustion air. Approximately 94 percent of the ash is removed through the wet-bottom ash handling system.

Ecologenics has obtained .25/grain/SCF particulate loadings without air pollution control equipment. They expect to meet or exceed Environmental Protection Agency (EPA). standards with an 80 percent efficiency filter system.

The hot flue gases are sent to a waste heat boiler to produce saleable steam.

Experience--

Ecologenics has conducted tests on a small pilot unit in Red Lion Borough, Pennsylvania. There are no commerical installations at the present.

\section{Cost--}

Ecologenics estimated the capital cost of a 200-TPD plant at $\$ 4,218,000$. The operating and maintenance costs, based on tests at their small pilot plant, were calculated to be $\$ 18.67$ per ton.

Research Needs--

1. A detailed test program to determine the system operating characteristics.

2. Test the feasibility of using a Harvestore Silo for storing solid waste.

3. Reduce the particulate emissions from the system.

STARVED-AIR INCINERATION/GASIFICATION

Modular Incinerators

The term -- modular incinerator -- is a generalized nomenclature for a group of small incinerators that is presently being used for the disposal of solid waste. This type of incinerator has been primarily developed for application to industrial and commercial wastes and has been applied on a limited basis to municipal solid waste. These units are differentiated from typical municipal waste incinerators because they are shop-fabricated to reduce capital costs and to improve quality control.

According to the manufacturers, the modular incinerators presently in use operate with approximately 140 percent of theoretical air and divide the combustion reaction between two distinct zones. The solid waste is processed in a primary reaction zone which is supplied with 50 percent of the theoretical combustion air, and the resulting combustible gases are burned to completion in a secondary zone using the balance of the air supplied to the incinerator. Typically, the two reactions occur in two connected vessels with the first vessel operated at $1500^{\circ}$ to $1800^{\circ} \mathrm{F}$ and the second vessel operated at $1800^{\circ}$ to $2000^{\circ} \mathrm{F}$. 
The low temperature in the primary zone is maintained to limit vaporization of metals from the waste, which pose a potential environmental hazard if emitted with the stack gases, and to minimize the likelihood of slag formation from glass particles. Low gas flow rates through the solids bed are 'maintained by restricting the airflow to the primary zone to limit particulate entrainment by high gas velocities and turbulence. Temperatures in the secondary processing zone are maintained above $2000^{\circ} \mathrm{F}$ to guarantee the elimination of any odors emanating from the primary zone and to assure the complete combustion of all,gases and carbon passing through this zone. The reactions occurring in the primary and secondary zones are controlled to minimize the emission of particulate from the incinerator to levels between 0.08 and $1 \mathrm{gr} / \mathrm{DSCF}$. This quality, along with their simple operation, low cost and maintenance, and minimal waste handling, makes modular incinerators attractive to small municipalities. Because they of ten do not require expensive and complicated emission control devices, the cost to own and operate the modular incinerators is below the costs of alternate comparable processing methods applied on a small scale.

Figure 8 shows a "typical" modular incinerator and its component sections. Typically the modular incinerators are operated with a stationary floor or hearth with the waste material being pushed along the floor of the unit by the material being fed behind it. To achieve this motion, material being fed to the unit is pushed into the primary reaction zone by a ram feeder positioned at the elevation of the hearth so that the entering material forces the material ahead of it forward. This process continues until the material being moved arrives at the far end of the primary zone and falls into a water quench for subsequent removal and disposal. The retention time of the waste (normally 10 to 15 minutes) in the unit is carefully controlled by the cycling period of the ram, the feed rate of material, and the dimensions of the primary reaction vessel. The ram feeder and water quench discharge are both designed to maintain an air seal between the interior of the' reaction vessel and the ambient atmosphere.

Modular incinerators are generally refractory lined (cast and brick) to protect the equipment and the vessels from the intense heat of the reactions occurring within them. Combustion air in the primary chamber is usually introduced in an underfired mode through air injection tubes in the vessel walls or floor. The more sophisticated units modulate the primary air to maintain proper process temperatures. Water sprays are used as an additional control mode to maintain process temperatues at the desired levels.

The flow of gases through the processing vessels is achieved by either an induced-draft fan, a natural draft, or an aspirator unit which maintains the units at a negative pressure. The flow of air into the units is controlled by fans operated in conjunction with the auxiliary heat burners. The burners are used to heat up the system prior to waste processing and to maintain process temperatures in the afterburner at $1600^{\circ} \mathrm{F}$ but are not necessary to sustain the normal processing reaction.

Modular incinerators applied to the processing of municipal waste are available in modules up to 25 TPD which can be combined to increase plant 


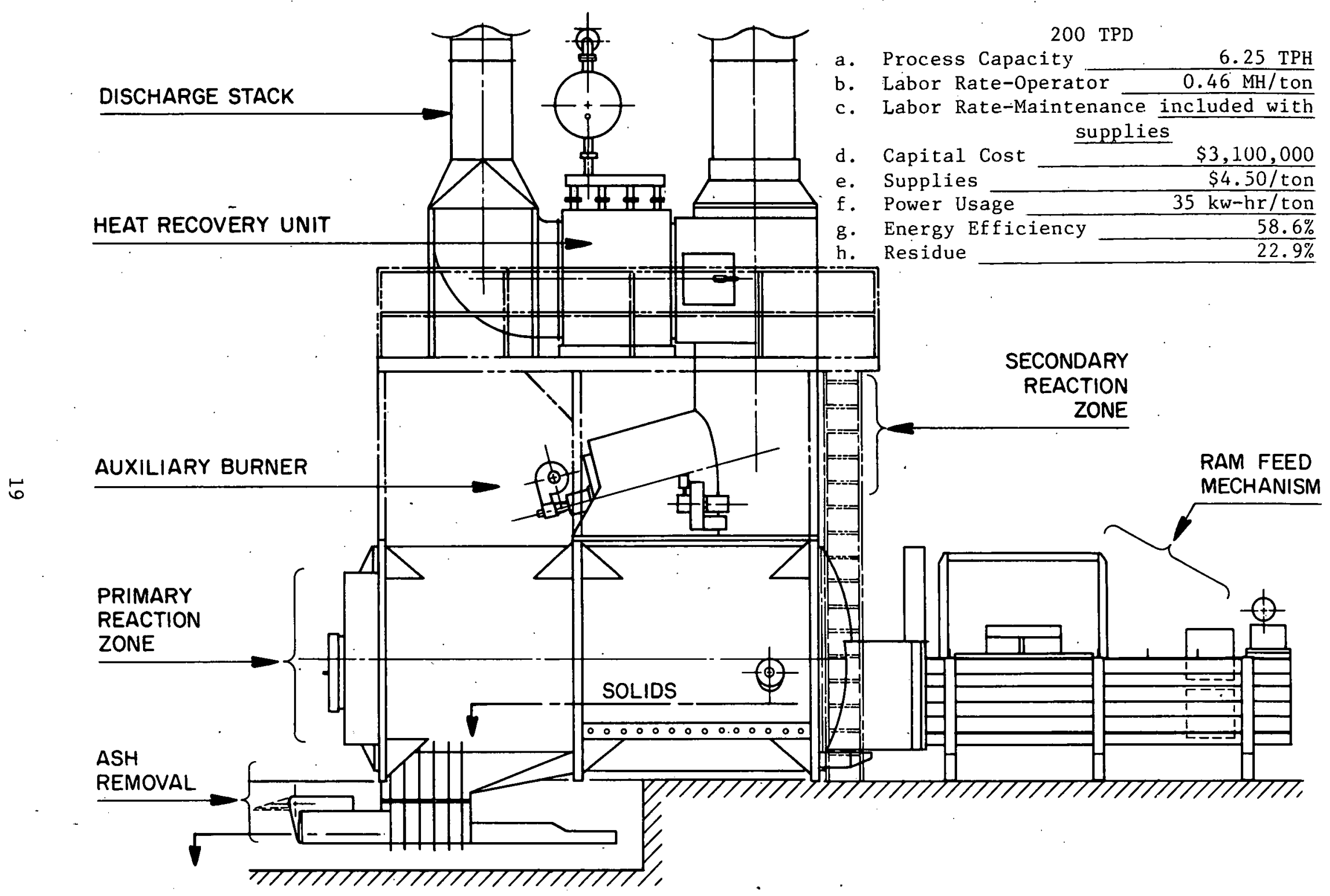

Figure 8. Modular incinerator schematic. 
capacity to required levels. The capital cost of these units is in the range of $\$ 10,000$ to $\$ 18,000$ per installed daily ton, and the net cost of processing waste is on the order of $\$ 10$ per ton, although operation at design levels may permit break-even operation for specific cases. Units applied to municipal waste are now being equipped to recover heat. in the form of steam or hot water and to operate at an overall thermal efficiency of from 40 to 60 percent. Heat recovery is only possible with units located near an appropriate user, placing a limitation on the applicability of the units.

Because modular incinerators have only been used for municipal wastes for the past 3 to 5 years, there is not a great deal of information available concerning the performance life, long term maintenance requirements, or performance characteristics of the units. Limited work has been done to evaluate the performance of the units when processing municipal waste. Reports on these evaluations include studies by Ross Hofmann Associates, "Evaluation of Small. Modular Incinerators," OSWM of the U.S. Environmental Protection Agency, 1976; Systems Technology Corporation's, "Operational Testing of a Controlled Air Incinerator with Automatic Ash Handling,". CEL Naval Construction Battalion Center, 1976; and "Operational Testing of a System for Solid Waste to Energy Conversion," CEL Naval Construction Battalion Center, 1976.

Evaluations:performed thus far have indicated that maintenance requirements on the units have been higher than anticipated, particularly for solids handling equipment. It has also become apparent that the method of rating units has tended to overstate unit capacities, probably because the ratings are based on commercial wastes. Further, because of the increasingly stringent emissions standards, the ability of in-service units to continue to meet these standards without careful attention to operation and maintenance requirements has been questioned. The increasing use of these systems by municipalities because of their applicability to small-scale applications requires increased research to characterize and improve the performance of these units.

- Specifically, the areas noted above (operational life, capacity, maintenance, operating requirements, and actual thermal efficiency) require additional research and development efforts.

Following is a listing of manufacturers of modular incinerators including addresses, varlations from the basic concept, and municipal applications.

Advanced Pollution Abatement Corporation--

First National Bank Building

124 Main Street

Hudson Falls, New York 12839

Variations from basic concept:

Units only come with manual feed and ash handling at capacities for commercial waste of .6-TPD heat recovery.

Municipal applications:

None exist. Although company w111 market municipal units, manual ash and feed unit drastically limits applicability. 
Basic Engineering, Inc.--

21 W 161 Hill

Glen Ellyn, Illinois 60137

(312) $429-5340$

Variations from basic concept:

Unit consists of a primary reaction chamber which includes heat recovery equipment. Ash removal is achieved by opening bomb bay doors in the bottom of the chamber.

Municipal applications:

No installed units for MSW. Capacity of available units is 86 TPD of commercial waste.

Cico, Inc.--

1600 West Hasket Street

Appleton, Wisconsin 54911

Municipal applications:

Unit presently under construction at Lewisburg, Tennessee.

Clear Air, Inc.--

P.0. Box 111

Ogden, Utah 84402

(801) $399-9828$

Variations from basic concept:

Units have patented reciprocating grate and three-chamber combustion vessel. Requires electrostatic precipitator.

Municipal applications:

Melrose Park, Illinols (closed down); Weber County, Utah; Hamilton, Montana.

Combustion Engineering, Bartlett-Snow--

220 West Monroe Street

Chicago, Illinois 60606

(312) $235-4044$

Variations from basic concept:

Rotary primary reaction zone. Wet scrubber stack cleanup. Wet ash handling using a slurry pump. No heat recovery available.

Municipal applications:

No units installed for MSW, but CE is interested in installing them.

Comtro--

Century Plaza Building

Suite 410

Lansdale, Pennsylvania 19446 
Variations from basic concept:

This unit is typical of the general unit described, having automatic feed and ash handling, heat recovery, and wet or dry ash handling system.

Municipal applications:

Three units Installed: Pelham, New Hampshire; Prudhoe Bay, Alaska;

Caracas, Venezuela

Consumat Systems, Inc.--

P.0. Box 9574

Richmond, Virginia 23228

Variations from basic concept:

Ram discharge of waste from containment vessel. Generally installed in pairs with common secondary zone and heat recovery.

Municipal applications:

33 installations, up to 100 TPD:

Kensett, Arkansas

Osceola, Arkansas

Donaldsonville, Louisiana

Plaguemine, Louisiana

Hope, Arkansas

Blytheville, Arkansas

August, Arkansas

Arkins, Arkansas

Pahokee, Florida

Tahlequah, Oklahoma

Coos County, Oregon

Refugio, Texas

Salem, Virginia

Shemya Air Force Base

Vancouver Island, Canada

Kurobane, Japan

Tripoli, Libya
Stuttgart, Arkansas

Bentonville, Arkansas

Rayne, Louisiana

Wrightsville Beach, North Carolina

Siloam Springs, Arkansas

Hot Springs, Arkansas

North Little Rock, Arkansas

Orlando, Florida

Port Orange, Florida

Cleveland, Oklahoma

Coqville, Oregon

Terrell, Texas

Bellingham, Washington

Shemya, Alaska

Lake Cowichan, B.C., Canada

University of Riyadh,

Saudi, Arabia

Environmental Control Products, Inc.--

Charlotte, North Carolina 29210

Variations from basic concept:

Temperature control is achieved completely through control of feed rate and combustion air supply. Spray quench for ash discharge.

Municipal applications:

One unit installed at Groveton, New Hampshire. Units rated at 12 TPD. 
Environmental Devices, Inc./Pacific Coast Incinerators-710 Delaware

Berkeley, California 94710

(415) 848-0210

The Giery Company, Inc.--

P.0. Box 17335

Milwaukee, Wisconsin 53217

(414) $351-0740$

Variations from basic concept:

Units use a rotating "basket" grate to effect excellent burnout. A vertical, cyclonic afterburner.

Municipal applications:

One 24-TPD unit installed in Grafton, Wisconsin.

Kelly Company, Inc.--

6720 North Teutonia Avenue

Milwaukee, Wisconsin 53209

(414) 352-1000

Variations from basic concept:

Primary combustion air is preheated before being injected under the solids bed. Unit is operated under positive pressure in the

reaction zones.

Municipal applications:

Six units installed for MSW in New Hampshire:

Notingham Bridgewater

Wolfboro Pittsfield

Meredith

Auburn

Morse Boulger--

53-09 97th Place

Corona, New York 11368

(212) $699-5000$

Variations from basic concept:

Units have dry ash removal.

Municipal applications:

No units installed for MSW

Rotary Kiln (Wright-Malta Corporation)

System Description--

The Wright-Malta process (Figure 9), which is still under development, uses a high-pressure, steam-heated, concurrent rotary kiln to convert municipal solid waste and sewage sludge into a low-Btu fuel gas. The product fuel gas is then used to power a gas turbine generator set which produces electricity for sale. The hot turbine exhaust is passed through a pair of heat exchangers that produce steam for heating the kiln and for a sludge preheater. 


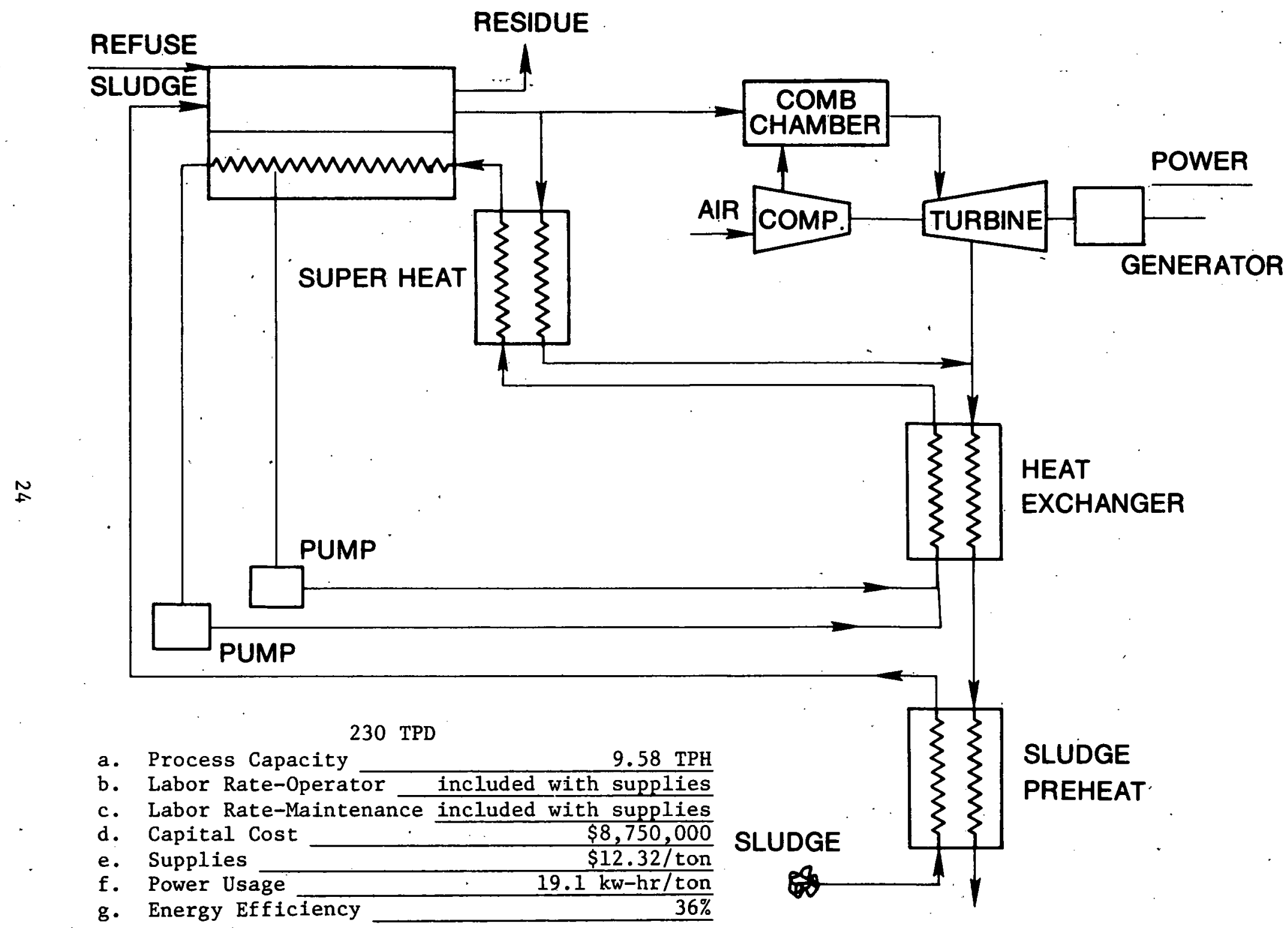

Figure 9. Wright-Malta process schematic. 
The primary component of this process is a pressurized rotary kiln reactor vessel. The kiln is $100 \mathrm{ft}$ long and $5 \mathrm{ft}$ in diameter and is declined slightly downward. The kiln rotates at $1-2 \mathrm{rpm}$.

Shredded solid waste, preheated municipal sewage sludge, and an alkaline catalyst $\left(\mathrm{NA}_{2} \mathrm{CO}_{3}\right)$ are mixed in a double lock hopper vessel. This material is introduced into the kiln by a metering auger. As the material progresses through the kiln, the temperature increases from $300^{\circ}$ to $900^{\circ} \mathrm{F}$ to dry the waste material and then to pyrolyze it. The ash and unconsumed char are discharged through a second set of lock hoppers.

The resultant product fuel, with a heating value of approximately $117 \mathrm{Btu} / \mathrm{SCF}$, is piped to a gas turbine generator where it is combusted. The electrical power produced by the generator can be sold to an electrical utility, a private user, or another buyer. A portion of the fuel gas is used for the steam super heater.

The hot exhaust gases are passed through two heat exchangers-- the first being used to produce steam to drive the reaction and the second being used to preheat the sludge. Steam exiting the first heat exchanger is approximately $900^{\circ} \mathrm{F}$. The gas is then passed through a super-heater, which is powered by the fuel gas, and it exits at a temperature of approximately $1200^{\circ} \mathrm{F}$. The super-heated 400-psig steam is introduced to the coils in the kiln wall, and it flows countercurrent to the flow of refuse. This coil provides the heat required to sustain the reaction in the kiln. The exiting steam is then condensed and returned to the feed water pump.

The major problem to be encountered in the development of this technology probably will be in the pressurized reactor vessel. This vessel is at 200- to 300-psi pressure, and the flow characteristics of solid waste and sewage sludge make it difficult to inject this material into the reactor while maintaining an air seal. The ability to maintain a high pressure seal on a rotating cylinder also will be a problem.

\section{Experience--}

Wright-Malta, Ballston Spa, New York, is in the process of completing a laboratory scale $(10 \mathrm{lb} / \mathrm{hr})$ study of their gasification process. Tests have been performed in a batch-feed, pressurized rotating autoclave "minikiln" and also in a higher pressure, continuous-feed reactor. The tests demonstrated the feasibility of the basic reaction chemistry and provided the quantitative evaluation process.

\section{Cost--}

The estimated cost of a 230-TPD facility is $\$ 8,750,000$. This price includes front-end sludge handling equipment, gasifier, gas turbine generator, heat exchanger controls, and miscellaneous equipment. The calculated net disposal cost is $\$ 18.85$ per ton.

Research Needs--

1. Assess the ability to maintain pressure seals on the pressurized rotary kiln. 
2. Determine the ability to burn the gas in the gas turbine.

3. Determine the effect of sludge on heat exchanger materials and heat transfer surfaces.

$\underline{\text { Rotary Kiln (Devco, Incorporated) }}$

System Description--

The Devco process is a rotary kiln pyrolysis unit that does not require a shredded feedstock. Devco of New York, New York, supplied a very limited amount of technical and economic information about its system. Therefore, it has not been possible to analyze the system or to describe it in detail.

Experience--

This system is reported to have been under development since 1968 at a site in College Point, Queens, New York.

Cost--

No cost or operating data was supplied by Devco.

Research Needs--

Documentation and testing of the process.

Packed Bed (Andco-Torrax System, Andco; Inc.)

\section{System Description--}

The Andco-Torrax system (Figure 10) produces a low-Btu fuel gas. The heat required to sustain the high temperature reaction is provided by hot air which is blown into the gasifier.

The central piece of equipment in this process is a vertical-shaft furnace that is used as a gasification vessel. Raw refuse is introduced into the system through a series of lock hoppers at the top of the vessel. As the material flows downward through the reactor vessel, it passes through successive zones of drying, heating, and pyrolysis. The hot pyrolysis gases flow upward through the packed bed and cool as they transfer the heat to the refuse. After the gases exit the reactor vessel, they are passed through a cyclone to remove any carbonaceous material which may be entrained in the gas stream. The carbonaceous solids from the cyclone are then pulverized and may be sold às a fuel.

The gases (1ow-Btu) from the cyclone pass through an induced-draft fan which forces the gas through the pipeline to the user. A small amount of gas is drawn off and burned in a secondary combustion chamber. The hot gases from the combustion chamber are then passed through a pair of regenerative heaters or "stoves." The stoves operate in a cycle with hot fuel gases heating up the ceramic lining, and alternatively cold air is passed through the stove which transfers heat to the air that is injected to the gasifier.

The heated air is then injected into the lower section of the gasifier through a series of ports into the pyrolysis zone, initiating the pyrolytic reaction. 


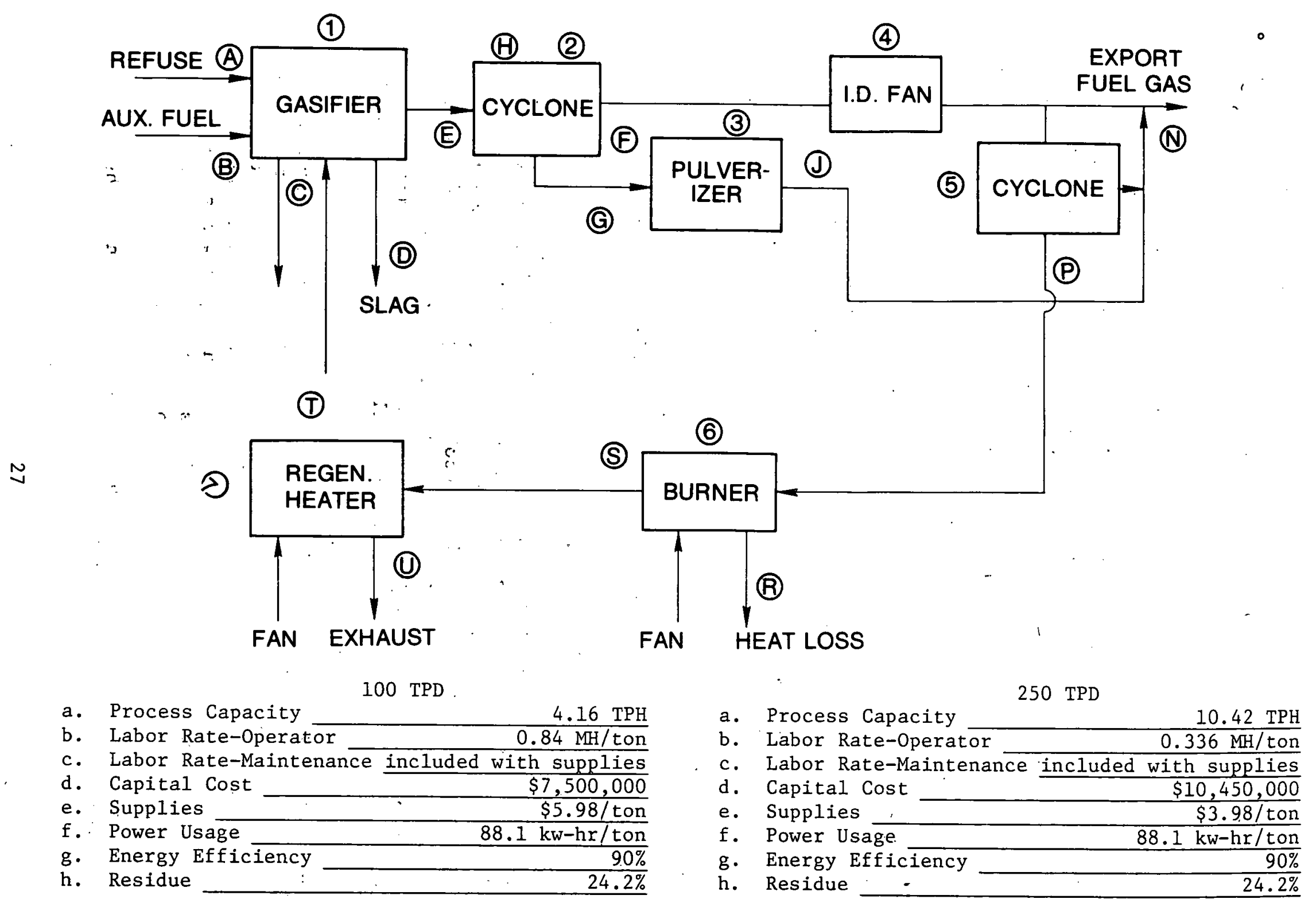

Figure 10. Andco-Torrax process schematic. 
Experience--

A prototype facility was built in 1971 and operated under an EPA demonstration grant in Orchard Park, New York. This facility was also used as an engineering development facility until it was closed in 1976.

Andco-Torrax of Buffalo, New York, is-presently building three smaller systems in Europe. Two 200-metric-TPD units are presently being installed, one in Luxemburg and the second in Frankfort, West Germany. The third is a 170-metric-TPD unit that is being installed in Grassee, France. At the present time, these plants are in startup, and their operating experience is limited.

Cost--

Andco has estimated the capital cost of a 100- and 200-TPD facility at $\$ 6,900,000$ and $\$ 9,500,000$, respectively. The calculated net disposal cost is $\$ 31.17$ and $\$ 13.34$ per ton, respectively.

Research Needs--

1. Verification of the recovered energy stream.

2. Confirmation of the system's emission levels.

3. A detailed technical and economic evaluation of the European installations.

Packed Bed (Simplex System, Dynecology, Inc.)

System Description--

The Simplex process (Figure 11) uses a vertical-shaft furnace to gasify a combination of coal and MSW to produce a medium-Btu fuel gas. The primary intent of this system is to use solid waste as a stabilizer and a binder for coal pellets to increase their mechanical strength at elevated temperatures.

Crushed coal and MSW are blended together at a rate of $1: 1$ and $3: 1$ coal-to-MSW ratio (by weight). This mixture is.briquetted prior to being introduced into the gasifier via lock hoppers.

The material charge passes through a drying and preheating zone where the feed is dried and heated. As the charge descends down the furnace, it passes through zones of successively higher temperatures. In passing through these zones, the organic components of the solid waste are pyrolyzed, and the volatile components of the solid waste are distilled.

At the bottom of the furnace, steam and oxygen are introduced through a series of tuyeres. The heat produced by the partial combustion of the coal/ solid waste mixture is used to sustain the reaction. The inorganics form a slag at the bottom of the furnace which is tapped off to a water quench.

The evolved gases, after exiting the gasifier, are passed through a spray scrubber which cools the gas. The gas stream then goes to a separator which is designed to remove the water and condensable tars and ofls from the gas. 


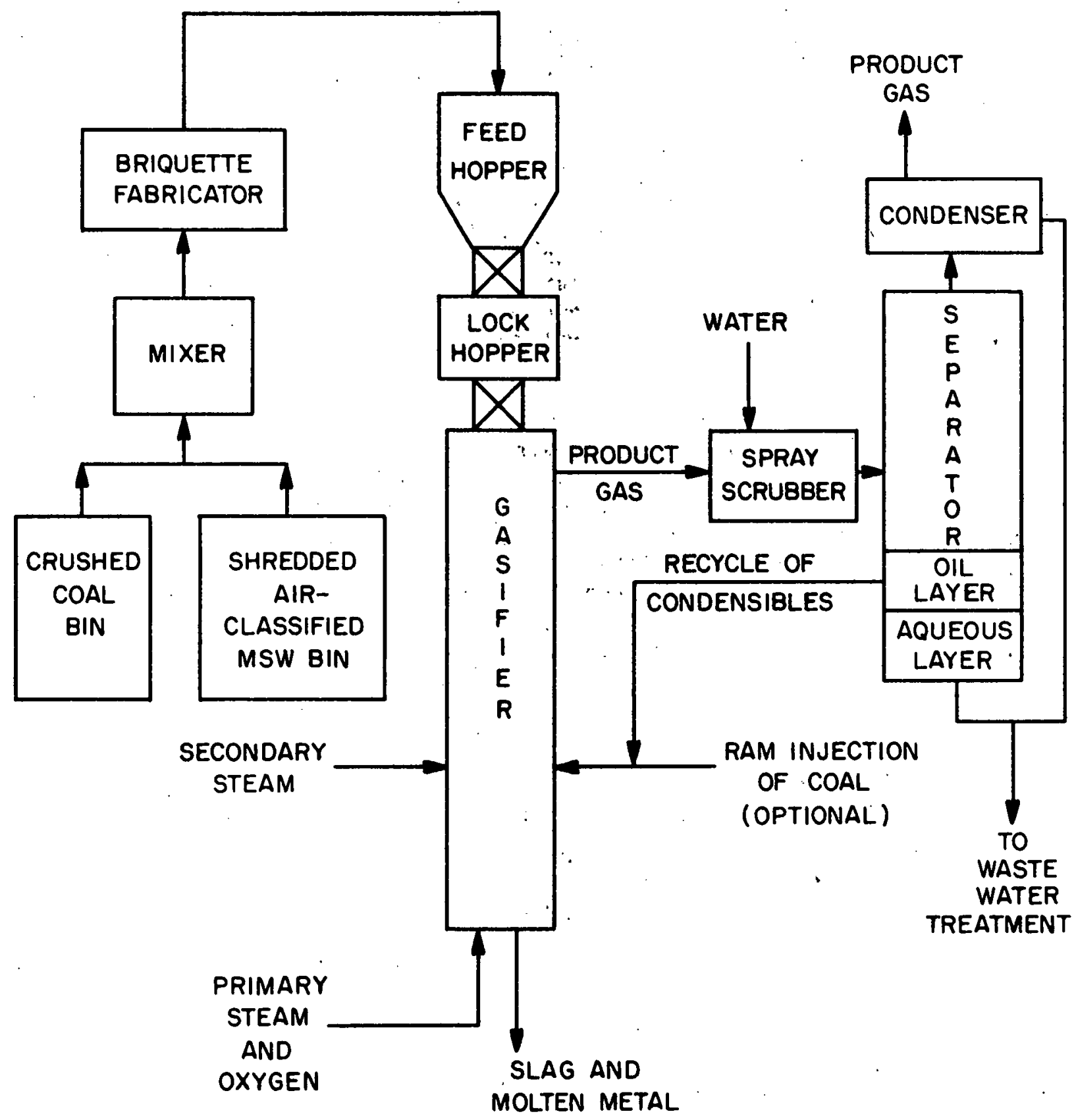

Figure 11. Simplex process schematic. 
The condensable oils and tars are recycled to the hearth. The gas from the separator is piped to the condenser where the remaining water is condensed before the gas is piped to the customer.

\section{Experience-}

Columbia University Department of Chemical Engineering has conducted lab scale (single pellet) experiments on this system at various coal:refuse ratios. Their primary objective was to obtain a stable coal pellet for coal gasification. Work is continuing on the development of this system.

Cost--

The capital cost of a 2700-TPD facility was estimated at $\$ 100,000,000$. Due to the limited amount of data available on this system, we did not include it in our evaluation. The progress of the lab scale testing indicates that substantial amounts of $R \& D$ will be required to make the system commercially viable.

Research Needs--

Lab scale tests to determine the system's technical operating characteristics and design data.

Packed Bed (Tech Air Corporation)

System Description--

The Tech Air system (Figure 12) is a directly heated gasifier with air injection that produces both a gas and a fuel oil fraction from solid waste. The reaction vessel is a vertical shaft packed bed which was originally developed for agriculture waste such as nut shells, cotton gin waste, and hogged wood waste. The shredded, magnetically separated solid waste to be pyrolyzed is introduced at the top of the gasifier, and 4 to 8 percent of the theoretical air is injected near the bottom of the vessel. The air reacts with the gaseous fuel and char, thereby liberating the heat required to sustain the endothermic reaction. Electric resistance heaters are used to initiate the reaction when starting from a cold condition.

The hot gases flow upward through the bed first drying the feed material, then elevating the temperature of the material. As the temperature of the waste rises, the solids begin to pyrolyze, liberating additional gases which flow up through the bed.

The char and other residue are continuously discharged as a solid from the bottom of the converter. The amount of carbon and volatile matter depends upon pyrolysis conditions in the lower zone of the gasifier.

The gases, which exit the top of the converter at $400^{\circ}$ to $500^{\circ} \mathrm{F}$, are passed through a condenser, a scrubber, and a demister to reduce the organics and moisture content of the gas. The liquid removed from the gas is filtered, and the filter cake is reinjected into the converter.

The recovered oil has a higher heating value (HHV) of $9081 \mathrm{Btu} / \mathrm{lb}$ with 26 percent moisture and a density of approximately $10 \mathrm{lb} / \mathrm{gal}$. The gas has a HHV of $125 \mathrm{Btu} / \mathrm{SCF}$. 
200 TPD
a. Process Capacity
8.33 TPH
b. Labor Rate-Operator
$0.44 \mathrm{MH} / \mathrm{ton}$
c. Labor Rate-Maintenance $0.04 \mathrm{MH} /$ ton
d. Capital Cost
$\$ 3,000,000$
e. Supplies $\$ 0.07 /$ ton
f. Power Usage
$\begin{array}{r}62.85 \mathrm{kw}-\mathrm{hr} / \mathrm{ton} \\ .93 \% \\ \hline\end{array}$
g. Energy Efficiency

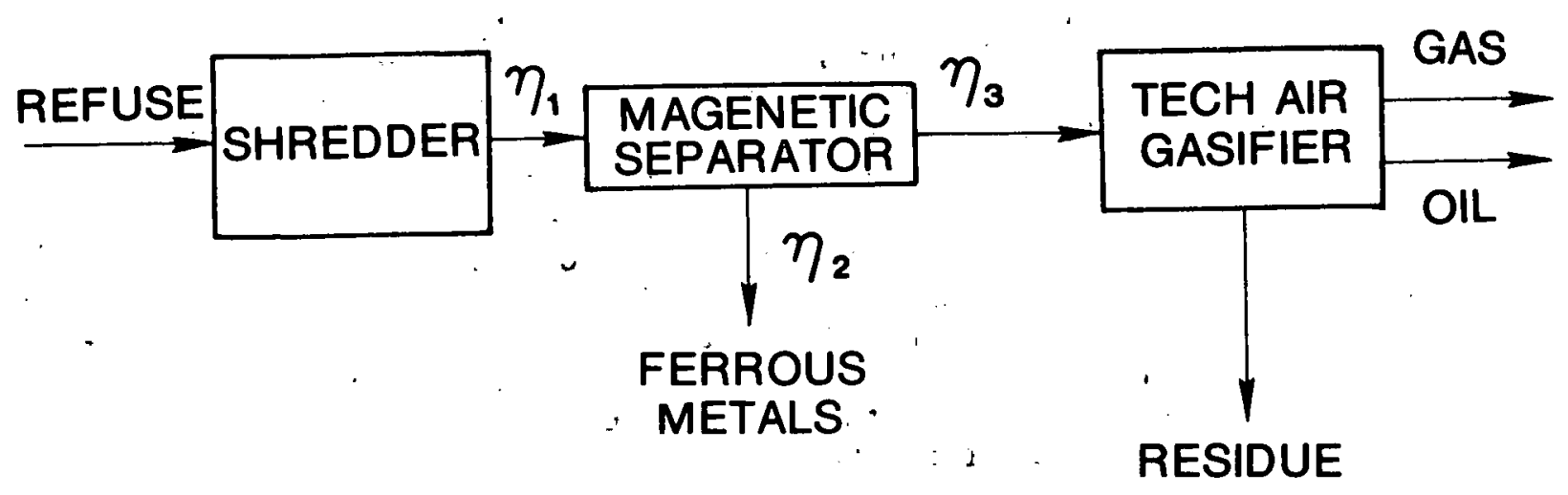

Figure 12. Tech Air process diagram. 


\section{Experience--}

Tech Air operated a $11 / 2$ ton per hour (TPH) pilot plant in Cordele, Georgia, on wood waste for 18 months: . They have also made over 50 runs of solid waste and sewage sludge.

Costs--

The estimated capital cost of a 200-TPD system, exclusive of preprocessing, is $\$ 3,000,000$. The calculated net cost of the system, based on their pilot plant experience is approximately $\$ 8.23$ per ton.

\section{Research Needs--}

1. Demonstrate this process using existing units with solid waste as a feedstock and determine its economics.

2. Verify system thermal efficiency when processing municipal solid waste.

Packed Bed (Century Research, Inc., Minimax Gas Producer)

System Description-

The Minimax system (Figure 13), is a partial oxidation process using air as an oxidizing agent to produce a low-Btu "producer gas." This system, which was originally developed in China during World War II, is based on technology that dates back over 1000 years. This system has been used to produce a fuel gas from a wide variety of feed stocks. The last of the operating producers was closed on Taiwan when natural gas was discovered there.

The feedstock for this process must be as uniform as possible. For solid waste, this will require shredding and the removal of all metal and glass. The feedstock is shaped (pelletized) before it is introduced to the producer. It is very important that the pellets have sufficient mechanical strength to maintain their structural integrity through all temperature ranges. It is the structural integrity of the pellets that maintains the distinct zones in the reactor.

The producer is a tall, vertical-shaft furnace with ash handling capabilities. During operation there are five zones in the reactor: ash zone, oxidation zone, primary reduction zone; secondary reduction zone, and preheating zone. The process converts all fixed carbons to a combustable gas. Steam (or water) is injected in the oxidation zone to increase the $\mathrm{H}_{2}$ yield of the gas via the watergas shift reaction.:

The evolved gases have a heat content of 125 to $165 \mathrm{Btu} / \mathrm{SCF}$. The gas producer has an energy effectiveness of approximately 90 percent, that is, the "producer gas" contains 90 percent of the energy in solid waste introduced to the system.

Experience--

Century Research of Gardena, California, and their subsidiary firms built many of these gas producers in China and Taiwan to operate on a variety of feedstocks. With the discovery of natural gas on Taiwan, the need for gas 


\section{CENTURY RESEARCH}

(1)

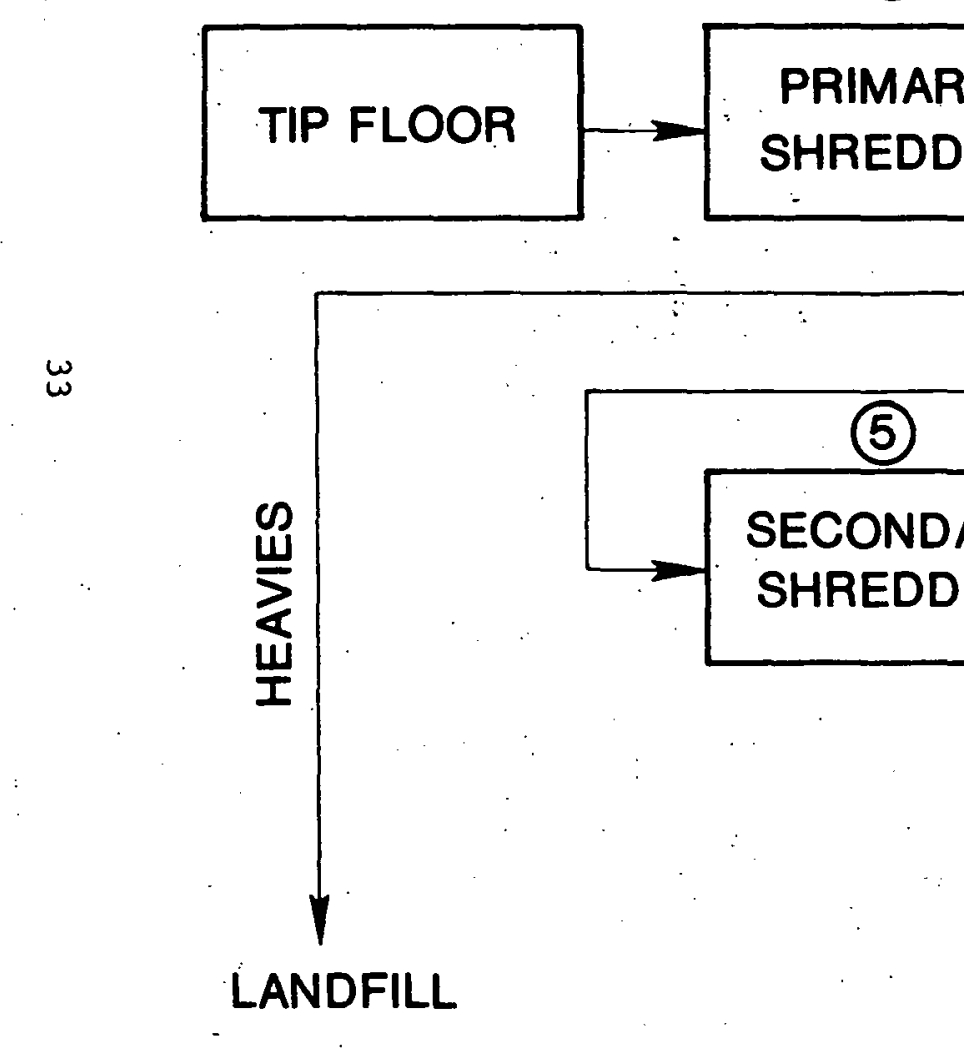

(2)
(3)

(4)
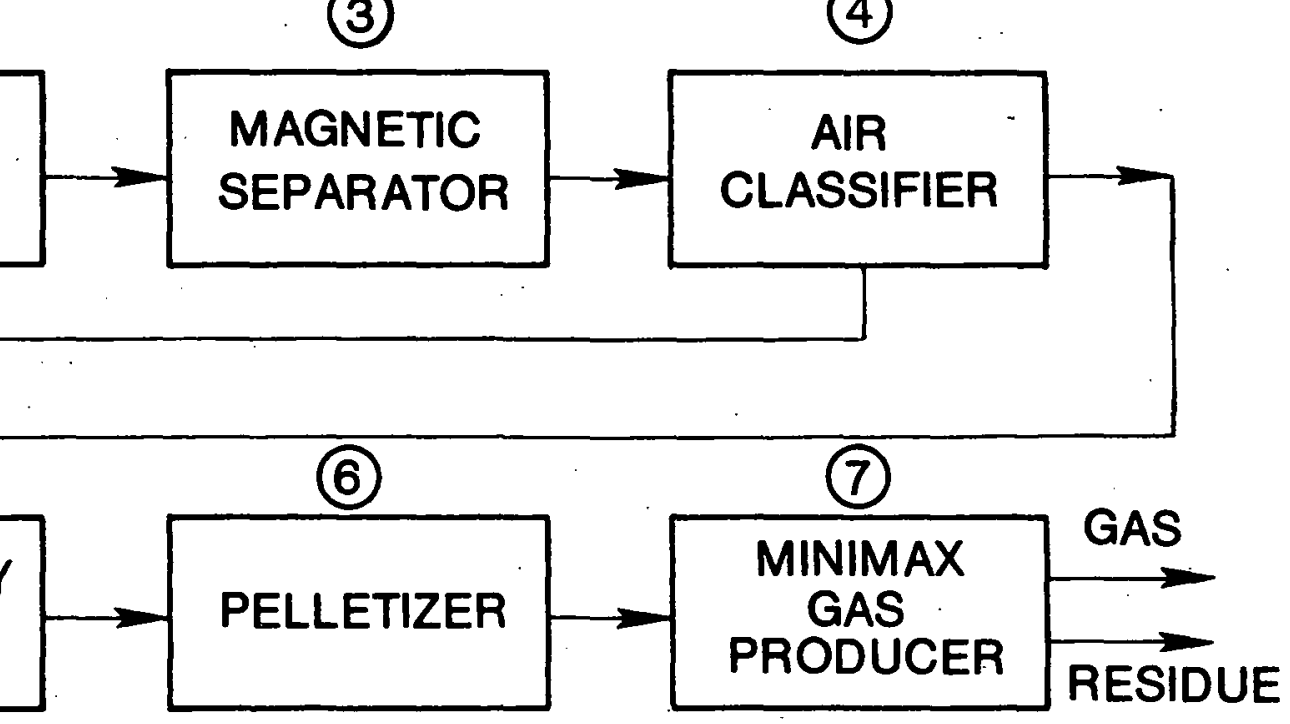

150 TPD
a. Process Capacity $\frac{6.25 \mathrm{TPH}}{\text { b. Labor Rate-Operator }}$
c. Labor Rate-Maintenance $0.12 \mathrm{MH} /$ ton
d. Capital Cost
e. Supplies
f. Power Usage
$\$ 1,500,000$
$18 \mathrm{kw}-\mathrm{hr} / \mathrm{ton}$
g. Energy Efficiency $90 \%$
h. Residue

Figure 13. Century Research process schematic. 
producers was eliminated. Although they have not built a gas producer in approximately 20 years, or one for solid waste, Century does not expect any great difficulties in building such a unit.

Century Research has submitted an unsolicited proposal to the Department of Energy and the Environmental Protection Agency for funds to do additional development work on this process.

Costs--

Century Research estimates the capital cost of a 150-TPD Minimax gasifier at $\$ 2,471,880$. The operating and maintenance costs, based on their past experiences, were calculated to be $\$ 8.96$ per ton.

Probiem--

It is expected that the greatest difficulty in using the Minimax gasifier on solid waste will be obtaining a pellet with sufficient mechanical strength to withstand degradation during the pyrolysis process. Also, any glass or metals present in the solid waste will have a tendency to create slagging in the converter.

Research Needs--

1. Determination of pellet mechanical strength requirements.

2. Small scale demonstration of the process.

3. Demonstration of an effective feed and ash (slag) removal system.

\section{Fluidized Bed (Stanford/Combustion Power Fluidized Bed Reactor)}

System Description--

Stanford University and Combustion Power Company of Menlo Park, California, have been studying the use of a fluidized-bed reactor with boiler tubes located inside the furnace to recover energy from municipal solid waste. The fluidized-bed combustor (Figure 14) uses a preheated airstream injected below the solid waste in the combustor to maintain solid waste and supporting sand media in suspension. This airstream rapidly mixes with the material in the reactor, thus permitting highly efficient combustion of the material. The boiler tubes located inside the combustion area have been shown to have substantially higher heat transfer rates than other types of boilers. The high efficiency of the fluidized-bed combustor with a combustion temperature of approximately $1400^{\circ} \mathrm{F}$ makes it possible to meet the current California and Federal EPA standards with minimum difficulty. This is especially important in California which has strict air pollution control codes.

It is expected that, for this system to operate efficiently, a nominal particle size of less than $5 \mathrm{in.} \mathrm{will} \mathrm{be} \mathrm{required.} \mathrm{This} \mathrm{particle} \mathrm{size} \mathrm{may}$ be easily obtained through the use of a trommel and a primary hammermill. A secondary shredder may be required, but this will be dependent upon local conditions. 


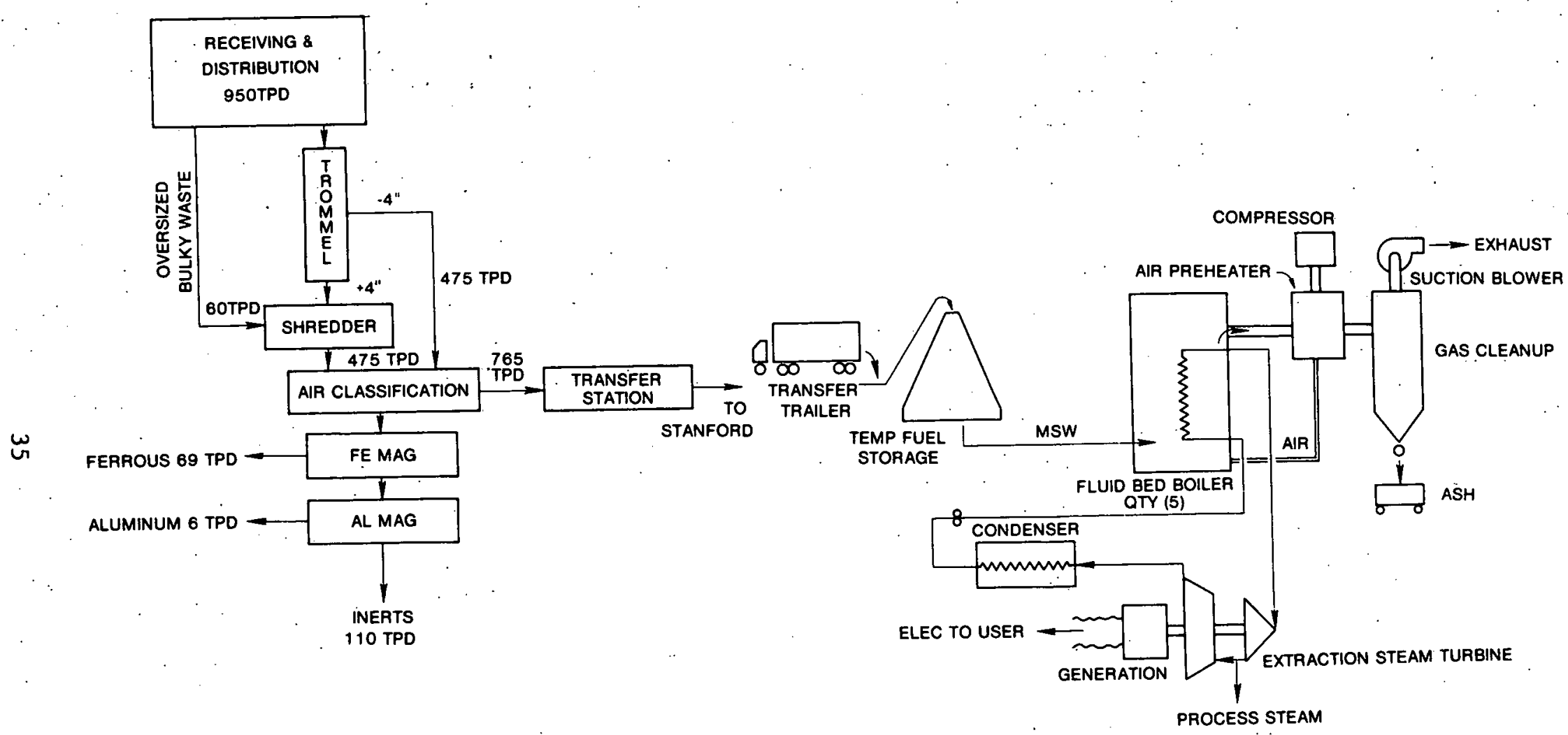

Figure 14. Stanford University/Combustion Power process schematic. 
The proposed fluidized-bed boiler would be $11.3 \mathrm{ft}$ wide by $12 \mathrm{ft}$ long by $20 \mathrm{ft}$ high. It would be equipped with its own economizer, air preheater, fans, feedwater treatment facility, condenser, and static gas cleanup system. The incoming solid waste fuel would be injected into the furnace by using large rotary feeder valves with flexible blades. Preheated combustion air (approximately $550^{\circ} \mathrm{F}$ ) will be injected into the boiler at a point below the MSW. The preheated air virtually lifts, separates, and evenly distributes the MSW into a tumbling mass for efficient combustion. A combustion temperature of $1480^{\circ} \mathrm{F}$ would be maintained in the combustion area. Because of the fluidized-bed action, there is a substantial quantity of particulate in the flue gas stream. A cyclone is used to capture this particulate and to recycle it back to the fluidized-bed boiler for further combustion. The gases exiting from the cyclone are passed through an economizer which preheats the feedwater to $490^{\circ} \mathrm{F}$. The gases are then passed through a heat exchanger which preheats the combustion air to $550^{\circ} \mathrm{F}$. The flue gases are then passed through a dry cyclone before they are discharged to the atmosphere. The resulting ash is hauled away to a landfill.

Unlike conventional boilers, boiler tubes pass through the combustion zone. The proximity of the boiler tubes to the combustion reaction and the violent mixing action can produce extremely high heat transfer rates. This permits the use of a smaller boiler to produce a given amount of steam. The immersion of the boiler tubes in the combustion zone may have a pronounced effect on erosion and corrosion rates of the boiler tubes.

Such a reactor with a capacity of 175 TPD could be expected to deliver $37,000 \mathrm{lb} / \mathrm{hr}$ of steam.

Experience--

Combustion Power Corporation has a $7-\mathrm{ft}^{2}$ experimental fluid bed combustor system that has been used for testing. Stanford University and the Combustion Power Company in association with Burns and Roe, Oradell, New Jersey, and the North County Joint Powers Authority, Santa Clara, California, have submitted a proposal for a program to demonstrate this concept.

\section{Cost--}

No cost information is presently available on this system.

Research Needs--

1. Detailed technical and economic performance data on the system.

2. The effect of the sand and MSW fuel on the boiler tube corrosion and erosion.

3. Determine emissions from the system:

\section{Fluidized Bed (Energy Resources Corporation)}

\section{System Description--}

Energy Resources Corporation, Cambridge, Massachusetts, over the past several years has been testing a 20-in. diameter fluidized-bed pyrolysis system. The system produces a pyrolytic char, a low-Btu fuel gas, and pyrolytic 
oil products from air-classified MSW. The relative proportions of the three energy products are a function of the reaction temperature.

This system requires shredded, magnetically separated, and air-classified solid waste with a nominal 2-in. particle size and containing 95 percent organics. Using 30 percent theoretical air, the partial oxidation process produces temperatures of $800^{\circ}$ to $1800^{\circ} \mathrm{F}$. Char production is maximized at the low end, pyrolytic oil production is maximized in the middle, and low-Btu gas production is maximized at the high end of the temperature range. The impact of operating temperatures on product yields is shown below.

$\begin{array}{lccc} & \mathrm{T}_{\text {Low }} & \mathrm{T}_{\text {High }} \\ \text { Char. } & 30 \% & - & 10 \% \\ \text { Pyrolytic 0il } & 5 \% & - \\ \text { Gas } & 65 \% & 90 \%\end{array}$

Energy Resources expects to recover 90 percent of the available heat contained in the incoming feed material as a useful energy product.

Experience--

Energy Resources Corporation, which has been operating a small pilot plant for several years, has conducted tests with various feedstocks including wood, agricultural waste, municipal solid waste, and sewage sludge.

Cost--

At present, no cost information is available from the vendor.

Research Needs--

Determine the technical and economic characteristics of the system for further evaluation.

\section{Fluidized Bed (Thermonetics)}

System Description--

The Thermonetics system (Figure 15) is a pressurized, oxygen-blown, gasification system that produces a medium-Btu fuel gas from shredded MSW. The heat required to sustain the reaction is provided by the reaction of. oxygen with the char in the secondary reactor vessel.

The incoming solid waste is shredded and introduced into the movingbed gasifier by a pair of pressurized lock hoppers. Inside the gasifier, the solid waste flows downward and countercurrent to the hot hydrogen synthesis gas mixture. Contact with the hot gases pyrolyzes the organic fraction of the refuse, thus producing a medium-Btu fuel gas. The solids continue to move downward through the nonslagging gasifier which has a maximum temperature of $1200^{\circ} \mathrm{F}$. 


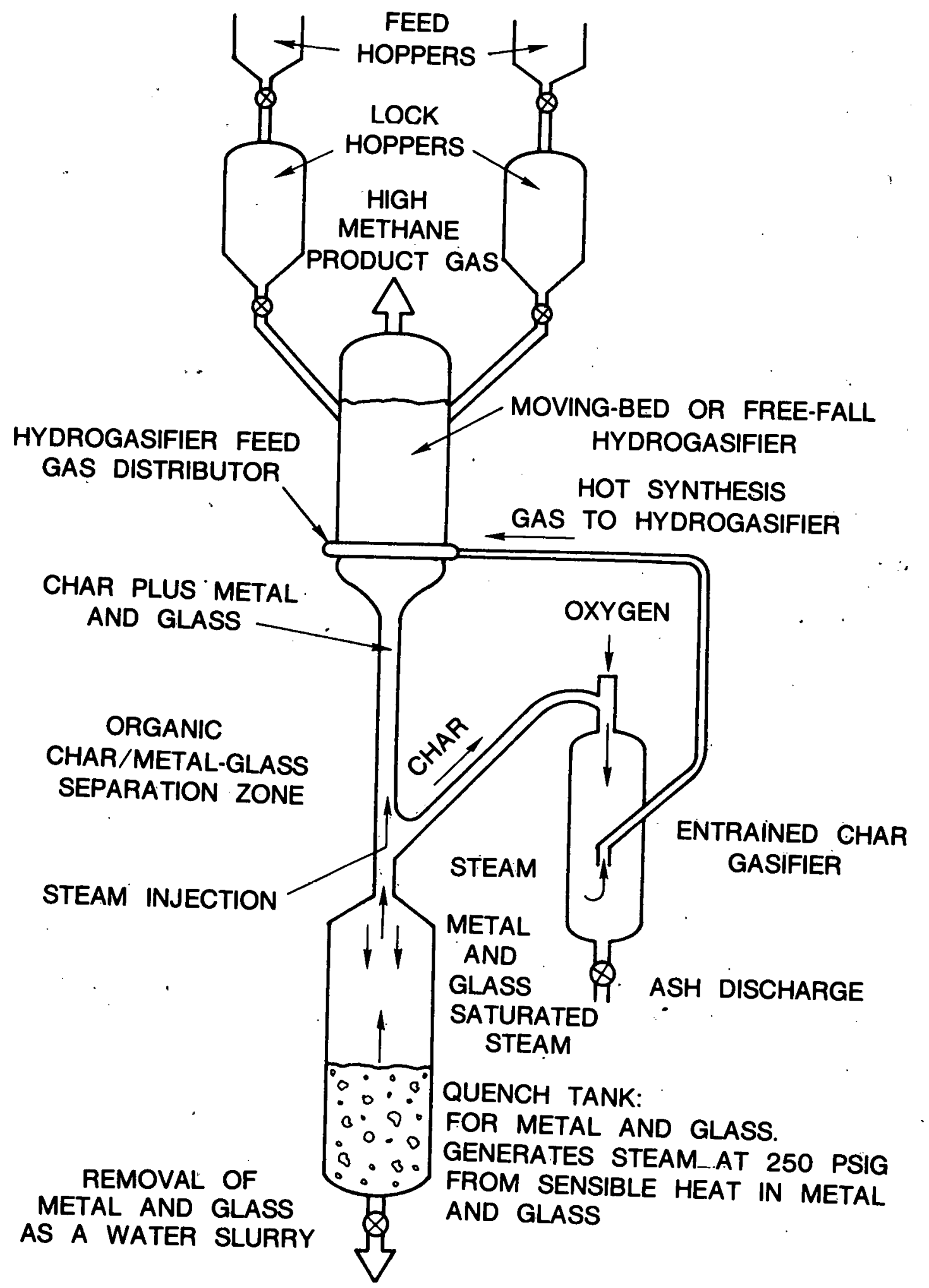

Figure 15. Thermonetics gasification system. 
After leaving the primary reactor, the solids fall through a "stripping zone" where steam entrains the organic char which is blown into an oxygen-fed ( 0.1 ton/ton) gasifier. The hot gas produced by the reaction of the oxygen and char is fed to the primary reactor.

Metal and glass fall through the stripping zone and are water quenched in the quench pot. They are discharged from the quench pot in a water slurry after the metals and glass have been removed.

Thermonetics of Oklahoma City, Oklahoma, estimates that this system has a net thermal efficiency of approximately 73 percent, including energy consumed by the system.

\section{Experience--}

A limited amount of information is available on this system since Thermonetics considers all unpublished information proprietary. They have conducted several tests in their pilot reactor unit and have published some of the results.*

\section{Cost--}

No cost information is available.

Research Needs--

1. Detailed information on the unit's performance to assess this process for small systems.

Horizontal Auger (Scientific Energy Engineering, Inc.)

System Description--

The Scientific Energy Engineering process employs a horizontal cylindrical chamber to gasify municipal solid waste with the resultant combustible gas burned to completion in an attached secondary chamber. Operating temperatures are $1500^{\circ} \mathrm{F}$ in the primary chamber and $1800^{\circ}$ to $2000^{\circ} \mathrm{F}$ in the secondary chamber.

Solid waste is moved through the primary chamber by a horizontal auger which also tumbles and mixes the waste during the 45-minute retention time in the vessel. Combustion air, preheated as it passes through the vessel walls, is carefully controlled to maintain proper process temperatures. Residue from the process is discharged to a wet quench and removed for subsequent disposal. Hot gases from the process are passed through a boiler to recover the energy contained in the gases (see Figure 16).

It has been concluded that the system operates most effectively when processing a refuse derived fuel product. Consequently, some preprocessing is performed ahead of the thermal processing system to upgrade the fuel value of the waste stream (see Figure 17).

* Feldman, H. F., G. W. Fennlton, H. Nack, and J. Alderstein. Syngas Process Converts Waste to SNG. Hydrocarbon Processing, November, 1976, pp. 201-205. 
200 TPD

a. Process. Capacity

b. Labor Rate-Operator

c. Labor Rate-Maintenance

d. Capital Cost

e. Supplies

f. Power

g. Effictency

h. Residue $10 \mathrm{TPH}$

Mitton

$1 \mathrm{MH} / \mathrm{ton}$

$\$ 3,500,000$

$\$ 2.50 /$ ton

$60 \%$

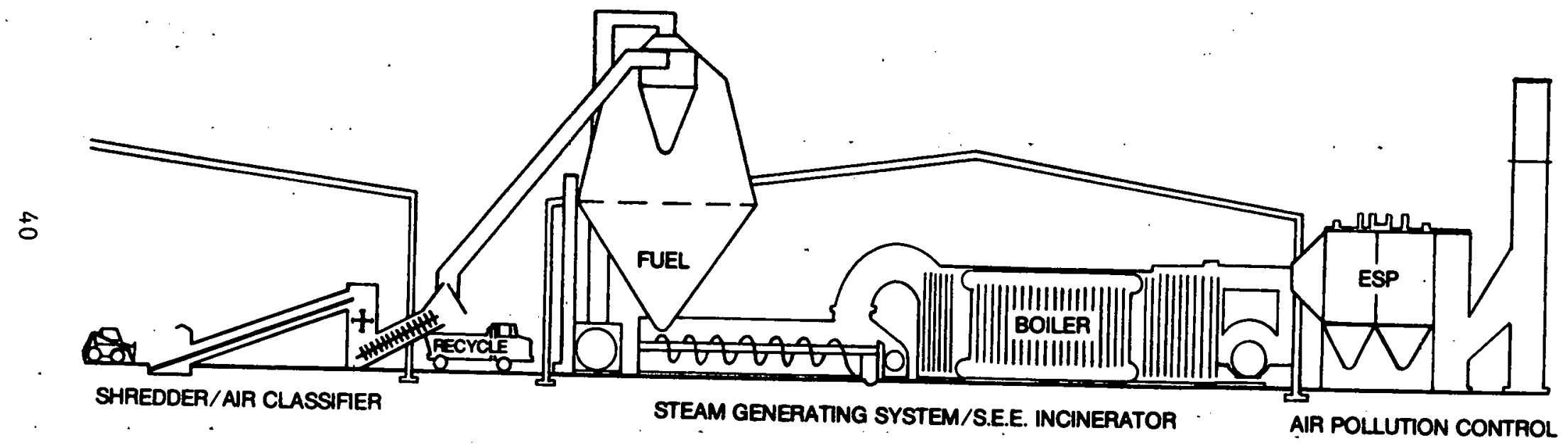

Figure 16. Scientific Energy Engineering Incineration System Configuration. 


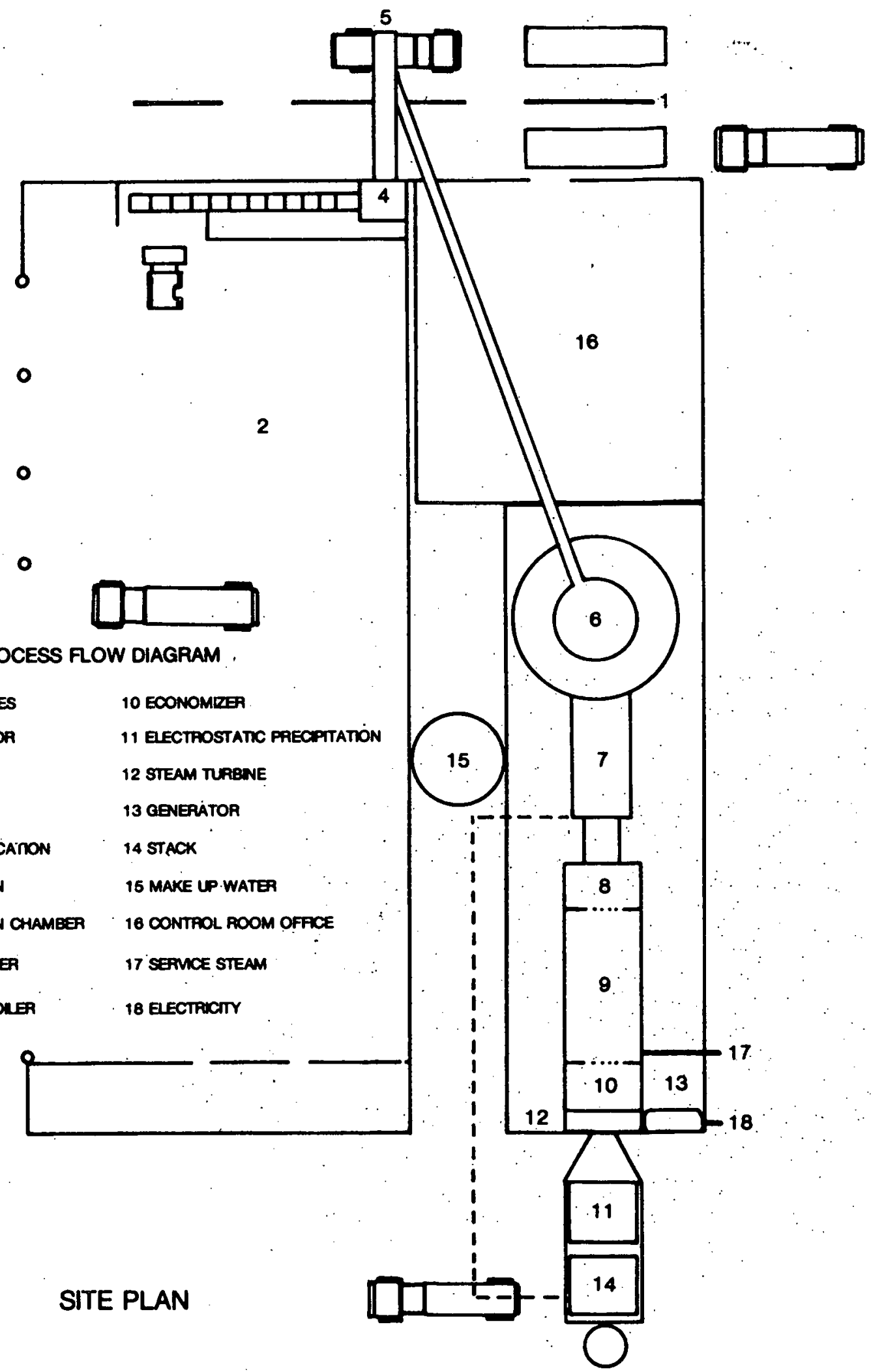

1 TRUCK SCALES

2 TIPPNG ROOA

3 CONVEYOR

4 SHPEDOER

5 AR CLASSIFCATION

- storace B.

7 COMBUSTION CHAMBER

6 SUPER HEATER

- package boven

10 ECONOMEEA

14 STACK

16 MAKE UP. WATER

8 ELETTRCTY

Figure 17. Scientific Energy Engineering Process Flow Diagram 41 
Experience--

A 250-TPD prototype facility has been in operation in Jacksonville, Florida, for $21 / 2$ years. This unit has undergone periodic testing during this time, and a series of modifications have been made to improve the unit's performance and reliability. The unit has been demonstrated to be capable of processing mixed municipal waste, mixed municipal waste and sewage sludge, and refuse derived fuel material. No detailed test results have been provided by the vendor to allow detailed analysis of system performance.

Cost--

The capital cost of a 250-TPD module has been estimated to be between 3.5 and 4 million dollars. Calculations provided for the system vendor indicate that the unit can be operated at a net profit without a tipping fee. These figures are believed to be somewhat optimistic.

Research and Development Needs--

1. Refine afterburner (secondary reaction chamber design).

2. Obtain detailed performance data from vendor or have required testing performed on the prototype.

3. Develop appropriate preprocessing system to reliably produce. feedstock material.

4. Perform detailed economic evaluation of the system.

PYROLYSIS (INDIRECT HEATING)

Travelling Grate (Kemp Reduction Corporation)

System Description--

The Kemp Reduction pyrolysis system produces combustible char, pyrolytic oil, and fuel gas from shredded and magnetically separated solid waste. The fuel gas is used to produce the heat required to sustain the reaction, and the pyrolytic oil is sold as a fuel.

The heart of the Kemp Reduction system is the pyrolytic reactor which consists of a high alloy steel conveyor that is contained in an elongated refractory-lined chamber. The shredded solid waste, which is carried on the conveyor, is radiantly heated by the gas-fired combustor surrounding the chamber. As the material increases in temperature, it pyrolyzes producing combustible gases which are then withdrawn from the chamber. The residual char remains on the conveyor and is removed at the end of the chamber. Very little data or information was available on the mechanical details of the sys tem.

The gases withdrawn from the chamber are cooled and condensed producing a fuel gas and a pyrolytic oil. The fuel gas is recycled and is burned in the chamber surrounding the reactor vessel to provide the heat required to sustain the reaction. The char recovered from the end of the chamber can also be used as a fuel. 


\begin{abstract}
Experience--
Kemp Reduction, Santa Barbara, California, has been working on the pyrolysis of various materials for over 20 years. They have completed tests on this process in both a lab scale and a 5-TPD prototype system. Modifications have been made to the system design based on these test results.
\end{abstract}

Cost--

Kemp Reduction estimated the capital cost of a 100-TPD system at approximately $\$ 3,900,000$. The calculated net cost of this system is $\$ 10.60$ per ton.

Research Needs--

1. Detail information on the process, mechanical design, and products produced by the facility.

2. Verify the quantities of energy products produced by the system.

3. Establish the value and marketability of the pyrolytic oil and char produced by the process.

Travelling Grate (Wallace-Atkins Oil Corporation)

System Description--

The Wallace-Atkins system is an indirectly heated pyrolysis process that produces fuel products and a residue. The fuel products are (1) three grades of pyrolytic oil, (2) fuel gas, and (3) combustible char. The various grades of pyrolytic oil and fuel gas are obtained by "refining" the pyrolytic gas produced in the reactor. The process requires a nominal 4-in. particle size feedstock.

The first step in the Wallace-Atkins process is shredding the incoming material to a nominal 4-in. particle size. Then, without magnetic separation, this material is conveyed to the feeder where it is introduced into the reactor.

The main component of the system is the indirectly heated rectangular reactor. The reactor is in essence a large, double-walled rectangular box. Steam pipes are placed between the two walls of the vessel to provide the heat required to sustain the reaction. Inside the box is a series of several slow moving (approximately $3 \mathrm{fpm}$ ) apron conveyors arranged in a staggered vertical pattern as shown in Figure 18. The conveyors are also heated to $600^{\circ}$ to $1000^{\circ} \mathrm{F}$ by steam tubes.

The shredded material is introduced onto the top conveyor by an auger type feeder that also provides the air seal for the unit. Burden depth on each conveyor is approximately 8 in., resulting in an estimated 25-minute residence time within the reactor.

Mixing and turning of the material is accomplished at the conveyor transfer points. This ensures thorough mixing and turning of the material which encourages uniform heating of the entire mass. At the bottom of the 


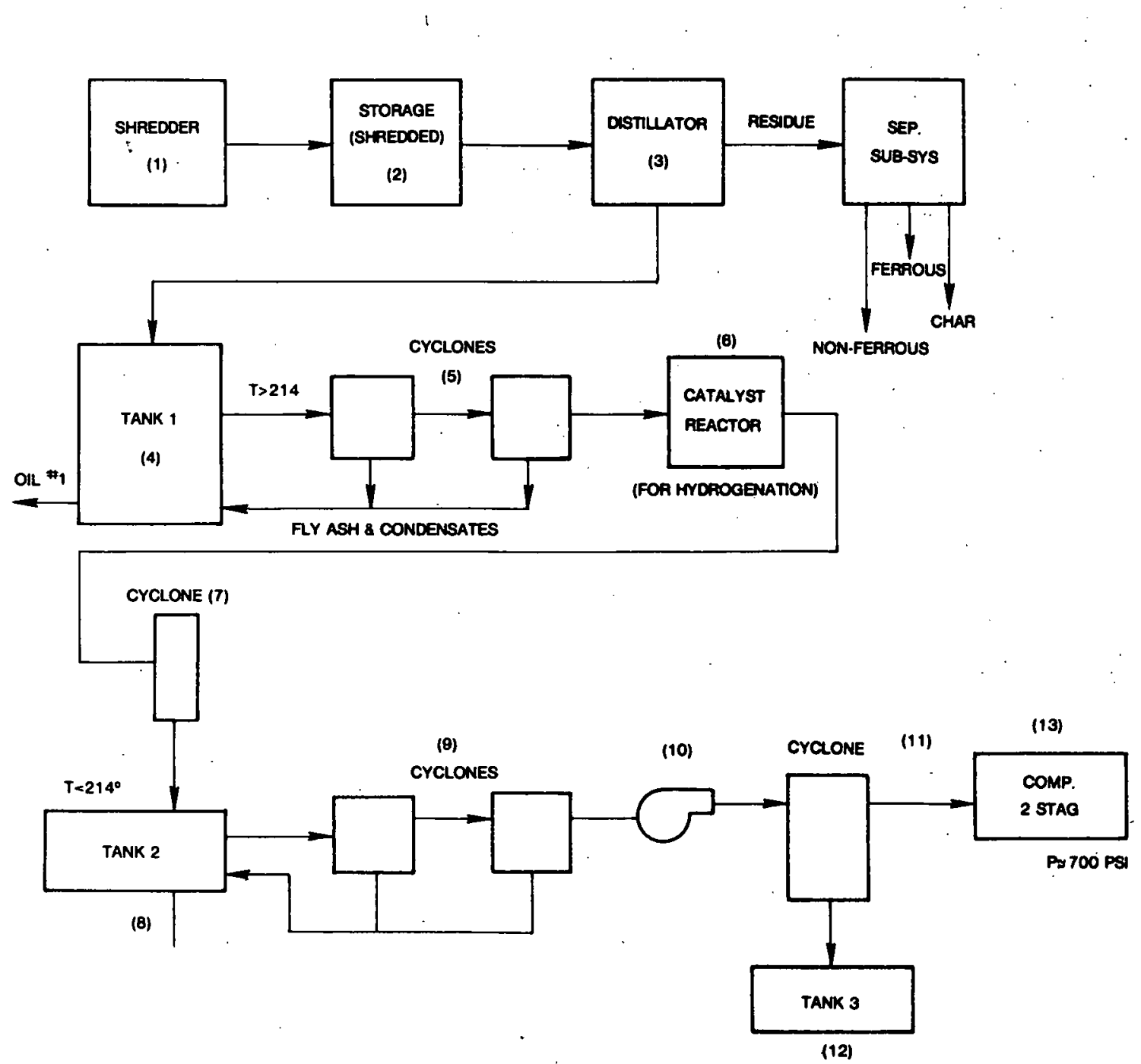

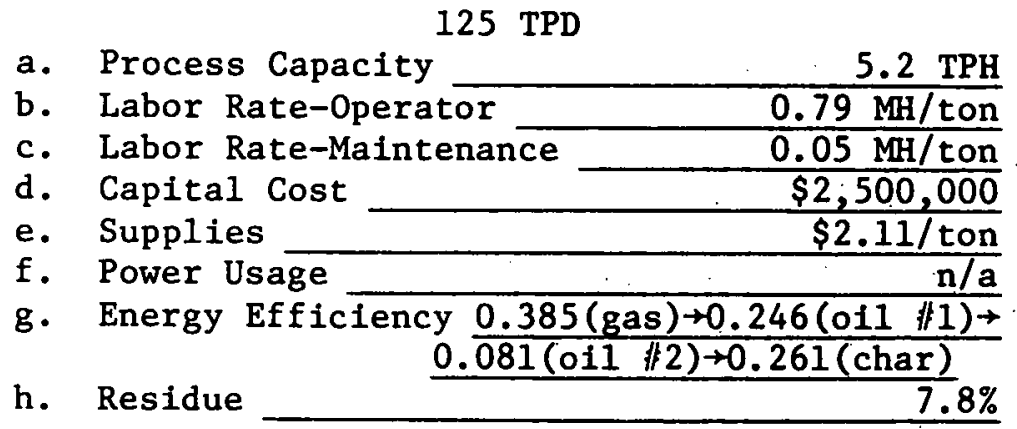

Figure 18. Wallace-Atkins process diagram. 
vessel, the last conveyor discharges the remaining residue into a small pit. A second auger is then used to remove this residue while maintaining an air seal. The evolved pyrolytic gases exit the reactor through a pipe near the top of the reactor. This pyrolytic gas is then "refined" to remove water and particulate and to produce the three grades of oil.

The residue is passed through a separation subsystem which separates it into three components: nonferrous, ferrous, and combustible char.

The hot pyrolytic gases are first introduced to the No. 1 settling tank. This consists of a large tank containing a substantial quantity of oil. Inside the tank the gas is released below the oil level, and it bubbles up through the layer of oil. During this process, the oil and tars condense, and the remaining particulate is retained in the oil (Figure 16). The temperature of the first tank is maintained at about $214^{\circ} \mathrm{F}$ to eliminate any water condensation in the tank. The gas is then passed through two cyclones in series to remove any suspended material. The material separated by the cyclone is then injected into the bottom of Tank No. 1 below the bottom oil level.

The gas is then passed through a "conventional" catalyst reactor by hydrogenation of the oxygen and hydrocarbon gases before it is injected into the cooling cyclone above 0il Tank No. 2 .

The gases are then introduced into 0il Tank No. 2 and are released below the surface of the oil where additional water and oil are condensed. Again, the gases leaving the tank pass through two cyclones in series to remove suspended material from the tanks. The separated material is added to the tank. The gases from the cyclones then pass through a third cyclone which cools and separates the remaining oils and the gas. This gas can then be compressed for pipeline transport or supplied to a burner to heat the reactor.

The recovered oils can be utilized in a cracking unit to produce a variety of, petrochemical products, such as aromatics, kerosene, and diesel oil.

The residue from the reactor vessel is first passed through a hammermill for size reduction and then through a crude air knife which liberates the char from the inert material. The char is then separated from the air stream by a pair of cyclones in series. The magnetic separator is used to remove the magnetic materials from the residue, and the vibrating screen is used to separate the nonferrous metal from the inerts.

\section{Experience--}

Wallace-Atkins has conducted laboratory experiments to determine the amounts and quantities of products produced by the system. They are currently in the process of building a 50-TPD pilot plant.

Cost--

The Texas Department of Community Affairs prepared a financial feasibility analysis for the Wallace-Atkins system based upon information supplied by Wallace-Atkins Corporation. Their study indicated that the operating, 
maintenance, ammortization, and office expenses for this project would be approximately $\$ 25.60$ per ton. Based on the estimated capital cost of $\$ 2,500,000$ for a 125-TPD system, the calculated net cost is $\$ 13.64$ per ton. Because of the system's predicted high operating costs and its complexity, the practicality of this system to small-scale applications is very doubtful. However, it does avoid, to some extent, the problems of selling the recovered gas to a nearby user, instead providing products which have readily available industrial markets.

Research Needs--

1. Assess the ability to operate and maintain the conveyor in the gasifier at elevated temperatures.

2. Conduct an independent technical and economic evaluation of the system.

Rotary Kiln (Pan American Resources, Inc.)

System Description--

The Pan American system (Figure 19) utilizes the Lantz Converter, an indirectly heated starved-air rotating retort, to produce a pyrolytic gas and a char from municipal solid waste. The heat required to sustain the reaction is transferred to the solid waste through the rotating tube by the hot exhaust gases that flow through the jacket surrounding the retort vessel. Tests conducted on this system indicated that the gas production process passes all applicable California air pollution control codes and produces a gas that can be burned in compliance with these codes.

The incoming waste material undergoes primary shredding, magnetic separation, and secondary shredding resulting in a particle size less than 1 in. This material is then stored in a feed bin to balance $24 \mathrm{hr} /$ day converter operation with $8 \mathrm{hr} /$ day front-end operation.

From the storage bin, the material is taken to a drier where the moisture content of the material is reduced. The semidry refuse is then injected into the reactor.

The reactor consists of a large rotating drum (retort) inside a refractorylined furnace. Heat is transferred into the rotating retort by passing the hot combustion produced by the char burner through the furnace that surrounds the retort. The retort is tilted to enable the material to flow through by gravity. The rotating motion gently mixes the material, exposing it all to the $1000^{\circ} \mathrm{F}$ temperatures inside the retort.

The low density char discharged by the reactor is air classified to separate it from the inert residue. The char entrained in the air classifier is blown directly into a char burner where it is combusted to supply heat to the reactor and the drier.

Experience--

Pan American Resources, Upland, California, has tested this process since approximately 1963. At present they have a 50-TPD pilot plant in Upland, 


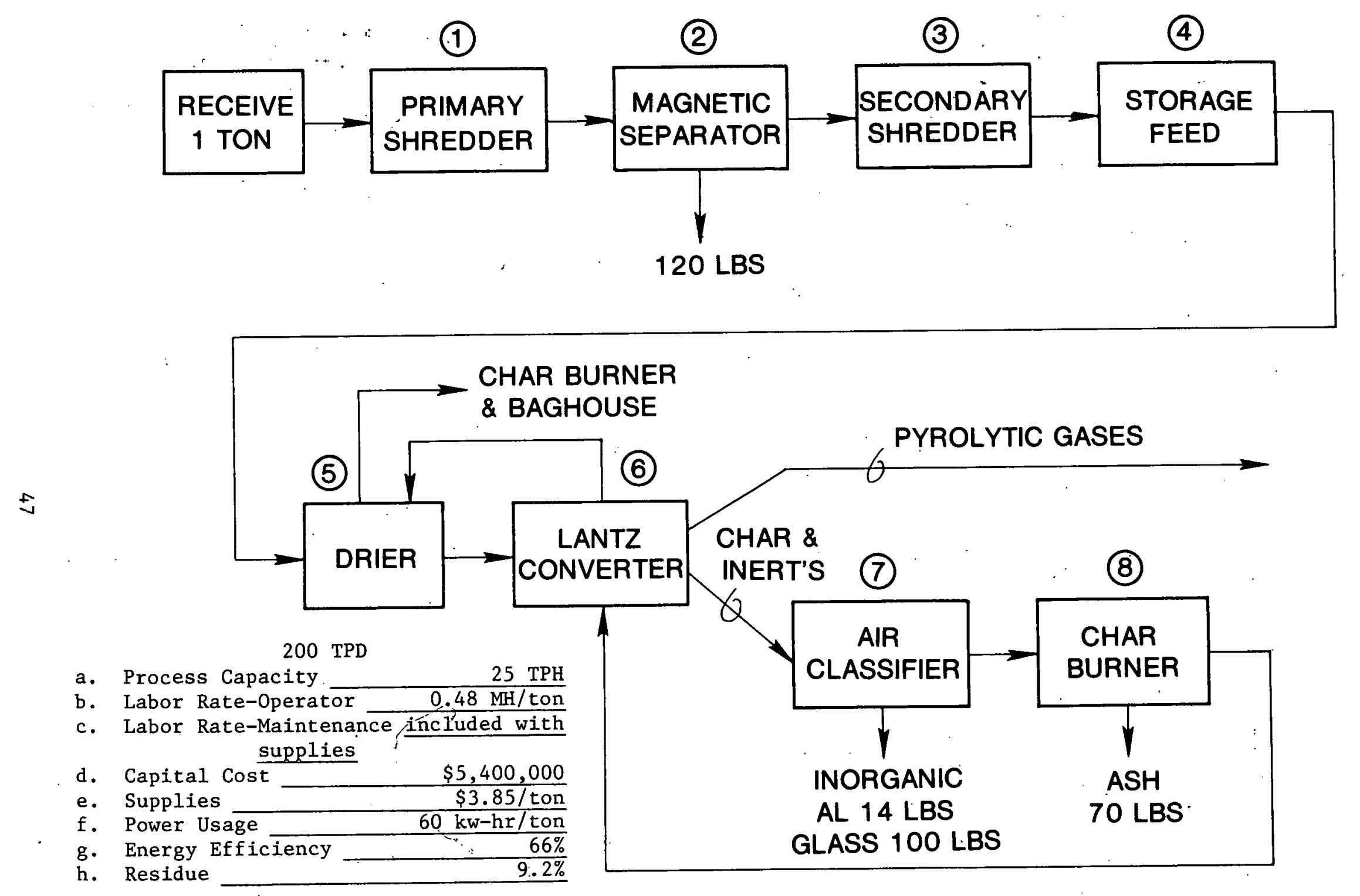

Figure 19. Pan American Resources energy conversion process schematic. 
California. Air emission tests conducted on the pyrolysis gas yielded the followng results:

$$
\begin{array}{ccc}
\text { Particulate } & \mathrm{NO}_{\mathrm{X}} & \mathrm{CO} \\
0.02-0.52 \mathrm{gr} / \mathrm{SCF} & 210-420 \mathrm{ppm} & 50-320 \mathrm{ppm}
\end{array}
$$

The South Coast Air Quality Management District conducted tests for $\mathrm{SO}_{2}, \mathrm{NO}_{\mathbf{x}}$, and $\mathrm{CO}$ on the pyrolysis gas and showed that they were within the District's guidelines.

Cost--

Pan American Resources' preliminary estimates indicate that the operating, maintenance, and ammortization costs for a 600-TPD facility are approximately $\$ 20.70$ per ton before fuel and material credits. It is expected that the cost for a smaller system will be somewhat higher.

Research Needs--

1. Obtain detailed information to permit an in-depth cost analysis of the process to verify cost projections.

2. Conduct an independent test and evaluation of the system to verify designers' claims if economics prove attractive.

3. Verify the cost, size, energy consumption, and other operating parameters of the refuse drier.

\section{Packed Bed (Pyro Sol, Incorporated)}

System Description--

The Pyro Sol unit (Figure 20) is an indirectly heated pyrolysis system that produces a low-Btu fuel gas and char in a cast, refractory-lined, vibrating-bed gasifier. This gas is fired in a boiler which makes steam to produce electricity for sale.

The incoming solid waste is shredded before being introduced to the reactor vessel through an air lock feeder. The reactor vessel consists of a vibrating, horizontal, refractory-lined bed which acts as both the furnace hearth and the conveyor for transporting the material through the reactor. The sidewalls, roof, and ends are also refractory lined. Heat is transferred into the reactor vessel by eight stainless steel heat radiating tubes that are internally heated by hot flue gas from the boiler passing through them. The char and ash resulting from the pyrolytic reaction are removed from the reactor vessel by a screw conveyor. Magnetic materials are removed from the char prior to its separation into heavy, medium, and light particles using a ballistic separator. The evolved gases from the reactor are first passed through a cyclone and then a venturi scrubber and gas quencher to remove any entrained particulate and to $\operatorname{cool}$ the gas. A gas storage tank is utilized to even out any pressure surges from the reactor. The gas is then burned in a combustor, and the flue gases are passed through a waste heat boiler to recover energy. The steam produced in the waste heat boiler is used to drive a condensing turbine generator to produce electrical power for sale. 

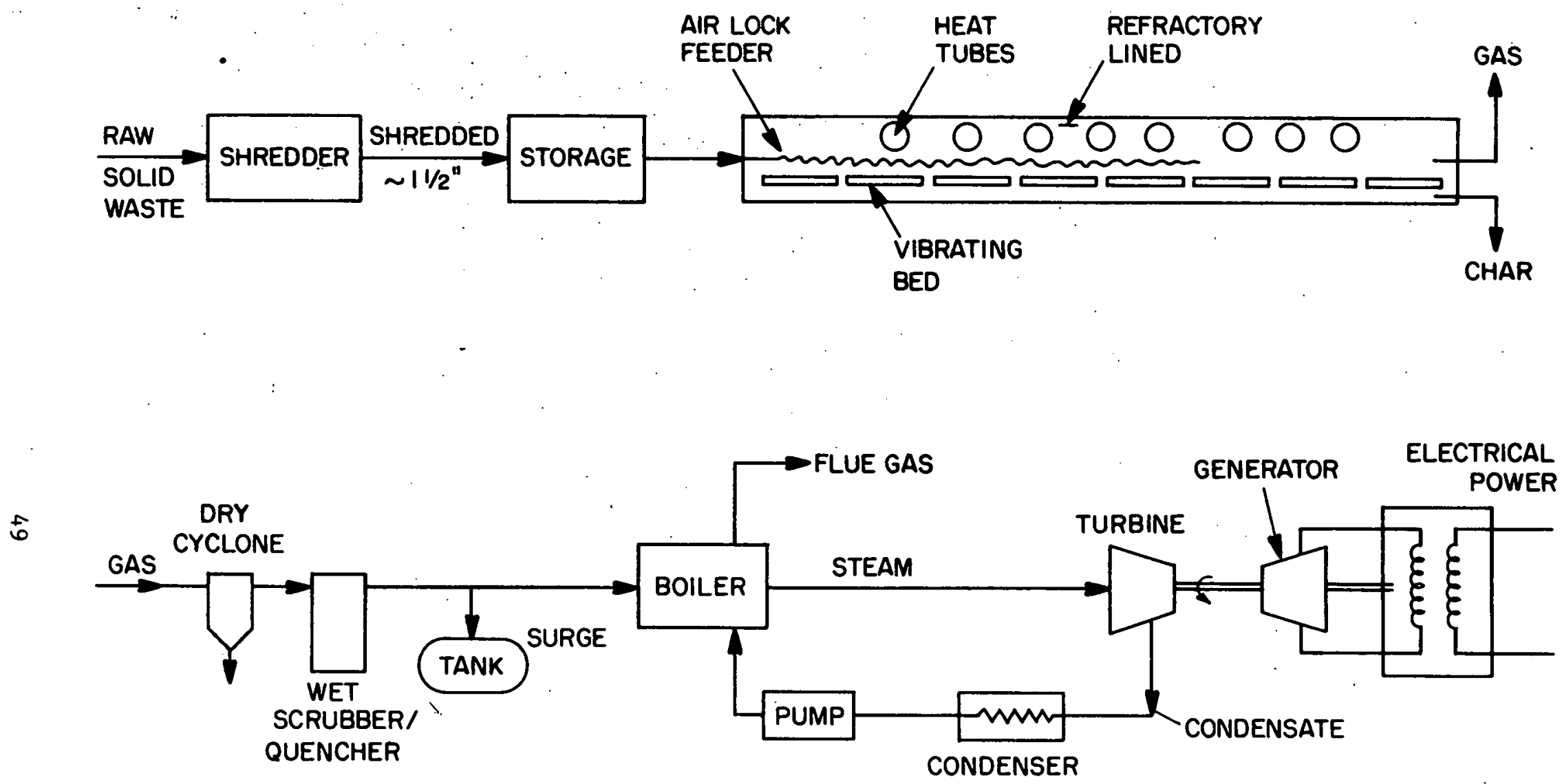

100 TPD
a. Process Capacity
b. Labor Rate-Operator
$5 \mathrm{TPH}$
c. Labor Rate-Main
d. Capital Cost
e. Supplies
$\$ 5.25 / \operatorname{ton}$
f. Power Usage
$50 \mathrm{kw}-\mathrm{hr} / \mathrm{ton}$
g. Energy Efficiency
$60 \%$
h. Residue

200 TPD

a. Process Capacity

b. Labor Rate-Operator

$10 \mathrm{TPH}$

d. Capital Cost $\$ 4,000,000$

e. Supplies

f. Power Usage

$\$ 5.25 /$ ton

h. Eesidue Eficiency

$60 \%$

Figure 20. Pyro Sol process diagram. 
The hot flue gas that is passed through the heat tubes in the reactor is also passed through. the waste heat boiler prior to discharge to the atmosphere.

Experience--

Pyro Sol, Redwood City, California, currently has a 56-TPD demonstration plant utilizing the combustible waste from an automobile shredding facility. They have plans to substitute preprocessed municipal waste for the automobile waste.

Cost--

The estimated capital cost of a $100-$ and 200-TPD facility is $\$ 2.5$ and $\$ 4$ million dollars, respectively. The calculated operating cost is $\$ 22.74$ and $\$ 13.63$ per ton, respectively.

Research Needs--

1. Determine the operating characteristics of this facility on autoderived fuel and municipal refuse.

2. Obtain detailed information on the quantity of combustible gas produced.

3. Determine amount of gas burned in the radiant heat tubes.

4. Determine the market for saleable power (interruptable) to the electrical grids.

Packed Bed (Leas Brothers Development Corporation)

System Description--

The Leas Brothers Energy Converter (Figure 21) is a gasification process for coal and municipal solid waste. Raw MSW and coal are loaded into separate pressurized lock hoppers which introduce the material to the reactor vessel. The reactor vessel is essentially a catalytic cracking tower. Hot nitrogen and carbon dioxide gases are introduced to the reactor which pyrolizes the material.

The evolved gases are piped to an oil absorber which removes condensable oils from the gas. The remaining gas stream is passed through a gas cleaning and separation train. The train separates the gas into a gaseous (1000 Btu/SCF) and an aromatic gasoline fraction.

The ash and residue are removed by a hot sand stream that flows downward through the reactor and exits at the bottom. The ash is removed from the sand in a secondary gasifier before the sand is reintroduced at the top of the reactor.

Experience--

Leas Brothers, Columbus, Ohio, has a pilot plant in Columbia City, Indiana, that has operated with coal. To our knowledge, they have not processed MSW in this unit. 


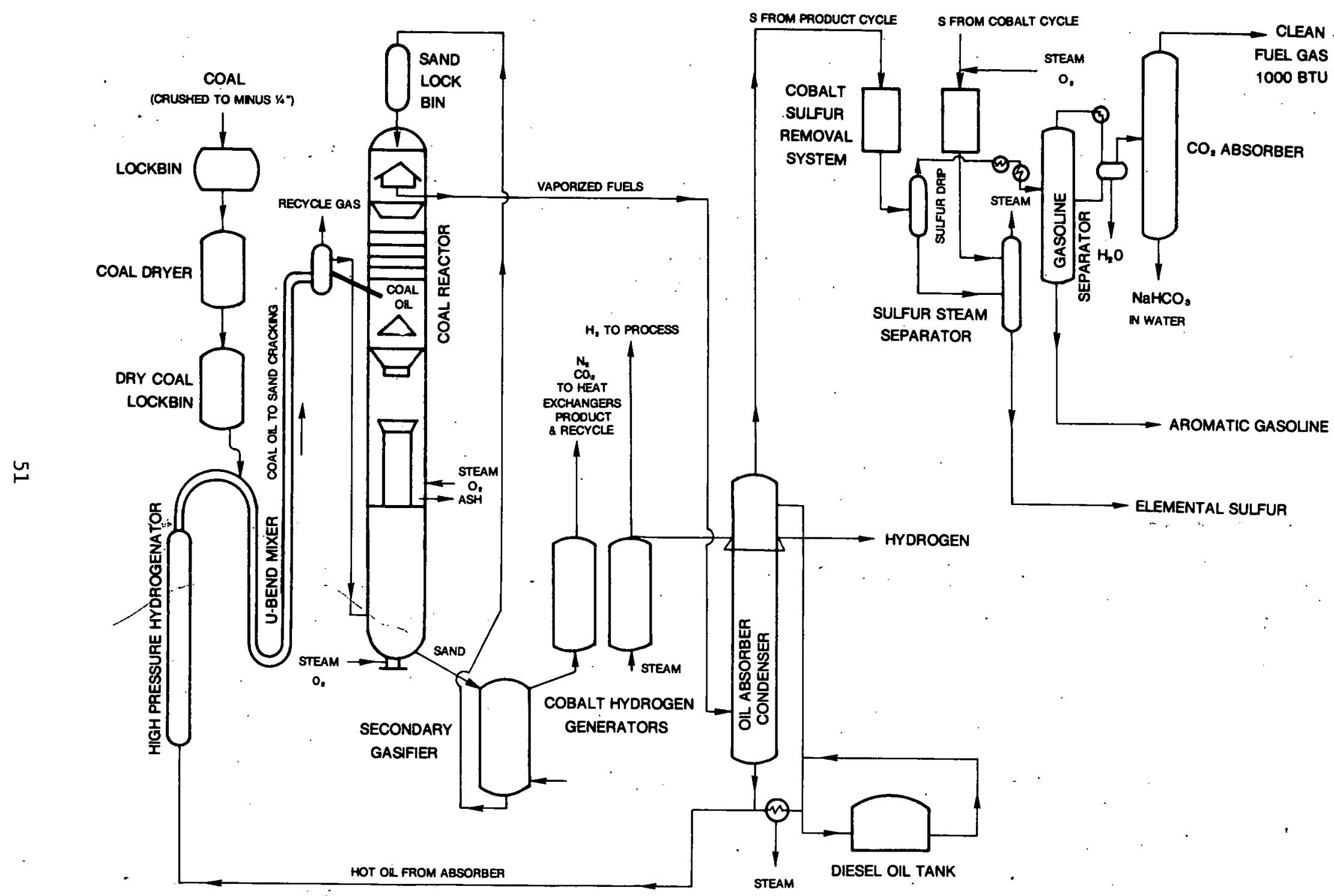

Figure 21. Leas Brothers energy converter schematic. 
Cost--

Leas Brothers estimated that the net refuse disposal cost would be approximately $\$ 4 /$ ton. . However, as with any system in this stage of development, the numbers appear to be overly optimistic. A detailed cost breakdown was not supplied to permit our analysis.

Research Needs--

1. Conduct tests in existing unit using MSW as the feedstock.

2. Determine the economics of the system.

Packed Bed (Environomics, Incorporated)

System Description--

The Environomics system (Figure 22) is a blue water gas generator in which pyrolysis and related processes convert carbonaceous material, such as city refuse, to a combustible gas and an inorganic residue. Known in the $1880^{\prime}$ 's as city or water gas, the combustible gas is mainly hydrogen and carbon monoxide.

The generator is a vertical pyrolytic-type chamber with an air lock for refuse input at the top, a grate at the base, and an air lock for ash removal below the grate. As the refuse is burned, steam formed within the chamber by injecting water through the orifices of a pipe agitates the combustible gas which is withdrawn by a vacuum pump. After the initial fire-up with auxiliary fuel, two burners beneath the grate combust some of the gas generated to sustain the pyrolytic process. The chamber is operated at temperatures between $1800^{\circ}$ and $2000^{\circ} \mathrm{F}$ and at pressures between 4 and 5 atmospheres. The refuse must be a liquid or a small-particle solid. If all the particles are not smaller than $1 / 2$ in., the refuse must be preprocessed.

\section{Experience--}

Currently under development in Austin, Texas, the Environomics system has been demonstrated in an experimental unit, called the Viking, which has a capacity of $3 \mathrm{lb} / \mathrm{hr}$ of dry sawdust. Thus far the Viking has undergone several 5-hour tests with dry sawdust under steady-state conditions. It has also been tested with other types of refuse.

$\therefore$ Cost--

Since the Viking is a small-scale experimental unit, no cost projections have been made for large-scale systems.

Research Needs--

1. Long-term (multiple-day) tests on various types of waste.

2. Cost projections for a preliminary design of a large-scale system.

3. A survey to determine the potential market for the blue water gas and the costs for the gas distribution. 


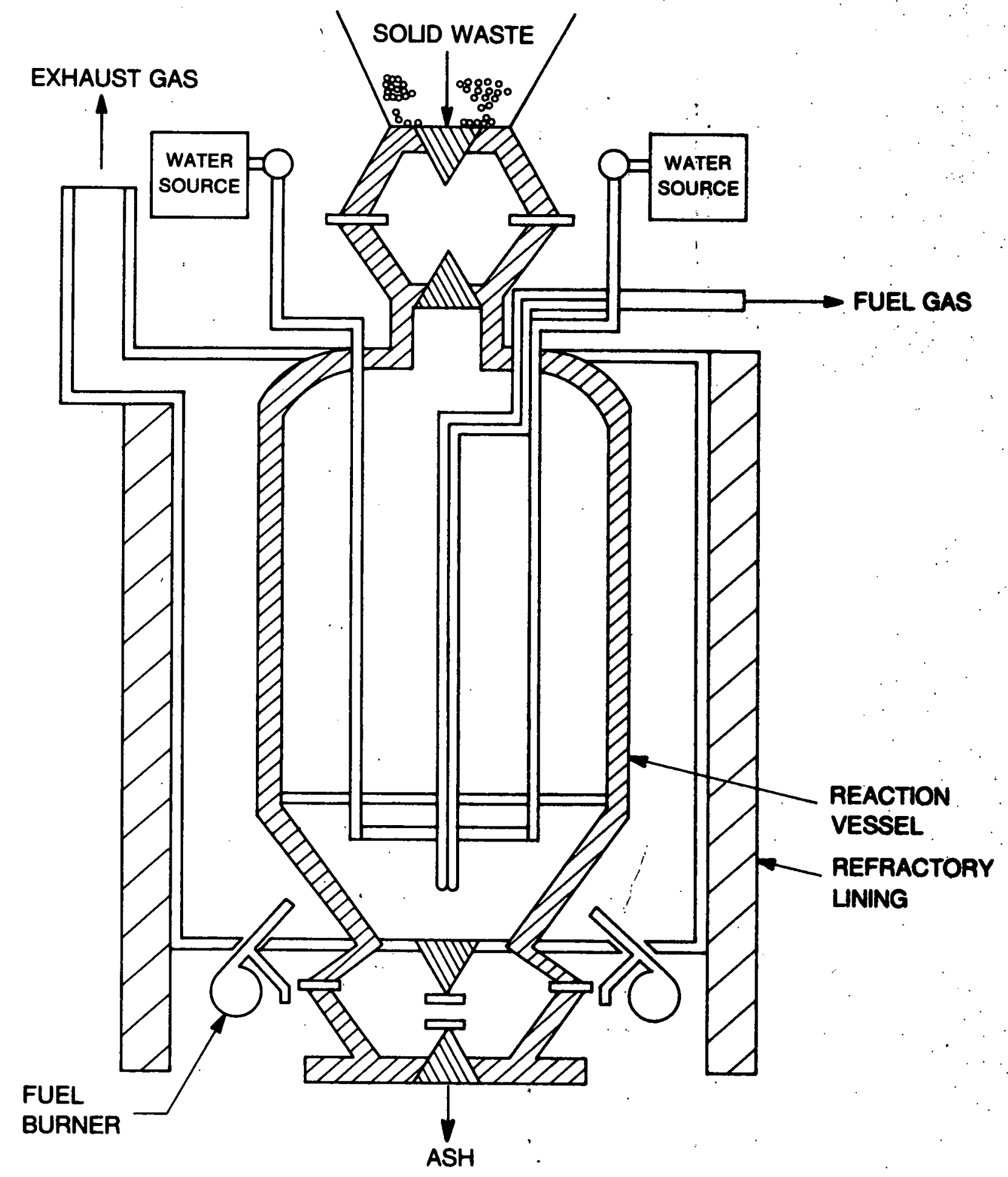

Figure 22. Environomics blue water gasifier. 
Fluidized Bed (Teknekron)

System Description--

Teknekron of Berkely, California, is proposing a gasification system (Figure 23) using two fluidized-bed reactors to provide a nitrogen-free gas with a heating value between 400 and $500 \mathrm{Btu} / \mathrm{SCF}$. The waste is pyrolyzed in the first reaction while the combustion reaction which supplies the heat required by the pyrolysis step takes place in a second reaction (combustor). The char and liquid produced in the pyrolytic reaction are separated from the gas and are subsequently used as the fuel for the combustion reaction. Since the combustion and pyrolysis product gases are not mixed, the product gas has a relatively high $\mathrm{HHV}$.

The incoming waste material is shredded to a 1/8-in. particle size and then dried to reduce the moisture content from 35 to 5 percent. The dried, prepared waste is then introduced into the fluidized-bed pyrolytic reactor. Preheated sand from the combustor is injected in the lower regions of the reactor. The combination of the sand and the feed is fluidized by injecting recycled pyrolysis gas into the bottom of the vessel. Char, sand, and ash are extracted from the upper section of the vessel. The sand is separated from the char and ash and reheated in the combustor before reintroduction into the reactor. The pyrolytic gases exit near the top of the reactor and go through a gas clean-up system to remove any suspended particulate matter and to cool the gas. This condenses out the heavier hydrocarbons contained in the gas.

The mixture of char, sand, and ash from the pyrolytic reactor and the solid and liquid from the gas cleaning train are introduced into the combustor. This mixture is fluidized with preheated combustion air and is burned to create the heat required to heat the sand to the necessary temperatures. The hot sand is withdrawn from the top section of the combustor and reintroduced into the pyrolytic reactor. The hot flue gas exiting the combustor is used to dry the incoming waste material.

Experience--

This process is still in the conceptual design stage. Gas yields, however, were based on the results of preliminary tests sponsored by the U.S. Environmental Protection Agency.

Coșt--

The expected capital cost of such a system scaled down from a 1000-TPD plant using the 0.6 exponent cost-to-capacity rule, is 4.15 and 6.45 million dollars for 100- and 200-TPD plants, respectively. The operating costs which are proportional to those in the $1000-$ TPD system are estimated at $\$ 29.67$ per ton and $\$ 25.15$ per ton for $100-$ and 200-TPD systems, respectively.

Research Needs--

1. More detailed technical and economic information on the system.

2. Separate and deentrain the solids and liquids in the product gas. 


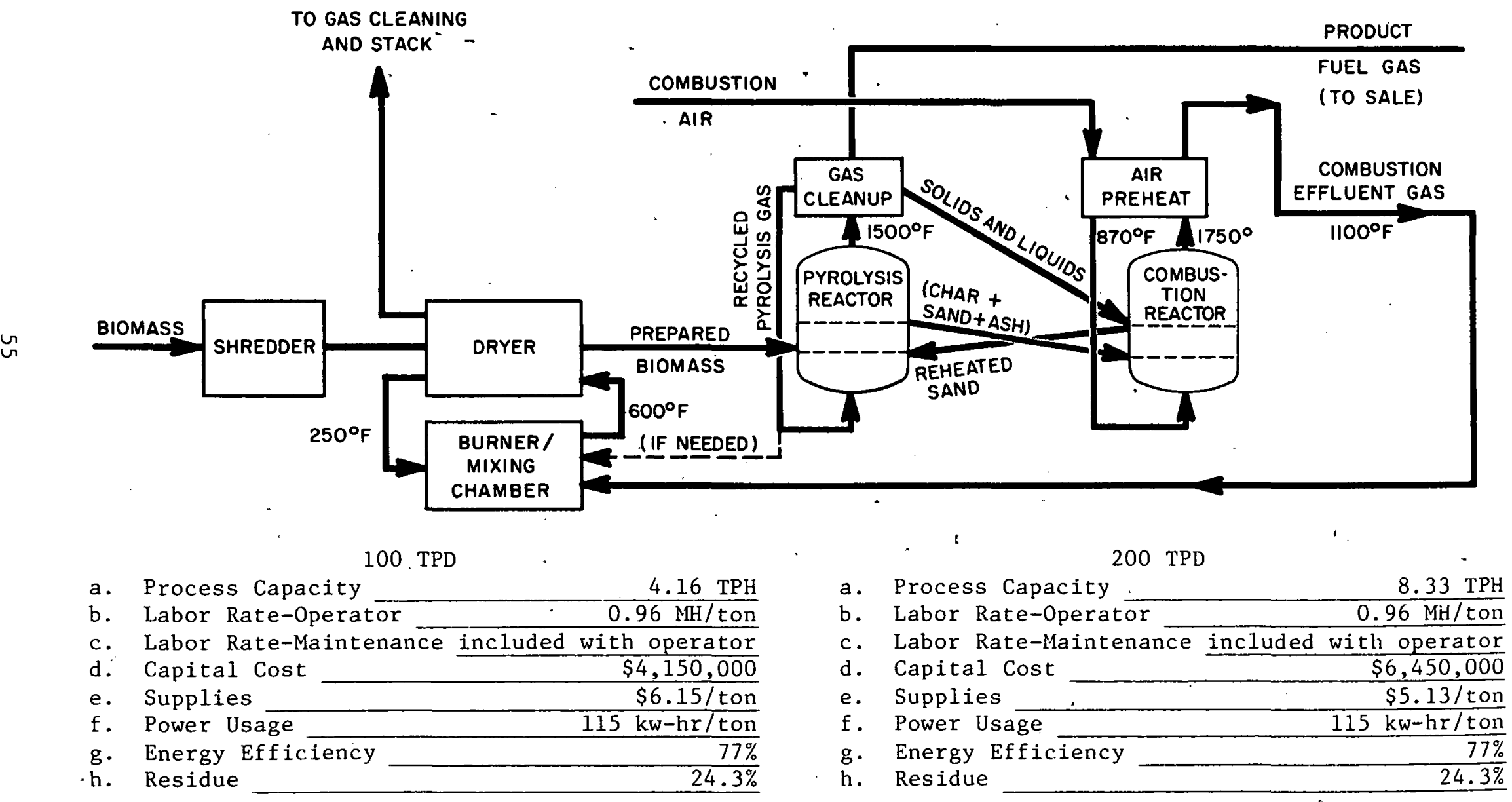

Figure 23. Teknekron process schematic. 
3. Separate the char and sand from the combustion reactor.

4. Plug the fluidized-bed combustion chamber.

Horizontal Auger (Enterprise Company/Decco)

System Description--

The Enterprise Company, Santa Ana, California, uses an indirectly-heated horizontal reactor (Figure 24) to produce a medium-Btu gas and an oil. A screw type conveyor (auger) is used to move the material through the horizontal reactor.

The incoming material is manually separated to remove any large oversized objects before shredding. Enterprises' dual-rotor shredder reduces the incoming material to a nominal particle size less than 4 in. A drum type magnetic separator and blower are used to separate the magnetics from the shredded material.

After magnetic separation, the shredded refuse is transported to a steel drag conveyor which distributes the material to one of three 8-ft by 8-ft by 100-ft rectangular storage modules. The object of the storage module is to balance the $8 \mathrm{hr} /$ day operation of the front end with the $24 \mathrm{hr} /$ day operation of the pyrolysis unit.

After storage, the shredded material is conveyed to cylindrical rotating driers which reduce the moisture content of the refuse to approximately 10 percent. The material moves through driers by gravity. Hydraulic cylinders at one end of the drier adjust the angle of the rotating drum, thereby regulating the feed rate to the reactors. The drier utilizes the excess heat from the reactiors to dry the material. Saturated air from the drier is vented to the flue gas scrubber which removes the moisture and dust, and the clean air is vented to the atmosphere.

Enclosed steel belt conveyors carry the material from the drier to the reactor inlet. A ram feeder is used to feed the material to the reactor which consists of two concentric cylindrical chambers with a screw type conveyor (auger) to move the material through the inner cylinder with process heat supplied by gas combustion occurring between the inner and outer walls. As the material moves through the reactor, it is subjected to temperatures of $1000^{\circ} \mathrm{F}$ in an oxygen-free environment, thus converting the material to a gas and a char.

The water and condensable oils and tars are removed from the evolved gases in the condenser. The gas is then piped to the product gas scrubber and filter before delivery to the consumer.

A clarifier separates the condensed oils and tars from water, and the recovered oil is then sold to a customer. An oil-water separator is used to remove the remaining oil from the water with the oil being recycled to the reactor. A small wastewater plant is used to clean up the water which is then either used as process water or sent to the drain. 
EQUIPMENT LEGEND

1. CONVEYOR

2. REJECT BIN

3. SHREDDER

4. MAGNNETIC SEPARTOR

5. FERROUS METAL BIN

6. SHREDDED REFUSE STROAGE

7. REFUSE DRYER

8. REACTOR

9. CONDENSER

10. CLARIFIER

11. OIL TRANSFER TANK

12. PRODUCT OIL STORAGE

$\because$ 13. SLUDGE STORAGE TANK

14. OIL/ WATER SEPARATOR

15. COOLING TOWER

16. METAL/CHAR SEPARATOR

17. STEEL/ALUMINUM SEPARATOR

18. FURNACE

19. PRODUCT GAS SCRUBBERS

20. PRODUCT GAS FILTER

21. FLUE GAS SCRUBBERS

22. WASTE WATER TREATMENT

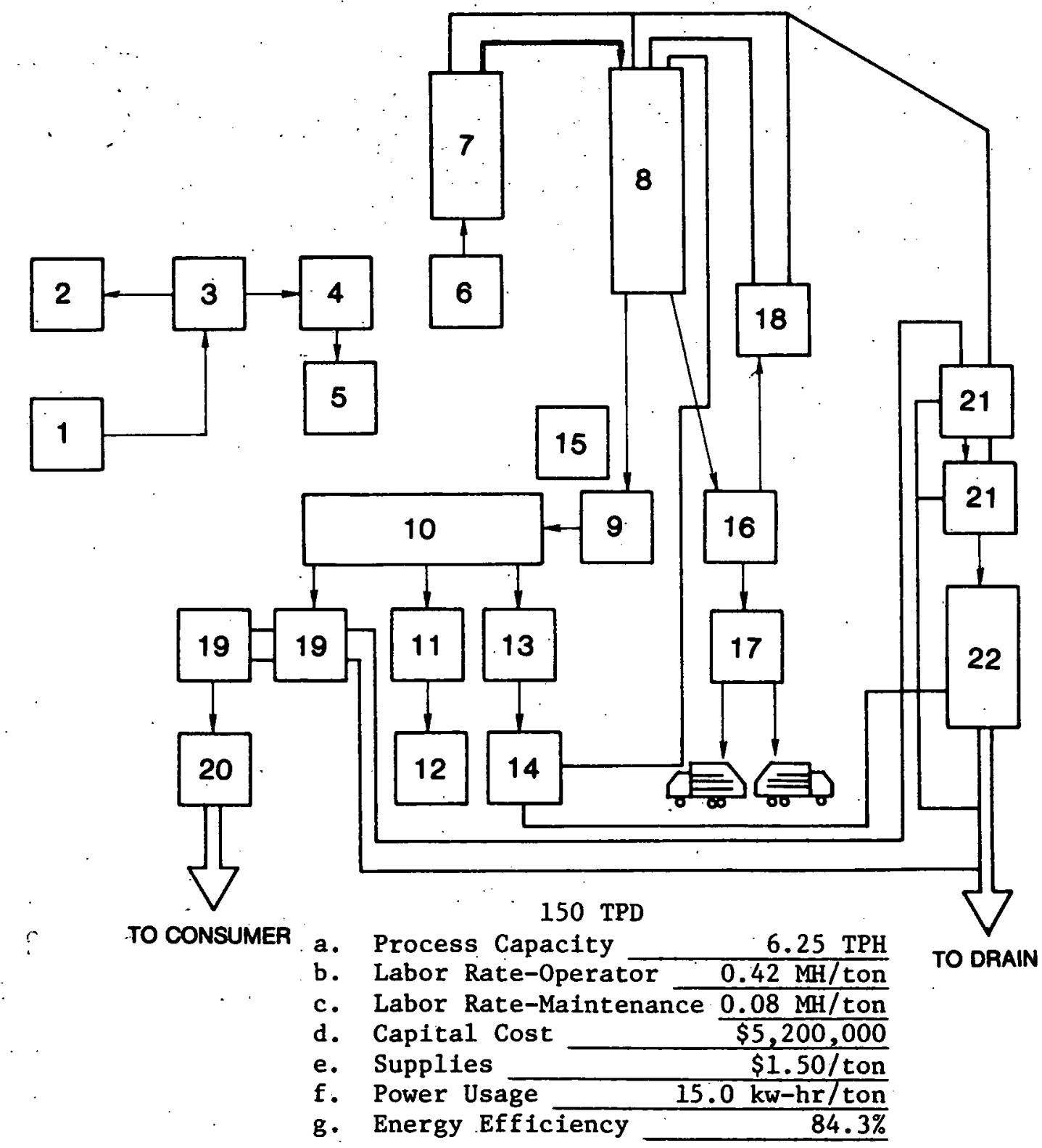

Figure 24. Enterprise Company process diagram: 
A vibrating conveyor is used to separate the char and metal. An "air. classifier" is used to separate char from the inert fines (i.e., glass, sand, etc.) and other heavier materials. A screw conveyor transports the char to a combustor where it is burned. The flue gases from the combustor are used to maintain the reactor and drier temperatures. After passing through the reactor heating ducts, the flue gases are used to dry the incoming refuse.

The metals that were separated from the char pass under a drum type magnet to separate the magnetics from the nonmagnetics.

\section{Experience--}

The Los Angeles County Sanitation District is presently testing an 80to 100-TPD unit on their property. They expect to have some preliminary test results by the end of 1978. Further consideration of their system should be postponed until these results are made available.

Cost--

Cost information supplied by Enterprise is preliminary since they have not yet operated a facility. In particular, the electric power consumption appears too low considering the amount of preprocessing required. The data obtained during the current test run should greatly improve the accuracy of their estimate. They estimated the capital cost of a 150-TPD facility at $\$ 5,200,000$. The calculated net cost was $\$ 17.56$ per ton.

Research Needs--

1. Verify the cost, size, energy consumption, and other operating parameters of the refuse drier.

2. Test the reactor screw conveyor. To date the experience with solid waste screw conveyors has not demonstrated them to be a reliable method of handling solid waste.

3. Confirm the emission level from the system's char burner.

4. Evaluate the tests being conducted by the Los Angeles County Sanitation Districts.

Horizontal Auger (Redker-Young Process, Inc./Ingham County)

System Description--

The Redker-Young system (Figure 25) which was originally developed by Redker-Young Process, Inc., with the assistance of Ingham County, Michigan, is a system which uses a dried RDF feedstock in an indirectly heated horizontal vessel to produce low- and medium-Btu gas. Ingham County, Michigan, now has the rights to the system.

Incoming solid waste is shredded and air classified to produce RDF fuel which is dried to 5 percent moisture. The dried RDF is then introduced to the reactor which is a doubled-walled vessel with an auger in the middle. The auger is used to move the material through the reactor. 


\section{COMBUSTOR}

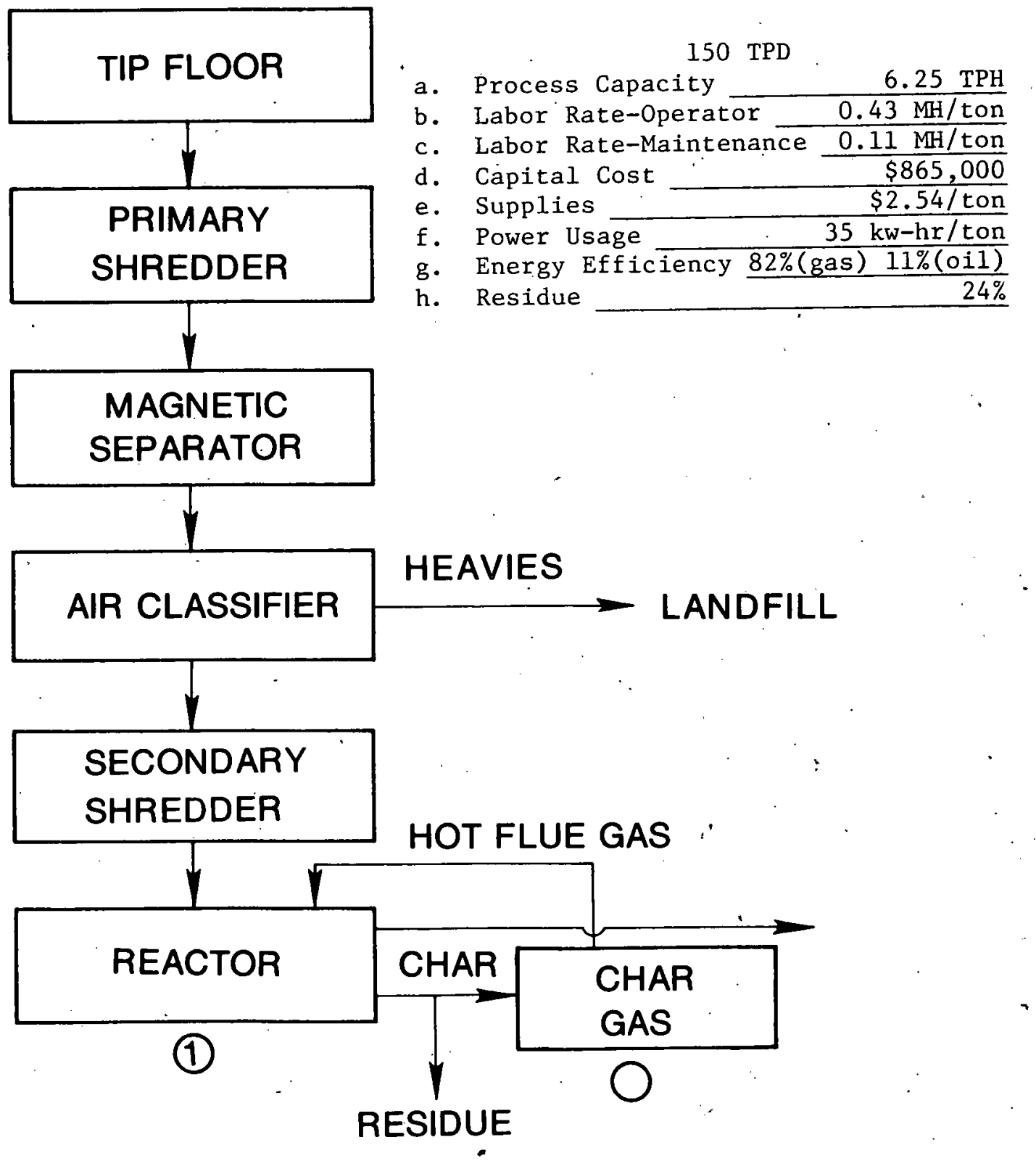

Figure 25. Redker-Young process diagräm. 
The evolved gases exit the vessel through a series of ports located along the length of the vessel. The quality and quantity of the gas removed at a given port is a function of the distance from the input point.

The char discharged by the auger is conveyed to a combustor where it is burned. The hot flue gases are passed between the inner and outer shells of the reactor to supply the heat required for the reaction.

\section{Experience--}

A pilot plant was built in Lansing, Michigan, to demonstrate the RedkerYoung process. This pilot plant was operated for a period of time. Ingham County has submitted an unsolicited proposal to the Department of Energy for further testing of the system and design of a commercial system. Such an effort would be required before the unit could be considered commercially or economically viable.

\section{Cost--}

Ingham County's technical consultant, Wheeler Industries. of Washington, D.C., estimates the capital cost of a 150-TPD reactor at $\$ 554,000$ and the operating and maintenance costs at approximately $\$ 8$ per ton before fue? and material credits. Their capital costs were escalated from the installed equipment cost of the test facility in Lansing, Michigan. Since the process design has not been finalized, their capital costs are suspected to be below the actual costs of the system. The calculated net disposal cost for a 150TPD system is $\$ 4.76$ per ton.

Research Needs--

1. Smal1-scale tests to determine the operating parameters.

2. Pilot tests to confirm the economics of the system.

3. An evaluation of a refuse drier to determine its characteristics and costs.

\section{Plasma Arc (Resource Recovery Corporation)}

\section{System Description--}

Resource Recovery Corporation, Raleigh, North Carolina, has the exclusive rights to a plasma refuse converter (Figure 26) developed by Technology Application Services Company. The plasma torch, which is a device that utilizes an electrical current to heat a gas to a high temperature, is used to supply the heat required by the pyrolytic reaction inside the refractory-lined converter vessel. The temperature produced by the plasma torch can exceed several thousand degrees. This process produces a combustible gas and a molten slag from shredded refuse.

\section{Experience--}

Resource Recovery Corporation is presently testing a 50-TPD prototype in Raleigh, North Carolina. The preliminary results of their, tests indicate that approximately 100 percent of the chemical energy in the refuse is converted to a combustible gas. 


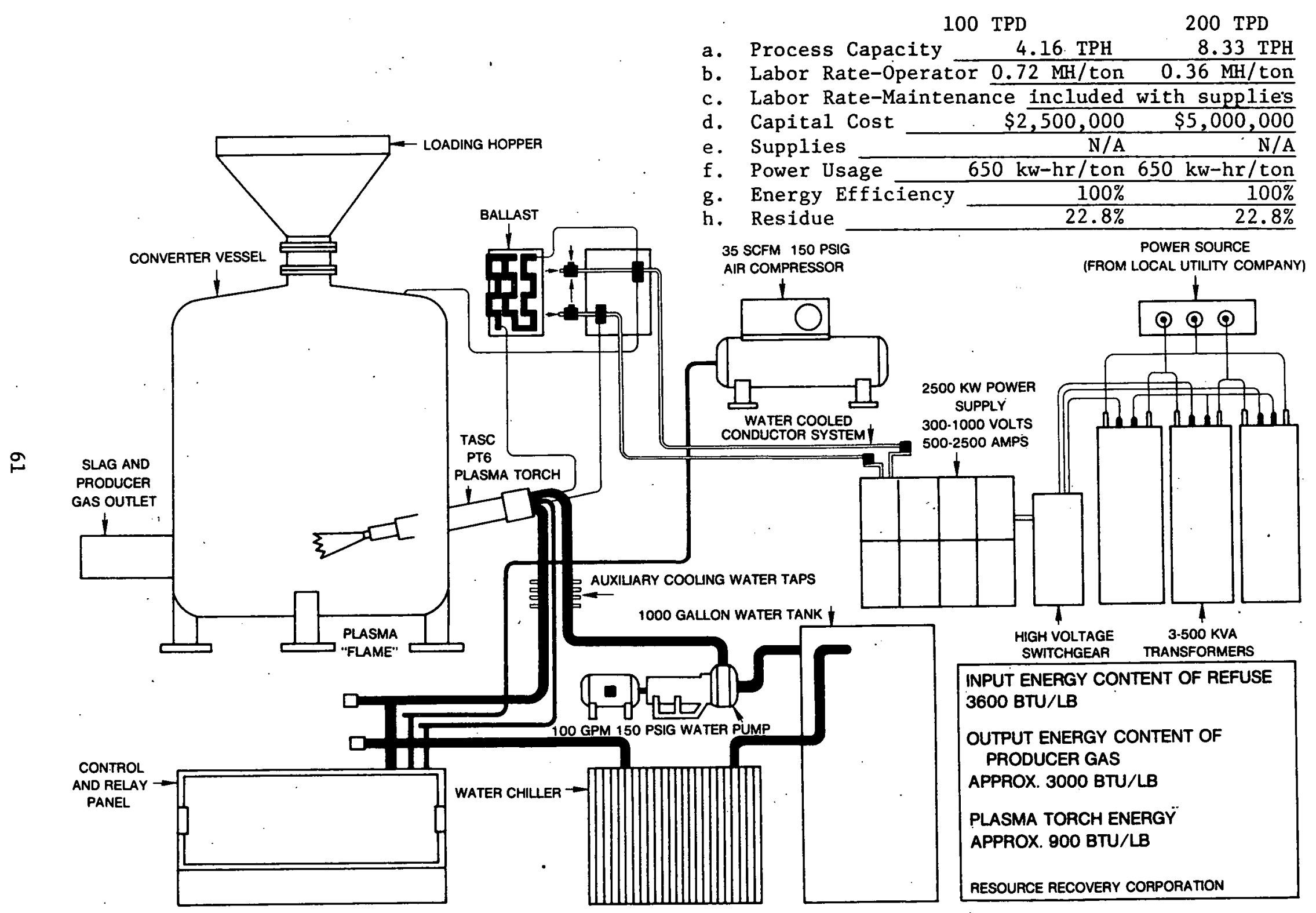

Figure 26. Resource Recovery plasma refuse converter schematic. 


\section{Cost--}

The capital cost of this system was estimated at $\$ 20,000$ to $\$ 30,000$ per daily ton of capacity. The calculated net disposal cost for this facility is $\$ 24.17$ per ton and $\$ 18.77$ per ton for a 100- and 200-TPD facility, respectively.

\section{Research Needs--}

1. Develop refractory materials to withstand the elevated temperatures produced by the plasma torch.

2. Prepare a detailed economic and technical evaluation of the system to study emissions resulting from such a high temperature process. 


\section{SECTION 3}

MECHANICAL PROCESS ING SYSTEMS

COARSE REFUSE DERIVED FUEL (AENCO, InC.)

\section{System Description}

AENCO, Inc., New Castle, Delaware, a subsidiary of Cargill, Inc., has developed a combination air classifier and fine rotary screen (Figure 27) which can separate raw municipal refuse into three streams: (1) light organics (RDF), (2) heavies, and (3) glass. Their rotary drum separator is a large, air-swept, rotating drum which is based on General Electric's air separator design.

The raw refuse feed conveyor deposits unshredded material into the drum where it is lifted several times. The light materials entrained by the air stream are carried up the drum into a large plenum chamber and dropped onto the light fraction conveyor. The heavy materials move down (due to gravity and the inclination of the drum) to the lower section of the drum which is perforated (like a trommel). The glass-rich fraction falls through the perforations to the glass conveyor below. The remaining heavy fractions are discharged from the drum onto a third conveyor.

The light fraction contains most of the paper, cardboard, light gauge plastics, aluminum cans, and foil. It can be transported and stored and, after secondary shredding, is suitable as an RDF fuel.

The heavy fraction contains most of the heavy-gauge metal, wood, steel beverage cans, wet garbage, building and demolition waste, and tires. The ferrous metals in this stream can be magnetically separated and sold.

The glass-rich fraction is, as its name implies, primarily glass and may be suitable for sale.

\section{Experience}

AENCO, Inc., conducted a test program at their shredding facility in New Castle County, Delaware. The results of the test program were the basis for the design of the full-scale unit. 


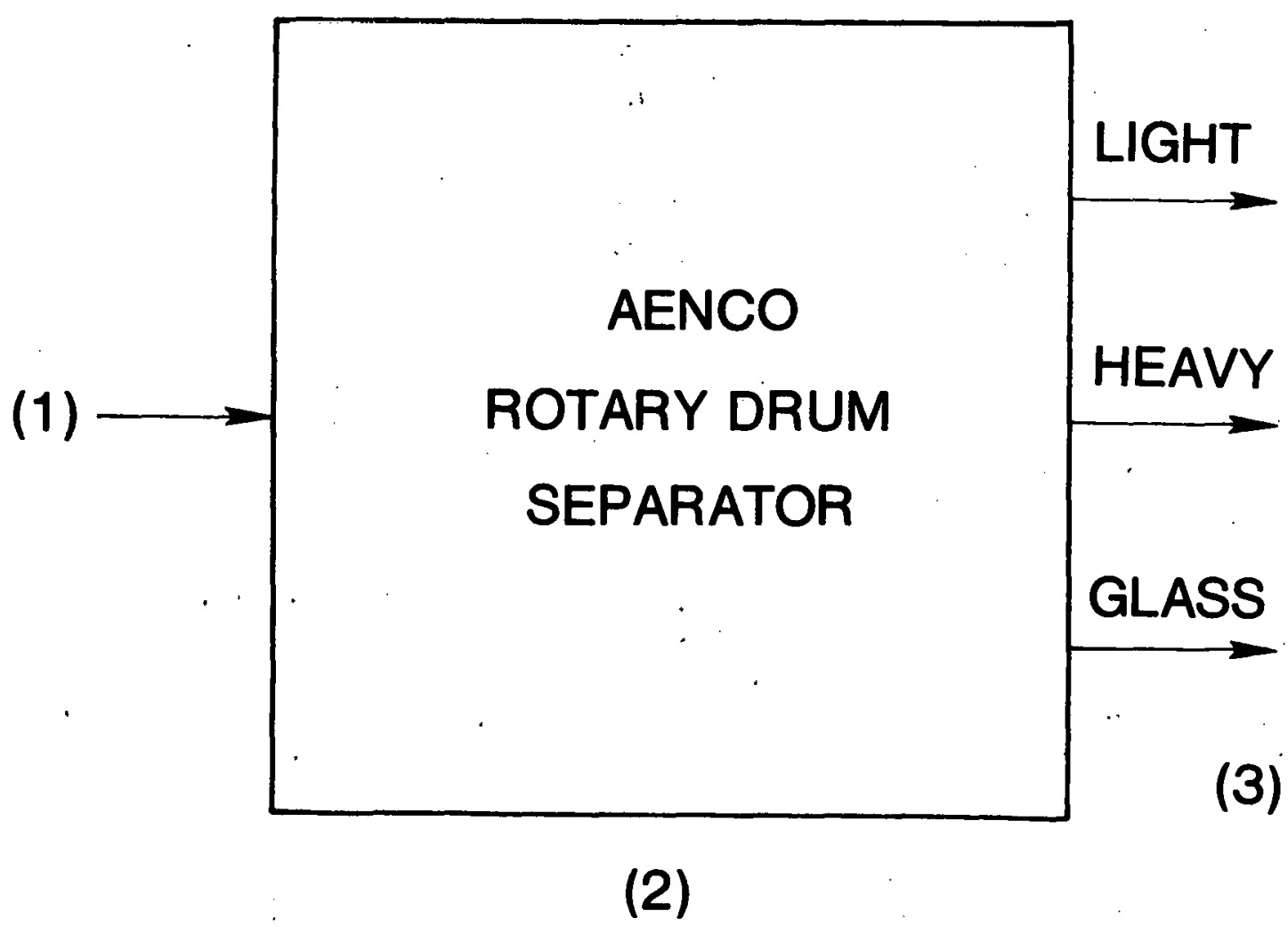

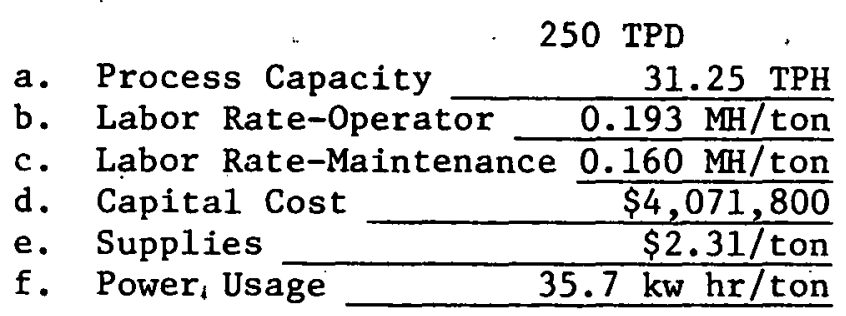

\begin{tabular}{|c|c|c|c|}
\hline \multicolumn{4}{|c|}{ PROCESS EFFICIENCY } \\
\hline COMPONENT & LIGHT & HEAVY & GLASS \\
\hline $\begin{array}{l}\text { Paper } \\
\text { Organics }\end{array}$ & $\begin{array}{l}0.90 \\
0.05\end{array}$ & $\begin{array}{l}0.1 .0 \\
0.90\end{array}$ & $\begin{array}{l}0.00 \\
0.05\end{array}$ \\
\hline Wood & 0.03 & 0.95 & 0.02 \\
\hline Iron & 0.02 & 0.98 & 0.00 \\
\hline Aluminum & 0.90 & 0.07 & 0.03 \\
\hline Other metals & 0.05 & 0.90 & 0.05 \\
\hline Glass & 0.00 & 0.02 & 0.98 \\
\hline Plastics & 0.90 & 0.05 & 0.05 \\
\hline Inerts & 0.00 & 0.10 & 0.90 \\
\hline Fines & 0.00 & 0.01 & 0.99 \\
\hline Textiles & 0.95 & 0.05 & 0.00 \\
\hline
\end{tabular}

Figure 27. AENCO system. 
Cost

AENCO estimates the capital cost of a 250-TPD plant at $\$ 4,071,800$. The operating and maintenance costs are estimated at $\$ 11.19$ per ton.

Research Needs

1. Verification of the recovered streams.

2. Combustion tests of the fuel product.

3. Verification of the design.

4. Development of a complete process design to supply existing markets, including economic evaluation.

MATERIALS SEPARATION (Cecchine-Sorain)

\section{System Description}

Scientific Energy and Recycling Group, Inc., Butler, New Jersey, is the U.S. licensee of the Cecchine-Sorain process which was developed in Italy. This process uses bag breakers, mechanical flails, rotary screens, magnetic separators, and other mechanical separation equipment to separate municipal. solid waste into paper, ferrous metal, nonferrous metal, plastics, glass, and dry compost fractions. Depending upon market conditions, the mixed paper can either be baled and sold as a secondary material, or it can be used as a boiler fuel to produce steam. Some of the steam produced is used to dry the compost, and the balance may be sold to a nearby user.

For descriptive purposes, the process may be considered as having a primary and several secondary processing modules. The primary processing system makes a preliminary separation into the various streams which the secondary processing systems upgrade to marketable quality. The various components of this process and their interrelationships are shown in Figure 28.

\section{Primary Separation Process--}

The first step in the process is the mechanical bag breaker (1) designed to open plastic film garbage bags. The waste material is then fed to a rotary drum separator (4) for the first size separation. The oversized fraction, comprised mainly of cartons, large containers, and brush bundles with some entrained paper and plastics, is fed to a flail mill (5) which reduces the size of the material. This $\mathrm{mix}$ is then air classified (6), and the heavies are sent to the furnace (41) as fuel. The light fraction is passed through a second air classifier (15) which separates the plastics. The plastics stream is further processed to remove paper which in turn is sent to the fiber process.

The undersized fraction from the first primary rotary separator (4) is conveyed to a second rotary drum separator (7). The oversized fraction is fed to a flail mill (8) for size reduction. The flailed material is then passed 


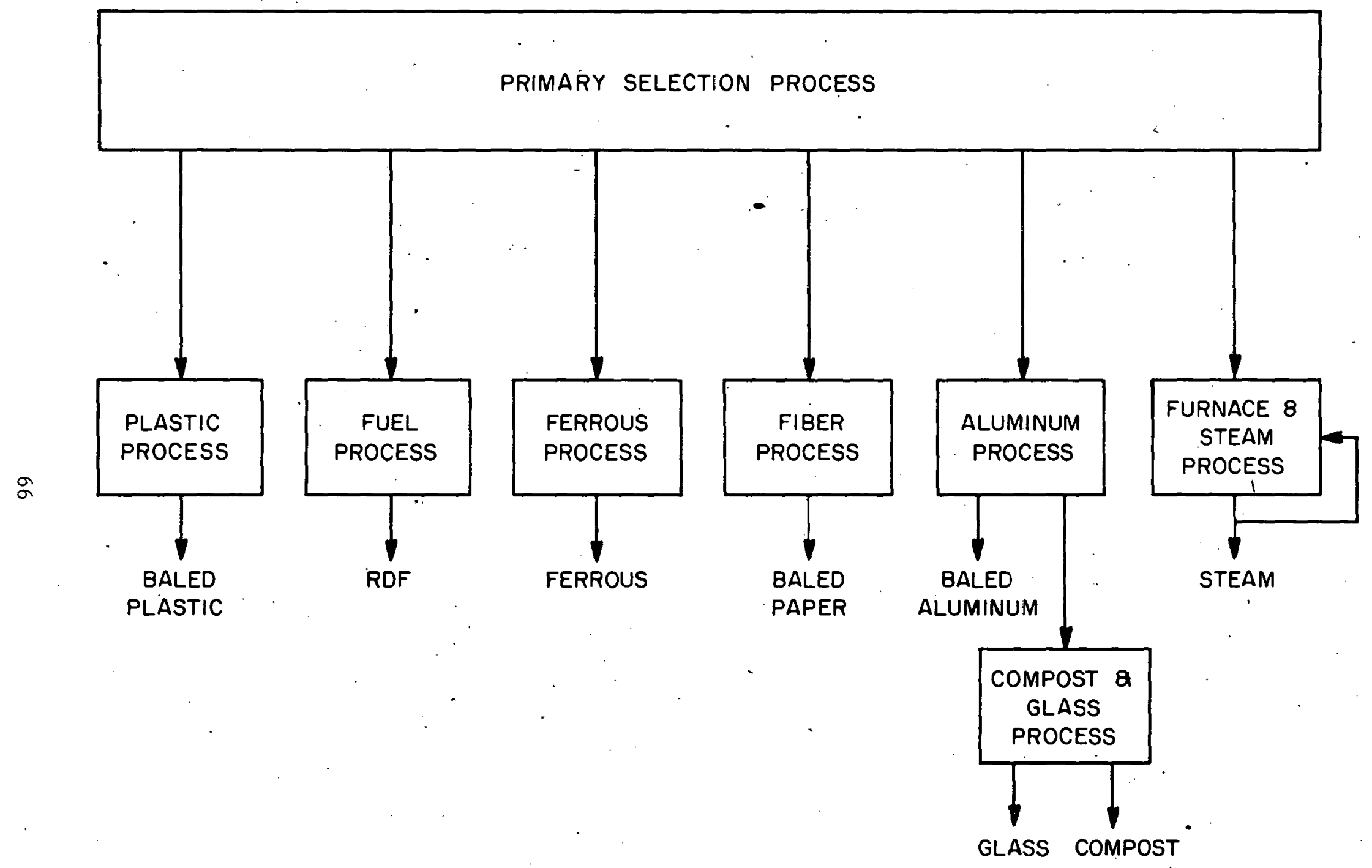

Figure 28. . Cecchini-Sorain process schematic. 


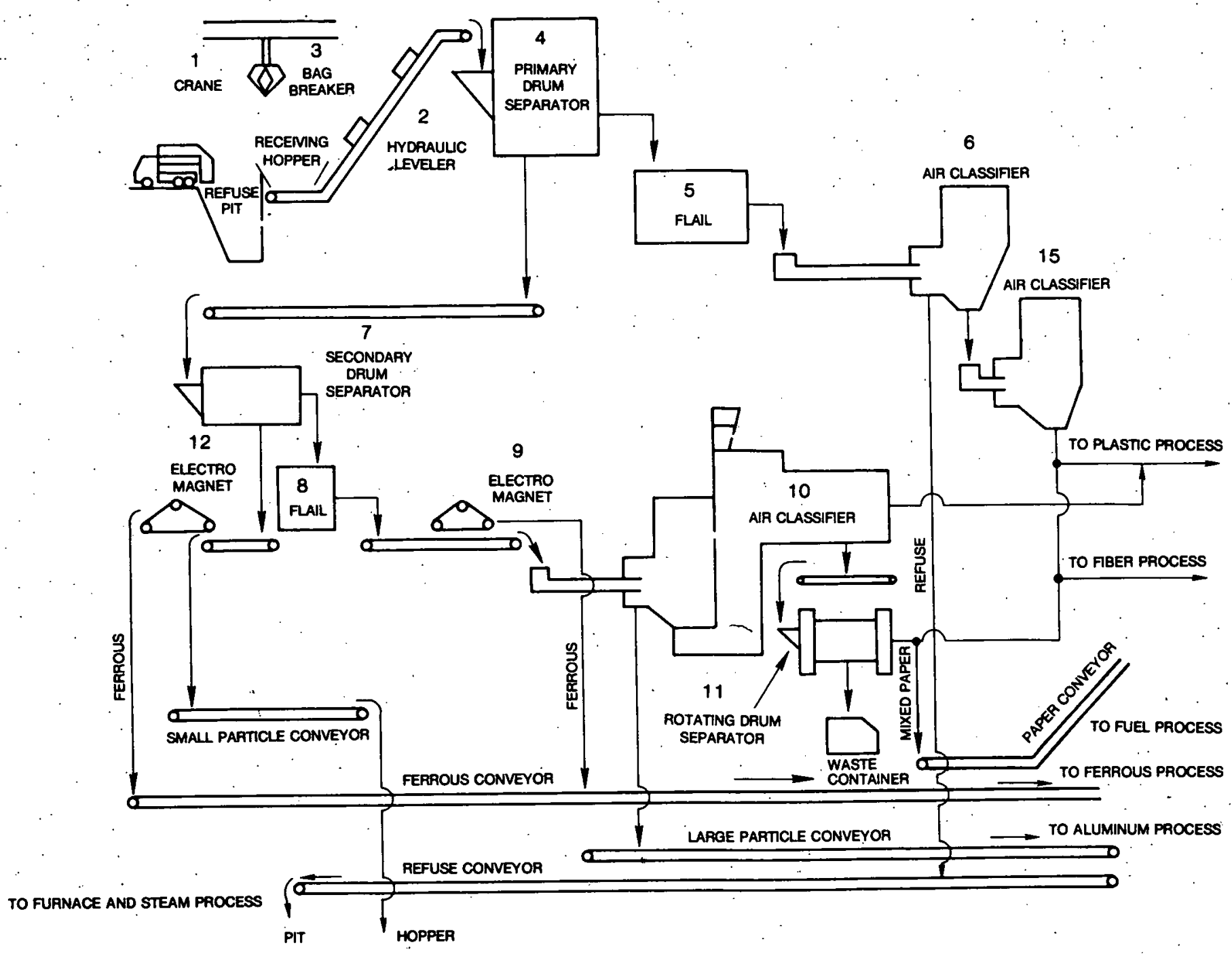

Figure 28 (continued) 


\section{FUEL PROCESS}

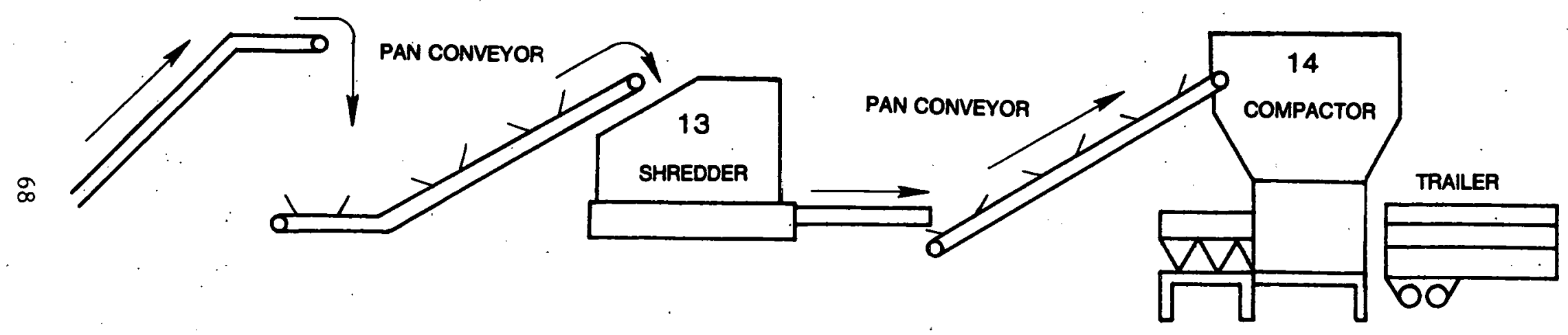


FIBER PROCESS

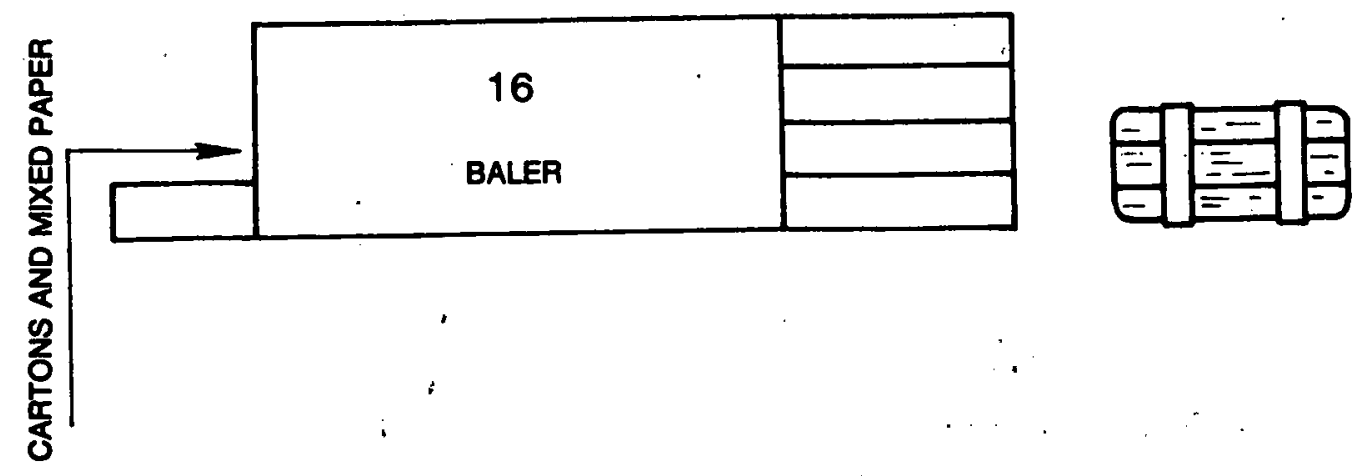

Figure 28 (continued) 


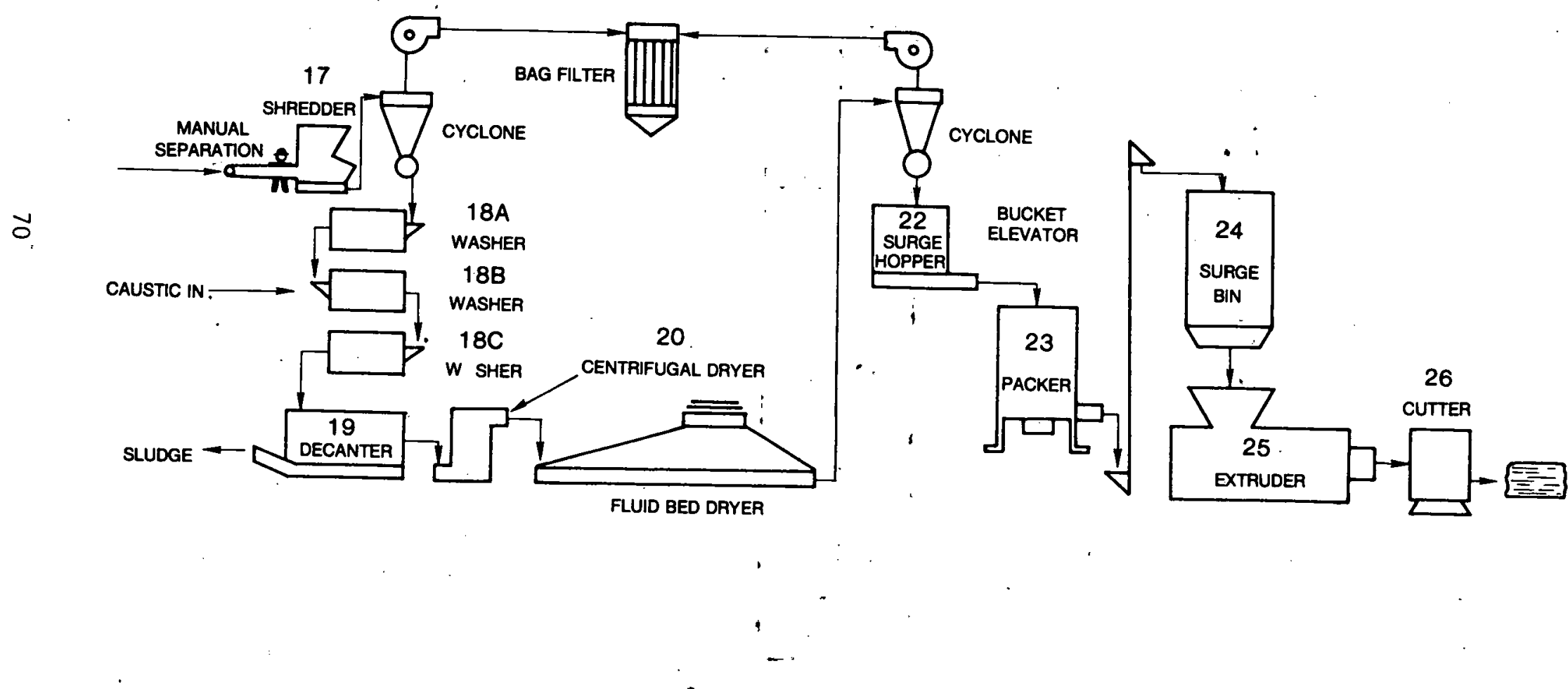

Figure 28 (continued) 


\section{FERROUS PROCESS}

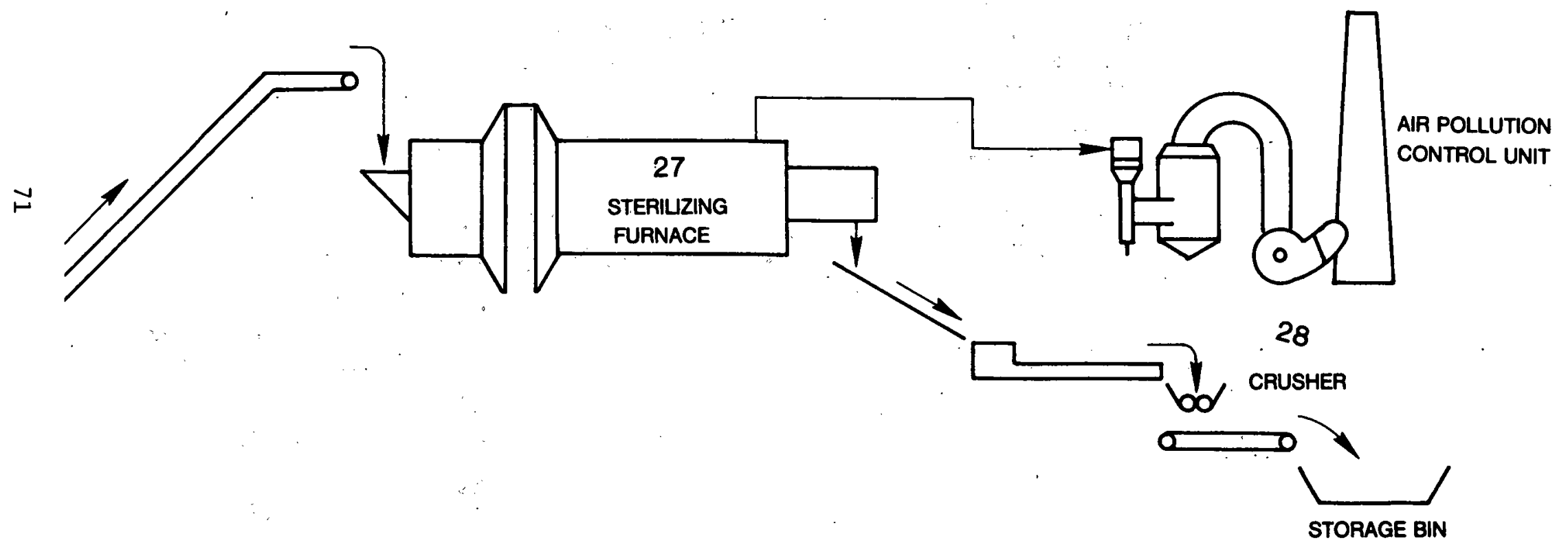

Figure 28 (continued) 


\section{ALUMINUM PROCESS}

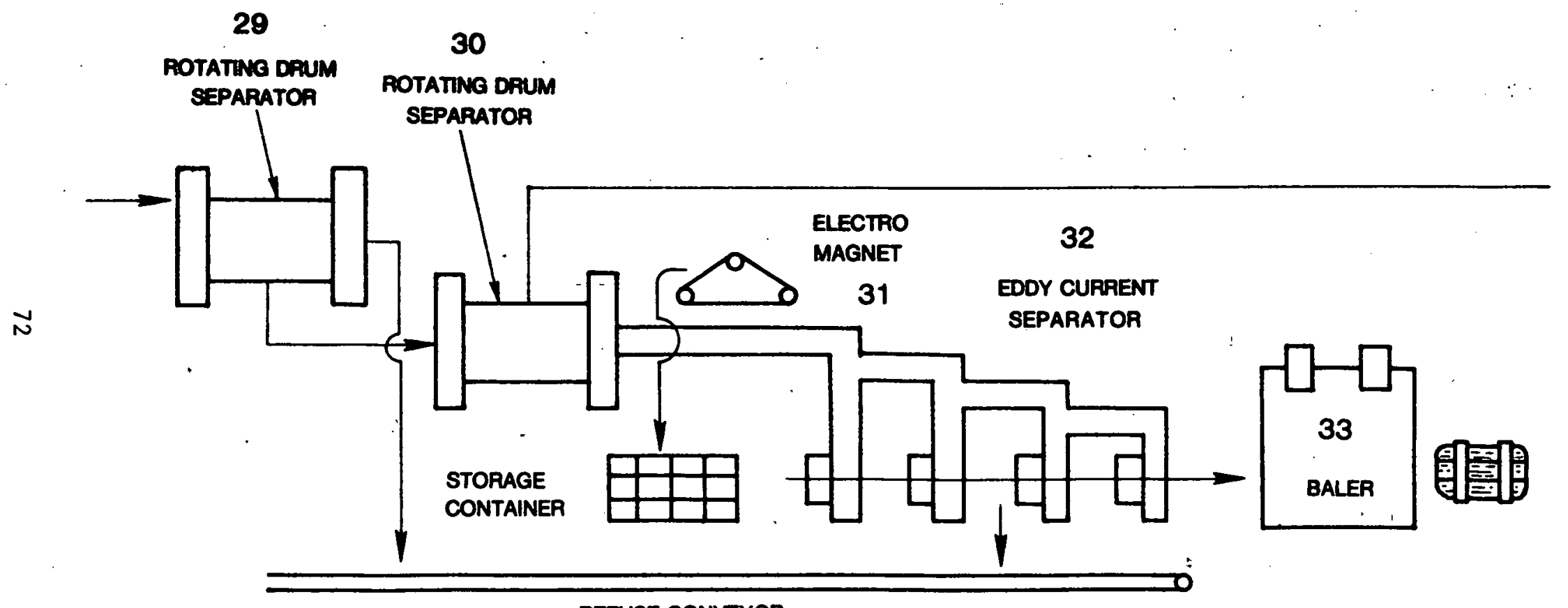

REFUSE CONVEYOR

Figure 28 (continued) 


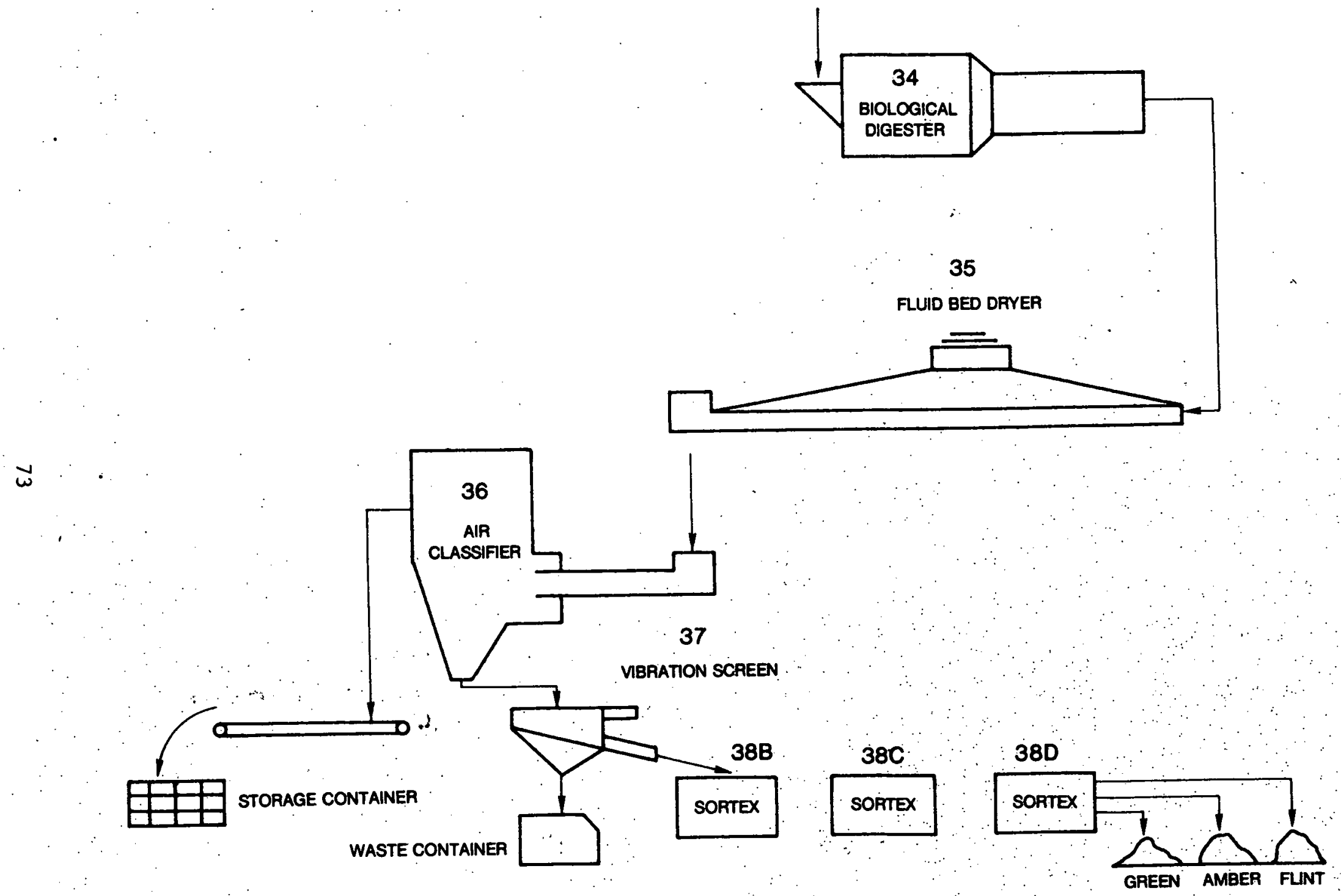

Figure 28 (continued) 


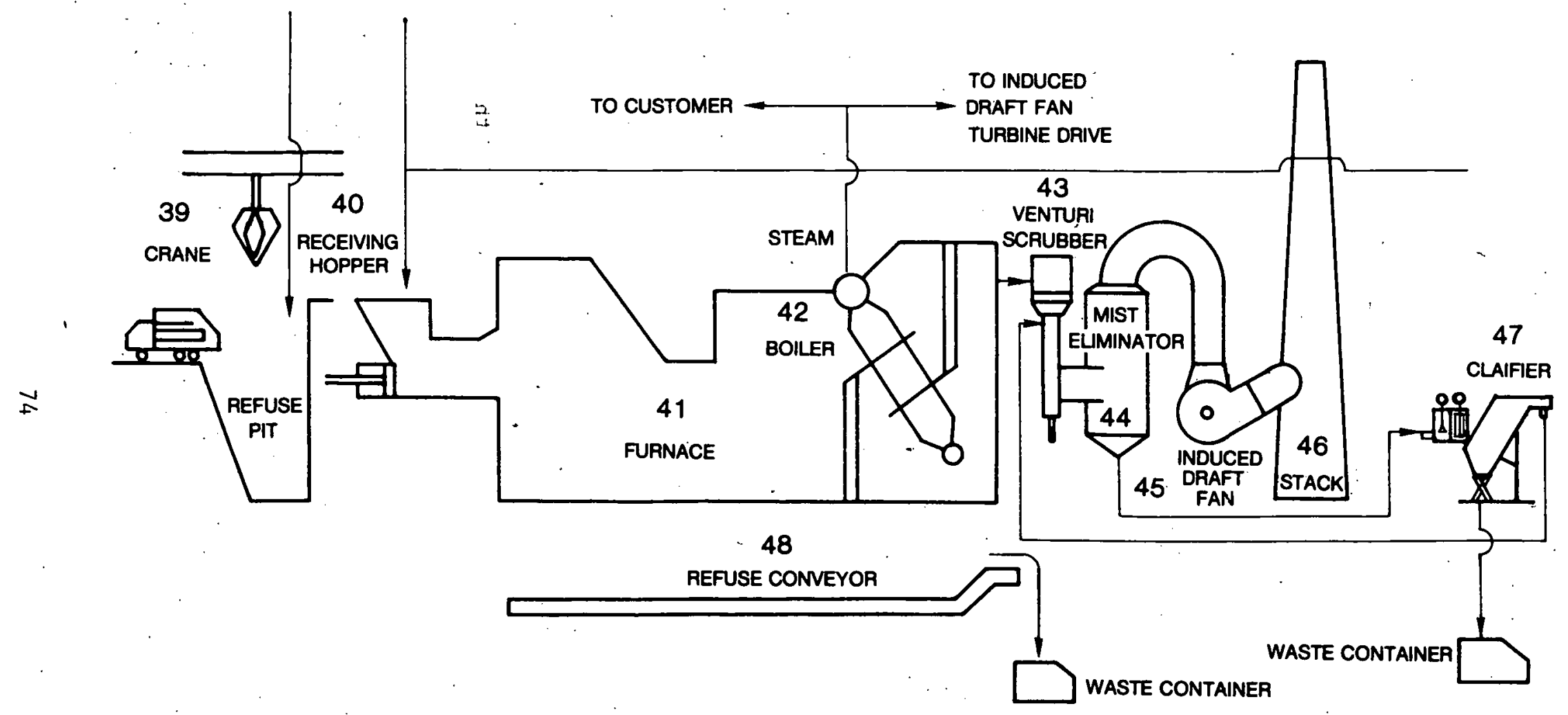

Figure 28 (concluded) 
under a magnetic separator (9) to remove any ferrous materials. The remaining material is introduced into a two-stage air classifier (10). The heavies from the first stage are sent to the secondary aluminum and (nonferrous metals) processing module. The light fraction from the first stage enters the second stage of the air classifier where plastic film is separated from the paper components which are conveyed to secondary processing and plastics recovery. The paper (heavies) fraction is passed through a fine rotary drum separator (11) to remove any impurities before being sent to the secondary fiber processing module.

\section{Fiber and Fue1 Process--}

The paper stream from the Primary Selection Process can be either baled (16) and sold as a secondary material or sold as an RDF fuel. When the paper is to be used as a secondary fuel, it will undergo secondary shredding (13) before transfer to the fuel user.

\section{P1astic Process--}

The plastic film from the Primary Selection Process is manually sorted. to remove any residual nonplastic material. It is then shredded (17) and pneumatically transported to a wash station (18) where it is processed through three sequential wash cycles. A decanter settling process (19) is used to drain the bulk of the wash solution from the plastic before centrifugal and final drying (20). The dry plastic film is pneumatically transported to a hopper (22), a densifier (23), and a blender (24) to prepare the plastics for extrusion. The densified and blended plastic is extruded (25) and cut (26) into pellets for shipment.

\section{Ferrous Process--}

The separated ferrous material is passed through one of two continuousflow, counter-current rotary kilns (27). Inside the rotary kilns, the included paper and organics are burned off the cans at $900^{\circ} \mathrm{F}$. The incinerated cans are then passed through a roll crusher (28) to increase their density before they are loaded into a trailer for shipment.
Aluminum Process--
The nonferrous metals from the primary separation process are introduced into a rotary drum separator (29). The oversized fraction is used as a fuel for the steam furnace (41). The undersized fraction is conveyed to a second rotary drum separator (30). The undersized fraction. from this separation, which consists of glass and nonorganics, is conveyed to the glass and com- posting process. The oversized fraction is magnetically separated (31) to remove any tramp iron and passed through a series of eddy current separators which separate the nonferrous stream into aluminum and tramp metals. The balance of the material from the induction classifier is utilized as a fuel for the furnace. (41).
Compost and Glass Process--
The mixture of fine organics and glass from the ferrous process is fed to the biological digester (34). The sludge from the digester is dried in a fluidized-bed drier (35) and then air classified (36). The light fraction is recovered as a dry compost. The heavy fraction is then conveyed to a series of vibrating screens (37) which separate the glass from lighter components. 
The resulting glass product is fed to an optical sorter (38) which separates the cullet into clear, amber, green, and optically opaque (which is landfilled) fractions. The lighter material fraction from the glass recovery is used as combustible fuel.

Furnace and Steam Process--

The combustibles from the primary and secondary separation systems are fed to a refractory-1ined furnace (41) with a waste heat boiler (42) for the production of steam that can be sold.

\section{Experience}

At present there are three plants of this design operating in Italy. Two of the plants are in Rome and were opened in 1964 and 1967. Their current capacities are 600 and 1200 TPD, respectively. A third plant was opened in 1972 in Perugia and has a capacity of 140 TPD.

$\underline{\text { Cost }}$

The Cecchine-Sorain process was developed in Italy and is probably very well suited to Italian refuse. It is well known that European refuse deviates substantially from American refuse both in composition and moisture content. In Italy all of the refuse is collected in plastic garbage bags, necessitating the plastic bag breaker and a plastics recovery module.

MATERIALS SEPARATION (Flakt, Inc.)

System Description

The Flakt system (see Figure 29) is a a dry separation process that was developed in Sweden to recover a high quality secondary flber as well as ferrous metals, aluminum, plastics, and glass from municipal solid waste. This process has been demonstrated on a 5.5-TPH pilot plant in Sweden. The primary source of revenue from this process is the sale of the secondary fibers.

The Flakt system can be considered as two systems--the first being primary separation and the other being product enhancement. In the primary separation system, the incoming waste is first passed through a flail mill to reduce the size of the material without reducing the glass and ceramics to a fine powder. The flailed material is then passed through a trommel to remove any oversized items (primarily plastics) from the waste stream since the flall mill does not regulate the maximum size of the discharged material. The undersize from the trommel is then passed through a zig-zag-type air classifier to separate the paper from the heavier components of the waste stream. The fluidizing air is introduced into the air classifier in the form of an "air knife" at high velocity through a small slot. Heavies from the air classifier are magnetically separated prior to landf111. The light fraction is passed through a cyclone to separate it from the air stream. This air is then recycled back into the alr classifier. 


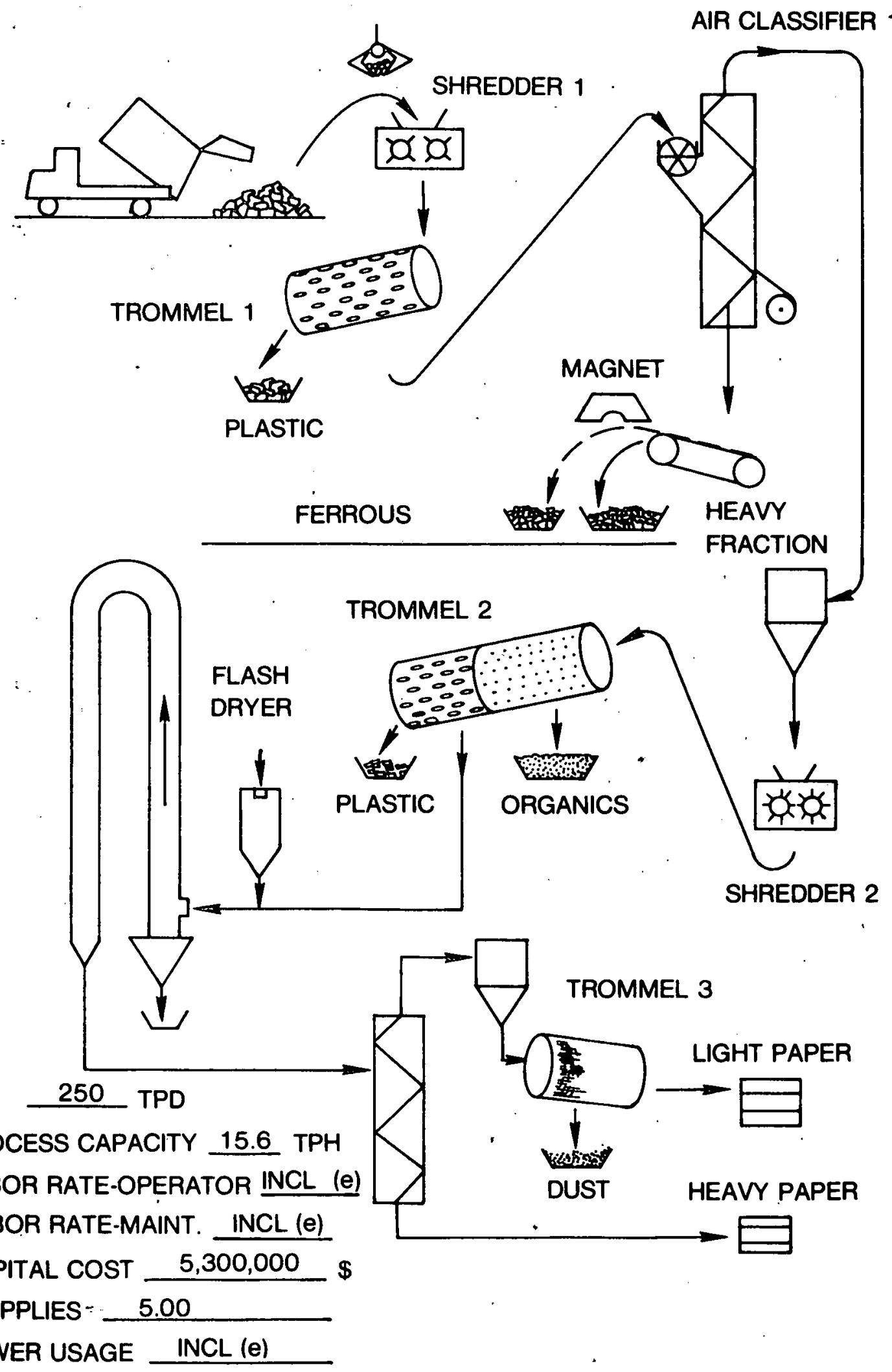

Figure 29. Flakt, Inc., materials recovery process. 
The product enhancement module accepts the light classified fraction from the cyclone. It is first shredded in a secondary shredder to produce a less than 4-in. paper product. It is then passed through a two-stage trommel which uses fine holes to remove any fine organics and employs a second set of holes (in the second stage) to remove the desired paper product. The oversize consists primarily of plastic. The paper fraction is then pneumatically conveyed to a flash drier to contract the thermosetting plastics which are contained in the steam and to reduce the moisture content. This material stream is then passed through a second air classifier which separates the material into light and heavy paper-rich fractions. The light fraction, which consists primarily of mechanical fibers, is passed through a trommel to remove any dust. The heavy fraction consists primarily of chemical fibers. These two grades are then saleable.

\section{Experience}

Flakt has operated a $5.5 \mathrm{TPH}$ pilot processing line that has been operating in Hogdalen, Sweden, since 1976. Based upon the operation of this plant, Flakt has received several orders for full-scale facilities. A plant ordered by the City of Stockholm is scheduled to be in operation by spring, 1980 .

Cost

The estimated capital cost of this facility is $\$ 3.5$ million and $\$ 5.3$ million for a 100- and 200-TPD system, respectively. Flakt estimates the operation cost of a 100- and 200-TPD facility at $\$ 9.42$ and $\$ 3$ per ton, respectively.

\section{Research Needs}

1. The market for recovered fibers in the United States.

2. The difference between Swedish and American refuse and its impact upon the operation of the Flakt system.

3. The operation of the flash drier and its effect upon the plastic content.

DUST REFUSE DERIVED FUEL (CEA/OXY)

\section{Process Description}

The process developed by Combustion Equipment Associates (CEA) of New York; New York, is a mechanical benefication process that produces a very fine powder RDF fuel (called ECO Fuel II) that is easily pelletized (if desired): The fine powder RDF is obtained by adding an embrittling agent to the trommelled and air-classified solid waste prior to grinding in a hot ball mill. The process (Figure 30) has been demonstrated in Brocton, Massachusetts, but CEA has not released any production or reliability statistics.

To produce the fuel, the solid waste is passed through a rotary screen which separates the material smaller than 8 in. in size from larger material. A flail mill is used to reduce the oversized material to 8-in. particles which 


\section{CEA/OXY PROCESS}

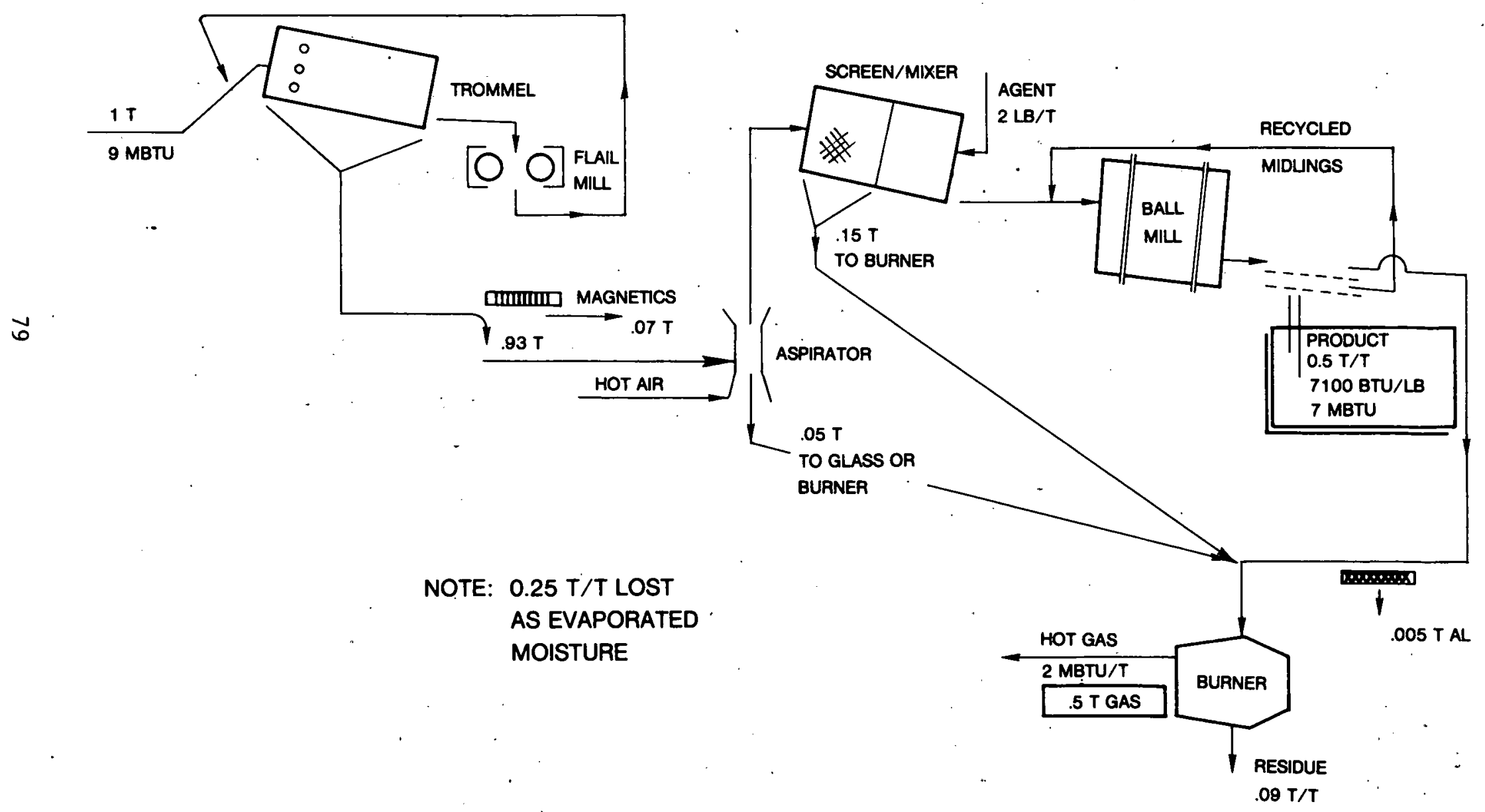

Figure 30. Combustion Equipment Associates process schematic. 
are then recycled back to the trommel. The undersize from the trommel is subjected to magnetic separation and then fed to the air classifier (aspirator). The air classifier is designed to reject only large, heavy items. Consequently, the air-classified fuel fraction contains dirt, broken glass, ceramics, and pieces of aluminum cans and foil. Some drying does occur because hot air is used in the air classifier.

The partially dried and air-classified material is then passed through a rotary screen to remove the small pieces of dirt, pottery, and broken glass. The embrittling agent is added to the screened material before introduction to the ball mill. The undersized material from the screen is conveyed to a burner called the "sterilizer." This unit is a small rotary kiln in which the combustibles are burned producing an inert residue. The sterilizer produces the heat required to dry the ECO Fuel II. The hot fuel gases from the sterilizer are vented through the ball mill and to the air classifier.

The dust RDF produced by this process is powdery in nature and can be stored in conventional pulverized coal or flour handling systems. It has a less than 10-mesh particle size, a relatively low moisture content, and minimal biological activity.

\section{Experience}

CEA has been operating a 10-TPH pilot plant in Brocton, Massachusetts, which has produced 600 to 700 tons of ECO Fuel II.

\section{Cost}

CEA has negotiated ful1-service contracts with several municipalities calling for tipping fees ranging from $\$ 4.50$ per ton to $\$ 12$ per ton. They are reluctant to release any detailed cost information.

\section{$\underline{\text { Research Needs }}$}

Independent verification of the process' technical and economic performance.

DENSIFIED REFUSE DERIVED FUEL (Lehigh Forming Company, Inc.)

\section{System Description}

The Palmer Process (Figure 31) produces a pelletized RDF product and consists of a series of mechanical benefication steps that are used to separate the ferrous and heavy noncombustible components of the refuse from the combustible fraction.

Incoming solid waste is first passed through a rotary drum conditioner to break open the bags. It is then passed over a magnetic separator to reclaim the steel cans. The nonmagnetics are passed through two air classifiers in series. The heavy fraction from both air classifiers is landfilled and the light fractions are passed through a secondary shredder for further size 


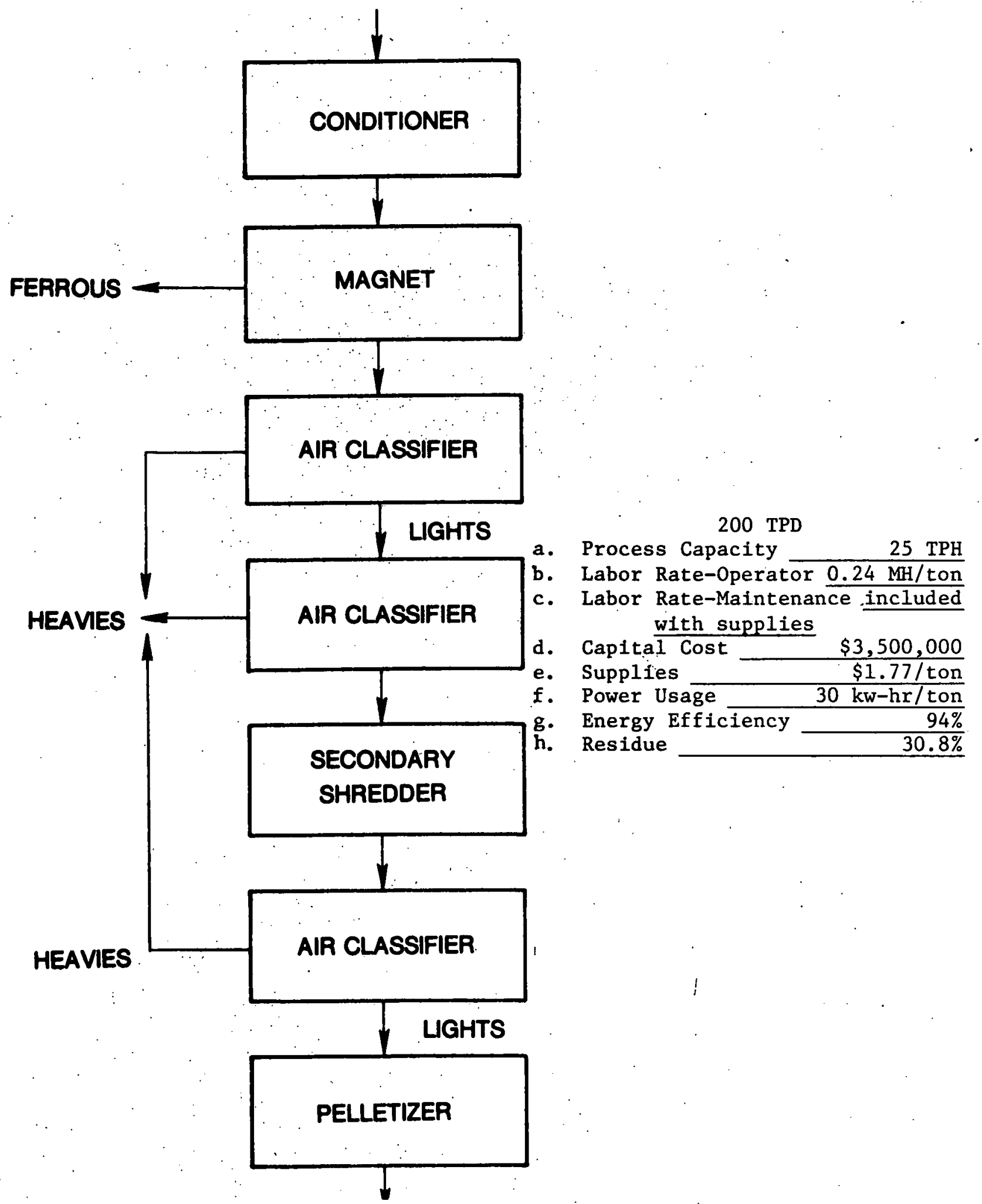

Figure 31. Lehigh Forming process diagram. 
reduction prior to being introduced into a third air classifier. Again, the heavy stream is landfilled while the light stream is pelletized and sold as a fuel.

This system is a mechanical benefication process using a conditioner instead of a primary hammermill. The conditioner is, in essence, a large diameter, inclined rotary drum similar to a rotary screen but without holes.

\section{Experience}

Lehigh Forming Company has constructed a pilot plant demonstrating the Palmer Process in Easton, Pennsylvania. Fuel pellets produced by this facility have been successfully tested as a fuel supplement at several locations.

Cost

No operating or capital cost data was supplied by the vendor. However, since the components of this system, with the exception of the conditioner, are commercially available, the capital and operating costs of the system were based on the data already available on these items. The conditioner was approximated as a large trommel for processing raw refuse. On this basis, the estimated capital cost of a $200-T P D$ system is $\$ 3.5$ million. The net cost was calculated to be $\$ 5.01$ per ton.

Research Needs

1. Additional information on the technical and economic operating characteristics of the solid waste conditioner.

2. Data on the effects of the combustion of refuse pellets, both alone and with a mixture of coal or other fuels, on energy recovery equipment.

DENSIFIED REFUSE DERIVED FUEL (Vista Chemical)

\section{System Description}

Vista Chemical and Fiber, Los Gatos, California, has developed a shredding, air classifying, and pelletizing system (Figure 32) for the production of a densified RDF (dRDF) from municipal solid waste. All of the components used in this system are standard equipment items with the exception of the air classifier which Vista considers to be a proprietary design. Vista Chemical and Fiber has been unwilling to provide any information about their system since they also consider it to be proprietary. Consequently, this system was simulated using the standard component in the SWIMS model.

\section{Experience}

Vista has operated their facility in Los Gatos, California, for several years. It is currently not in operation. 
VISTA

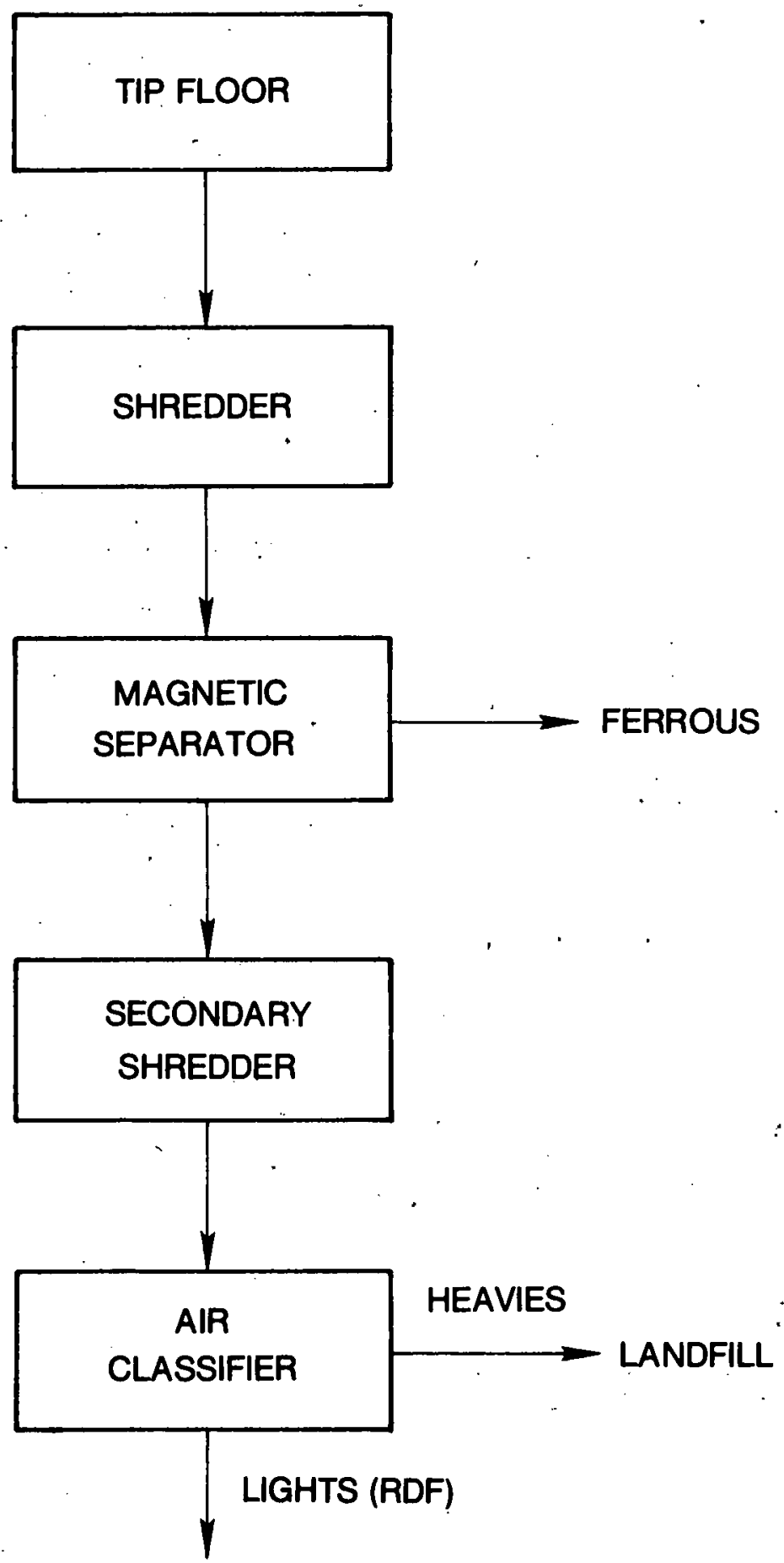

Figure 32. Vista Chemical and Fiber product process diagram. 
$\underline{\text { Cost }}$

The calculated capital cost, based on the SWIMS model, for the 100- and 200-TPD facility is $\$ 2,520,000$ and $\$ 3,148,000$, respectively. The calculated net disposal cost is $\$ 12.03$ and $\$ 4.95$ per ton, respectively.

FINE REFUSE DERIVED FỤE (Waste Control Science)

System Description

The Waste Control Science (WCS) process (Figure 33) is a dry recovery process that recovers fuel fraction, glass, and ferrous and nonferrous metals. They consider 1000 TPD to be the minimum economic plant size because several components must be that large to function properly.

The WCS process consists of several stages. First the raw incoming material is conveyed to the "conditioning" unit. This unit appears to be a dual-axis flail mill which: reduces the particle size of the material, especially the glass fraction.

A 12-ft-diameter, 60-ft-iong trommel with 3/4-in.-diameter holes is then used to separate most of the glass, dirt, and grit from the flailed material to be carried off by a scavenger conveyor for additional processing.

The material is then shredded in two steps with the first stage reducing the material to a 4-in. particle size. The ferrous material is removed by a magnetic separator, and a second trommel is used to remove any remaining glass and small fines. The resulting light fraction is then reduced in the second grinder to a less than $1 / 2-i n$. particle size.

The less than 1/2-in. material is air classified with the light fraction being blown into a fuel storage bin. The heavy fraction is removed through an air lock at the bottom of the air classifier and sent to the resource recovery area. This light, air-classified fraction can be used as a fuel either as is or densified.

- The undersize from the two trommels and the heavy fraction from the air classifier are further processed in a materials recovery module. This module utilizes vibrating screens, a rising current separator, heavy media separators, and grinders to separate out the wood, glass, plastics, aluminum, copper/brass, and ferrous metals.

\section{Experience}

WCS, of Santa Rosa, California, operated a 200-TPD pilot plant to aid in development of the process. The design of the 1000-TPD system was based on the data obtained from that plant. The pilot plant work also indicated that the smallest size facility, based on minimum equipment size constraint, is 1000 TPD. 


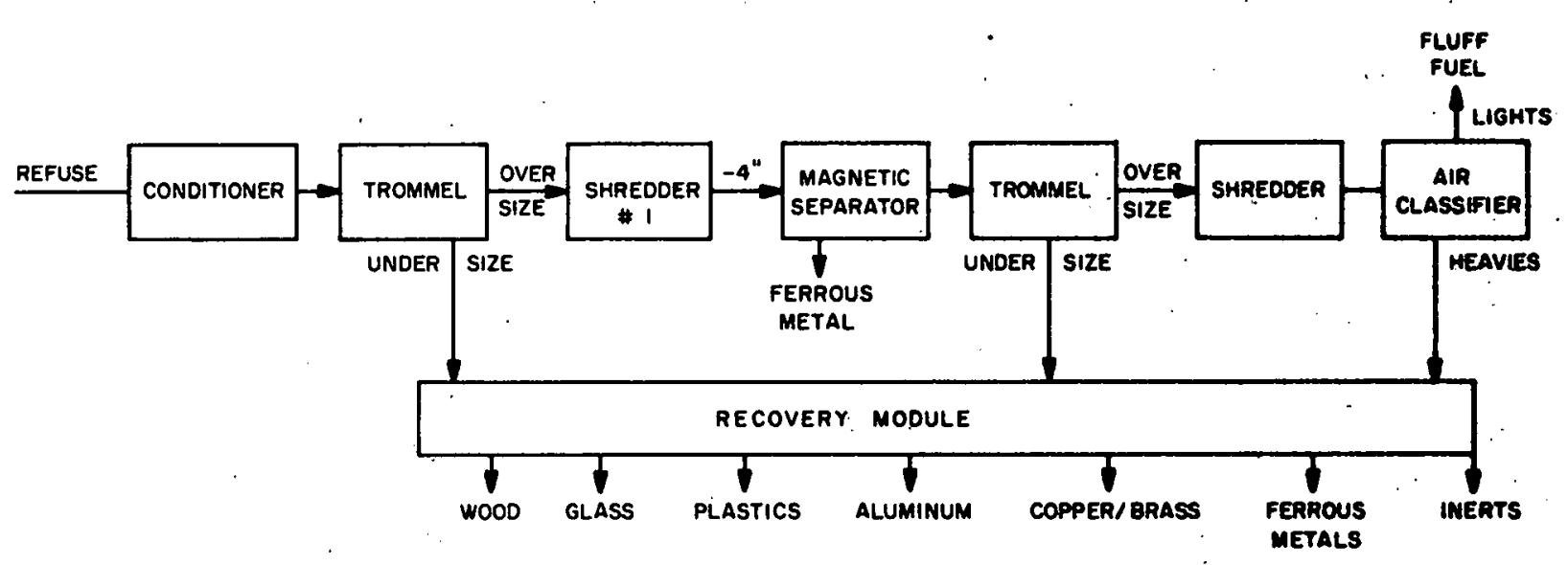

Figure 33. Waste Control Science process schematic. 


\section{Cost}

They estimate the cost of a 1000-TPD (1974) plant at $\$ 15,000,000$. The economics are based on selling all of the recovered materials. Since wCS does not have units of less than 1000 TPD available, it does not meet our criteria for small systems. 


\title{
SECTION 4
}

\author{
MECHANICAL PROCESSING COMPONENTS
}

\section{RECEIVING MODULE}

The purpose of the receiving module is to accept solid waste from the collection/transportation vehicle and to introduce it into the recovery plant. To accomplish this goal, all alternatives must perform three functions:

(1) accept the refuse, (2) introduce the refuse into the processing plant, and

(3) provide surge capacity.

Since the delivery of refuse to the processing plant is very cyclical throughout the day, all refuse must be accepted on a demand basis. All alternative components are sized to permit the rapid unloading of the transportation vehicles in order to accommodate traffic flow during the peak periods of the day. Since virtually all resource recovery and thermal processing systems require that the feed stock be introduced into the processing plant at a controlled rate, the receiving module must perform a leveling of the cyclical refuse delivery. Another requirement placed on the receiving module is that it provide surge capacity which is necessary to accommodate the cyclical reception of refuse as it is delivered to the processing plant and to provide storage in the event of minor plant shutdowns: All processing options are sized to provide a 1 1/2-day storage capacity for the raw refuse. This storage capacity is typical of the level currently observed within the industry. However, other values can be used depending upon specific plant design factors such as number of operating shifts, redundacy of equipment, availability of alternate disposal sites, etc.

All of the receiving modules were designed to have the material transferred from them by a steel apron conveyor at the nominal plant throughput capacity. It is only in the case of the crane pit concept that the conveyor outfeed rate is variable because of the cycle time of the crane.

The concepts included in the receiving area study are: the receiving floor, the conveyor'pit, the crane/push pit, the crane pit, and the dozer pit.

\section{Tipping Floor}

The principal components of the tipping floor (Figure 34) are a large covered slab (4), a front-end loader (3), and a recessed steel apron conveyor ( 1 ) to feed the next processing step. In operation, the transportation vehicles (5) enter the receiving building, deposit their load of solid waste 

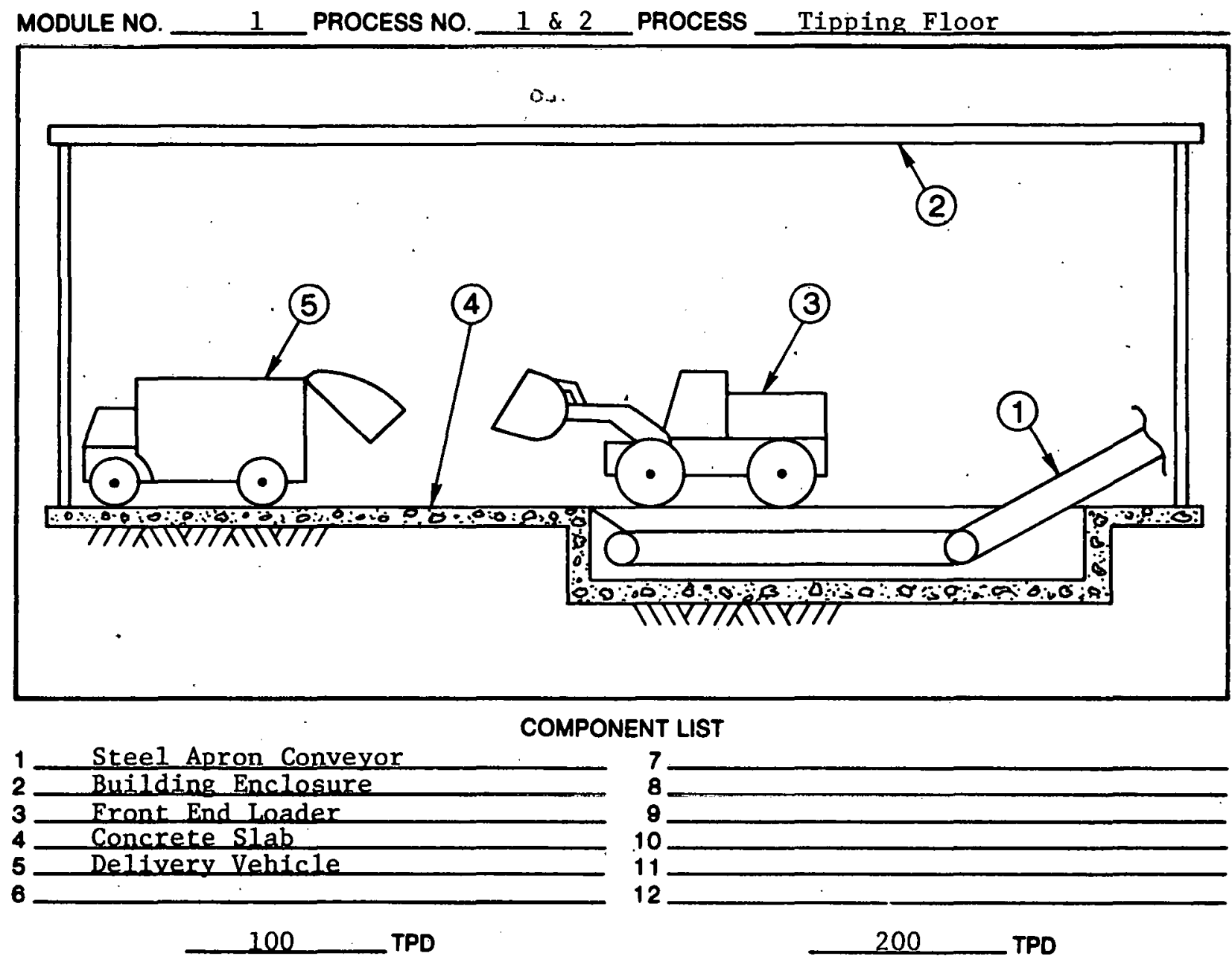

a. PROCESS CAPACITY TPD 15 TPH

b. LABOR RATE-OPERATOR I $\mathrm{I} \mathrm{MH} / \mathrm{mach} \mathrm{hr}$

c. LABOR RATE-MAINT. $\quad 0.016 \mathrm{MH} / \mathrm{t}$ -

d. CAPITAL COST $296.000 \$$

๑. SUPPLIES so.36/ton

f. POWER USAGE $0.4 \mathrm{kw}-\mathrm{hr}$. It ton

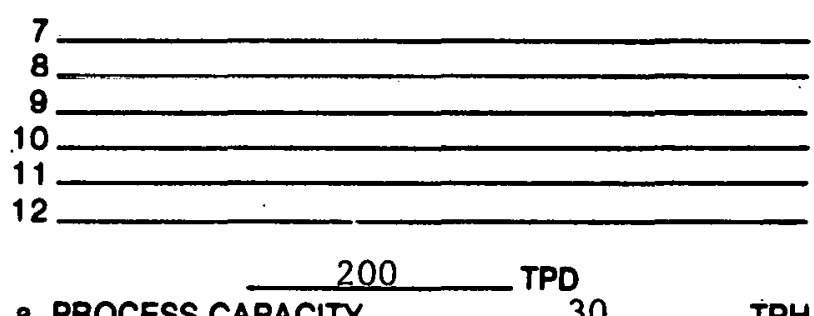

a. PROCESS CAPACITY $\quad 30$

b. LABOR RATE-OPERATOR $1.2 \mathrm{MH} / \mathrm{mach}$ hr.

c. LABOR RATE-MAINT. $0.012 \mathrm{MH} / \mathrm{tan}$

d. CAPITAL COST $403,000 \$$

o. SUPPLIES

f. POWER USAGE $\quad 0.28 \mathrm{kw}-\mathrm{hr} / \mathrm{t}$ ton

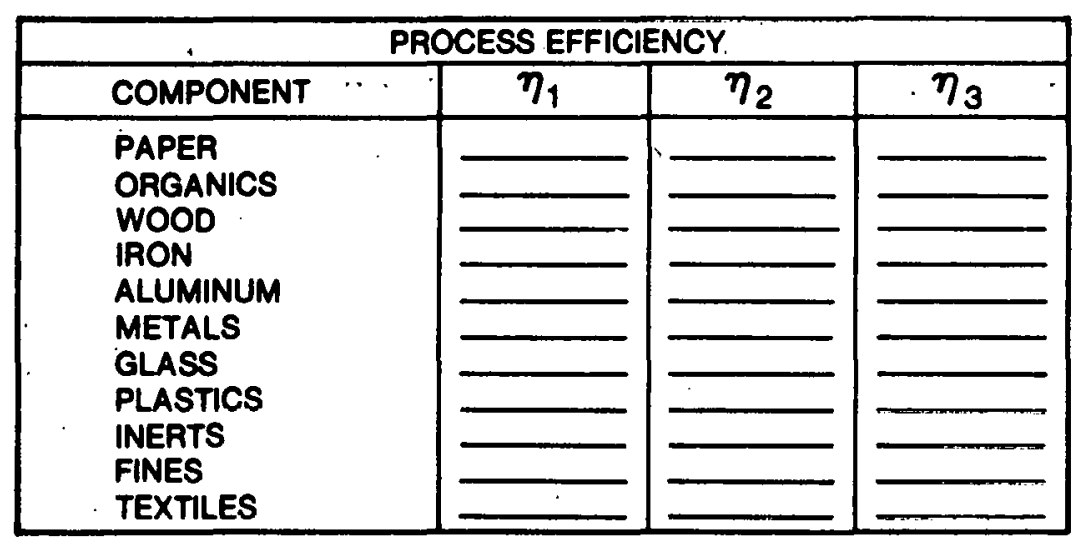

Figure 34. Tipping floor schematic and operational data. 
on the "tipping floor," and leave the facility. The deposited material is then moved to either a storage area located on the tipping floor or directly onto the steel pan conveyor for transportation to the processing 1 ine. The primary feeding of the conveyor is from the storage area. The metering of the refuse on the conveyor is generally controlled by the skill and attentiveness of the equipment operator. Leveling bars have been used in some installations to achieve a constant flow of material, but they have had limited success because of a tendency of the refuse to jam at the leveling bar and to stall or damage the conveyor.

The principal advantage of the tipping floor is that all the refuse received at the plant is under the direct view of the front-end loader operator. This exposure of the refuse to scrutiny increases the probability of identifying and removing any item which may interfere with subsequent material handling or processing steps. The main disadvantage of this approach is that one man is required at all times to operate the front-end loader. Operating and maintenance costs for this module are quite consistent because of its extensive application.

The Conveyor Bottom Pit

The conveyor bottom pit (Figure 35) consists of three principal components: a large pit $30 \mathrm{ft}$ deep (1), a conveyor placed along the entire bottom of the pit (2), and an elevating conveyor (3). In operation, the transportation vehicle backs up to the edge of the pit and deposits its load of solid waste. The refuse is moved across the bottom of the pit by the horizontal conveyor and is then transferred to the elevating conveyor which subsequently feeds the next processing module.

The advantages of this system include the elimination of an operator associated with the transfer of the refuse from the transportation vehicle to the outfeed conveyor, the smaller space requirements as compared to the tipping floor, and the fact that the refuse may be processed on a "first-infirst-out" basis. However, this system does present some significant disadvantages. The conveyor that forms the bottom of the pit supports most of the weight of the refuse in the pit, requiring that it be of a heavy duty construction. This design does not readily lend itself to segregating items that may present difficulty in subsequent processing operations. It also promotes jamming at the transfer point. Further, should a conveyor failure occur, its repair would be extremely difficult with a large loading of refuse on the conveyor. Since there is very little operational experience concerning this approach, accurate estimates of maintenance costs and mean time between failures are approximations.

\section{The Crane/Push Pit}

The example used for this component system (Figure 36) was the unit operated at the Maryland Resource Recovery Facility located in Baltimore County (Cockeysville), Maryland. In operation, the transportation vehicle backs up to a large, deep pit (2) and deposits its solid waste load. This pit provides a 1 1/2-day storage capacity. Refuse is then transferred from the 

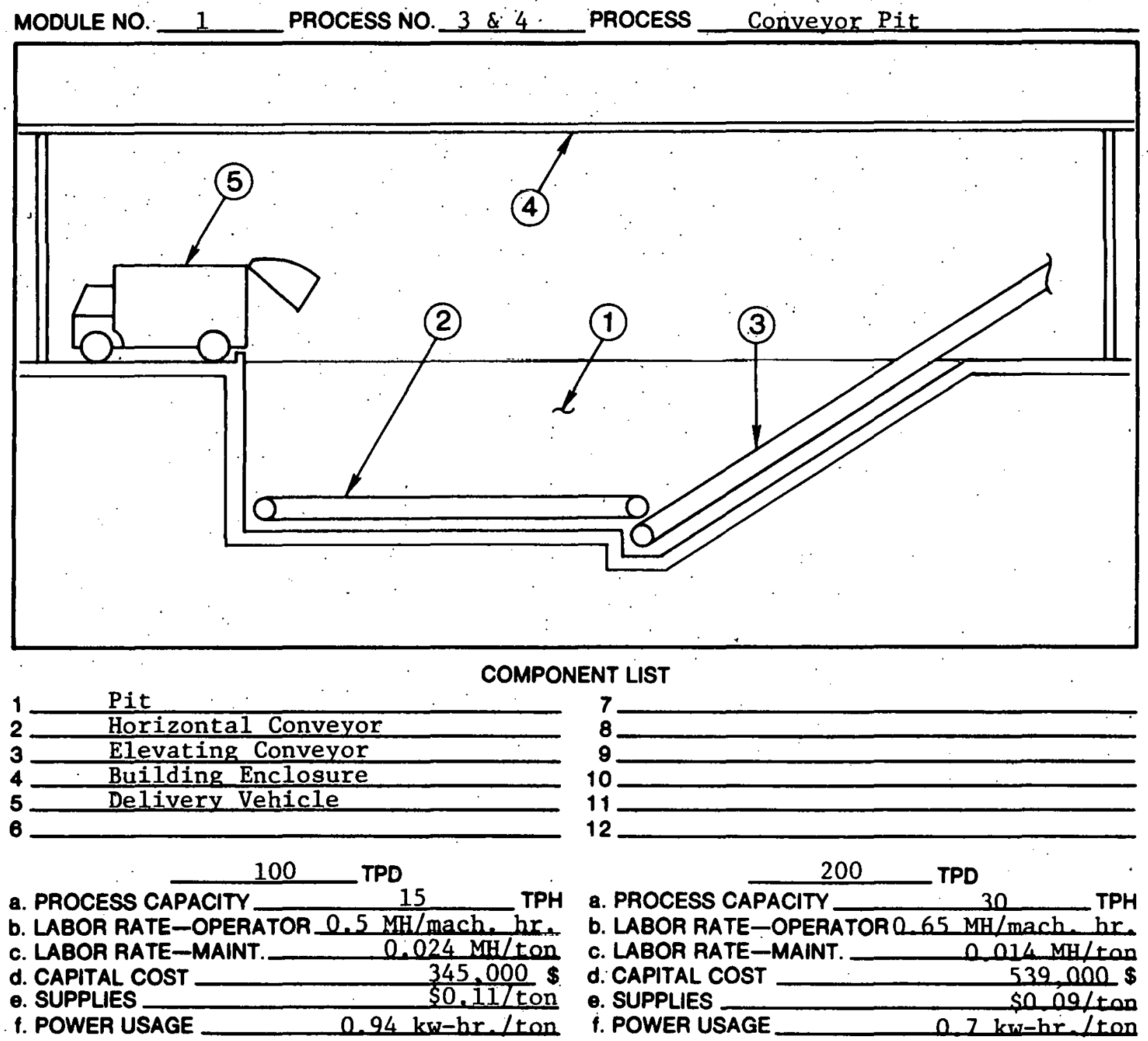

\begin{tabular}{|l|l|l|l|}
\hline \multicolumn{3}{|c|}{ PROCESS EFFICIENCY } \\
\hline COMPONENT & $\eta_{1}$ & $\eta_{2}$ & $\eta_{3}$ \\
\hline PAPER \\
ORGANICS \\
WOOD \\
IRON \\
ALUMINUM \\
METALS \\
GLASS \\
PLASTICS \\
INERTS \\
FINES \\
TEXTILES
\end{tabular}

Figure 35. Conveyor pit schematic and operational data. 


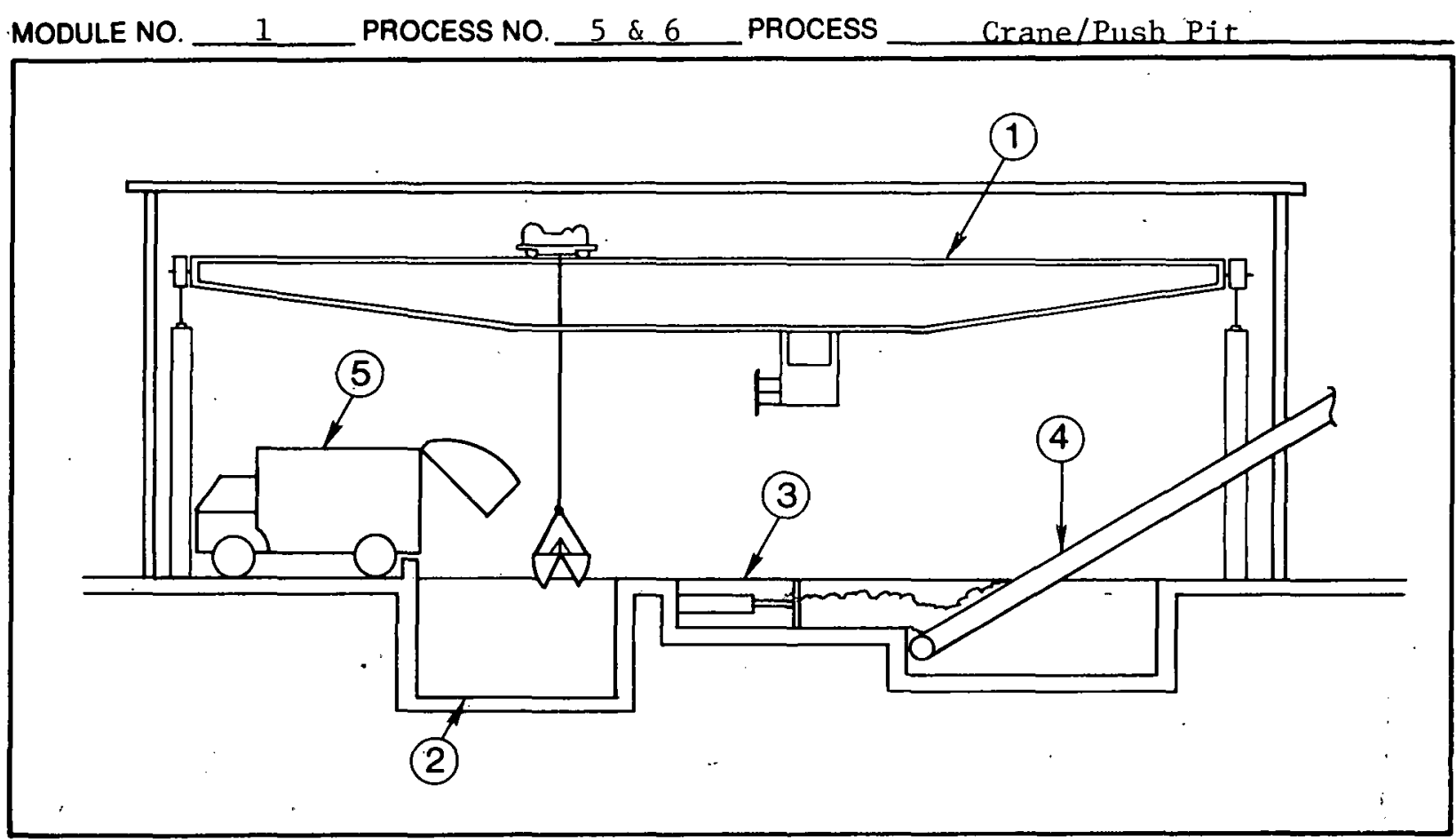

COMPONENT LIST

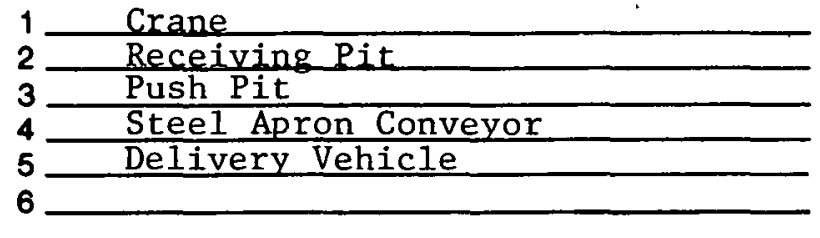

PROCESS CAPACITY TPD 150 TPH

b. LABOR RATE-OPERATOR 1.6 MH/mach./hr.

c. LABOR RATE-MAINT.

d. CAPITAL.COST

$0.028 \mathrm{MH} / \mathrm{tan}$

. SUPPLIES

$787000 \$$

f. POWER USAGE

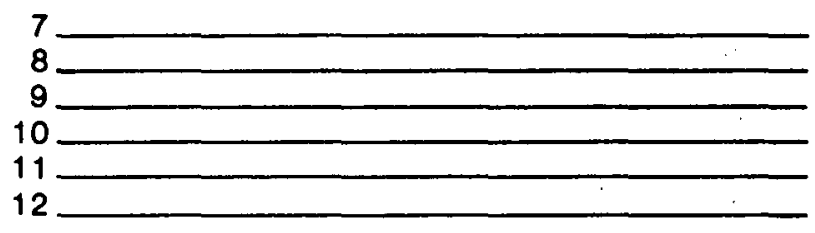

a. PROCESS CAPACITY

b. LABOR RATE-OPERATOR $17 \mathrm{MH} / \mathrm{mach}$ hr. c. LABOR RATE-MAINT. $0.021 \mathrm{MH} / \mathrm{t}$.

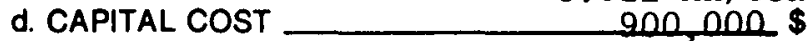

e. SUPPLIES

f. POWER USAGE $3.5 \mathrm{kw}=\mathrm{hr} / \mathrm{tan}$

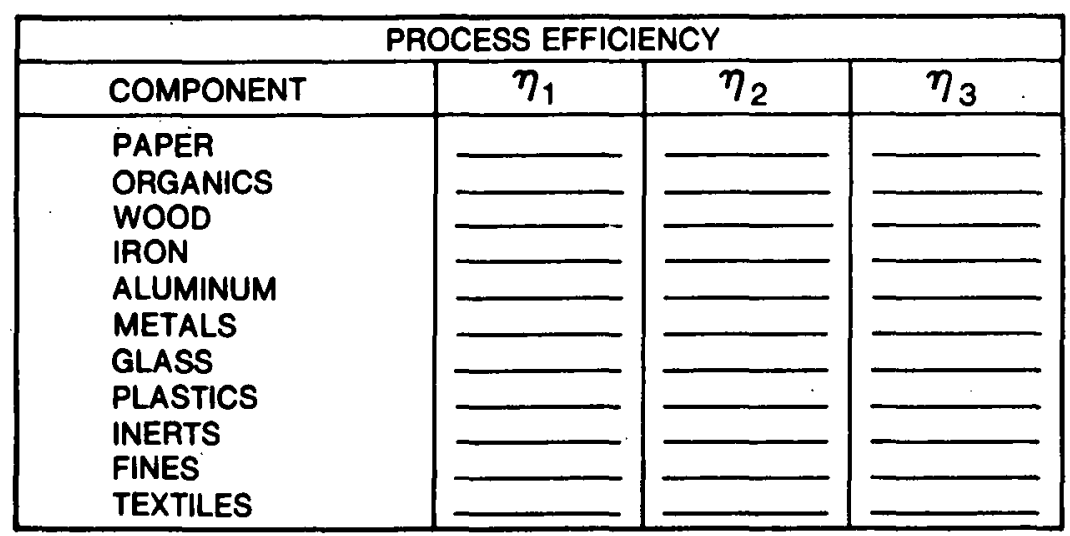

Figure 36. Crane/push pit schematic and operational data. 
deep pit to either of two push pits (3) via a bridge crane (1). The push pits are approximately $10 \mathrm{ft}$ wide by $10 \mathrm{ft}$ deep by $20 \mathrm{ft}$ long and are lined with steel wear plates. The pits have a hydraulically operated platen that pushes the refuse from the pit onto an inclined steel pan discharge conveyor (4). The discharge of the refuse from the push pit is under direct operator control.

This type of system has several advantages. Minimal direction is required by the plant operators for traffic control. The system uses a highly reliable overhead traveling crane and has redundancy designed into it by having twin push pits. Lastly, the use of push pits and direct operator control provides accurate metering of the outfeed to subsequent processing steps. The primary disadvantage to this system is that it is a capital intensive approach. Additionally, the operator labor requirements associated with both the bridge crane and the manlpulation of the push pits is very high. Little information has been made avallable concerning the operation of the unit in Maryland, and additional data will be necessary to effectively characterize the unit.

The Crane Pit

The crane pit model (Figure 37) for this study is typical of those used at numerous incinerator installations throughout the country. In the case of the crane pit, the transportation vehicle backs up to the edge (2) and discharges its load of waste into the p1t. The refuse is transferred from the pit to an outfeed conveyor (3) by a bridge crane (1) equipped with a grapple bucket. The primary advantage of this system is its proven reliability in the field. The primary disadvantage is that this receiving system results in surge feeding which is likely to decrease throughput rates or even stop the downstream unit processes requiring level feeding. However, this disadvantage is not significant when applied with thermal processing approaches.

The data used to characterize this system is considered to be extremely accurate because of the extensive operating experience available pertaining to this unit.

The Bulldozer Pit

The bulldozer pit (Figure 38) is a cross between a tipping floor and a conveyor bottom pit. Material is discharged from the collection trucks to a recessed pit (1) where a bulldozer (2) operates to distribute the waste and deposit a portion of the material on conveyors (3) located in the pit. In operation, the transportation vehicles back up to the edge of the pit and deposit their waste load. The dumped refuse is spread evenly in the pit by a bulldozer equipped with a landfill blade. This spreading action, which requires the bulldozer to operate on a layer of refuse, accomplishes some size reduction and mixing of the refuse. As in the tipping floor, the bulldozer will either transfer the refuse to the outfeed conveyor for removal or spread and compact it for storage. The metering of the outfeed is controlled by both the angle of incline of the discharge conveyor and the expertise of the bulldozer operator. 

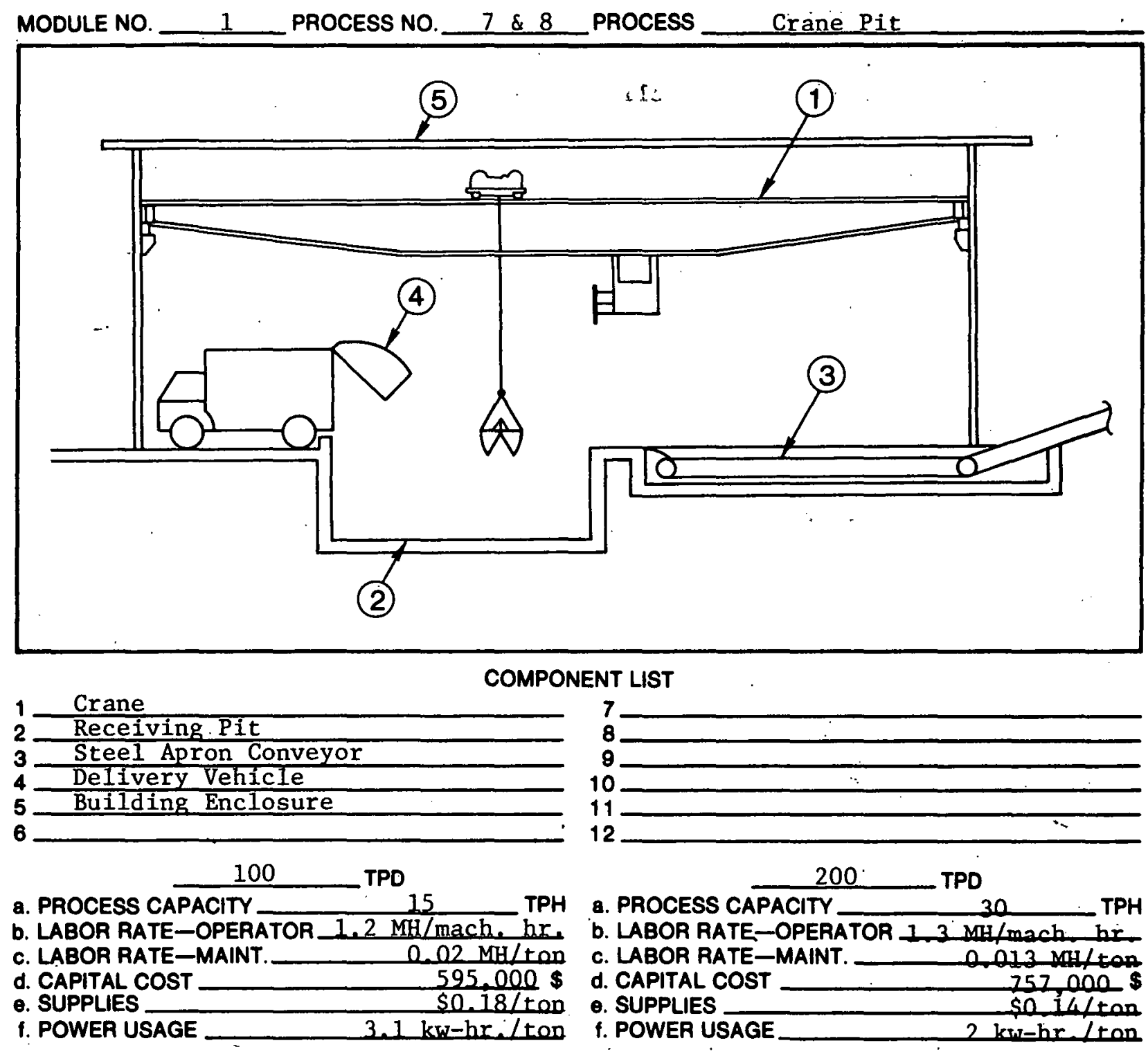

\begin{tabular}{|l|c|l|l|}
\hline \multicolumn{4}{|c|}{ PROCESS EFFICIENCY } \\
\hline COMPONENT & $\eta_{1}$ & $\eta_{2}$ & $\eta_{3}$ \\
\hline PAPER & & & \\
ORGANICS & & & \\
WOOD & & \\
IRON \\
ALUMINUM \\
METALS \\
GLASS \\
PLASTICS \\
INERTS \\
FINES \\
TEXTILES & $\square$ & $\square$ & \\
\hline
\end{tabular}

Figure 37. Crane pit schematic and operational data. 
MODULE NO. 1 PROCESS NO. $9 \& 10$ PROCESS Dozer Pit

r.)

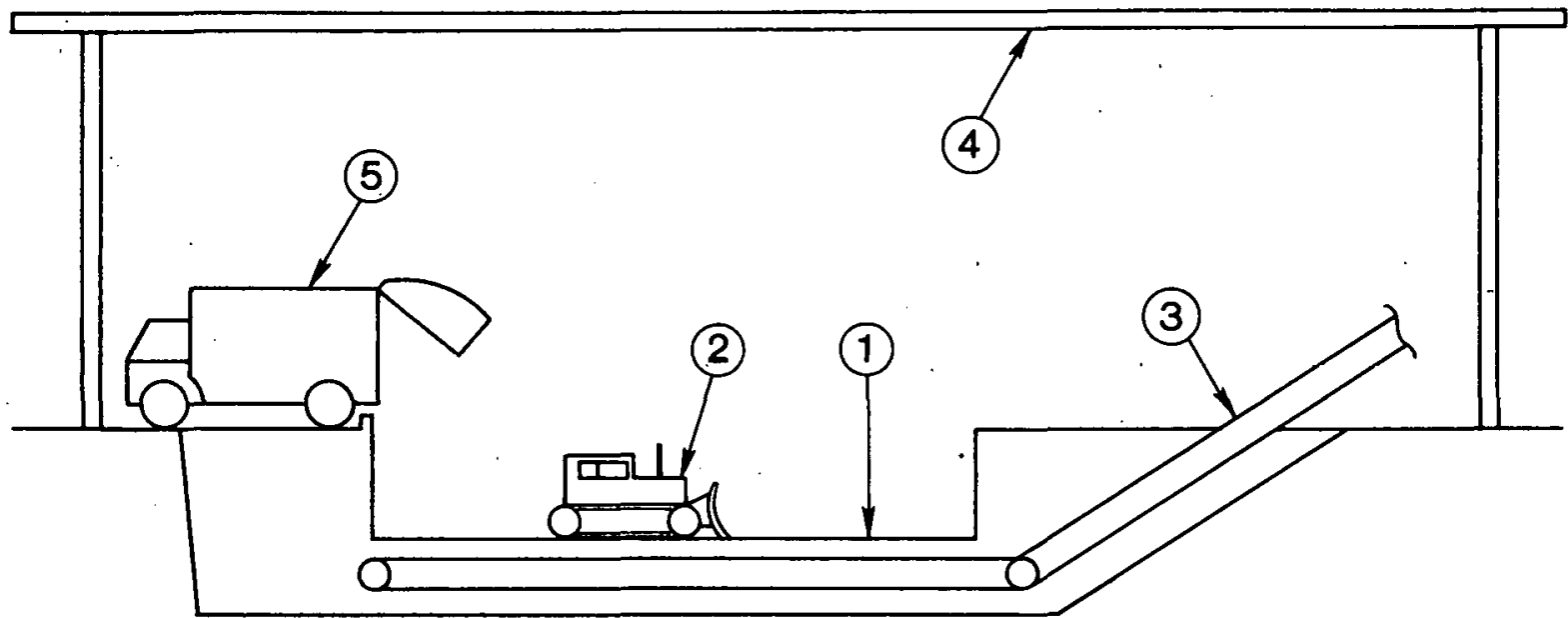

COMPONENT LIST
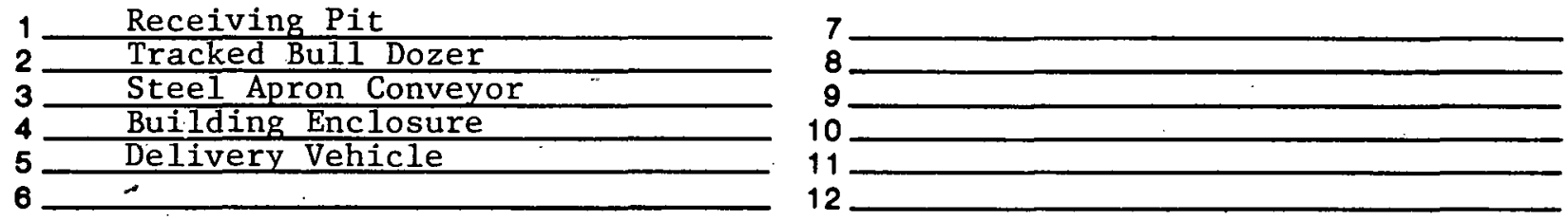

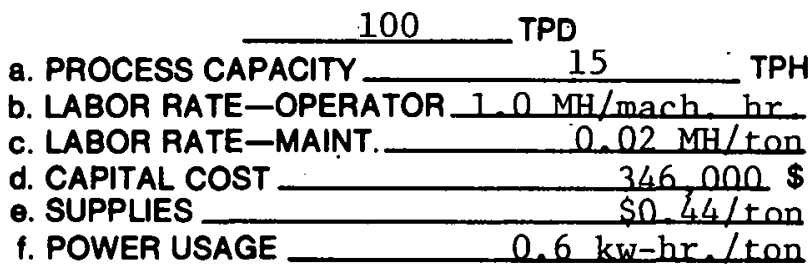

a. PROCESS CAPACITY TPD

b. LABOR RATE-OPERATOR $12 \mathrm{MH} / \mathrm{mach}$ hr. c. LABOR RATE-MAINT. $0.012 \mathrm{MH} / \mathrm{t}$. d. CAPITAL COST $\frac{409,000}{\$ 0.2814}$

e. SUPPLIES SO $28 / \mathrm{itan}$

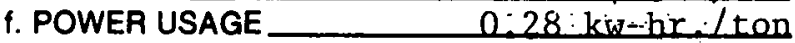

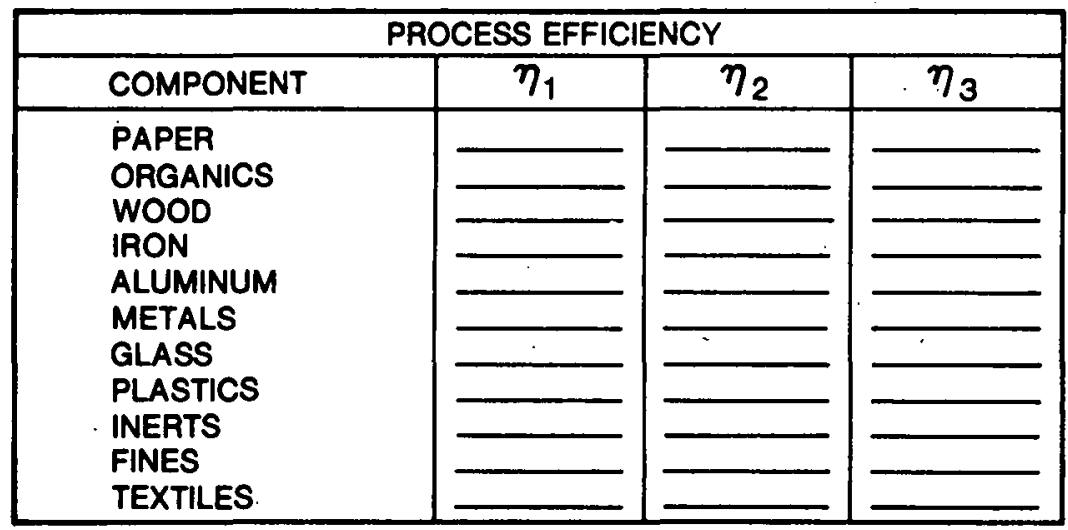

Figure 38. Dozer pit schematic and operational data. 
The advantages of this system include multiple handling of the refuse to identify and remove items which would negatively impact the subsequent material processing, preprocessing of the refuse, accurate outfeeding of the refuse, and low space requirements. The disadvantages include the "first-in-last-out" method of refuse handling, the increased maintenance problems associated with plugging of air filters and radiators on the bulldozers, and the need for a full-time equipment operator.

\section{PRIMARY SIZE REDUCTION MODULE}

The purpose of the size reduction module is to convert the heterogeneous as-received waste into a waste stream having a nearly uniform size. In a resource recovery plant this action is intended to facilitate the subsequent separation of the mixed waste stream into distinct material categories and to improve its material handling characteristics. Four alternatives that have the most merit as primary "shredders" are: horizontal axis hammermills, vertical axis hammermills, flail mills, and shear shredders. A separate data base has been compiled for both the horizontal and vertical axis hammermills shredding both raw waste and waste that has been preprocessed in a coarse rotary screen.

In all cases, the performance of these processing units is predicted on shredding municipal solid waste having a minimal amount of oversized bulky. waste (OBW) and large white goods. The output specification used in this study for all primary shredders except the flail mill is a nominal 4-in. particle size typical of existing primary shredding designs.

In the majority of installations, solid waste shredders are driven by electric motors specifically designed to withstand the severe duty encountered in this type of operation.

Because of the wide variation in the materials that compose solid waste, shredders are routinely subjected to loads ranging from 50 percent to 250 percent of their rated torque. This loading is even more significant in smaller shredders because of lower momentum of moving parts.

The Horizontal Axis Hammermill

The solid waste is conveyed from the receiving module to the size reduction module where the solid waste enters the shredder. (Figure 39) through a feed hood ( 1 ) of sufficient strength to contain any item that is thrown upward by the shredder. In the shredder, the solid waste is size reduced by the impact and shearing action of the hammers until the waste is passed through a grate (1) with appropriately sized openings. The outfeed from the shredder is deposited onto a vibrating pan conveyor (8) of adequate strength to absorb the impact of objects ballistically ejected by the hammers. The outfeed from the vibrating pan conveyor is to a covered trough belt conveyor connecting the hammermill system with the next processing step. Support equipment for the hammermill system includes a dust collection system (7) connected at the inlet and discharge points of the shredder, an explosion suppression system (5), a vented explosion relief duct, and a $\mathrm{CO}_{2}$ fire suppression system (6) located on the discharge conveyor. 
MODULE NO. 2 PROCESS NO. $1 \&$ PROCESS Horizontal Hanmer $\mathrm{Mill}$

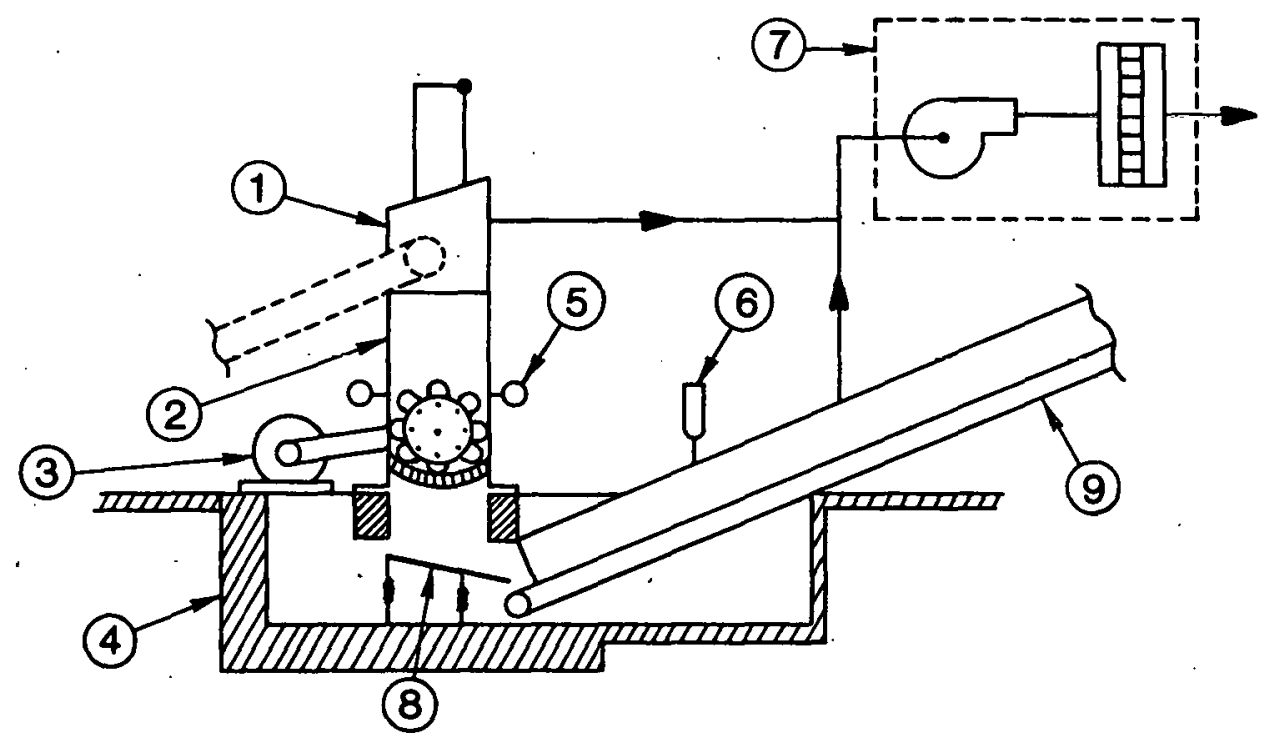

COMPONENT LIST

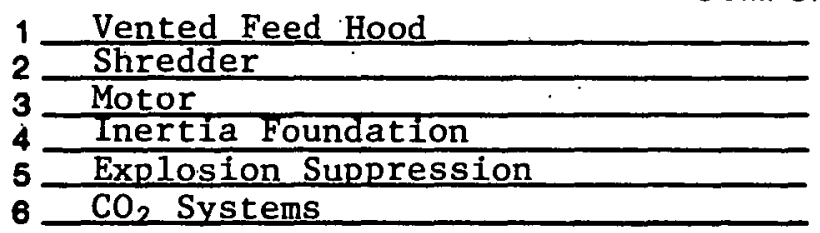

a. PROCESS CAPACITY $\frac{100}{1}{ }^{T P D} 20 \quad$ TPH $0.04 \mathrm{MH} /$ ton

b. LABOR RATE-OPERATOR

c. LABOR RATE-MAINT.

d. CAPITAL COST

๑. SUPPLIES $0.05 \mathrm{MH} / \mathrm{ton}$

f. POWER USAGE
7 Dust Control System

8 Vibrating Pan Conveyor

9 Relt Conveyor

10

11

12
. $\frac{200}{T P D}$

a. PROCESS CAPACITY $\quad 35$ TPH

b. LABOR RATE-OPERATOR $-0.02 \mathrm{MH} / \mathrm{t}$ D

c. LABOR RATE-MAINT. $0.03 \mathrm{MH} / \mathrm{t}$ On

d. CAPITAL COST $357500 \$$

e. SUPPLIES

S1 0 in/ton

f. POWER USAGE _ $10 \mathrm{kw}-\mathrm{hr} . / \mathrm{tan}$

\begin{tabular}{|l|c|l|l|}
\hline \multicolumn{3}{|c|}{ PROCESS EFFICIENCY } \\
\hline COMPONENT & $\eta_{1}$ & $\eta_{2}$ & $\eta_{3}$ \\
\hline PAPER & & \\
ORGANICS & & \\
WOOD \\
IRON \\
ALUMINUM \\
METALS \\
GLASS \\
PLASTICS \\
INERTS \\
FINES \\
TEXTILES
\end{tabular}

Figure 39. Horizontal hammermill schematic and operational data. 
The principal advantages of horizontal axis hammermills are that there is more operational experience with them than with any other alternative, they can be sized to handle most types of solid waste, and they will produce the required size reduction. Disadvantages include being susceptible to damage from unshreddable items, inability of low capacity units to economically reduce $O B W$ and white goods, high hammer wear requiring frequent maintenance and replacement, and the formation of a large quantity of fines often imbedded in other items.

Performance After A Preprocessing Rotary Screen--

All components for the horizontal axis hammermill module as described above would be required when shredding refuse after preprocessing in a rotary screen (Figure 40). It is anticipated that there will be a reduction in the operating costs and associated maintenance labor costs of the shredder because the majority of the abrasive glass particles in the waste are removed by the rotary screen. Conversely, it is anticipated that there will be a slight increase in the shredder power requirements, on an actual tonnage shredded basis, due to removal of dense friable material before shredding because this material will be replaced by material that does not shatter on impact with the hammers. Since the data reported for this type of operation has not been quantified, these conclusions are qualitative only, and further study efforts should be made to verify this contention. However, by applying this processing concept to size reduction of the solid waste, total system throughput has been reported to be increased.

The Vertical Axis Hammermill

The arrangement of the vertical axis hammermill (Figure 41) is essentially the same as that of the horizontal axis hammermill. The vertical axis hammermill employs the same mechanism for size reduction as employed in the horizontal axis hammermill. The final particle size control in the vertical hammermill is established by the number of hammers, the hammer pattern, and the hammer clearance with the shredder wall rather than the use of grate bars as used in horizontal shredders. This equipment item has essentially the same advantages and disadvantages as the horizontal axis hammermill. Vertical shredders, however, tend to have a larger average particle size for the same nominal particle size and more long, stringy items. Vertical shredders require smaller foundations than horizontal shredders because of their geometry and force characteristics. Information on the performance of vertical shredders is limited, and more study is required to adequately characterize these units.

Performance After A Preprocessing Rotary Screen--

The vertical axis hammermill operation after a preprocessing rotary screen (Figure 42) is anticipated to have the same change in performance functions as stated with the horizontal axis hammermill. No test data is available concerning this mode of operation for a vertical shredder, and extensive testing is needed to adequately characterize unit performance. 
MODULE NO. PROCESS NO. $3 \& 4 \quad 3 \quad$ PROCESS

Post Screen Hammer Mill

(3)

(2)
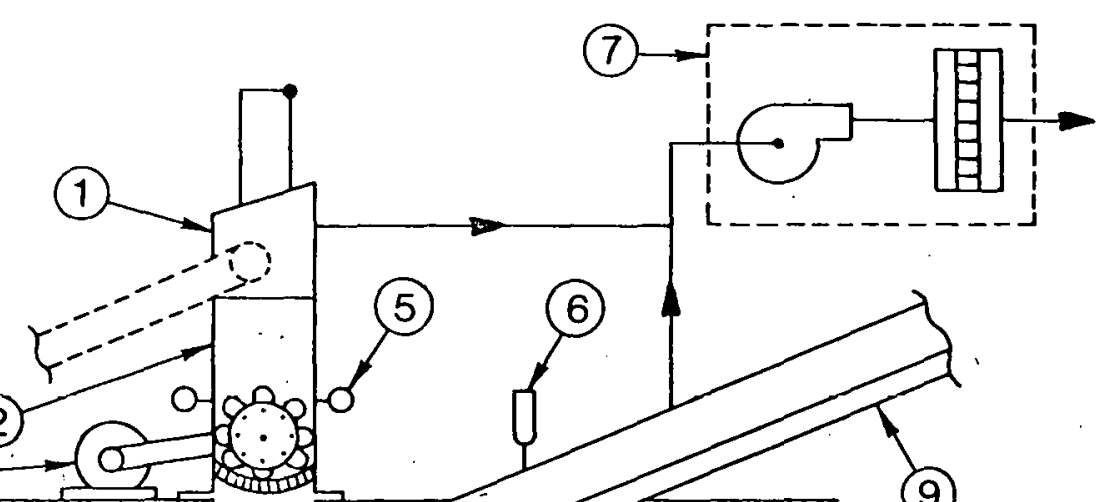

(5)

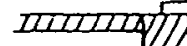

(4)

(6)

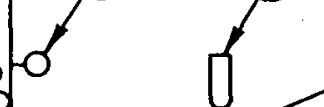

包

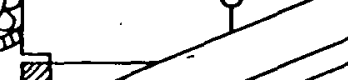

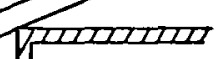

(9)

COMPONENT LIST

1 Vented Feed Hood
2 Shredder
3 Motor
4 Inertia Eeundation
6 Explosion Suppression
$6-\mathrm{CO}_{2}$ System

$100 \quad T P D$
7 Dust Control System

8 Vibrating Pan Conveyor

9 Be1t Conveyor

10

11

12

\section{TPD}

a. PROCESS CAPACITY

b. LABOR RATE-OPERATOR $-0.02 \mathrm{MH} / \mathrm{tan}$

c. LABOR RATE-MAINT. $\quad 0 \mathrm{O} 2 \mathrm{MH} / \mathrm{t}$ n

d. CAPITAL COST $\frac{357,500 \$}{5025 / 5}$

e. SUPPLIES $\$ 0.75 / 50 n$

f. POWER USAGE $11 \mathrm{kw}-\mathrm{hr} / \mathrm{tan}$
$0.04 \mathrm{MH} / \mathrm{TOn}$ $04 \mathrm{MH} /$ ton $11 \mathrm{kw}-\mathrm{hr} / \mathrm{ton}$

PROCESS EFFICIENCY

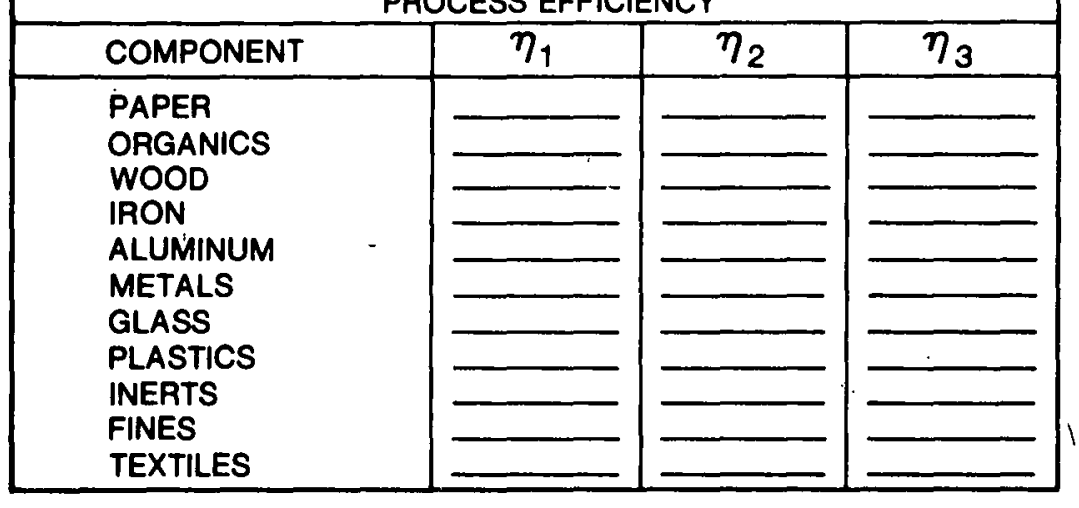

Figure 40. Post rotary screen horizontal hammermill operational data. 
MODULE NO. PROCESS NO. $5 \& 6$ PROCESS Vertical Hammer Mi11
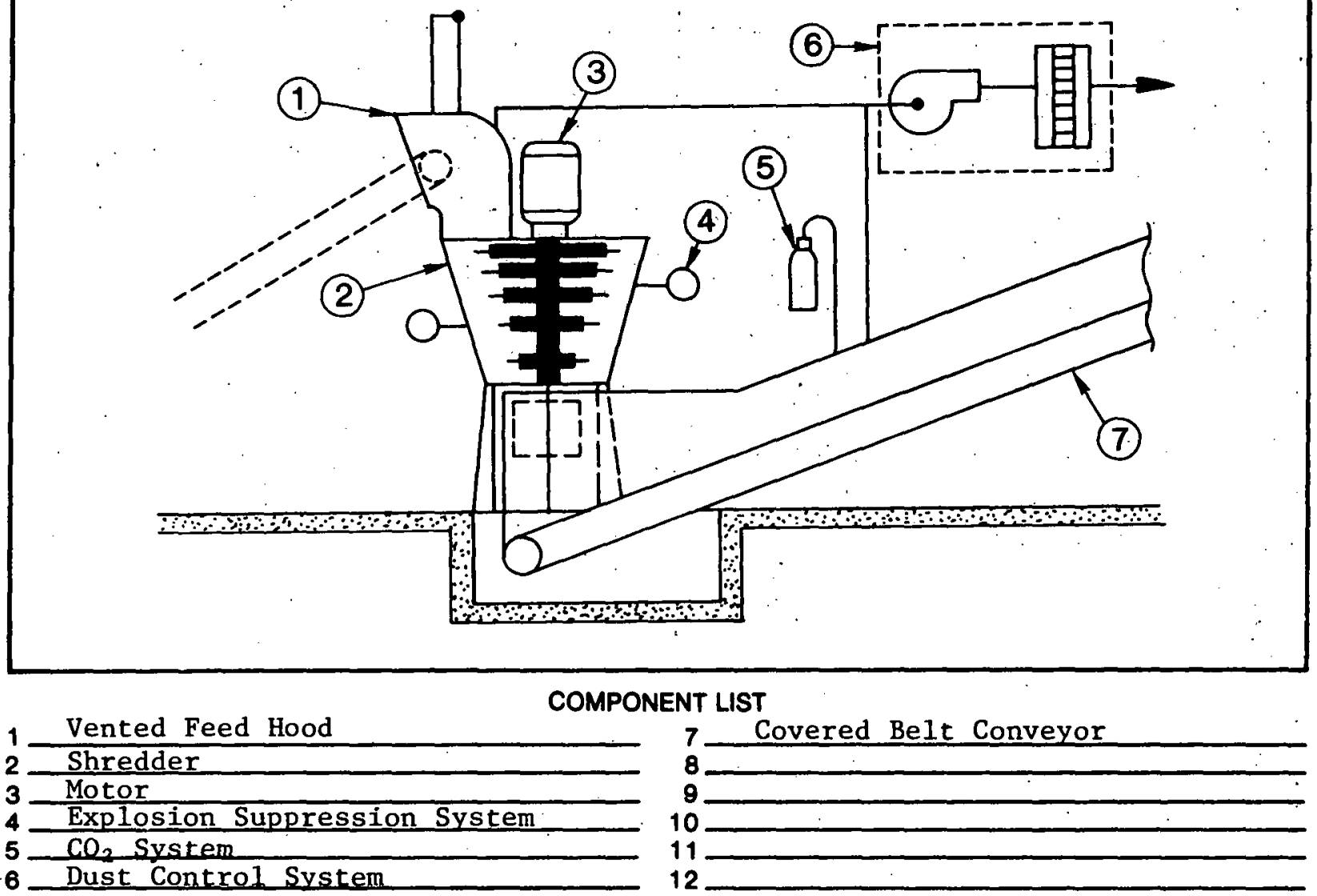

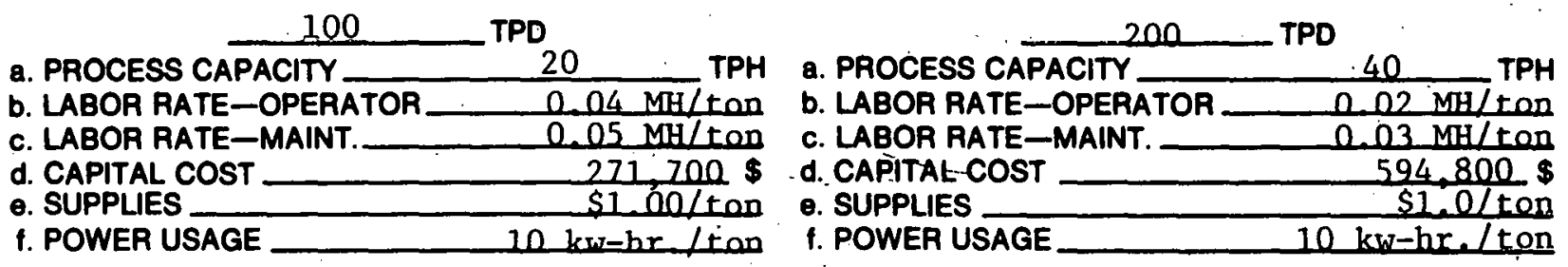

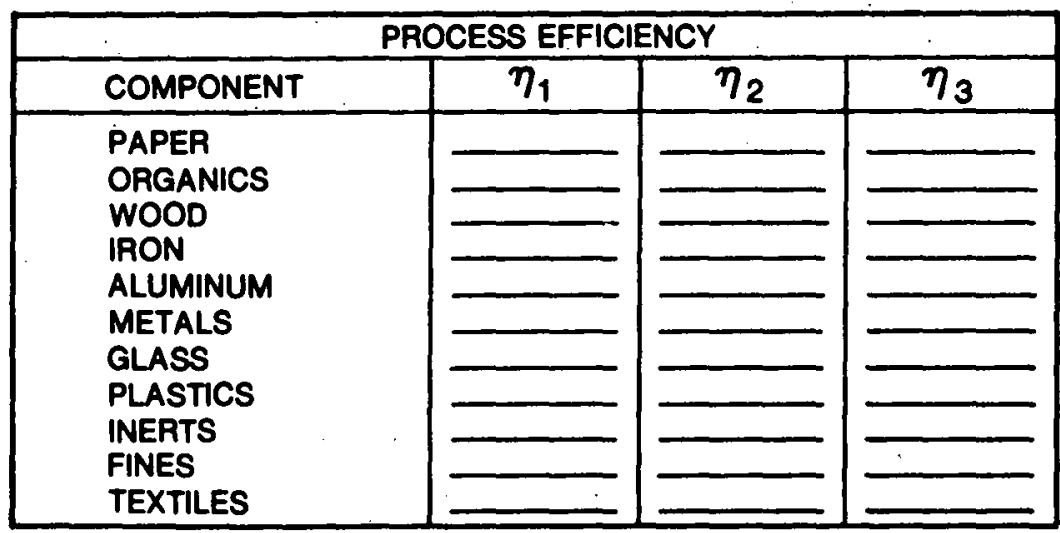

Figure 41. Vertical hammermill schematic and operational data. 
MODULE NO. PROCESS NO.

$7 \& 8$ PROCESS

Post Screen Hammer Mill

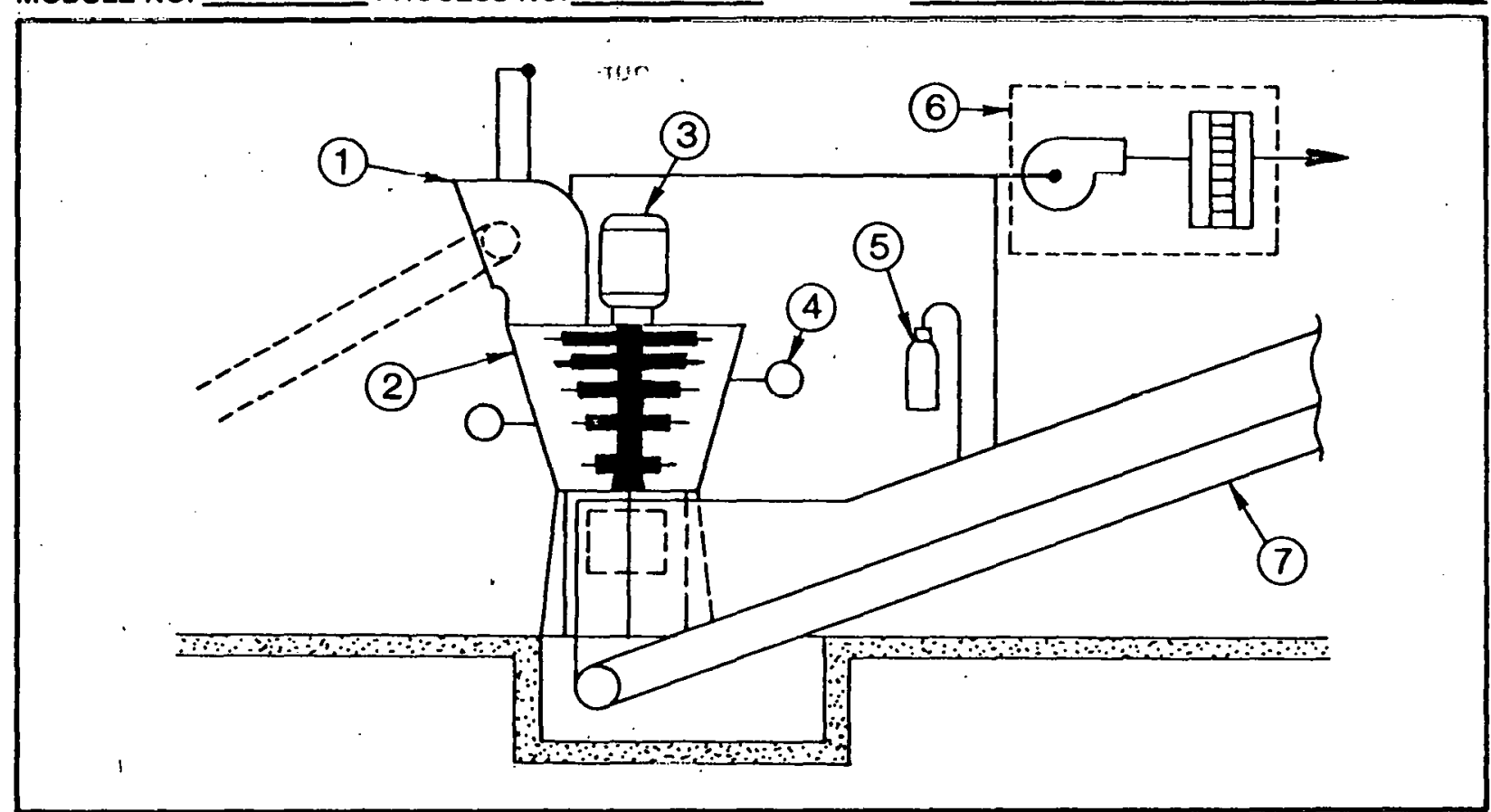

COMPONENT LIST

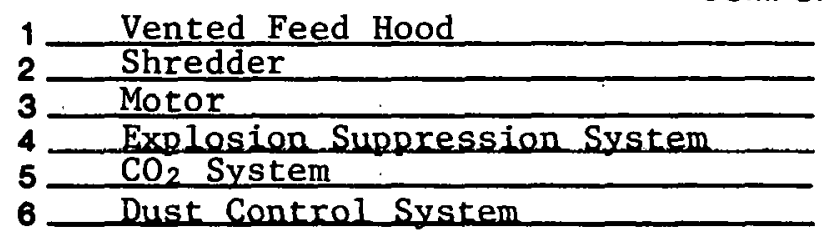

7 Covered Belt Conveyor

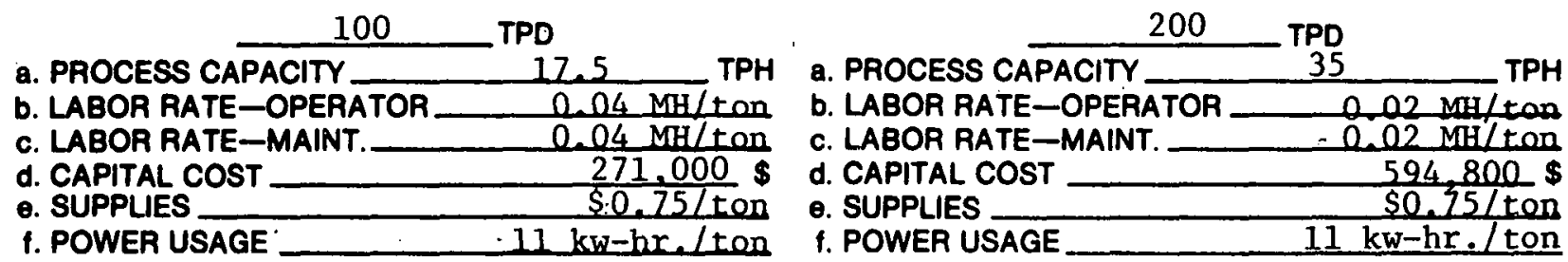

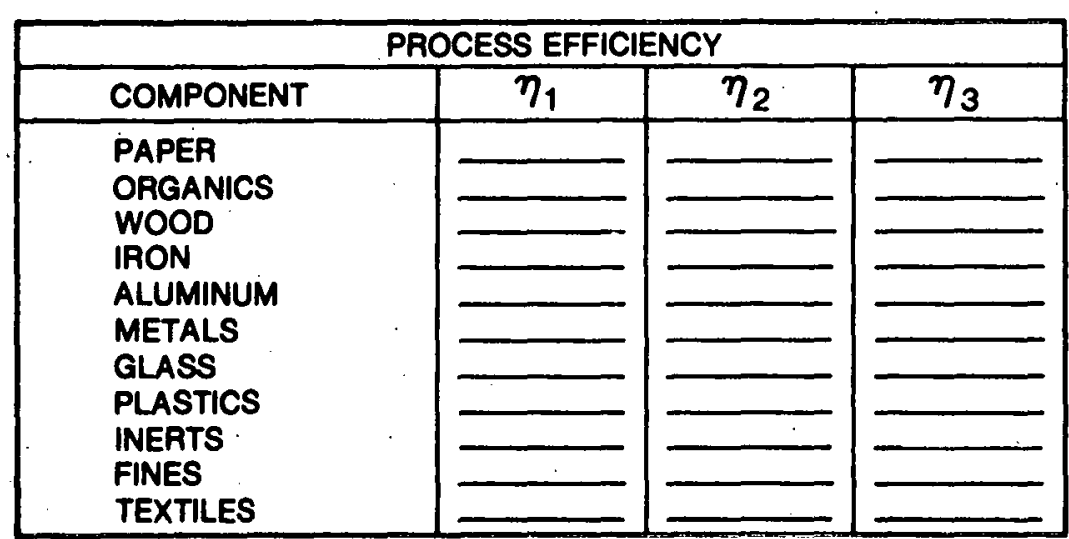

Figure 42. Post rotary screen vertical hammermill operational data. 
The flail mill (Figure 43) is a horizontal axis type size reduction unit employing hinged, articulated, bar flails mounted on dual opposing rotor assemblies. The bar flails reduce the size of the feed product by impact or by pulverization. This type of shredder does not utilize discharge grates, and consequently this shredding operation does not provide a uniformly sized product.

A second type of flail mill uses a single horizontal rotor and a flat steel plate mounted below. The material to be flailed is passed between the rotor and the plate.

The primary advantages of a flail mill compared to a conventional hammermill are: it requires a significantly lower capital expenditure, it appears to have significantly less maintenance costs, it does not require an elaborate foundation, and it has the ability to pass unshreddable items without damaging the machine. The disadvantages include the fact that there is very little long-term operating data to verify reliability or operating costs. Also, without particle size control, it is not known how suitable the product of this unit is to subsequent processing steps for material and fuel separation. Additional study should be done on this equipment to ascertain its suitability to resource recovery processes.

\section{The Shear Shredder}

The shear shredder (Figure 44) consists of two horizontal shafts which rotate in opposite directions. The low rotational speed shafts ( 0 to $40 \mathrm{rpm}$ ) carry a number of knives that shred the refuse by a combination of shearing and tearing rather than impacting as in hammermill type shredders. Each shaft is separately driven at different speeds by hydraulic motors to create the desired shearing action. When equipped with a force feed hopper, these units are capable of shredding municipal solid waste, car tires, and truck tires. Should an unshreddable item be fed to the shredder, the shafts automatically reverse direction when a predetermined overload torque is reached. This unit will execute the shred-reverse cycle until the item is either shredded or manually removed from the shredder. Protection of the unit can be accomplished by automatically stopping the shredder after a predetermined number of reverse cycles has been reached.

The advantages of this type of shredding system include lower capital cost than conventional hammermills, lower operating costs due to less wear, and the fact that the unit does not require elaborate dust collection because of the low speed operation. The primary disadvantage of this unit is that there is very little long-term operating data to substantiate the aforementioned conclusions. At this time, only two units of this type are in operation shedding municipal solid waste. Because of the advantages this type of unit may provide, a program to study the performance characteristics of a shear shredder shredding solid waste would appear worthwhile. 
MODULE NO. PROCESS NO. $9 \& 10$ PROCESS

Flail Mill
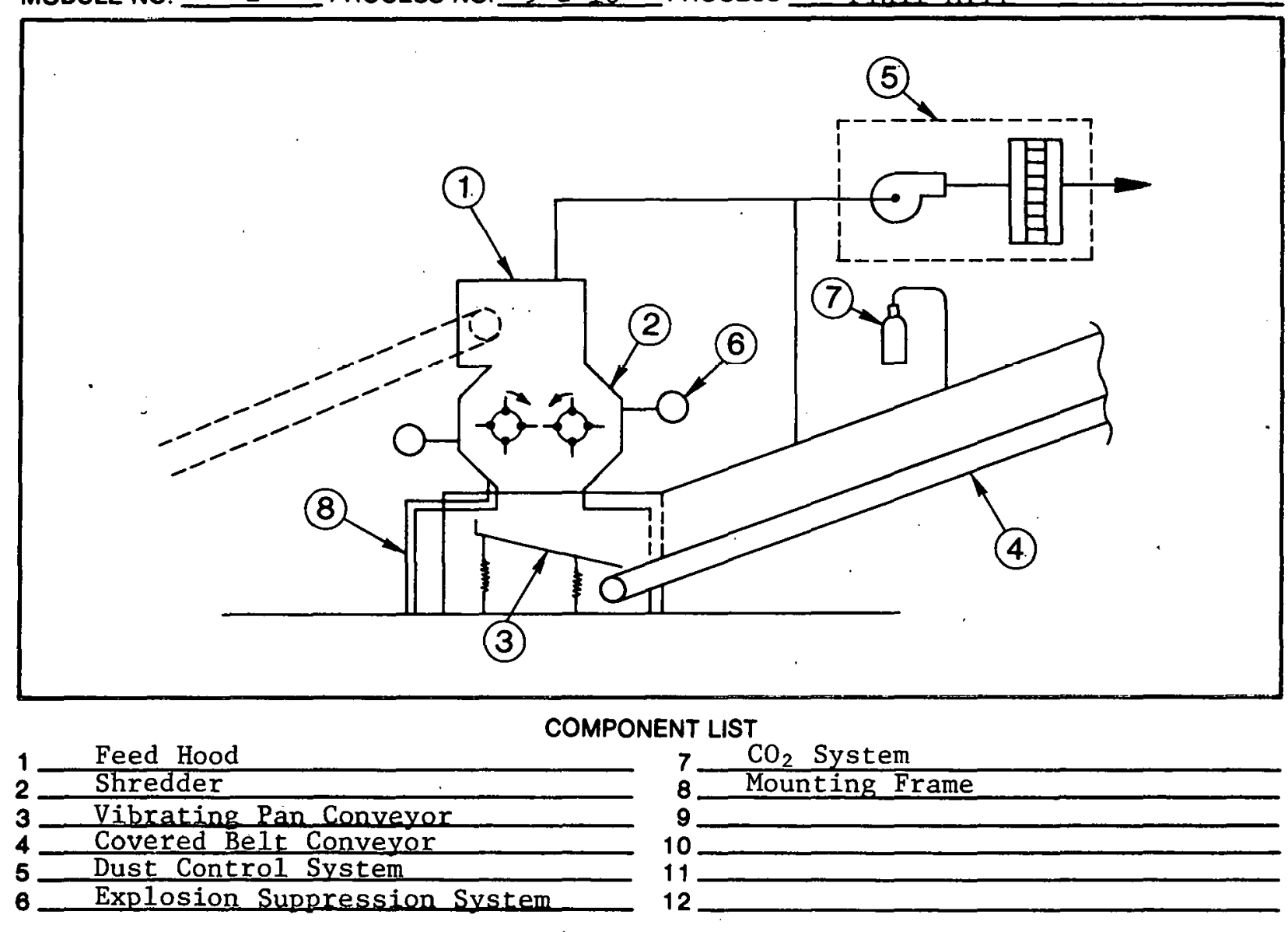

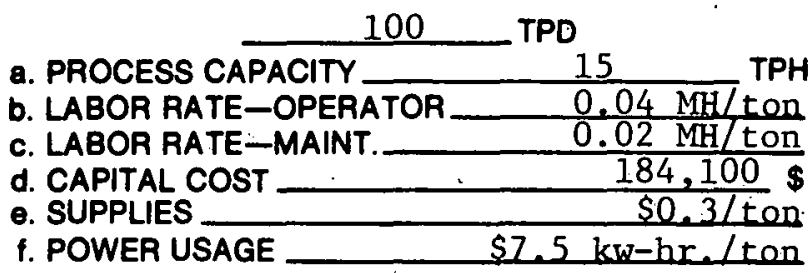

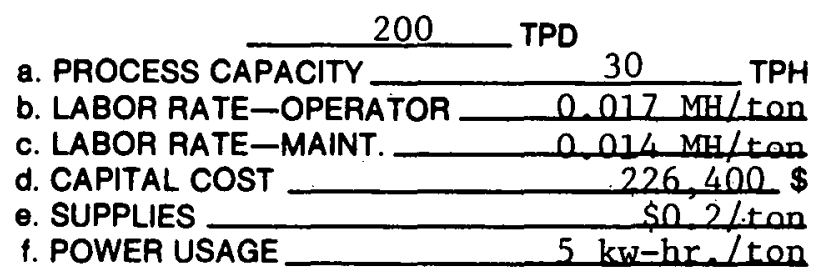

\begin{tabular}{|l|l|l|l|}
\hline \multicolumn{4}{|c|}{ PROCESS EFFICIENCY } \\
\hline COMPONENT & $\eta_{1}$ & $\eta_{2}$ & $\eta_{3}$ \\
\hline PAPER & & & \\
ORGANICS & & & \\
WOOD & & \\
IRON & & \\
ALUMINUM & & \\
METALS & & \\
GLASS & & \\
PLASTICS & & \\
INERTS & \\
FINES & \\
TEXTILES & & & \\
\hline
\end{tabular}

Figure 43. Flail mill schematic and operational data. 
MODULE NO. _ 2 PROCESS NO. $11 \& 12$ PROCESS_Shear Shredder

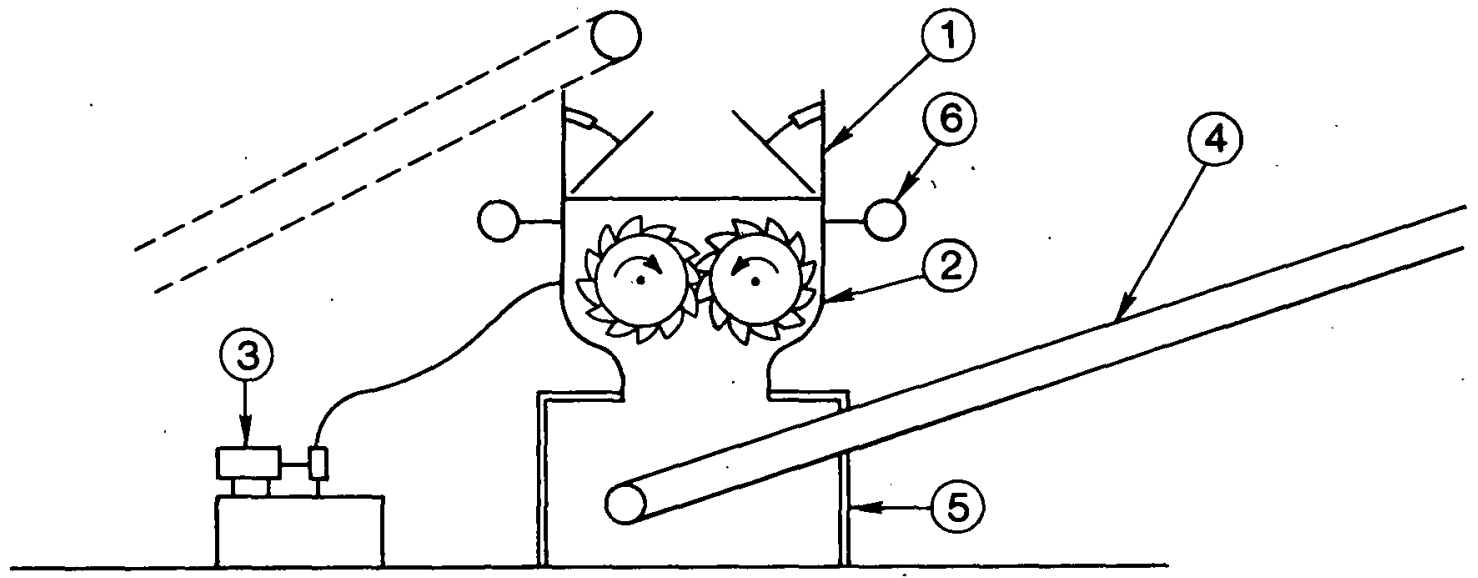

COMPONENT LIST

$\int_{3}^{1} \frac{\text { Force Feed Hopper }}{\text { Shredder. }} \frac{\text { Hydraulic System }}{6} \frac{\text { Belt Conveyor }}{\text { Mounting Frame }}$

100

TPD

a. PROCESS CAPACITY 15

5

TPH

b. LABOR RATE-OPERATOR_ $0.04 \mathrm{MH} / \mathrm{tan}$

c. LABOR RATE-MAINT.

$0.015 \mathrm{MH} / \tan$

d. CAPITAL COST

$187,300 \$$

e. SUPPLIES \$0.47/ton

f. POWER USAGE

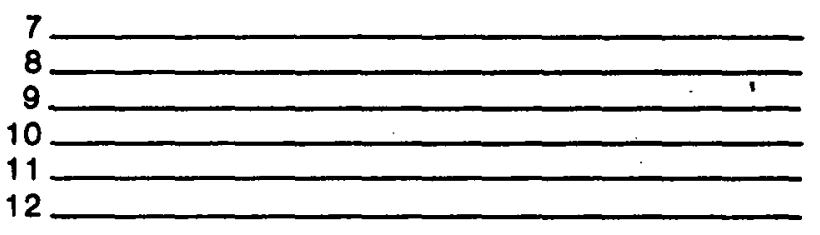

200

TPD

a. PROCESS CAPACITY 30 .

b. LABOR RATE-OPERATOR $-0.02 \mathrm{MH} / \mathrm{t}$.

c. LABOR RATE-MAINT. _ R

d. CAPITAL COST $289,600 \$$

o. SUPPLIES — $\$ 0,31 /$ ton

f. POWER USAGE $\quad 5.8 \mathrm{kw}=\mathrm{hr} / \mathrm{t}$ ton

\begin{tabular}{|l|l|l|l|}
\hline \multicolumn{4}{|c|}{ PROCESS EFFICIENCY } \\
\hline COMPONENT & $\eta_{1}$ & $\eta_{2}$ & $\eta_{3}$ \\
\hline PAPER & & & \\
ORGANICS \\
WOOD \\
IRON \\
ALUMINUM \\
METALS \\
GLASS \\
PLASTICS \\
INERTS \\
FINES \\
TEXTILES
\end{tabular}

Figure 44. Shear shredder schematic and operational data. 


\section{COMBUSTIBLE SEPARATION MODULE}

The purpose of the combustible separation module is to divide the mixed waste into combustible and inert fractions. The two output streams from the separation devices are usually referred to as lights (combustible materials that rise in the air classifier) and heavies (inert materials that fall in the air classifier). Depending upon the specific design of the unit, the amount and composition of material reporting to each fraction will vary.

The two types of separation systems that have historically been applied in this area are air classifiers and rotary screens. Air classifiers are almost always installed to process shredded solid waste, while rotary screens are often installed prior to primary shredding.

\section{Air Classifiers}

Air classifiers employ the varying physical characteristics of the component items contained in the waste stream to achieve separation. In a steady-state condition, the three primary factors which determine the category the material will report to are particle size, particle density, and particle orientation in the separation zone. With mixed municipal solid waste, the separation process becomes extremely complex.

Shredded municipal waste, as it is introduced into an air classifier, is a mixture of particles of various sizes, densities, and shapes. Virtually all concepts for air classification have a unique design aimed at being able to break up the particle agglomerations. The discussion on the following concepts for air classification of municipal refuse will center on the individual designs employed for the deagglomeration of the feed to the air classifier. The common items employed in most air classifiers are a surge bin to level the variable output of the shredder, a metering feed device, a separation chamber, pneumatic transport tubing for the light fraction, a light fraction deentrainment cyclone, an air mover, a final filter to remove the entrainment dust from the transport air, and a discharge conveyor to transport the heavy fraction.

It is extremely difficult to make a comparison of the various concepts for the air classification of municipal solid waste. Currently there are a number of approaches used. However, these devices have been applied in widely varying applications. Some process applications have dictated maximizing the quantity of fuel (1ights) recovered from the waste while others have dictated maximizing the quality of the fuel recovered, goals which tend to be mutually exclusive. Most units are either in startup or in the prototype stage with very limited data available. Finally, no comprehensive, standard data reporting format has been developed for use in characterizing unit performance. The U.S. Environmental Protection Agency is presently sponsoring a program to study the performance of various air classifiers installed throughout the country. Controlled parametric studies should follow this initial evaluation effort. 
The Dual Vortex Air Classifier

The Dual Vortex concept (Figure 45), as its name implies, uses two turbulent zones to affect the separation of the light fraction from the heavy fraction. The metered feed enters into a vertical separation chamber where it first encounters a "mild" turbulent zone created by a baffle where preliminary separation of the light fraction from the heavy fraction occurs. A second baffle is installed lower in the chamber to create a second, more turbulent zone of air circulation. Refuse particles, which have clumped together in shredding and transport and which have resisted deagglomeration in the upper zone, are acted upon in the second zone to achieve deagglomeration. This concept also employs an adjustable cross-sectional area to increase or decrease the velocity in the throat area of the unit to affect separation. 'An example of this air classification system has been installed in Outagamie County, Wisconsin, and another is in startup in Lane County, Oregon. The Lane County installation is scheduled to be evaluated under an EPA contract to determine overall system performance.

\section{Air Density Separator}

The air density separator system (Figure 46) uses a combination of material metering and air control in an adjustable throat "venturi" to affect separation. The use of manual controls to vary the configuration of the separation zone allows the separator to be finely tuned for the particular application. The unique aspect of this approach is the automatic air control which senses air volume changes caused by variations in the refuse and which activates controllers to maintain a constant airflow volume.

This system has been applied in installations where the maximum amount of fuel from the refuse was the desired product. These units have been installed at both Ames, Iowa, and St. Louis, Missouri, and were evaluated under EPA evaluation contracts. The data obtained in those studies is inadequate to effectively characterize the performance of this unit.

\section{The Vibrolutriator Air Classifier}

The vibrolutriator (Figure 47) uses a combination of air classification and mechanical vibration to effect separation of the light from the heavy components. The unit employs air that is directed from the elutriation process to assist in the separation and pneumatic transfer of the material. Once inside the separator, the material is moved through the treatment zones by either a vibrating-horizontal or an inclined surface. This vibrating action causes the refuse to stratify prior to moving the waste over a series of air jets which fluidizes the bed and permits elutriation. The lofted light fraction is entrained in an air column composed of both the fluidizing air and the entrained air within the system. Reported advantages of this system include reduced airflow and minimal contamination of heavies and light fractions. These systems have been installed at NCRR's test facilities in Washington, D.C., New Orleans, and Chicago. Testing has been done on, or is scheduled for, all of these facilities. 


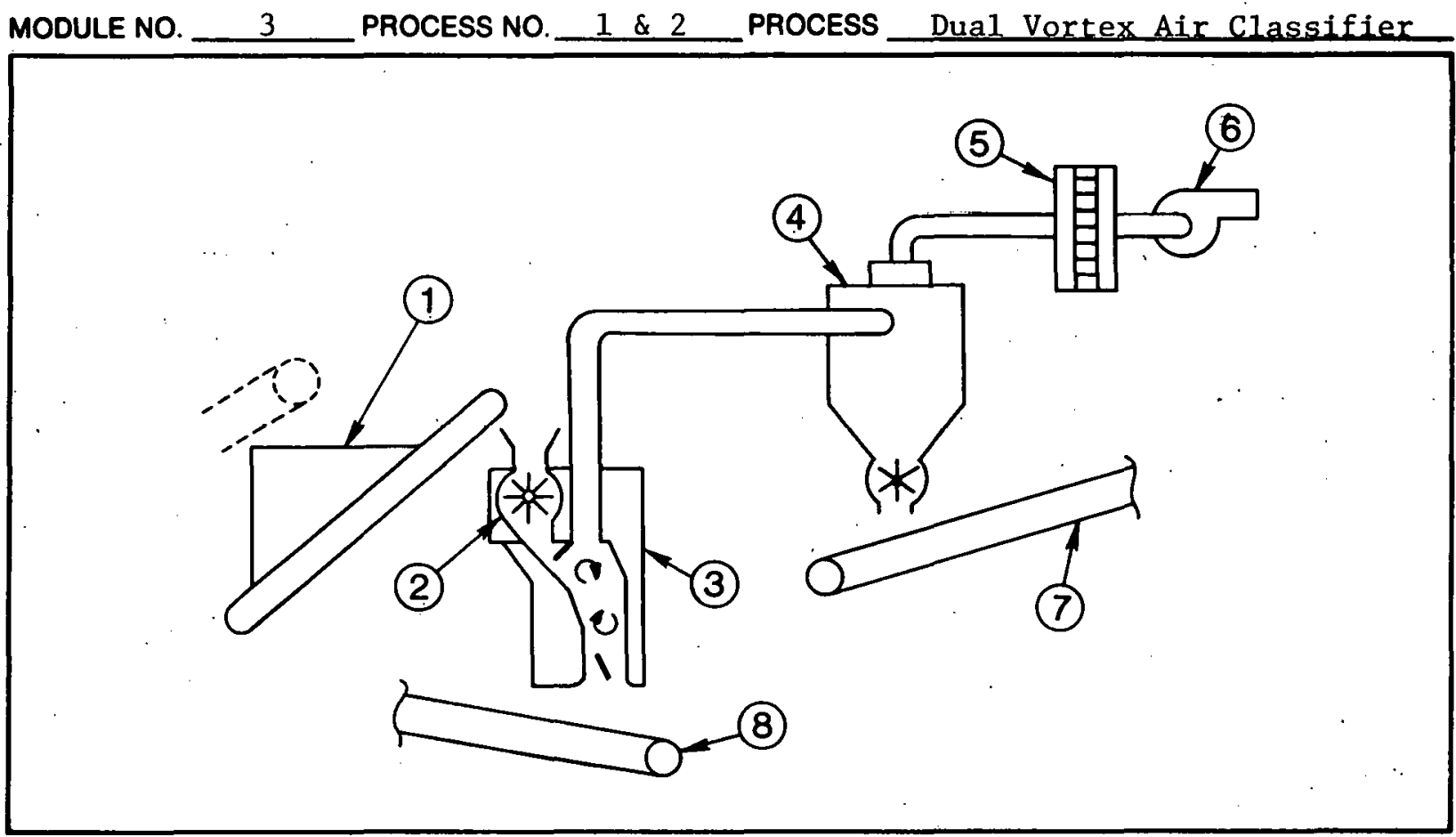

COMPONENT LIST

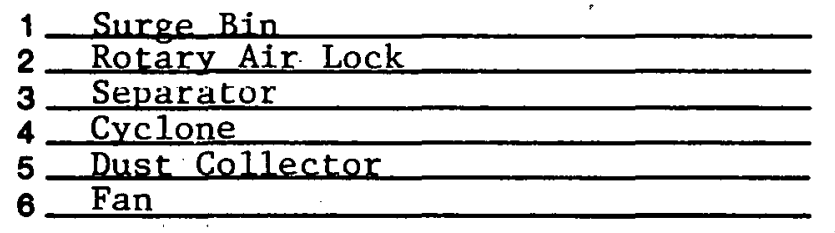

7 "Lights" Belt Conveyor

1 Surge Bin

8 "Heavies" Belt Conveyar

3 Separator

4 Cyclone

6 Fan

100

a. PROCESS CAPACITY

TPD TPH

b. LABOR RATE-OPERATOR $0.25 \mathrm{MH} / \mathrm{mach}$. hr.

c. LABOR RATE-MAINT. $0.25 \mathrm{MH} / \mathrm{mach}$ hr

d. CAPITAL COST

e. SUPPLIES $263.700 \$$

f. POWER USAGE $\$ 1.50 /$ mach.hr. $63 \mathrm{kw}-\mathrm{hr}$./mach. br.

\begin{tabular}{|c|c|c|c|}
\hline \multicolumn{4}{|c|}{ PROCESS EFFICIENCY } \\
\hline COMPONENT & $\eta_{1}$ & $\eta_{2}$ & $\eta_{3}$ \\
\hline $\begin{array}{l}\text { PAPER } \\
\text { ORGANICS } \\
\text { WOOD } \\
\text { IRON } \\
\text { ALUMINUM } \\
\text { METALS } \\
\text { GLASS } \\
\text { PLASTICS } \\
\text { INERTS } \\
\text { FINES } \\
\text { TEXTILES }\end{array}$ & $\begin{array}{r}0.93 \\
0.40 \\
0.68 \\
0.03 \\
0.08 \\
0.03 \\
0.03 \\
0.83 \\
0.03 \\
0.83 \\
0.93 \\
\end{array}$ & $\begin{array}{l}0.07 \\
0.60 \\
0.32 \\
0.97 \\
0.92 \\
0.97 \\
0.97 \\
0.17 \\
0.97 \\
0.17 \\
0.07 \\
\end{array}$ & \\
\hline
\end{tabular}

. Figure 45. Dual vortex air classifier schematic and operational data. 

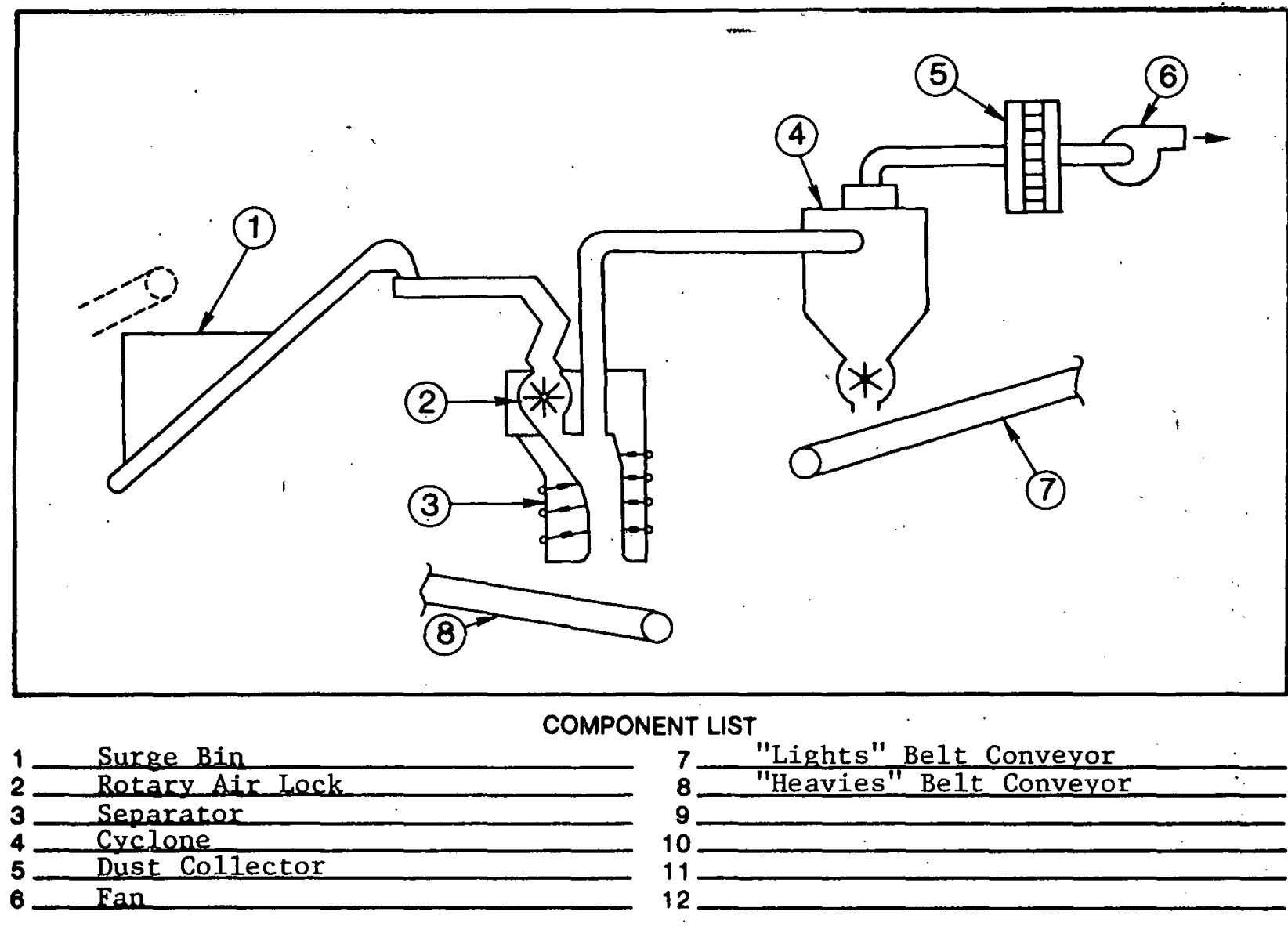

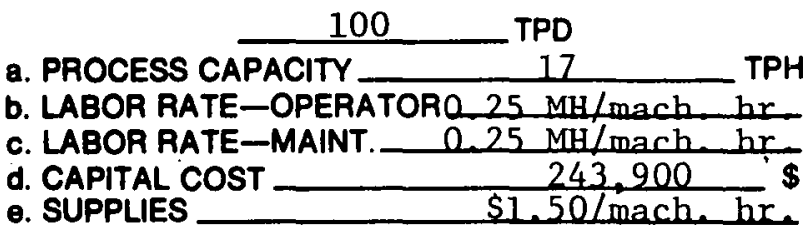

a. PROCESS CAPACITY $\quad$ TPD b. LABOR RATE-OPERATOR $0.25 \mathrm{MH} / \mathrm{mach}$. $\mathrm{hr}$. c. LABOR RATE-MAINT. 25 MH/mach hr d. CAPITAL COST 317 7مn $\$$ $63 \mathrm{kw}-\mathrm{hr}$./mach. hr.

๑. SUPPLIES

f. POWER USAGE $\$ 2$ 10/mach. hr. $104 \mathrm{kw}-\mathrm{hr} /$ mach. $\mathrm{hr}$.

\begin{tabular}{|c|c|c|c|}
\hline \multicolumn{4}{|c|}{ PROCESS EFFICIENCY } \\
\hline COMPONENT & $\eta_{1}$ & $\eta_{2}$ & $\eta_{3}$ \\
\hline $\begin{array}{l}\text { PAPER } \\
\text { ORGANICS } \\
\text { WOOD } \\
\text { IRON } \\
\text { ALUMINUM } \\
\text { METALS } \\
\text { GLASS } \\
\text { PLASTICS } \\
\text { INERTS } \\
\text { FINES } \\
\text { TEXTILES }\end{array}$ & $\begin{array}{r}0.92 \\
0.50 \\
0.50 \\
0.05 \\
0.20 \\
0.05 \\
0.05 \\
0.80 \\
0.05 \\
0.60 \\
0.90 \\
\end{array}$ & $\begin{array}{r}0.08 \\
0.50 \\
0.50 \\
0.95 \\
0.80 \\
0.95 \\
0.95 \\
0.20 \\
0.95 \\
0.40 \\
0.10 \\
\end{array}$ & \\
\hline
\end{tabular}

Figure 46. Air density separator schematic and operational data. 


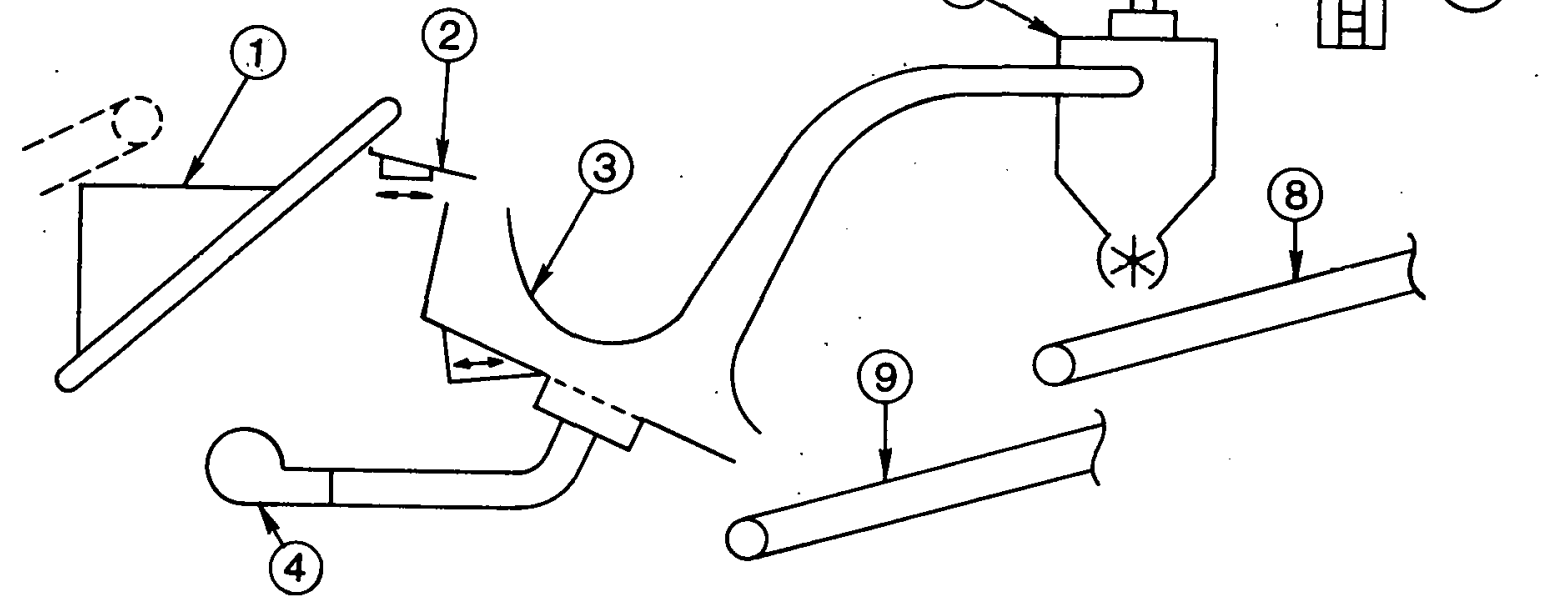

COMPONENT LIST
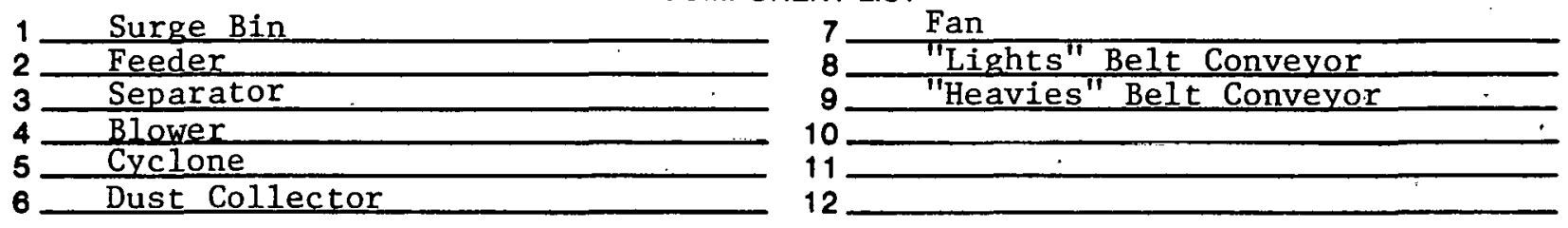

$$
100 \& 200 \text { TPD }
$$

a. PROCESS CAPACITY 30

TPH a. PROCESS CAPACITY

TPD

b. LABOR RATE-OPERATOR $0.25 \mathrm{MH} / \mathrm{mach}$, br. b. LABOR RATE-OPERATOR

c. LABOR RATE-MAINT. $0.25 \mathrm{MH} / \mathrm{mach}$ hr. c. LABOR RATE-MAINT.

d. CAPITAL COST 312,600

d. CAPITAL COST

๑. SUPPLIES $\$ 207 /$ mach hr. e. SUPPLIES

f. POWER USAGE $\quad 59 \mathrm{kw}-\mathrm{hr} / \mathrm{mach} \mathrm{hr}$. f. POWER USAGE

\begin{tabular}{|c|c|c|c|}
\hline \multicolumn{4}{|c|}{ PROCESS EFFICIENCY } \\
\hline COMPONENT & $\eta_{1}$ & $\eta_{2}$ & $\eta_{3}$ \\
\hline $\begin{array}{l}\text { PAPER } \\
\text { ORGANICS } \\
\text { WOOD } \\
\text { IRON } \\
\text { ALUMINUM } \\
\text { METALS } \\
\text { GLASS } \\
\text { PLASTICS } \\
\text { INERTS } \\
\text { FINES } \\
\text { TEXTILES }\end{array}$ & $\begin{array}{r}0.95 \\
0.70 \\
0.40 \\
0.05 \\
0.20 \\
0.05 \\
0.01 \\
0.20 \\
0.07 \\
0.50 \\
0.80 \\
\end{array}$ & $\begin{array}{r}0.05 \\
0.30 \\
0.60 \\
0.95 \\
0.80 \\
0.95 \\
0.99 \\
0.80 \\
0.99 \\
0.50 \\
0.20 \\
\end{array}$ & $\bar{t}$ \\
\hline
\end{tabular}

Figure 47. Vibrolutriator schematic and operational data. 


\section{Rotary Drum Air Classifier}

The rotary drum air classifier is a rotary air classifier that uses an internally flighted, rotating cylinder and a countercurrent air stream to effect the separation of the lights from the heavies. The shredded refuse is fed to the rotating cylinder where it is lifted by the internal flights and then allowed to fall through the airstream. This process provides a deagglomeration and separates the light from the heavy fractions. The light fraction is entrained as it falls in the moving airstream and is removed from the separator. The heavy fraction remains and is conveyed from the separator. This system is to be installed in Monroe County, New York, and a unit has been operated in Houston, Texas. It has been impossible to secure either economic or performance data from the manufacturer of this unit.

\section{$\underline{\text { Rotary Screen }}$}

The rotary screen (Figure 48) is a large cylindrical screen, approximately $10 \mathrm{ft}$ in diameter with nominal 4-in. screening openings and $1 \mathrm{~s}$ usea to process raw refuse. This unit is intended to perform a dual purpose: open bags and remove "fine" materials such as glass, metal, dirt, etc., from the light fraction.

Initial data from Recovery I in New Orleans, where the rotary screen is located ahead of the primary shredder, has indicated that the rotary screen is reducing the amount of material being fed to the shredders by approximately 50 percent. The material removed from the refuse stream consists primarily of cans, glass, fines, and wet organics. The impact of this process on system performance should be twofold--the removal of a significant amount of the abrasive items should reduce the wear on the shredder; and, by reducing the total amount of material to the shredder, a reduction in the size of the shredder may be achieved.

Long-term operational data on this process is not available, however preliminary findings are encouraging.

Although little operational data is available on the performance of a rotary screen prior to shredding, the unit may prove to be an attractive separation mechanism because of its low capital cost, low maintenance requirement, and low power requirement. Disadvantages of this unit stem from the fact that separation is achieved based on size differences only; therefore, a percentage of the fuel fraction will always report with the heavies stream. The performance characteristics of the rotary screen should be studied to determine the applicability of this unit to resource recovery processes.

\section{REFUSE DERIVED FUEL PREPARATION MODULE}

Refuse derived fuel preparation is implemented after the refuse stream has been processed through primary size reduction and has been separated into the combustible and noncombustible fractions. The processes involved in RDF preparation are applied to improve the fuel quality and/or its suitability for 


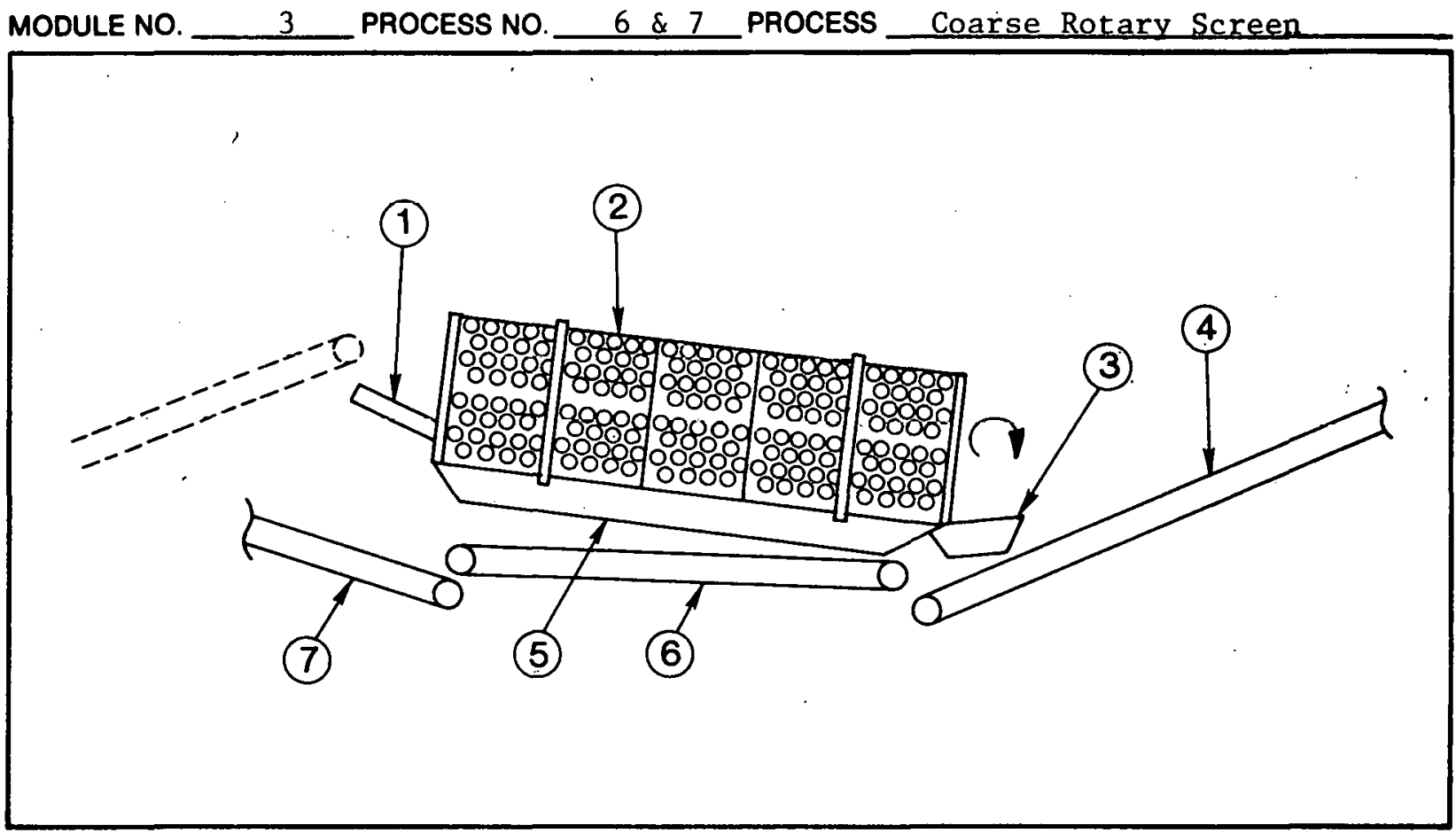

COMPONENT LIST

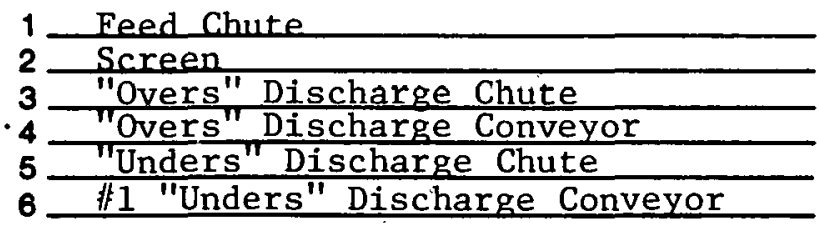

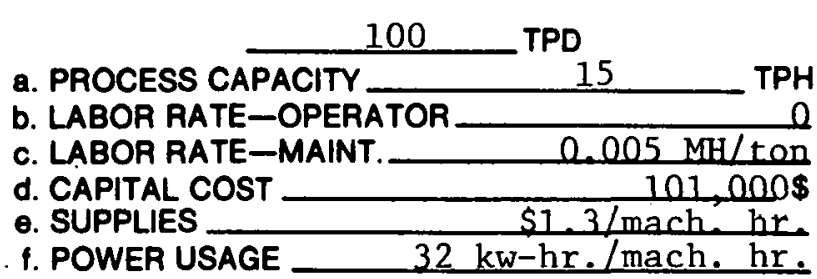

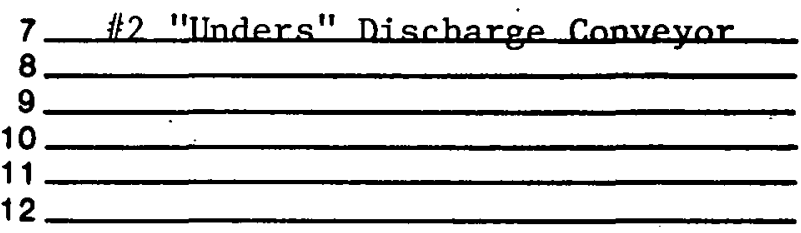

200 TPD

a. PROCESS CAPACITY 20 b. LABOR RATE-OPERATOR — 0 c. LABOR RATE-MAINT. $-0.004 \mathrm{MH} / \mathrm{t}$. d. CAPITAL COST $116,700 \$$ ๑. SUPPLIES f. POWER USAGE $42 \mathrm{kw}-\mathrm{hr}$./mach. $\mathrm{hr}$.

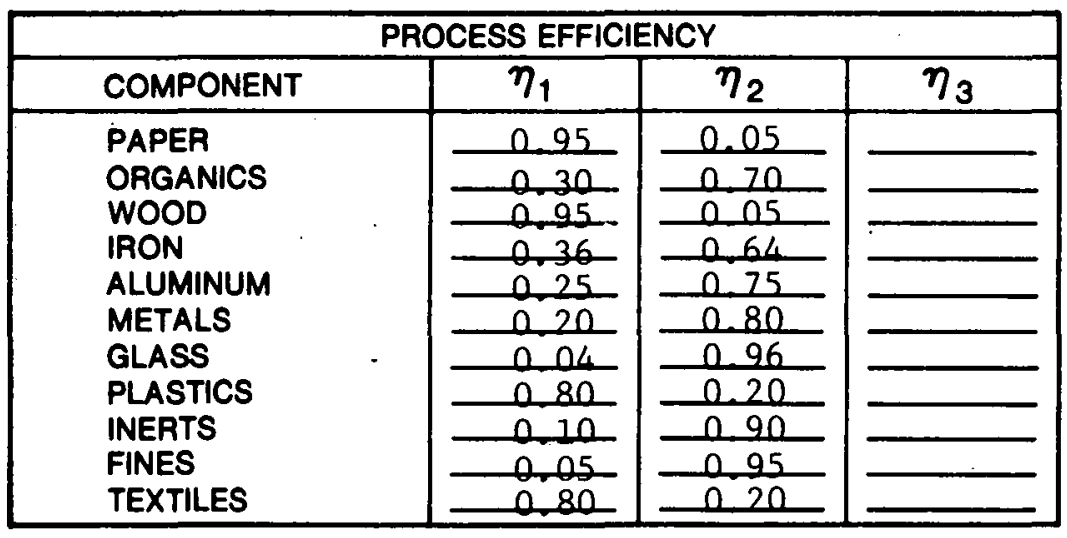

Figure 48. Coarse rotary screen schematic and operational data. 
specific combustion applications. The processes appearing to have applicability for small systems include magnetic separation, screening, and secondary shredding.

\section{Fine Rotating Screen}

The shredded combustible fraction is processed in a fine rotating screen (Figure 49) to reduce its ash content by removing the "fines" which contain a significant amount of glass, ceramic, and other abrasive and inert material. By removing these components from the fuel, two benefits are derived. First, a reduction in the glass content of the fuel fraction results in a higher ash fusion temperature. than with unscreened RDF. Second, the removal of these inert components will reduce the wear on the densifier and/or pneumatic conveying systems.

A 6-ft-diameter by 16- to 20-ft-long rotary screen is the approximate size that would be applied for systems of the capacity being evaluated. Hole size would range from $3 / 16$ to $1 / 2$ in. in diameter depending upon whether the screen is installed before or after the secondary shredder. Comprehensive data on optimum hole size and shape has not been developed. Ancillary equipment for the rotary screen includes a feed chute, a dust cover, a discharge chute and conveyors for both the "overs" and "unders," and drop boxes for storage of the unders.

The principal advantage of a rotary screen over a flat screen is that, by constantly rotating the cylindrical screen, material accumulation on the surface (b1inding) is minimized. Consequently, improved separation is achieved by continually exposing the feed to a clean surface.

\section{Magnet}

The magnetic separators (Figure 50) in use today have a nominal recovery efficiency of 95 percent of the magnetics in shredded waste. If the shredded waste has also been air classified, some of the magnetics are carried over into the light fuel fraction. While this nonrecovered magnetic fraction has minimal impact on the material recovery economics, it can cause significant wear on subsequent densification processing equipment. Additionally, this metal content can cause problems if the fuel is combusted, i.e., boiler corrosion, heavy metal emissions from the boiler, and heavy leaching from boiler ash.

The magnet consists of a cross belt electromagnet suspended above a trough belt conveyor which transports material from the combustibles separation or another benefication step. The recovered magnetics and "tagalongs" are collected in drop boxes and can be either marketed or disposed of in a landfill. Little actual data has been accumulated on magnetic separation. Most of the available.data is based on manufacturer's claims. 
MODULE NO. $\quad 4 \quad$ PROCESS NO. $1 \& 2$ PROCESS Fine Rotary Screen

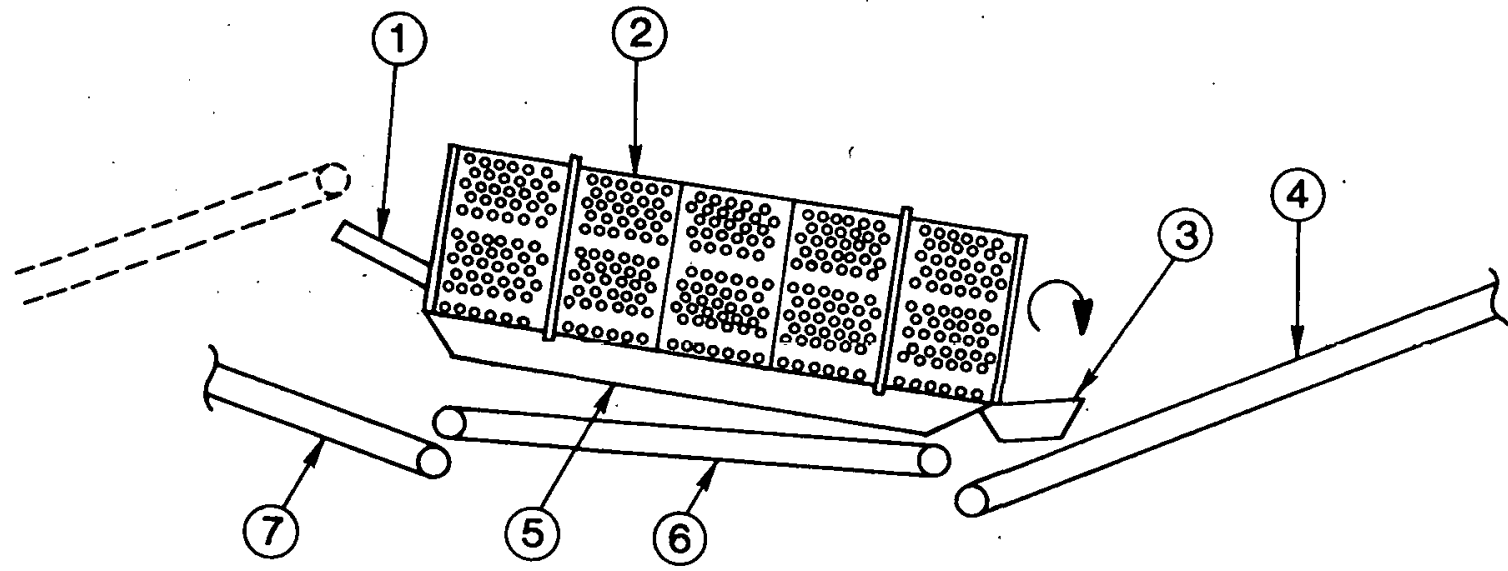

COMPONENT LIST

1 Feed Chute

2 Screen

3 "Overs" Discharge Chute

4 "Overs" Discharge Conveyor

5 "Unders" Discharge Chute

6 \#1 "Unders" Discharge Conveyor

$\frac{100}{7 P D}$

. PROCESS CAPACITY

b. LABOR RATE-OPERATOR 0 O5 $\mathrm{MH} / \mathrm{mach}$ hr

c. LABOR RATE-MAINT. $0.05 \mathrm{MH} / \mathrm{mach}, \mathrm{hr}$.

d. CAPITAL COST

๑. SUPPLIES 73,600 \$

f. POWER USAGE so.94/mach. hr. 17 kw-hr. /mach. br. PROCESS EFFICIENCY

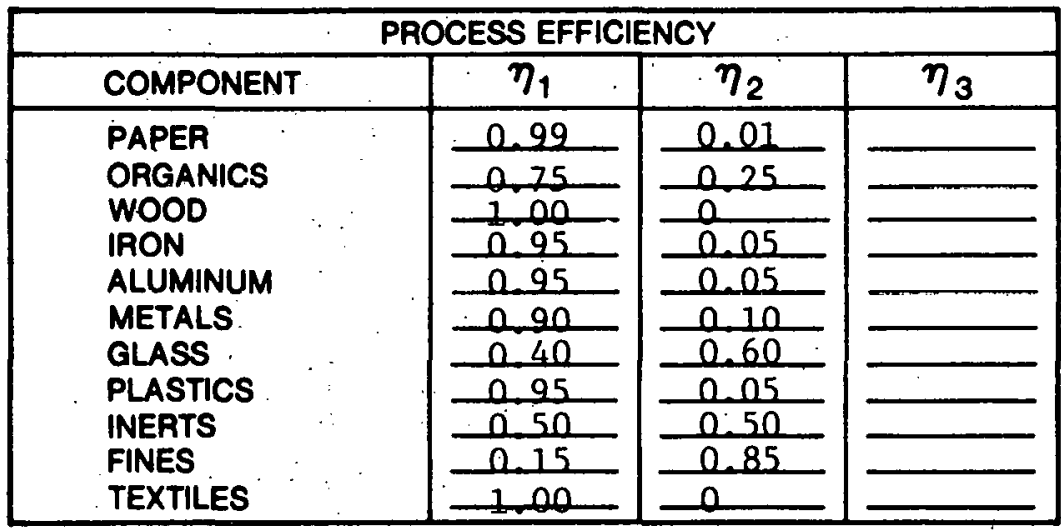

Figure 49. Fine rotary screen schematic and operational data.
7 非2 "Unders" Discharge Conveyor

8
9
10
11
12

a. PROCESS CAPACITY 15

b. LABOR RATE-OPERATOB $075 \mathrm{MH} / \mathrm{mach}$. br.

c. LABOR RATE-MAINT. $0.050 \mathrm{MH} / \mathrm{mach}$. hr. d. CAPITAL COST

๑. SUPPLIES $81,500 \$$

\$lid/mach. hr. 
MODULE NO. PROCESS NO. $3 \& 4$ PROCESS Tramp Metal Magnet
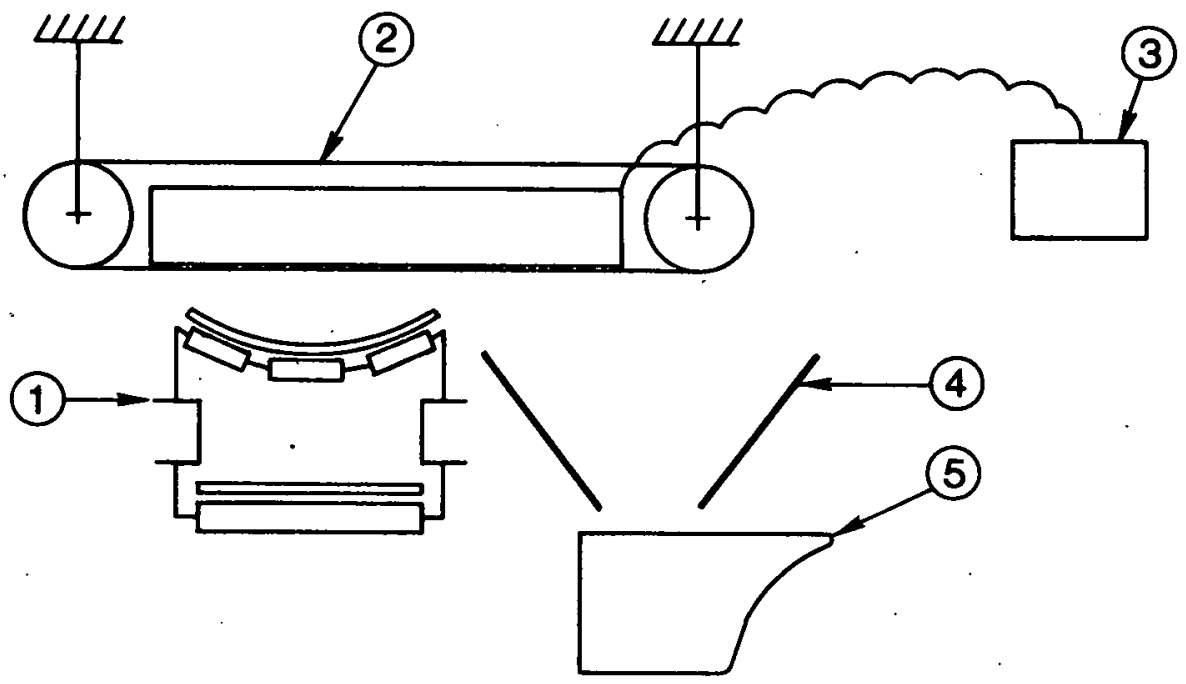

(4)

(5)

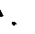

COMPONENT LIST

1 $\mathrm{RDF}$ Conveyor

2 Belt Magnet

3 Rectifier

4 Discharge Chute

5 Dron Box

6

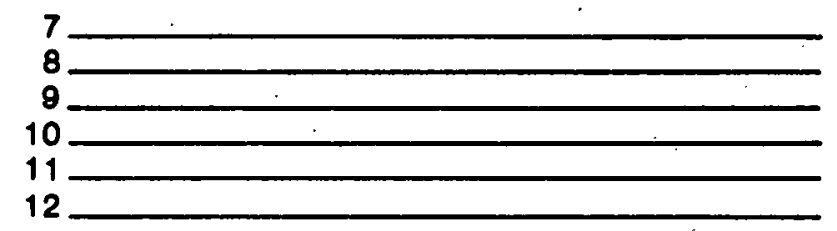

a. PROCESS CAPACITY $\frac{100}{1}-7.5$ TPD, TPH

b. LABOR RATE-OPERATOR $0.02 \mathrm{MH} / \mathrm{mach}$. hr.

c. LABOR RATE-MAINT. $-0.03 \mathrm{MH} / \mathrm{mach}, \mathrm{hr}$.

d. CAPITAL COST $26.400 \$$

๑. SUPPLIES so.29/mach. hr.

f. POWER USAGE _. 13 kw-hr. /mach. hr.

a. PROCESS CAPACITY TPD 15 TPH

b. LABOR RATE-OPERATORQ_03/MH/mach $\mathrm{hr}$ c. LABOR RATE-MAINT. O 03 MH/mach $\mathrm{hr}$ d. CAPITAL COST $\frac{28.300}{2}$

๑. SUPPLIES s0.29/mach. hr. f. POWER USAGE $13 \mathrm{kw}-\mathrm{hr} / \mathrm{mach} \ldots \mathrm{hr}$

\begin{tabular}{|c|c|c|c|}
\hline \multicolumn{4}{|c|}{ PROCESS EFFICIENCY } \\
\hline COMPONENT & $\eta_{1}$ & $\eta_{2}$ & $\eta_{3}$ \\
\hline $\begin{array}{l}\text { PAPER } \\
\text { ORGANICS } \\
\text { WOOD } \\
\text { IRON } \\
\text { ALUMINUM } \\
\text { METALS } \\
\text { GLASS } \\
\text { PLASTICS } \\
\text { INERTS } \\
\text { FINES } \\
\text { TEXTILES }\end{array}$ & $\begin{array}{r}0.99 \\
1.00 \\
0.95 \\
0.10 \\
0.95 \\
0.99 \\
1.00 \\
1.00 \\
100 \\
0.99 \\
100\end{array}$ & $\begin{array}{l}0.01 \\
0 \\
0.05 \\
0.90 \\
0.05 \\
0.01 \\
0 \\
0 \\
0 \\
0.01 \\
0\end{array}$ & \\
\hline
\end{tabular}

Figure 50. Tramp metal magnet schematic and operational data. 
Secondary shredding is a size reduction process similar to primary size reduction. It is performed as an intermediate step to other fuel benefication processes such as densification, or to size the material to permit direct combustion of the fuel in suspension-fired boilers. Although the degree of size reduction is process specific, the data base provided herein is based upon a shredder input of a nominal 4-in. particle size reduced to a nominal 1/2-in. product size.

Like primary shredders, both horizontal (Figure 51) and vertical (Figure 52) axis shredders have found applicability in secondary shredding. However, quantitative data does not exist to suggest the preferred type for secondary shredding. Because of the lighter characteristics of the feed stock, secondary shredders are usually smaller and less rugged than primary shredders. The hammer configurations are also different since most of the size reduction is accomplished through shearing rather than impact. However, the per ton power requirements for secondary shredding are higher than those for primary shredding. This is attributed to the increased number of "divisions" of the individual particles that must take place to reach the ultimate particle size.

The ancillary equipment associated with the secondary shredder is similar to that employed with the primary shredder. However, secondary shredders typically do not require vibrating pan discharge conveyors or explosion suppression systems.

\section{FUEL DENSIFICATION}

Densification is a material benefication process that increases the density of a refuse derived fuel. The type of RDF that is typically densified is fluff $\mathrm{RDF}$, although some tests have been made on dust $\mathrm{RDF}$ and wet process $\mathrm{RDF}$. The process of densification increases the bulk density of the fuel product from 4 to $6 \mathrm{lb} / \mathrm{ft}^{3}$ to 26 to $45 \mathrm{lb} / \mathrm{ft}^{3}$. This product is commonly called dRDF.

A significant amount of interest has been shown in densification because of the potential for $\mathrm{dRDF}$ as a stoker coal substitute. As such, dRDF can be introduced into a boiler plant with minimal modifications to the fuel handling and combustion system. Other benefits of densification of the fuel include increasing the material resistance to wetting; improving material handling characteristics and reducing transportation costs; reducing sophistication of storage requirements; and, in special cases, blending $d R D F$ easily with other types of fuel prior to pulverization for a suspension fired boiler. The three types of densification processes evaluated for application in a resource recovery system are pelletizer, cubetters, and briquetters. The data is extremely limited on the performance of these units, with approximately 2000 to 3000 tons of dRDF produced to date. Once test burns have been completed to verify feasibility, unit evaluations should be made of densification processes.

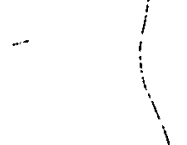


MODULE NO. 4 PROCESS NO. $5 \& 6$ PROCESS Secondary Hammer Mil1

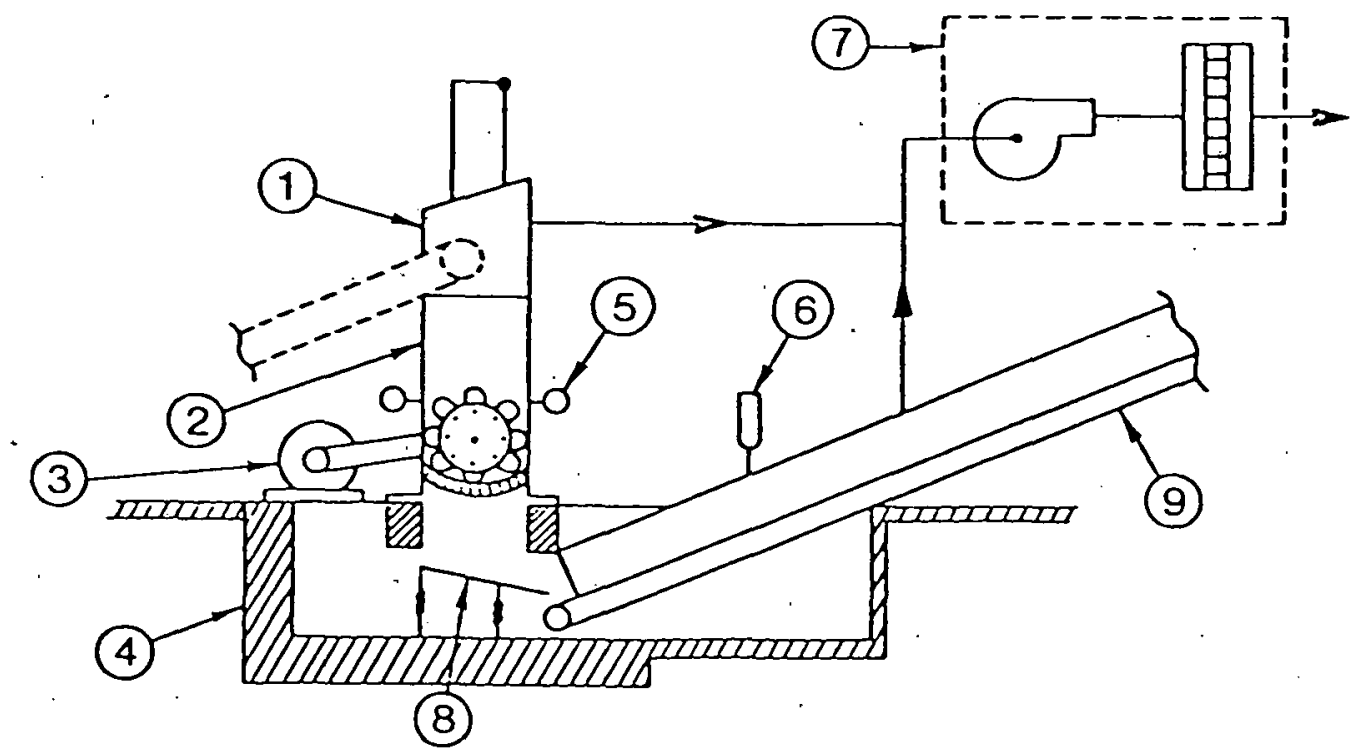

COMPONENT LIST

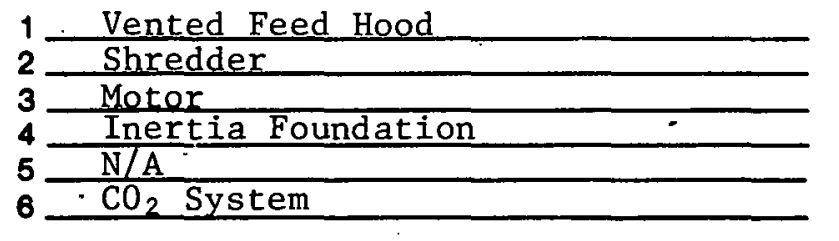

7 . Dust Control System

8 - Vibrating Pan Convevor

9 Belt Conveyor

10

11

$\frac{100}{\text { TPO }_{7.5}}{ }^{100}{ }^{2}$

a. PROCESS CAPACITY $\frac{7.5}{102 \mathrm{MH}}$ TPH

b. LABOR RATE-OPERATOR $-0.01 \mathrm{MH} / \mathrm{tOO}$

d. CAPITAL COST

๑. SUPPLIES

$232,400 \$$

f. POWER USAGE

$\$ 0.5 /$ ton

$12 \mathrm{kw}-\mathrm{hr} \cdot / \mathrm{ten}$

12

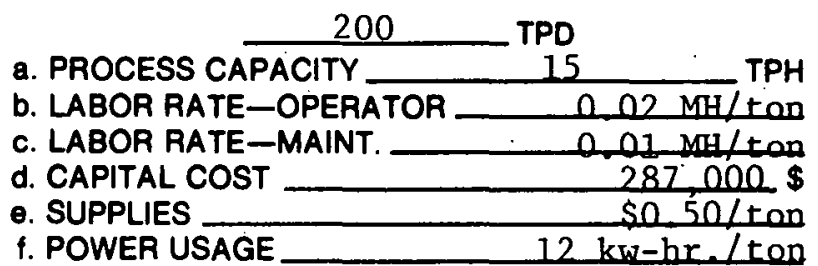

\begin{tabular}{|l|c|l|l|}
\hline \multicolumn{4}{|c|}{ PROCESS EFFICIENCY } \\
\hline COMPONENT & $\eta_{1}$ & $\eta_{2}$ & $\eta_{3}$ \\
\hline PAPER & - & & \\
ORGANICS & - & \\
WOOD & - & \\
IRON \\
ALUMINUM & - & \\
METALS & - & \\
GLASS & - & \\
PLASTICS & - & \\
INERTS & - & \\
FINES \\
TEXTILES
\end{tabular}

Figure 51. Secondary horizontal hammermill operational data. 
MODULE NO. $4^{\circ}$ PROCESS NO. $7 \& 8$ PROCESS Secondary Vert. Hammer Mill

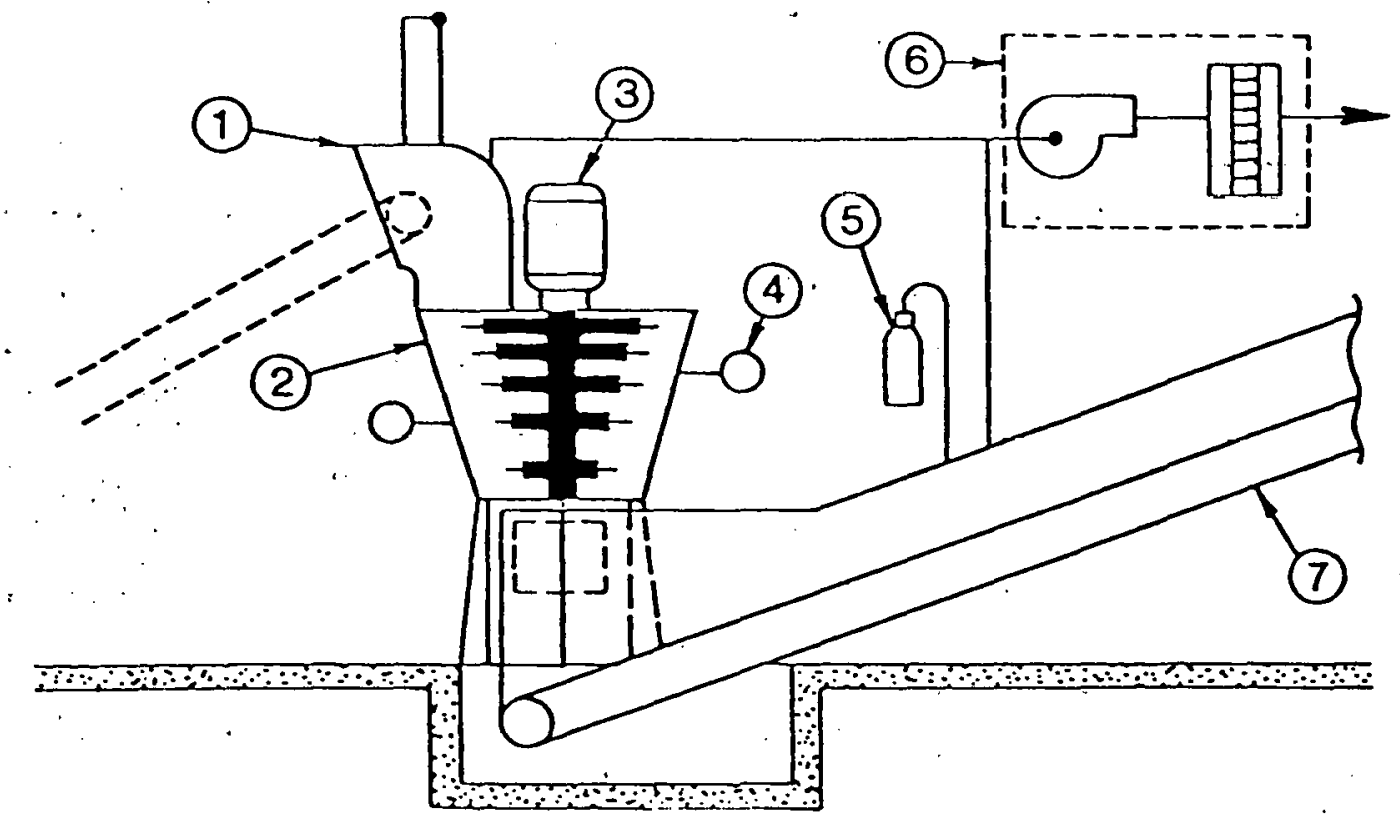

COMPONENT LIST

1 Vented Feed Hood

2 Shredder

3 Motor

4 N/A

6 Explosion Suppression System

6 Dust Control System

$\frac{100 \text { TPO }}{100}$

PROCESS CAPACITY

a. PROCESS CAPACITY $\frac{1.5}{0.02 \mathrm{MH} / \text { TPH }}$

c. LABOR RATE-MAINT. $0.01 \mathrm{MH} / \mathrm{t}$ On

d. CAPITAL COST

๑. SUPPLIES $234,500 \$$

f. POWER USAGE

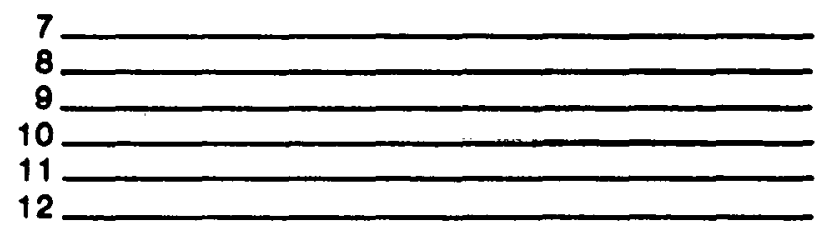

$\frac{200}{200}$ TPD

a. PROCESS CAPACITY 15 b. LABOR RATE-OPERATOR $\quad 0.02 \mathrm{MH} / \mathrm{tOn}$ c. LABOR RATE-MAINT. 0.01 MH/ton d. CAPITAL COST $\frac{453.100}{50.50 \%}$ o. SUPPLIES $\$$ \$0.50/ton f. POWER USAGE $\quad 12 \mathrm{kw}-\mathrm{hr}$. $/$ ton

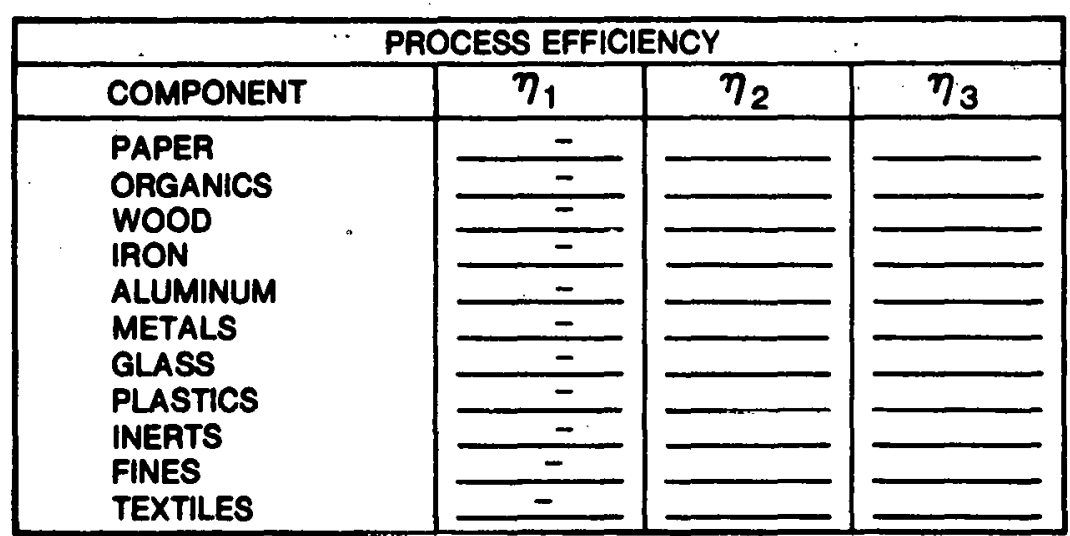

Figure 52. Secondary vertical hammermill operational data. 


\section{Pelletizers}

Pelletizers (Figure 53) process waste into dense cylindrical pellets from $3 / 8$ in. to $21 / 2$ in. in diameter and up to 2 in. long, depending upon die and breaker bar arrangements. The product can have a density ranging from 26 to $42 \mathrm{lb} / \mathrm{ft}^{3}$. The preferred form of the product has not yet been estab1ished. An ongoing EPA research program is aimed at answering the form question. The pelletizer accepts fine-shredded, air-classified waste that has been screened to remove as much of the grit as possible and has been processed for removal of magnetic materials. Preliminary data indicate that the nominal incoming particle size should be no larger than the diameter of the pellet.

Fluff RDF is conveyed to a live bottom feed bin located above the pelletizer where it is metered into a series of transportation screws for introduction into the head of the pelletizer. The head of the pelletizer consists of a rim extruder die with slightly tapered holes. The rim die rotates about stationary idlers that force the shredded material trapped between the idlers and the die through the holes in the die. The extruded material is broken off at the desired length by a series of breaker bars to form the pellets which drop out of the head area of the pelletizer and are conveyed to the storage hopper.

The principle advantage of pelletizing over the other forms of densification is that more operating data exists on pelletizers than on cubetters and briquetters. Despite the fact that the strongest data base exists for pelletizers, much of the data that has been reported on operational costs are extrapolations rather than historical data.

\section{Cubetter}

The cubetting process (Figure 54) is very similar to the pelletizing process. Consequently, the process flow diagram is identical. 'The major difference between the cubetter and the pelletizer is that the cubetter die is held stationary while the idlers rotate to force the material out through the holes in the die. A variety of densities and sizes of dRDF can be prepared with the cubetter. This material is generally square instead of round. The claimed advantage to cubetting as opposed to pelletizing is a lower operating cost with similar capital costs. The principle disadvantage to cubetting is that less data exists on the operation of a cubetter to allow quantification of its economics or technical merits.

\section{Briquetter}

The briquetting processing employs an entirely different method for densifying the waste. Instead of extruding the waste through holes in a die, the material is trapped between two counter rotating halves of a die and is compressed. The product has an appearance similar to charcoal briquettes. The briquetting process is the least developed of the RDF densifying processes. The most successfui application of briquetting has been with the densification of the CEA ECO Fuel II. Attempts to densify conventional fluff RDF have met with limited success and suggest that the use of a binder may be required. 
MODULE NO.

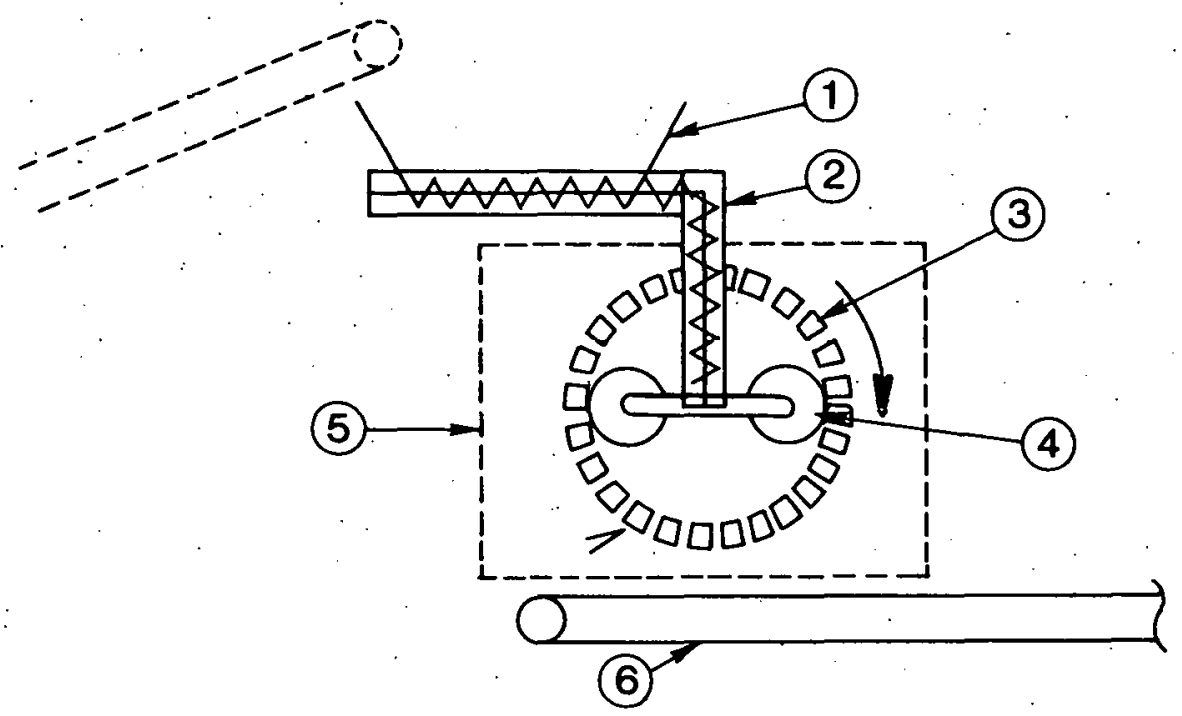

COMPONENT LIST

Live Bottom Surge Bin

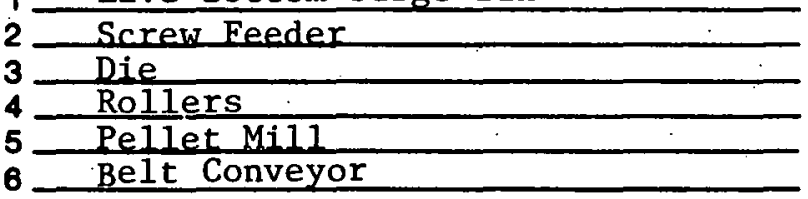

Belt Conveyor

a. PROCESS CAPACITY 10.5 TPH

b. LABOR RATE-OPERATOR $0.33 \mathrm{MH} / \mathrm{mach}$. $\mathrm{hr}$

c. LABOR RATE-MAINT. $0.10 \mathrm{MH} / \mathrm{mach}$. hr.

d. CAPITAL COST $122,700 \$$

o. SUPPLIES S1.49/tan t \$7.00/mach. hr

f. POWER USAGE $73 \mathrm{kw}$ hr /mach hr

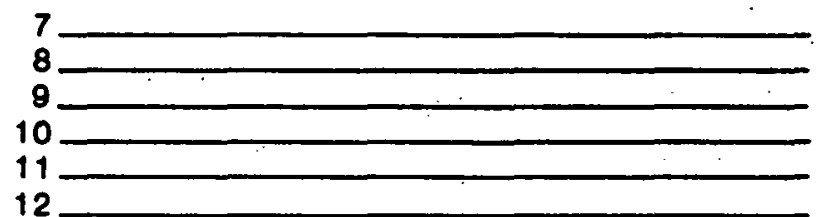

200 TPD

a. PROCESS CAPACITY $21 \quad \cdots-T P H$

b. LABOR RATE-OPERATOR _66 MH/mach $\mathrm{hr}$. c. LABOR RATE-MAINT. $0.2 \mathrm{MH} / \mathrm{mach}$. hr. d. CAPITAL COST $236,300 \$$

o. SUPPLIES $\$ 1: 49 / \mathrm{ton}+\$ 13.73 / \mathrm{mach}$. $\mathrm{hr}$. f. POWER USAGE _. $145 \mathrm{kw}-\mathrm{hr}$./mach. $\mathrm{hr}$.

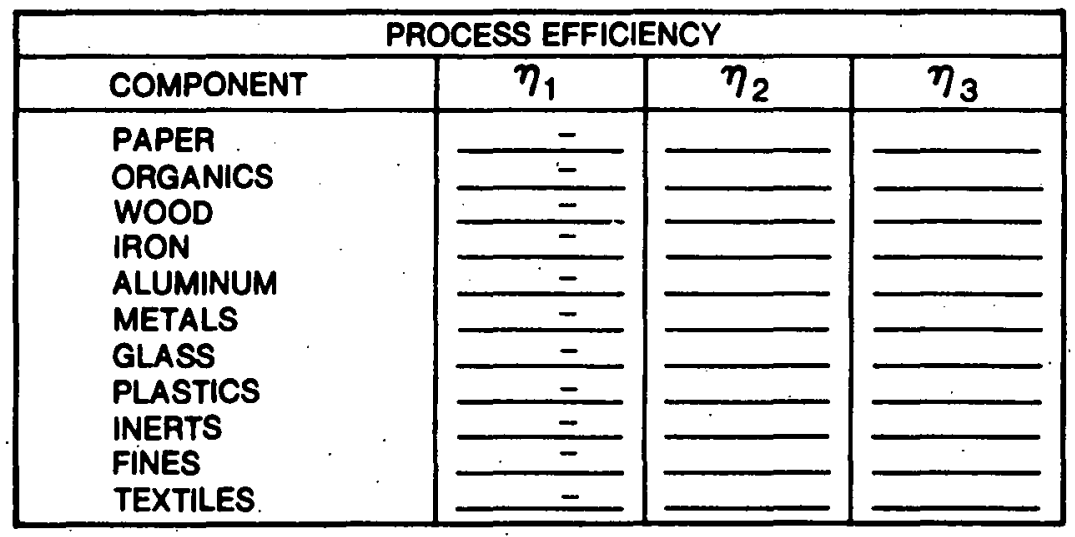

Figure 53. Pelletizer schematic and operational data. 
MODULE NO.
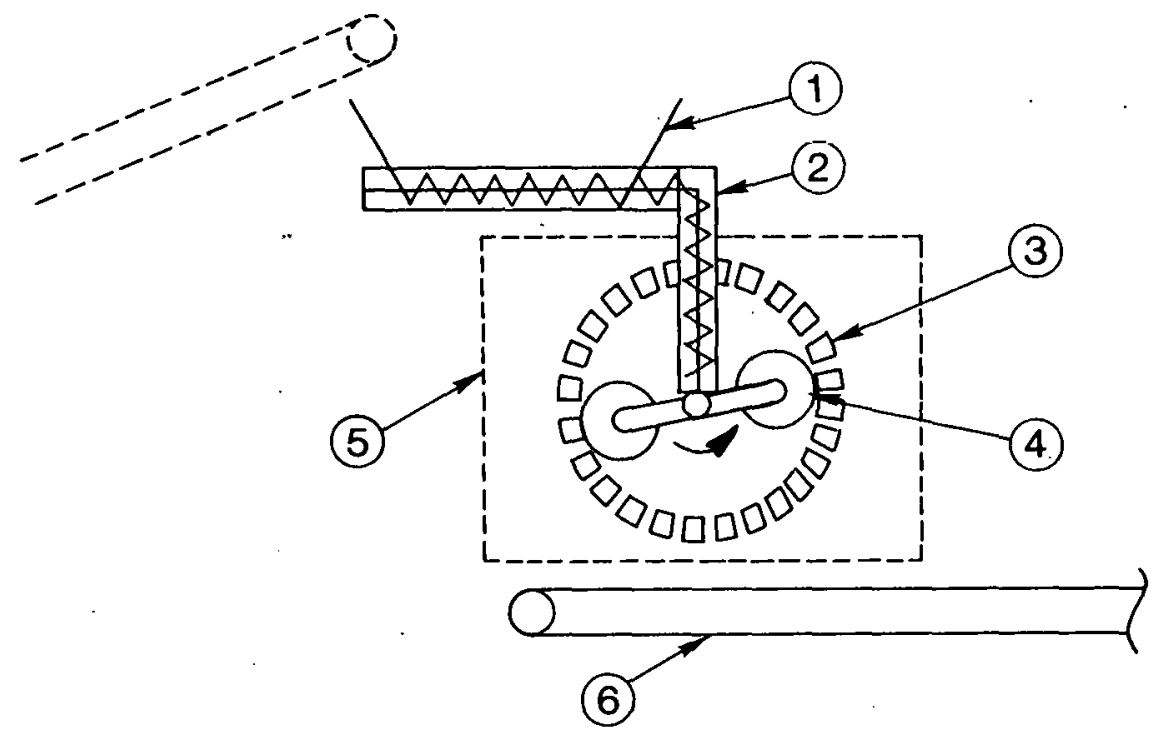

COMPONENT LIST

1 Live Bottom Surge Bin

2 Screw Feeder

3 Die

4 Roller

5 Mil1

6 Belt Conveyor

a. PROCESS CAPACITY $\frac{100-\text { TPD }}{8.5}$

b. LABOR RATE-OPERATOR $0.33 \mathrm{MH} / \mathrm{mach}$. hr.

c. LABOR RATE-MAINT. $0.1 \mathrm{MH} / \mathrm{mach}$. $\mathrm{hr}$.

d. CAPITAL COST 132,800\$

o. SUPPLIES \$0.55/ton $+1 \$ 0.68 / \mathrm{mach}$. hr.

f. POWER USAGE _. $113 \mathrm{kw}-\mathrm{hr}$./mach, hr

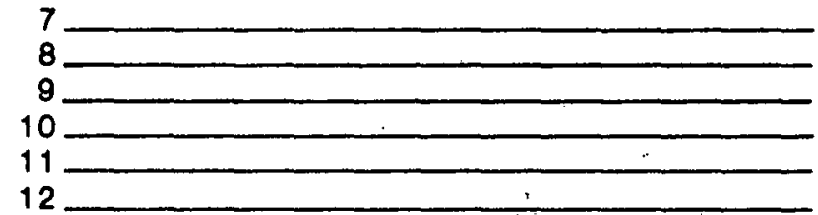

200

TPO

a. PROCESS CAPACITY_ 17

b. LABOR RATE-OPERATORO $66 \mathrm{MH} / \mathrm{mach}$ hr c. LABOR RATE-MAINT. $0.2 \mathrm{MH} / \mathrm{mach} . \mathrm{hr}$. d. CAPITAL COST $\frac{248,000 \$}{2}$

e. SUPPLIES SO $55 / \mathrm{tan}+\$ 1.36 / \mathrm{mach}$. hr. f. POWER USAGE $223 \mathrm{kw}-\mathrm{hr}$ : /mach. hr.

\begin{tabular}{|l|c|l|l|}
\hline \multicolumn{4}{|c|}{ PROCESS EFFICIENCY } \\
\hline COMPONENT & $\eta_{1}$ & $\eta_{2}$ & $\eta_{3}$ \\
\hline PAPER & - & & \\
ORGANICS & $-\frac{-}{-}$ & \\
WOOD & & \\
IRON & - & \\
ALUMINUM & - & \\
METALS & - & \\
GLASS & - & \\
PLASTICS & - & \\
INERTS & - & \\
FINES & - & \\
TEXTILES & - & \\
\hline
\end{tabular}

Figure 54. Cubetter schematic and operational/âta. 
Finally, the aforementioned characteristics are based on tests performed on laboratory scale briquetters rather than the production scale units used for testing the pelletizers and cubetters.

Without a stronger data base, statements as to operating characteristics and economics would be pure conjecture. Tests should be performed to determine the efficiency of briquetting relative to other densification techniques.

FUEL STORAGE MODULE

The concepts applicable to the storage of refuse derived fuel in smallscale applications are based on those developed for larger systems. The technology is basically an extension of the storage criteria developed for power plants which dictates the necessity of having an adequate supply of fuel on site to permit continuous operation of the plant. Hence, storage capacity of 4 days is specified for each system to permit operation over a long weekend. However, it should be noted that a substantial savings can be realized by reducing this capacity.

The storage and retrieval of RDF is difficult. Shredded waste tends to bridge, has an angle of repose in excess of 90 degrees, will ignite by spontaneous combustion, and will become biologically active if allowed to become wet. In order to circumvent these problems, specialized storage systems for this material have been developed. Foremost are the RDF bins previously used in waste wood applications. Other options investigated include the transfer tailer concept for fluff RDF and coal silos for densified RDF.

All modules were developed to provide three functions: accept the refuse as it is generated, provide the required four day storage capacity, and meter the feed to the fuel user at a rate equal to the nominal dial generation rate divided by 24 hours. All the operating costs and labor requirements have been normalized to an 8-hour, 5-day per week operation, although some components may operate 24 hours, per day, 7 days per week. The high cost of storage facilities indicates that an effort should be made to minimize the need for these units in small systems. The lack of available data indicates a need to evaluate the performance of existing storage systems.

The Live Center Bin

The live center bin (Figure 55), storage concept employs a spaceous covered bulk storage area similar to the tipping floor and a surge/metering bin called a live center bin. The refuse derived fuel is conveyed to the center of the storage bin by a stacking conveyor. The stacking conveyor is employed to provide stacks of the fuel to keep it from binding; thus facilitating material handling. The fuel is moved from the stacks by a front-end loader to the storage area where it is placed in a continuous pile approximately $8 \mathrm{ft}$ high. The front-end loader then conveys the fuel to a bucket elevator that feeds the live center bin and from which the fuel is outfed at: a constant rate to a pneumatic conveying system feeding the boiler. The live, center bin is an interim storage metering mechanism that allows the outfeeding of the fuel without the problems normally associated with RDF. These problems, which are usually a result of packing, are averted by the use of center augers 
MODULE NO. 6 PROCESS NO. $1 \& 2$ _ $\quad$ PROCESS Live Center Bin

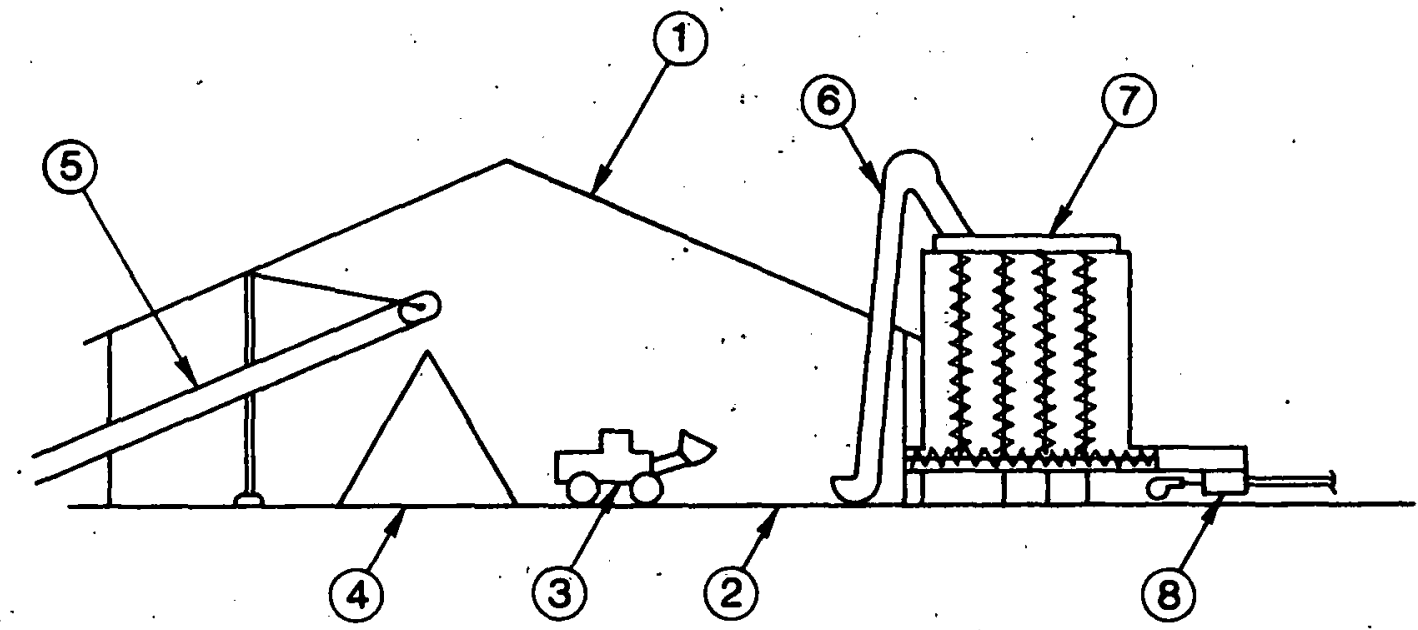

COMPONENT LIST

1 Building Enclosure

2 Stacking Floor

3 Front End Loader

4 Fuel Stack

6 Stacking Conveyor

6 Bucket Elevator

6. PROCESS CAPACITY TPD

b. LABOR RATE-OPERATOR $2,6 \mathrm{MH} / \mathrm{mach}$ hr

c. LABOR RATE-MAINT. 0.15 MH/mach $\mathrm{hr}$

d. CAPITAL COST

๑. SUPPLIES

i. POWER USAGE 577,400 s s10.60/mach hr $157 \mathrm{kw}-\mathrm{hr} / \mathrm{mach}$. hr.

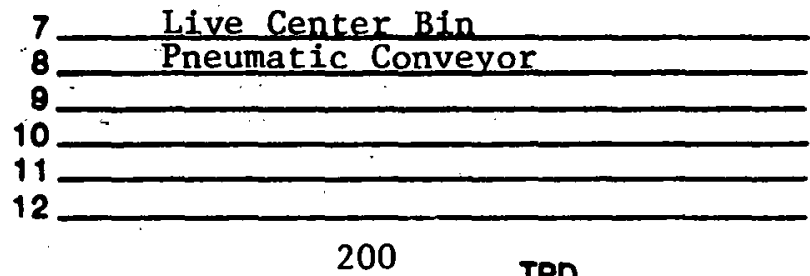

TPD

a. PAOCESS CAPACITY $15 \quad$ TPH b. LABOR RATE-OPERATOR $3 \mathrm{MH} / \mathrm{mach}$ hr. c. LABOR RATE-MAINT. $0.28 \mathrm{MH} / \mathrm{mach}$. hr. d. CAPITAL COST $820.000 \$$ o. SUPPLIES $-\$ 13.23 / \mathrm{mach}$.hr. f. POWER USAGE _ $177 \mathrm{kw}=\mathrm{hr} / \mathrm{mach}$ _hr.

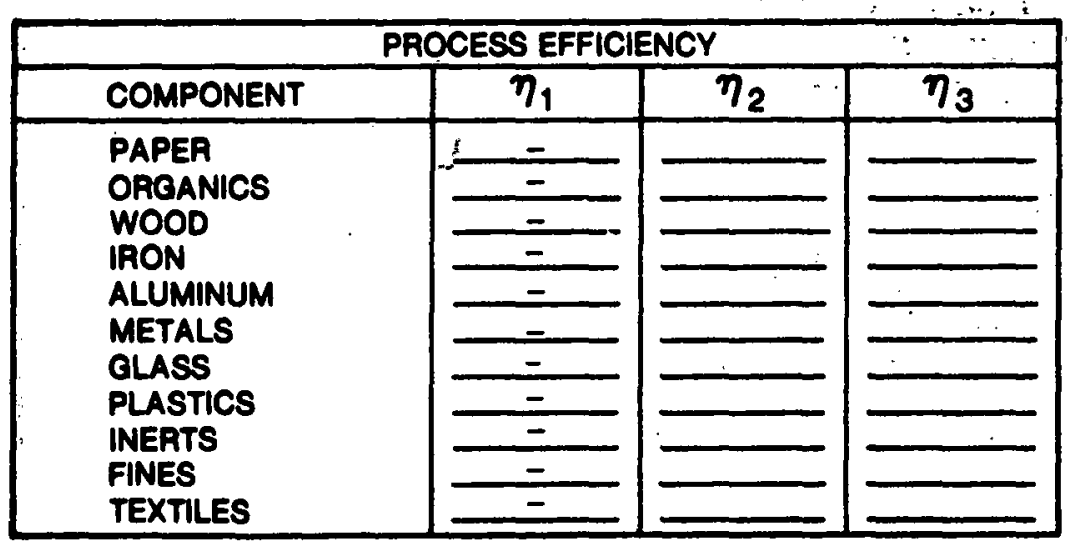

Figure 55. Live center bin schematic and operational data. 
which constantly lift the material and keep it loose. Outfeeding is by screw augers at the bottom of the bin. The bin and, ancillary equipment are sized so that one operator per shift is able to maintain continuous fuel delivery to the fuel user.

The principal advantage of this concept is that it appears to solve the problems of material compaction and bridging and that it employs a first-in, first-out concept on the stored material. The disadvantages include high capital costs, the lack of a full-scale installation to assess the viability of the concept, and the potential for textiles to wrap around the augers.

\section{Covered Pile}

The "Atlas" bin (Figure 56) is a patented storage method developed by Atlas Systems that uses a covered pile storage concept. The fuel is fed to the bin, resembling a giant Indian Teepee, by a covered trough belt conveyor. Inside the bin the refuse forms a large, free-standing, conical pile. The fuel is discharged from the bin by drag chains that circulate around the rim of the pile and feed a drag conveyor recessed in the floor of the vessel. The recessed conveyor then feeds a pneumatic conveying system which transports material to the boiler.

Several bins are presently installed but have experienced problems of high wear rates on drag chains and the bin floor, chain breakage, and nonuniform outfeeding. If the material is allowed to stay in the bin for long, it tends to solidify so that the drag chains cannot move it to the outfeed conveyor. However, a number of the reported problems with this type of storage system have been the result of misapplication and failure to follow manufacturer's guidelines.

It is expected that storage of a final fuel product in the Atlas bin may be a feasible approach. The large bin installed at the City of Baltimore, Maryland, has indicated that the storage of shredded raw refuse causes difficulties in an Atlas bin. Several recent installations for the storage of a final fuel product will better indicate viability of the Atlas system for the storage of $\mathrm{RDF}$.

\section{The Silo}

Once RDF has been densified, it can be handled in a manner similar to that employed with coal. As a result, conventional coal storage equipment (Figure 57) may prove effective. This equipment tends to be small, to have a history of reliability, and to be easily maintained. One caution is necessary, if the dRFD has deteriorated so that it is no- Longer densified, it will bridge and resist discharge from the bin. As a result, strict quality control (size and moisture content of the RDF and die wear) on the densification process is necessary to ensure proper operation.

The $\mathrm{dRDF}$ is fed to the silo by a bucket elevator. The silo is a large cylindrical concrete structure sized to hold the required 4-day supply of 
MODULE NO. 6 PROCESS NO.

$3 \& 4 \quad$ PROCESS Atlas Bin
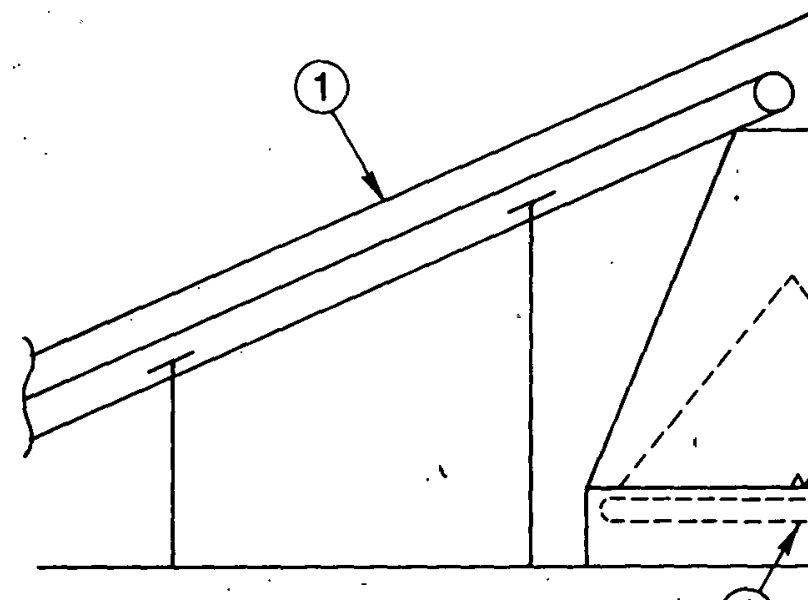

(4)

\section{' COMPONENT LIST}

1 Covered Belt Conveyor

2 Atlas Bin

3 Bucket-Sweep Chain

4 Outfeed Conveyor

5 Pneumatic Conveyor.

6

100

TPD

a. PROCESS CAPACITY $\quad 7.5$

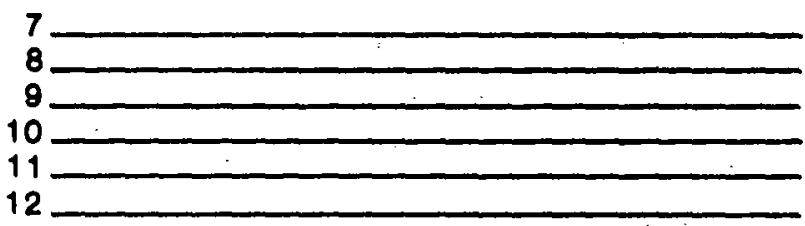

b. LABOR RATE-OPERATOR $0.38 \mathrm{MH} / \mathrm{mach}$ hr

c. LABOR RATE-MAINT. $0.75 \mathrm{MH} / \mathrm{mach}$. $\mathrm{hr}$

d. CAPITAL COST $637,700 \$$

๑. SUPPLIES $\$ 3.03 / \mathrm{mach} . \mathrm{hr}$.

1. POWER USAGE $204 \mathrm{kw}-\mathrm{hr}$ /mach. $\mathrm{hr}$.

200 TPD

a. PROCESS CAPACITY TPH b. LABOR RATE-OPERATOR 0.5 MH/mach. hr.

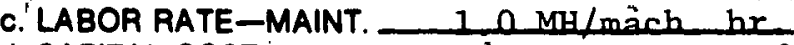
d. CAPITAL COST _ 871,600 S e. SUPPLIES $-\$ 4.11 / \mathrm{mach} \cdot \mathrm{hr}$ f. POWER USAGE $256 \mathrm{kw}-\mathrm{hr} / \mathrm{mach}$. hr.

\begin{tabular}{|l|c|l|l|}
\hline \multicolumn{3}{|c|}{ PROCESS EFFICIENCY } \\
\hline COMPONENT & $\eta_{1}$ & $\eta_{2}$ & $\eta_{3}$ \\
\hline PAPER & ORGANICS & - & \\
WOOD & - & \\
IRON & - & \\
ALUMINUM & - & \\
METALS & - & \\
GLASS & - & \\
PLASTICS & - & \\
INERTS & - & \\
FINES & - & \\
TEXTILES & - & \\
\hline
\end{tabular}

Figure 56. Atlas bin schematic and operational data. 
MODULE NO. 6 PROCESS NO. $\quad 7 \& 8$ PROCESS Bunker

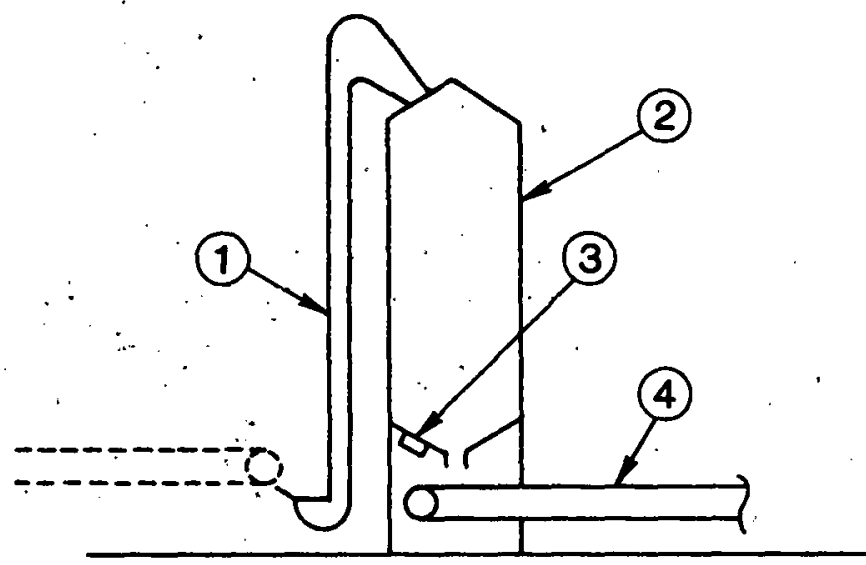

\section{COMPONENT LIST}
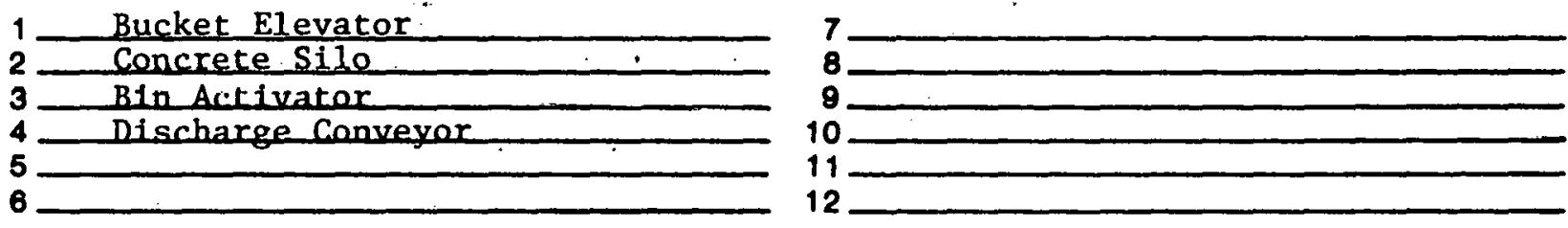

a. PROCESS CAPACITY 100 TPD 7.5

b. LABOR RATE-OPERATOR.001 MH/mach. $\mathrm{hr}$.

c. LABOR RATE-MAINT. $0.001 \mathrm{MH} / \mathrm{mach}$. $\mathrm{hr}$.

d. CAPITAL COST

e. SUPPLIES 82,400

f. POWER USAGE S0.03/mach. $\mathrm{hr}$ $3.4 \mathrm{kw}-\mathrm{hr}$ /mach. hr.

a. PROCESS CAPACITY TPD TPH

b. LABOR RATE-OPERATOQ $.001 \mathrm{MH} / \mathrm{mach}$. hr. c. LABOR RATE-MAINT. 0,001 $\mathrm{MH} / \mathrm{mach}, \mathrm{hr}$ d. CAPITAL COST

๑. SUPPLIES 101.600 s

f. POWER USAGE S0.04/mach. hr.

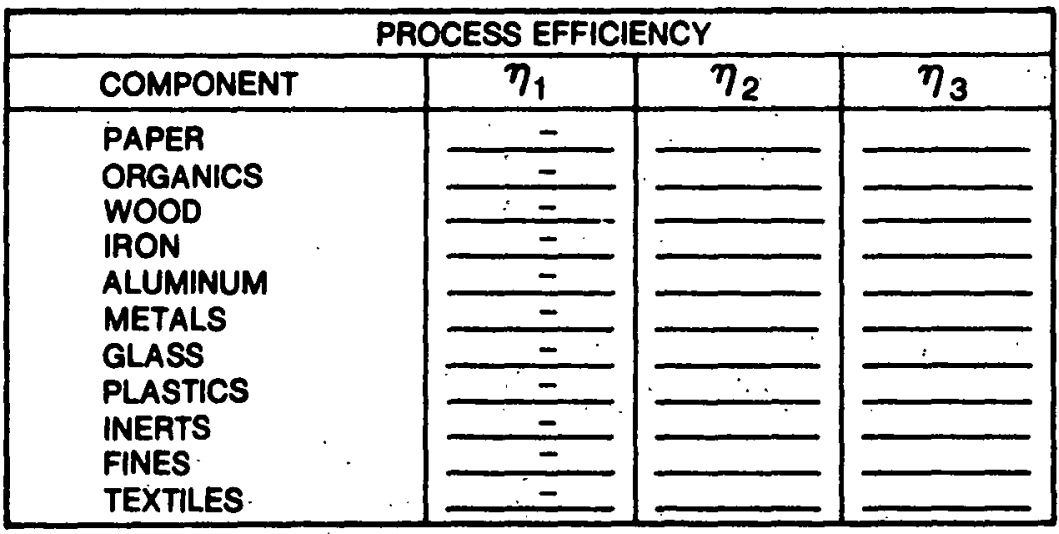

Figure 57. Bunker schematic and operational data. 
fuel. The material is outfed from the silo by a belt conveyor which feeds the boiler. To ensure a continuous flow of material from the silo, a bin activator is used.

The Transfer Trailer

The transfer trailer (Figure 58) concept has its widest application when the fuel production plant is located at a distance from the fuel user so that material cannot be mechanically conveyed between the two facilities. The transfer trailer concept employs essentially all the mechanisms used in the conventional transfer station. The fuel is conveyed to the compaction unit which loads it into the transfer trailer. The compaction unit has a surge hopper that is sized to permit continuous infeed while transfer trailers are being changed. The transfer trailer is then towed to the fuel user by a tractor. At the fuel user, the trailer is unloaded into a delumping surge hopper which feeds a pneumatic conveyor to the boiler. The principal. advantage of this system is that it uses proven high reliability components. The primary disadvantage is that it requies a great deal of capital investment in rolling stock.

\section{FERROUS SEPARATION}

\section{Multistage Magnet}

The multistage magnet (Figure 59) is an underfed belt magnet that employs two or more separate magnets, usually with air spaces and reverse polarity, to recover the magnetics and reject contaminants. These magnets are essentially short, flat belt conveyors with individual magnets mounted between the head and tail pulleys. The magnet is mounted over the feed conveyor near its head pulley. A combination of magnetic flux and the inertia of the dense ferrous materials is applied to recover the ferrous products from the shredded waste.

The unique aspect of this design is that it uses air gaps and reverse polarity magnets to reduce the contaminant level. The ferrous material and the "tagalong" contaminants are separated by a flipping action that occurs when they reach the air gap section of the magnet. At this point the ferrous particle falls away from the magnet, but its forward momentum keeps it close to the magnet so that the next stage will reattract it. During the separation the reverse polarity of the next magnet causes the ferrous material to rotate 180 degrees before reattachment. This action helps the tagalong contaminants to separate from the ferrous material. The principle advantages of this system are good material recovery, high product quality, and capital and operating costs that are slightly lower than the drum magnet system.

\section{Drum Magnet}

The drum magnet (Figure 60) employs two drum magnets in series to recover ferrous material while achieving a low contamination leve1. The drum magnets use fixed magnets mounted inside the rotating, abrasion resistant 


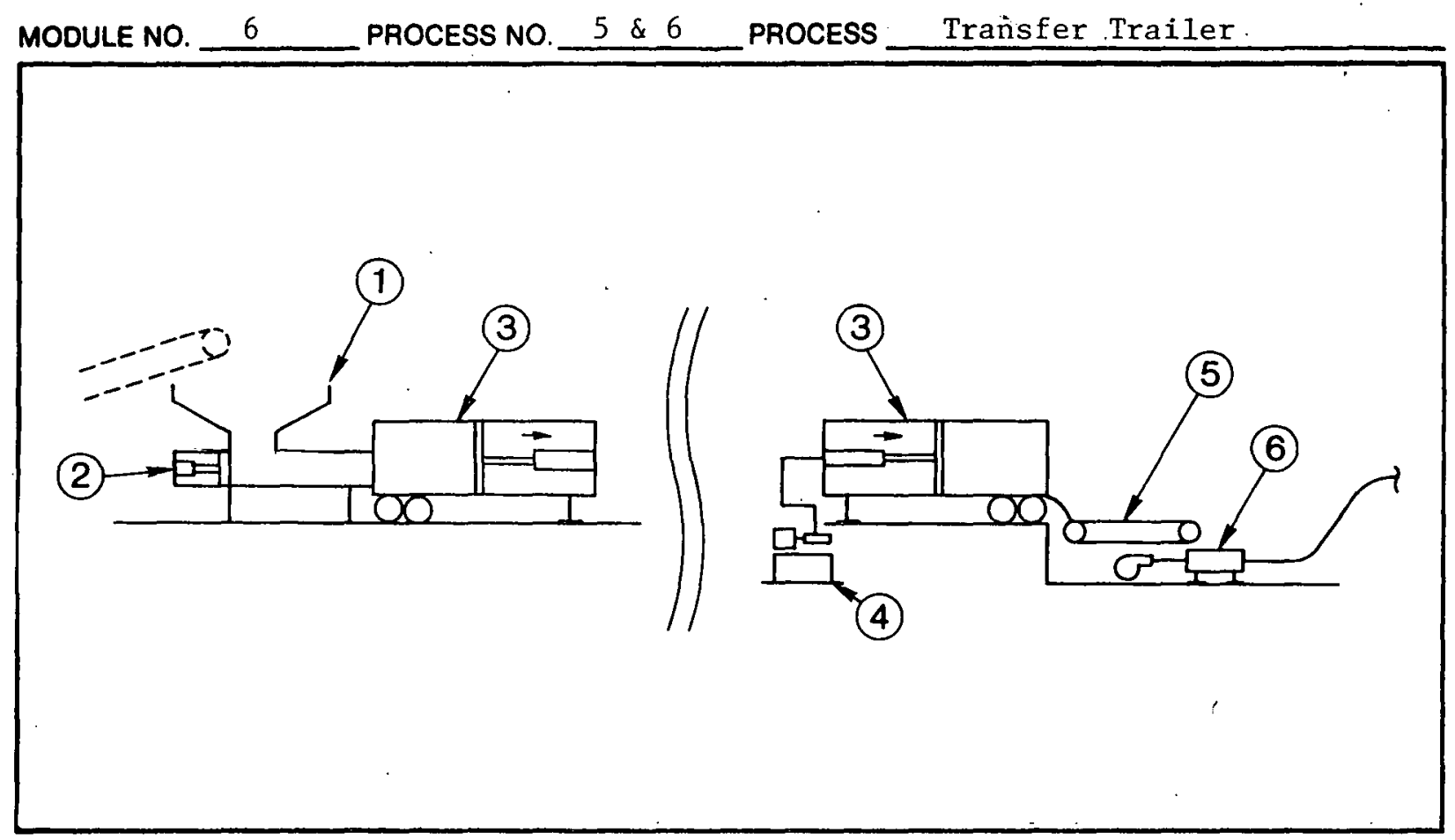

COMPONENT LIST
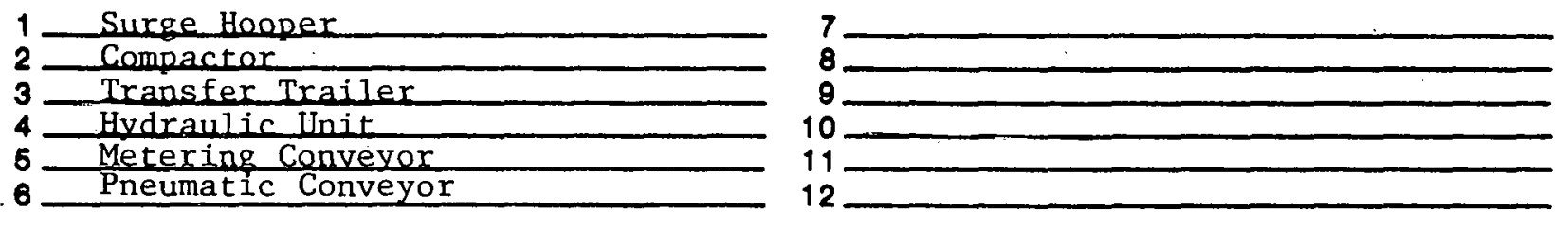

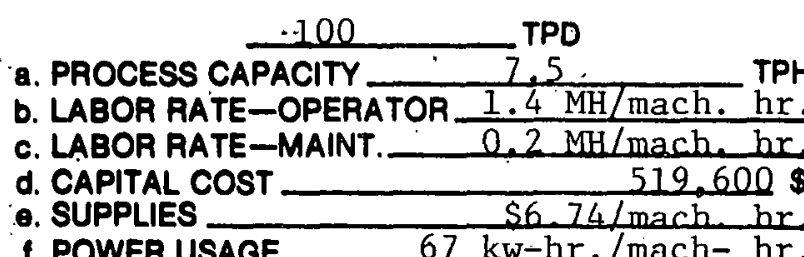

a. PROCESS CAPACITY TPD

b. LABOR RATE-OPERATOR 1 \& MH $/ \mathrm{mach}_{\mathrm{hr}}$

c. LABOR RATE-MAINT. O $3 \mathrm{MH} / \mathrm{mach} \mathrm{hr}$

d. CAPITAL COST $831,900 \$$

$\theta$. SUPPLIES

f. POWER USAGE \$11.47/mach hr.

f. POWER USAGE _ $67 \mathrm{kw}-\mathrm{hr}$. /mach- hr.

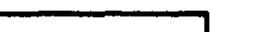
$87 \mathrm{kw}-\mathrm{hr} / \mathrm{mach} . \mathrm{hr}$

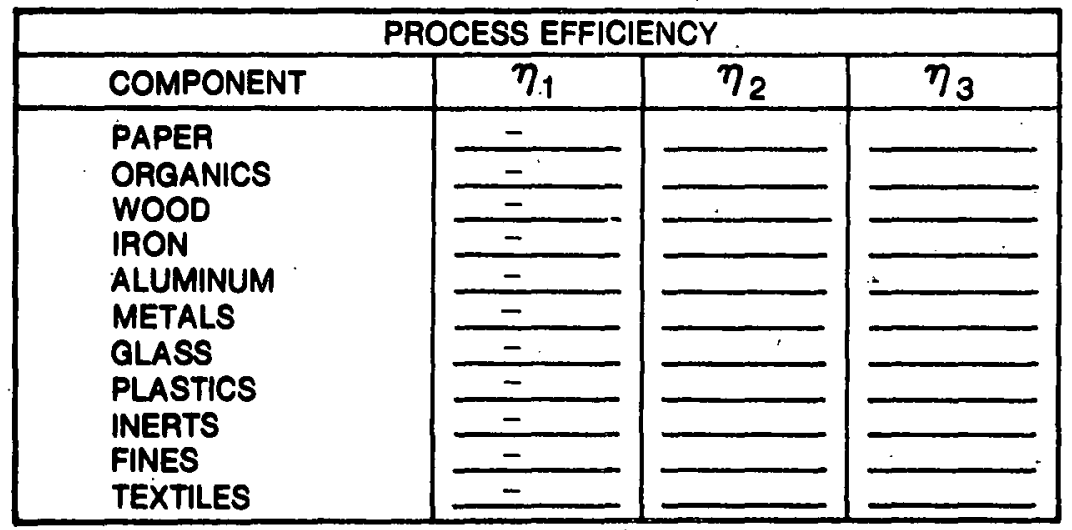

Figure 58. Transfer trailer schematic and operational data. 

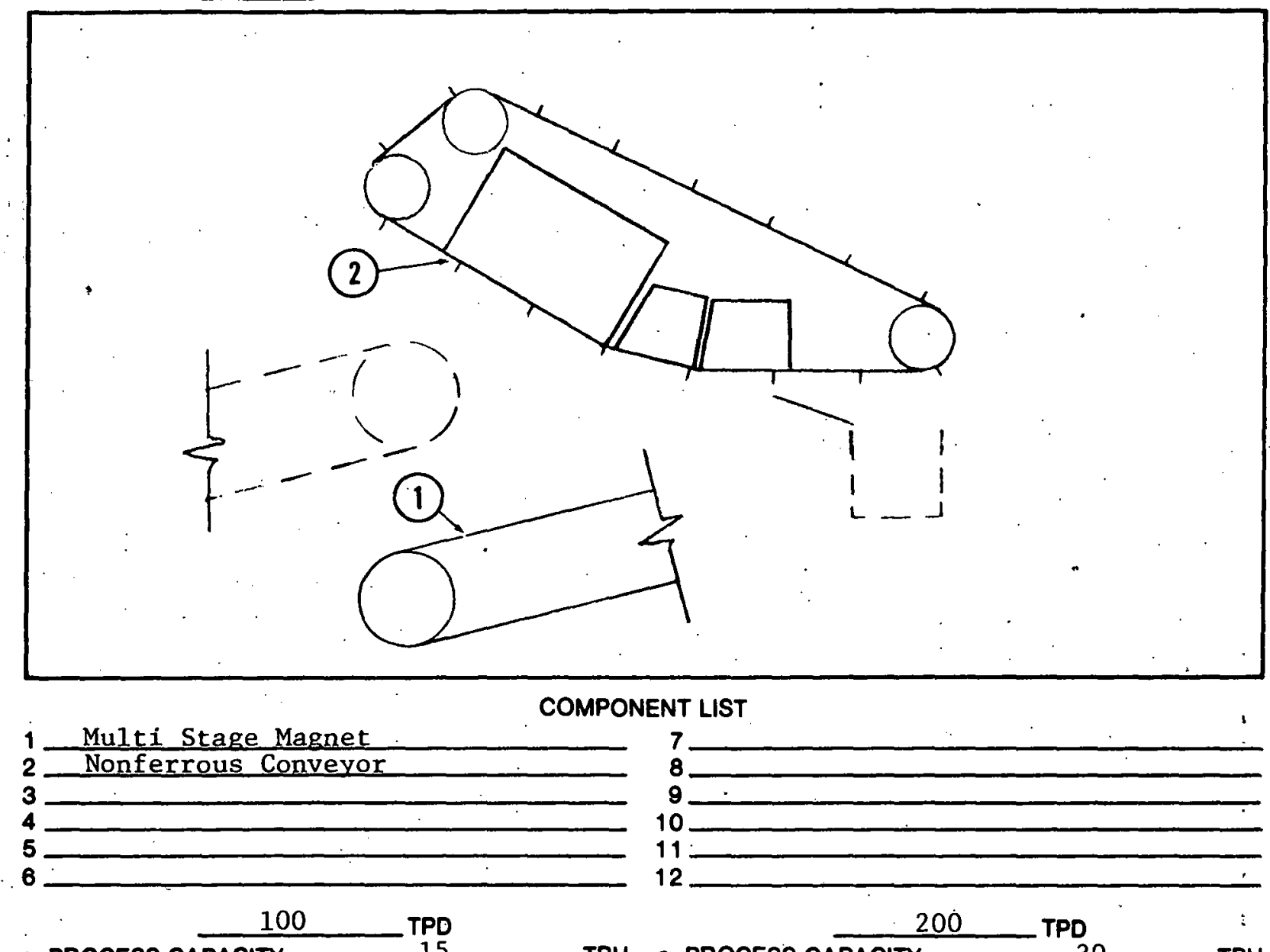

a. PROCESS CAPACITY $-15 \quad$ TPH

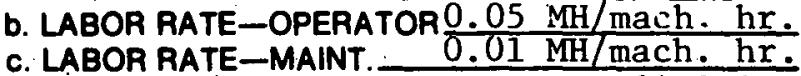

d. CAPITAL COST $64,300 \$$

Q. SUPPLIES

$\$ 1.00 / m a c h . h r$.

f. POWER USAGE $18 \mathrm{kw}-\mathrm{hr}$./mach: hr.

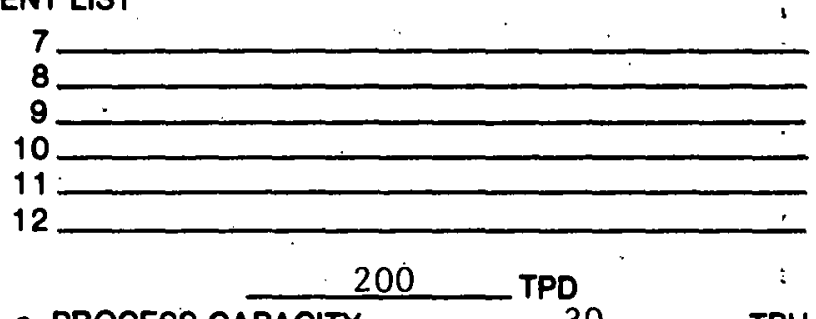

a. PROCESS CAPACITY b. LABOR RATE-OPERATORO 05 MH/mach. hr. c. LABOR RATE-MAINT. 0.01 NH/mach. $h r_{\text {. }}$ d. CAPITAL COST e. SUPPLIES $\$ 1.10 / \mathrm{mach} . \mathrm{hr}$. f. POWER USAGE $18.1 \mathrm{kw}-\mathrm{hr}$. /mach. $\mathrm{hr}$.

\begin{tabular}{|c|c|c|c|}
\hline \multicolumn{4}{|c|}{ PROCESS EFFICIENCY } \\
\hline COMPONENT & $\overline{\eta_{1}}$ & $\eta_{2}$ & $\overline{\eta_{3}}$ \\
\hline $\begin{array}{l}\text { PAPER } \\
\text { ORGANICS } \\
\text { WOOD } \\
\text { IRON } \\
\text { ALUMINUM } \\
\text { METALS } \\
\text { GLASS } \\
\text { PLASTICS } \\
\text { INERTS } \\
\text { FINES } \\
\text { TEXTILES }\end{array}$ & $\begin{array}{l}0.005 \\
0.001 \\
0 \\
0.95 \\
0.01 \\
0 \\
0 \\
0 \\
0 \\
0.01 \\
0 \\
\end{array}$ & $\begin{array}{l}0.995 \\
0.999 \\
1.0 \\
0.05 \\
0.99 \\
1.0 \\
1.0 \\
1.0 \\
1.0 \\
0.99 \\
1.0 \\
\end{array}$ & 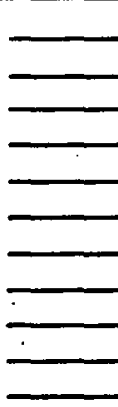 \\
\hline
\end{tabular}

Figure 59. Multistage magnet schematic and operational data. 
MODULE NO.

7 PROCESS NO. $1 \& 2$

PROCESS

Drum Magnet
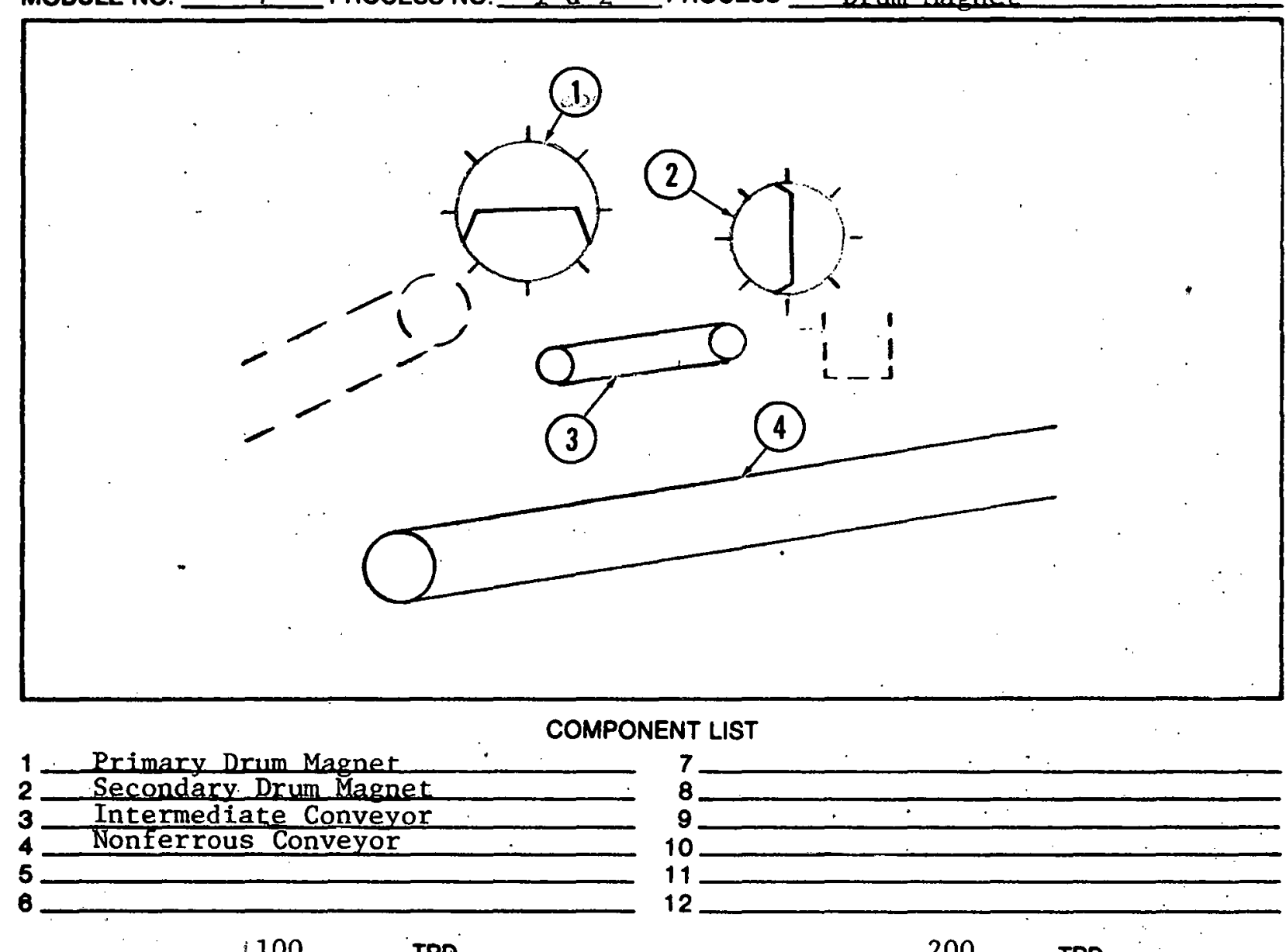

a. PROCESS CAPACITY 15 TPH a. PROCESS CAPACITY 15 b. LABOR RATE-OPERATOR $0.05 \mathrm{MH} / \mathrm{mach} \mathrm{hr}$. b. LABOR RATE-OPERATOR $0.05 \mathrm{MH} / \mathrm{mach}$. hr. c. LABOR RATE-MAINT. $0.02 \mathrm{MH} / \mathrm{mach}$. hr. c. LABOR RATE-MAINT. 0.02 M/mach, he d. CAPITAL COST_ $87,800 \$$ d. CAPITAL COST 92800 \$

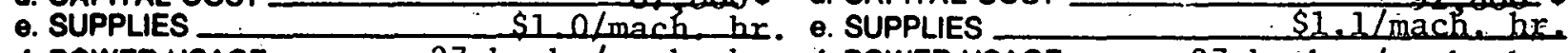
f. POWER USAGE $\quad 27 \mathrm{kw}-\mathrm{hr} / \mathrm{mach} . \mathrm{hr}$. f. POWER USAGE $27 \mathrm{kw}-\mathrm{hr} / \mathrm{mach} . \mathrm{hr}$

\begin{tabular}{|c|c|c|c|}
\hline \multicolumn{4}{|c|}{ PROCESS EFFICIENCY } \\
\hline COMPONENT & $\eta_{1}$ & $\eta_{2}$ & $\eta_{3}$ \\
\hline $\begin{array}{l}\text { PAPER } \\
\text { ORGANICS } \\
\text { WOOD } \\
\text { IRON } \\
\text { ALUMINUM } \\
\text { METALS } \\
\text { GLASS } \\
\text { PLASTICS } \\
\text { INERTS } \\
\text { FINES } \\
\text { TEXTILES }\end{array}$ & $\begin{array}{l}\frac{0.005}{0.001} \\
0.05 \\
0.95 \\
0.01 \\
0 \\
0 \\
0 \\
0.01 \\
0 \\
\end{array}$ & $\begin{array}{l}0.995 \\
0.999 \\
1.0 \\
0.05 \\
0.99 \\
1.0 \\
1.0 \\
1.0 \\
1.0 \\
0.99 \\
1.0 \\
\end{array}$ & \\
\hline
\end{tabular}

Figure 60. Drum magnet schematic and operational data. 
drum. The magnets have a flux arc of approximately 180 degrees with the magnets typically aligned as shown in the figure.

The drum magnet system is mounted outboard of and below the head pulley of the infeed conveyor. As the shredded refuse drops off of the infeed conveyor, the magnetic materials are picked up by the first drum magnet. The entrapped magnetic materials are conveyed on the drum through an arc until they leave the magnetic flux of the magnet and are dropped on an intermediate conveyor. The intermediate conveyor feeds a secondary drum magnet which picks up the ferrous material while leaving the contaminants. The recovered clean. ferrous product is collected in a drop box.

The principal advantage of this system compared to the multistage. magnet is that it has high process efficlencies. Its disadvantages are primarily that it has slightly higher capital and operating costs.

Performance data on the magnetic separation units are based on vendor claims. Evaluation of unit performance should be accomplished to verify these claims.

\section{BUILDING AND FACILITIES}

To complete the cost basis of the various processing options, estimates were made for buildings to house the processing components. These buildings were costed by a square foot approach rather than by specific design. This approach is valid for this study because the most significant concern is the comparative values of the options, rather than their absolute value.

Three different-sized buildings are developed for the systems. Because of the logic built into the computer program, the size of the building is a function of the number of components specified. The break point for each of the building sizes was predicated on the assumption that the small building would only be applied for processes making a coarse RDF, the intermediate size building would be applied when the process includes the production of an air-classified coarse $\mathrm{RDF}$, and the large building is for more refined fuel types. The cost of these buildings does not include the structure or the utilities for either the receiving or storage modules. Because of the variation in space requirements for these modules, the cost of these are included in each of the module component costs.

In addition to the costs for the building shell, foundation, site development, etc., the various square foot costs also include known significant parameters such as controls, ventilation systems, and plant fire detection and suppression systems. Other costs developed separately include electrical. transformers, sprinkler system, truck scales, and site development. When combined, these figures result in a building cost of approximately $\$ 40: a$ square foot. The total building cost was calculated by multiplying this rate by the building size: 5,000 $\mathrm{ft}^{2}$ for a small building, $10,000 \mathrm{ft}^{2}$ for a large building. These costs do not include the price of land. 


\title{
SECTION 5
}

\author{
BIOLOGICAL PROCESSING
}

\section{INTRODUCTION}

Each of the biological conversion processes being considered for application to MSW require some pretreatment of the wastes. Furthermore, there is usually a requirement for the cleanup of the recovered product. There are a limited number of basic bioconversion processes along with limited types of pretreatment processes and a large number of ultimate cleanup techniques (Figure 61). The cleanup procedures generally are product specific and thus can be considered a necessary part of the basic bioconversion process. However, the various pretreatment options can be suitable for several of the basic processes and, in fact, can be combined to work in several different ways. This section, therefore, will discuss the various pretreatment options and will indicate the basic treatment processes for which they are suitable and then will discuss the several basic treatment processes along with the product treatment requirements for each.

The pretreatment processes to be considered include mechanical separation technology for the size reduction and separation of organic and inorganic constituents of the solid waste, enzymatic hydrolysis of cellulose, and acid hydrolysis of cellulose. Obviously mechanical pretreatment is similar to the dry mechanical separation processes discussed in Section 4 of this report.

\section{PRETREATMENT PROCESSES}

\section{Mechanical Size Reduction and Separation}

The most universally required pretreatment processes for bioconversion are the mechanical processes for size reduction and organic separation. Any of the processes discussed in Section 4 are suitable for such pretreatment as long as they result in a product stream that is high in organics and free of most metals and other inert materials.

\section{Enzymatic Hydrolysis of Cellulose to Glucose}

Process Description--

All methods for hydrolyzing the cellulose component of municipal solid waste are important because cellulose is the major cQmponent of the organics in solid waste and it has crystaline portions that aréresistant to biological degradation. The occurrence of lignin in the cellulosic material increases 


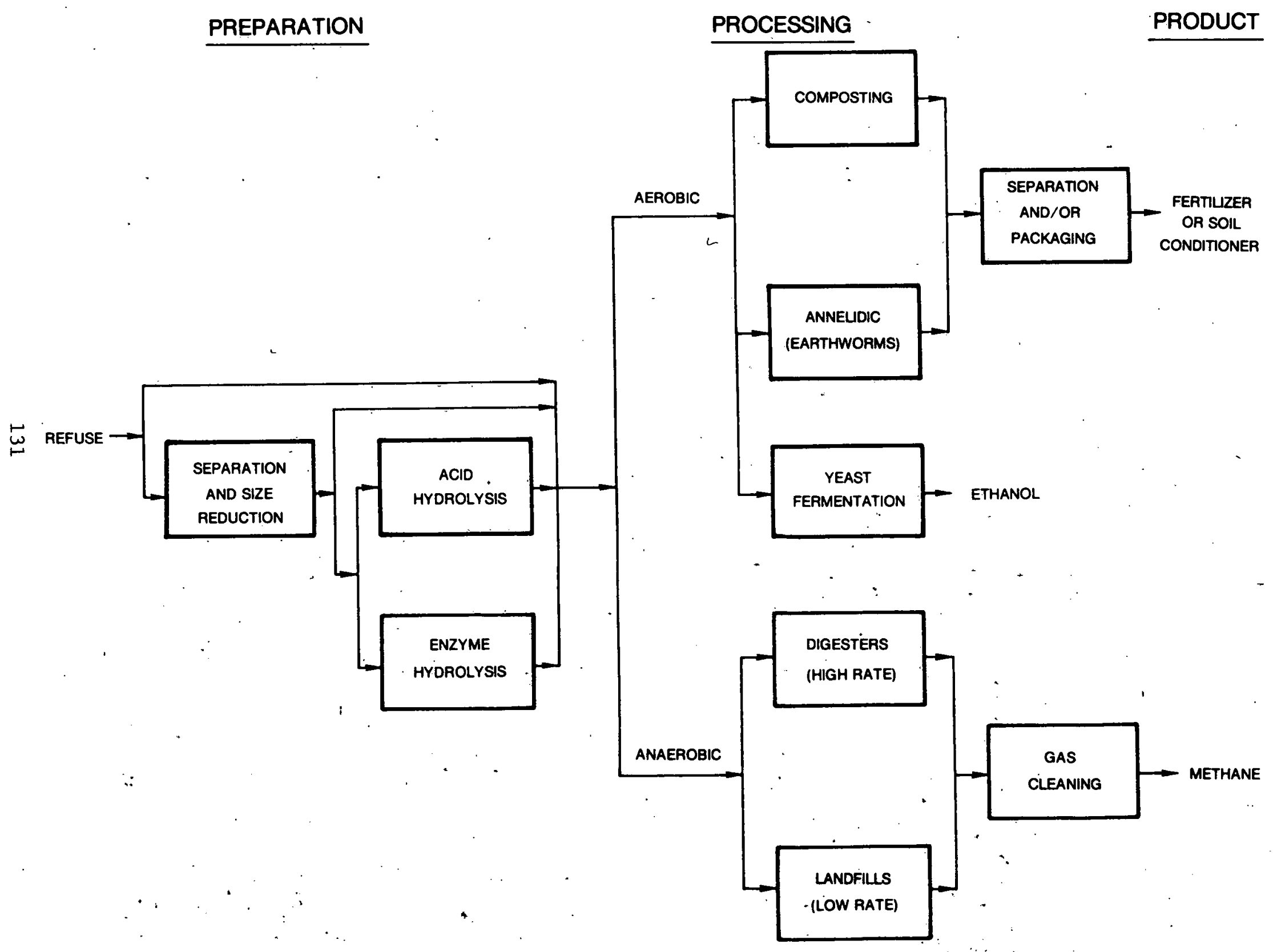

Figure 61. Biological processing systems. 
this resistance. All of the pretreatment methods are aimed at increasing susceptibility of the MSW organics to biological attack.

Native cellulose conversion to glucose occurs in several steps as follows:

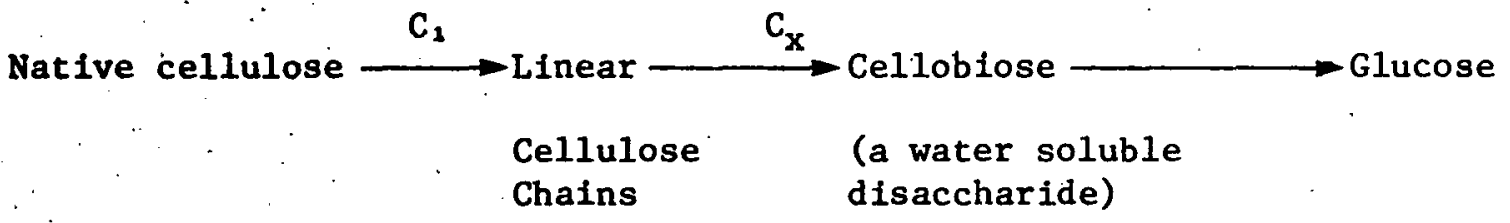

Greatest success has been achieved with enzymes produced by the fungus Trichoderma viride which has a high $C_{1}$ activity. Its cellulase enzymes break down crystaliine and amorphous cellulose to glucose with up to 90 percent efficiency. Process operation should result in conversion of at least 50 percent of the cellulose to glucose in a 24-hour retention time.

Enzyme production is accomplished by growing Trichoderma viride on a nutrient enriched cellulose diet at $25^{\circ}$ to $28^{\circ} \mathrm{C}$ and a controlled $\mathrm{pH}$ in an aerated fermentor. The fungus produces enzymes that are removed by filtration or centrifugation. The enzyme-rich filtrate is fed to a hydrolysis vessel with ball-milled cellulose. The hydrolysis vessel should be maintained at a pH of 4-to 6 and at a temperature around $50^{\circ} \mathrm{C}$. The glucose produced is removed from the unhydrolyzed cellulose by filtration. See Figure 62 .

\section{Cost--}

Reports show production of approximately 25 pounds of glucose for 100 pounds of milled print feed. Process costs range from $\$ .10$ to $\$ .35$ per pound of glucose produced. Then, assuming that each ton of MSW contains 1200 pounds of cellulosics, the gross cost of enzyme treatment per ton of MSW processed would be $\$ 90$.

Research Needs--

1. Optimize process variables, especially $\mathrm{pH}$ and temperature.

2. Develop methods of recovery and reuse: of enzyme-rich broth.

3. Implement pilot-scale operations to better estimate process costs.

Acld Hydrolysis of Cellulose to Glucose

\section{Process Description--}

Acid hydrolysis, while not really a biological process, is included since it is a pretreatment process used in concurrence with biological processes. Acid hydrolysis is accomplished using dilute acid solutions at high temperatures. Bench scale studies have been performed in which cellulosic wastes are heated with 0.5 percent sulfuric acid and sent to a steel tube reactor at $200^{\circ} \mathrm{C}$ for 20 seconds under controlled pressure. The hydrolysis products are cooled in a quencher and collected at $25^{\circ}$ to $30^{\circ} \mathrm{C}$. The efficiency of sugar production by acid hydrolysis is 52 to 54 percent. 


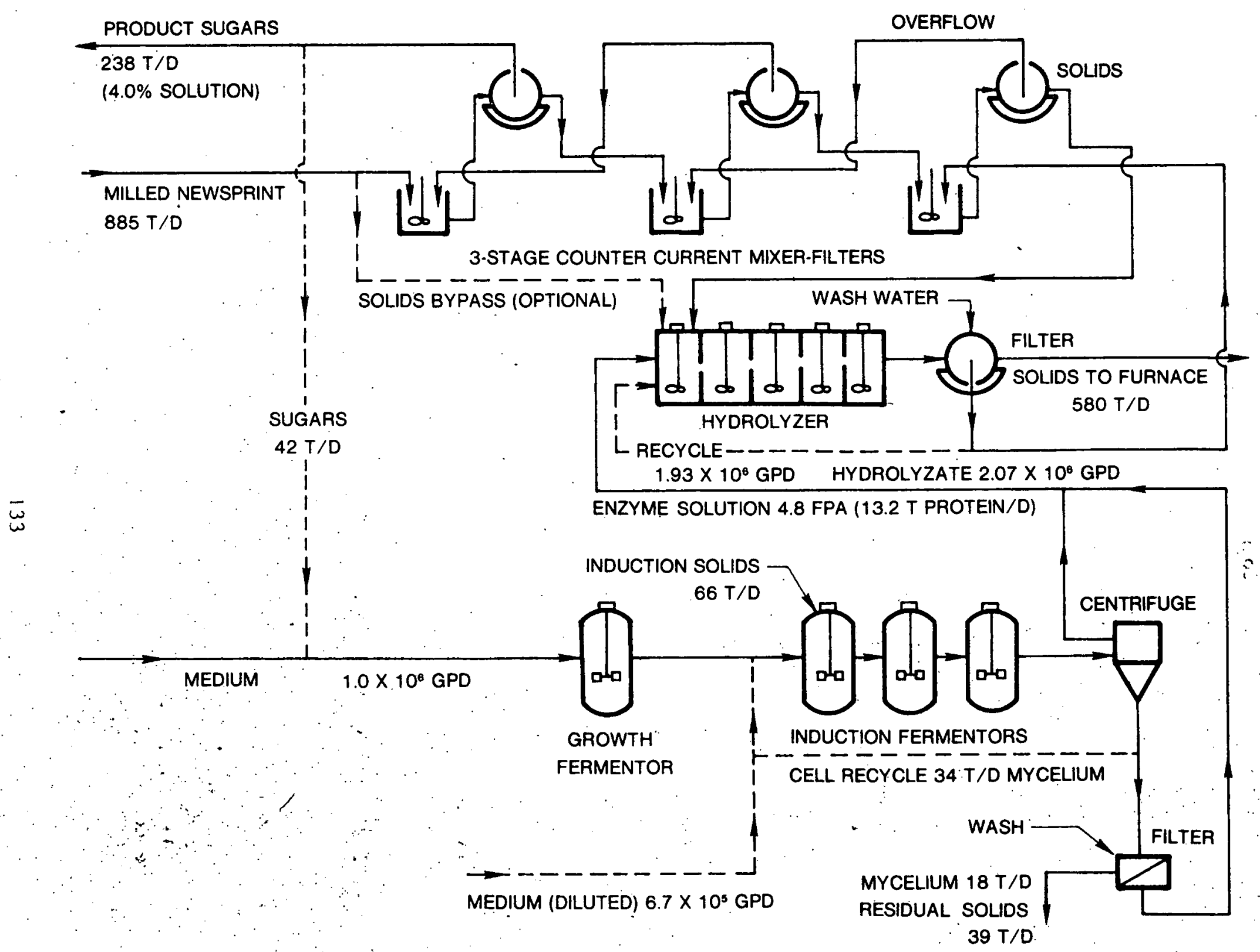

Figure 62. Enzyme hydrolysis process schematic. 
Experience--

New York University is currently scaling up the process from 1- and 5-liter vessels to a 1-TPD demonstration plant utilizing a continuous acid hydrolysis system with 1 percent $\mathrm{H}_{2} \mathrm{SO}_{4}$ solution, temperatures of $220^{\circ}$ to $230^{\circ} \mathrm{C}$, and a reaction time of 10 to 20 seconds.

Cost--

Economics of the whole process have not yet been published: However the researchers project favorable economics based on their in-house calculations.

Research Needs--

1. Extensive 11terature searches into the purported commercial processes utilized earlier in this century (including, if possible, personal contacts with some of the people who engineered or worked on those processes including those currently involved in the paper industry).

2. Bench-scale studies of these processes to ascertain their validity when applied to the contaminated cellulose as it exists in municipal solid waste.

3. Extensive cost study to ascertain the economics of these processes today.

PRINCIPAL METHODS OF BIOCONVERSION OF MSW

Aerobic Bioconversion

Composting--

Composting is a process in which microorganisms break down organic matter to a humus-like material and carbon dioxide. The substrate exists mainly as solid particles with pore spaces rather than as a liquid slurry. The biological decomposition can occur anaerobically or aerobically, however aerobic processes are much more widely used. Therefore this discussion will refer to aerobic composting.

As with any biological system, composting requires several environmental conditions for proper decomposition to occur. The nutritional balance influences the time required for waste stabilization. Carbon-to-nitrogen ratios ranging from 20:1 up to $30: 1$ are desirable. The carbon-to-nitrogen ratio of municipal solid waste is generally about $60: 1$. Therefore dewatered sewage sludge is often mixed with solid waste to provide extra nitrogen. The $\mathrm{pH}$ generally should be about 5 during the early stages of decomposition followed by a rise to a $\mathrm{pH}$ of 8 . Aeration is required to keep the pile aerobic. Moisture content should be 45 to 50 percent. Commercial composting of municipal solid waste involves five steps: preparation, digestion, curing, finishing, and storage. Preparation generally consists of sorting, magnetic separating, grinding, and adding sewage sludge or other nutrients. 
Fairfield-Hardy Experience--

Process Description--Approximately 20 composting plants were in operation in the United States in the late 1950 's to the early $1970^{\prime} \mathrm{s}$, but only a couple of these plants remain in operation. "The Fairfield-Hardy process, operating in Altoona, Pennsylvania, is one of the few composting plants operating in the United States. As shown in Figure 63, municipal solid waste is sorted, crushed, wet pulped with sewage sludge, dewatered to about 50 percent moisture content, and digested. The composting occurs in round digesters equipped with a rotating bridge with augers. The waste enters from the periphery. As the bridge rotates, the augers agitate the material and move it to the center for discharge. A blower and a set of pipes aerate the material. After 3 to 5 days the remaining material is pelletized, dried, and bagged for sale.

The Altoona plant has a capacity of 45 TPD. For each 100 tons of municipal solid waste, 25 tons of sewage sludge (dry solids) can be processed, and 25 to 30 tons of dried humus product is produced. This is sold for $\$ 25$ per ton. Twenty to 25 percent of the incoming refuse consisting of glass, nonferrous metals, and other inorganic materials is currently landfilled. Ferrous metals is recovered and marketed.

Cost--Costs estimated by the Fairfield Engineering Company are $\$ 7.50$ per ton for a 125-TPD plant and $\$ 6$ per ton for a 250-TPD plant. These figures do not include real estate, amortization and interest, and property taxes.

Geochemical/Eweson Experience--

Process Description--A second composting plant at Ambassador College in Big Sandy, Texas, utilizes the Geochemical/Eweson process (Figure 64). Municipal solid waste, with only large metal objects removed, is dumped into a receiving hopper. A, hydraulic ram forces the material into a rotating, three compartment drum digester. Sewage sludge and circulating air are added to provide nutrients, moisture, aeration, and carbon dioxide. The carbonic acid formed dissolves nonwater-soluble nutrients. The material is microbially decomposed by passage through the three zones and is discharged in about 6 days. The material is then screened. The fine material is used as compost, course material is returned to the front.end, and large nondegradeable material is landfilled.

The capacity rating for the Ambassador College plant is 40 TPD. This is composed of 30 TPD of municipal solid waste and 10 TPD of sewage sludge. Twenty to 25 tons of compost are produced from this with 2 to $2-1 / 2$ tons of tailings for landfill. The wet compost is 40 to 45 percent of the volume of the incoming waste. The wet compost has a heat value of 3000 Btu per pound; the dried compost contains 4800 Btu per pound.

Cost--The Geochemical/Eweson process operated at Big Sandy is mechanically simple, requiring very little front-end processing. Thus the manpower, power, and capital costs are low. Estimated cost per ton, exclusive of land, interest, and amortization, is $\$ 5$ to $\$ 6$ per ton based on the 40-TPD plant in Big Sandy, Texas. 


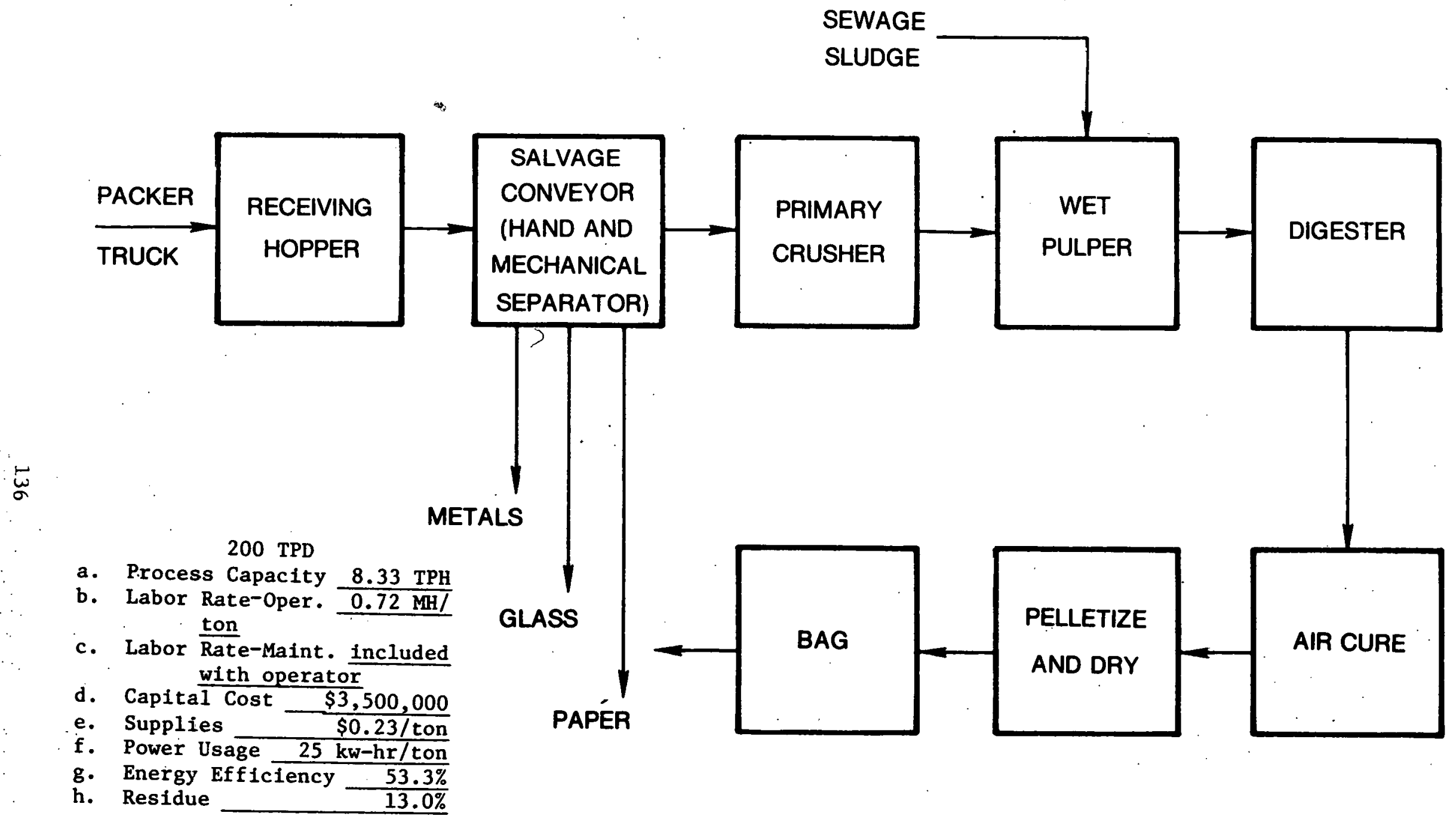

Figure' 63. Fairfield-Hardy digester process flow. 


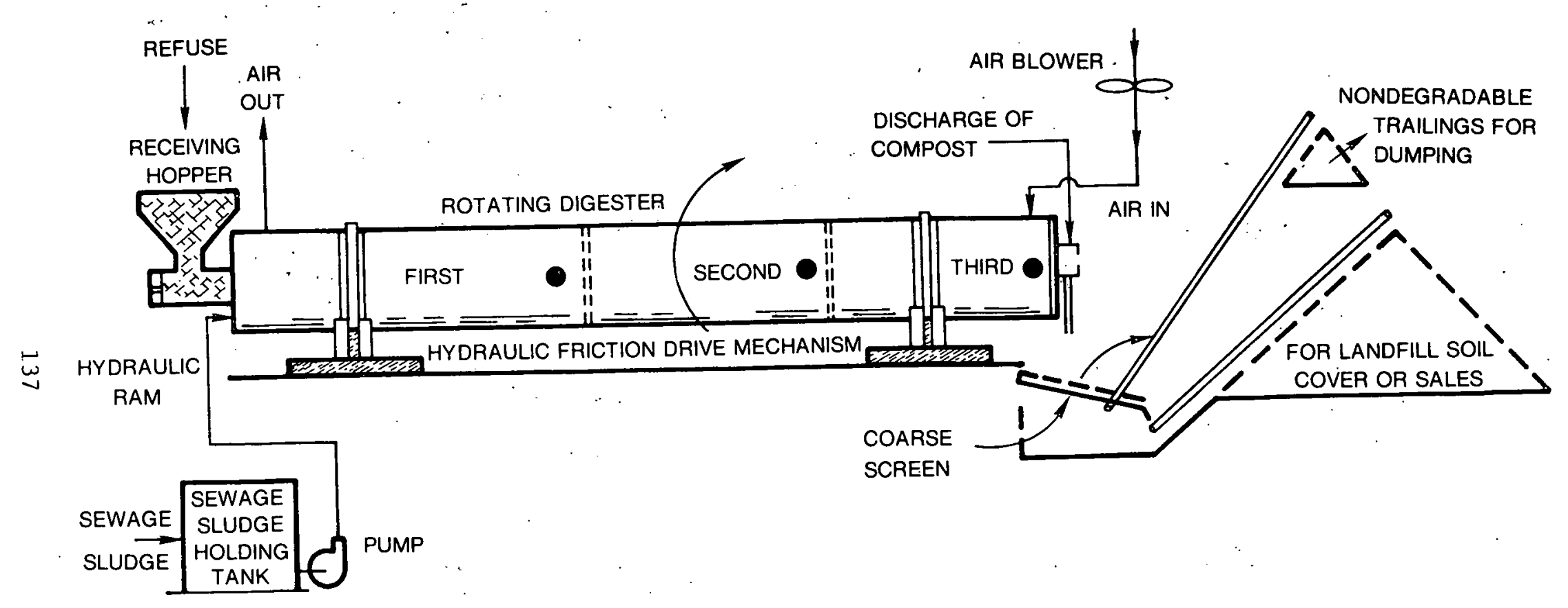

Figure 64. Geochemical/Eweson digester schematic. 
Research Needs--

Extensive bench-scale and demonstration-scale work has been done on composting municipal solid waste. It is felt that no extensive research needs exist in this area since so much work has previously been done and especially in light of the fact that the economics of the process in the United States do not appear profitable in the near- or long-term future.

\section{Conversion to Ethanol}

Procéss Description--

A yeast, Saccharomyces cerevisiae, can be used to aerobically ferment cellulose-derived sugars to ethanol. An 85 to 93 percent ethanol yield has been reported after 20 hours in an $800-\mathrm{m} 1$ fermenter. It is reported in the literature as economically competitive, but the basis for the economic analysis is not presented. Ethanol is the starting point for many other chemicals presently derived from fossil fuels, thus resulting in energy savings. Ethanol-derived chemicals are produced industrially but are generally used internally by the companies that make them. The chemical product syntheses are not discussed in any more detail. They are each separate technologies in themselves and are presented only as a brief summary of the possible uses of the ethanol made from cellulose in municipal solid waste.

\section{Experience--}

The use of yeast fermentation to produce ethanol is as old as civilization. The basic process has been understood since Pasteur. The number of commercial breweries and distilleries in the United States attests to the economic viability of the process.

Research Needs--

1. Assess possible toxicity to the yeasts and bacteria of any contaminants in the refuse-derived sugars.

2. Devise and assess methods of recovery and purification of either the refuse-derived sugars or of the "final" products of protein and/or ethanol.

\section{Anaerobic Bioconversion}

As stated in the introduction, anaerobic decomposition of MSW results in the production of a medium-Btu gas. The fuel gas so produced contains approximately 50 percent $\mathrm{CH}_{4}$ and 50 percent $\mathrm{CO}_{2}$ with measurable water vapor and traces of $\mathrm{H}_{2} \mathrm{~S}, \mathrm{SO}_{2}$, and volatilized organic acids. The nature of any gas cleanup procedures depends upon the final use of the product fuel gas.

\section{Landfill Gas Recovery}

Process Description--

Landfill gas is collected by a series of wells sunk into the refuse which are connected by collection piping to a suction blower. The wells are made by drilling a hole in which PVC pipe is set. The hole is backfilled around the pipe with 3-in. rock wherever a collection pipe opening exists, and the rest of the space around the pipe is filled with clay. This results 
in cylinders of clay in the refuse with rock-filled spaces creating controlled escape routes for the gas generated in the refuse mass. When the suction blower is used, gas is drawn from the refuse to the rock-filled areas and up the piping. The collected gas can then be "cleaned and used for fuel.

\section{Experience--}

An EPA sponsored project was conducted in Mountain View, California, in which gas was collected from a completed landfill for upgrading and use by a local utility. Southwestern Portland Cement Company in Los Angeles is privately collecting landfill gas for sale. Reserve Syn Fuels is also collecting and upgrading landfill gas for sale as a high-Btu fuel at Palos Altos, California.

These projects successfully demonstrate the technical and economic feasiblity of the process.

\section{Cost--}

The total cost estimate for collection, compression, and treatment of landfill gas is $\$ 1.94$ per million Btu (MMBtu). A significant portion of this cost is in gas cleanup. The most economically attractive means of treating. landfill gas to produce a dried gas of about $500 \mathrm{Btu} / \mathrm{scf}$ are molecular seive dehydration and treatment with triethylene glycol (TEG). According to Pacific Gas and Electric, the estimated costs are $\$ 0.31$ per MMBtu for molecular sieve dehydration to $\$ 0.50$ per MMBtu for TEG treatment.

Research Needs--

Design and operation of landfills specifically for gas recovery.

\section{Anaerobic Digesters}

\section{Process Description--}

The anaerobic digestion process occurs in two basic steps, acidogenesis and methanation. These functions are carried out by two sets of microorganisms, generally referred to as the acid formers and the methane formers. The acid formers are saprophytic, facultative bacteria which secrete extracellular enzymes into the liquid medium. The enzymes hydrolyze and liquify the volatile solids. The soluble organic compounds are then absorbed and converted by the bacteria to simpler compounds, generally organic acids. Note that waste stabilization has not yet occurred, only a change in the form of the organic substrate. This is a necessary step, however, for digestion of all solid organic materials. The strictly anaerobic, methane-forming bacteria utilize the organic acids as a food substrate and break them down to methane and carbon dioxide.

The methane formers are more efficient than the acid formers (especially $\mathrm{pH})$ at different environmental conditions. Historically, digestion has most often been accomplished in one vessel operated at optimum conditions for the more fastidious methane formers. Most recent work has been focused on separating the two types of bacteria into two vessels, each operated at optimum environmental conditions and retention times. 
Experience--

The research involving digestion of municipal solid waste portions is relatively recent. Results from lab-scale studies have shown that hydrolysis of cellulose fibers is the rate limiting step in anaerobic digestion of cellulose. In addition, normal wastewater treatment operation does not provide adequate mixing of municipal solid waste slurries. Scum layer formation occurs readily, resulting in decreased cfficiency due to loss of effective volume. Grit and glass in the waste stream causes excessive wear on equipment.

Full-scale operation of a digester using MSW mixed with sewage sludge as a substrate has been performed by SYSTECH. Results on a 100,000-gallon vessel verify those obtained from lab-scale research. The most recent results indicate that 4 percent total solids feedstock can be adequately mixed and digested. However power consumption is high, and economics may not be extremely favorable.

The Department of Energy is sponsoring a large-scale experimental facility for production of methane from urban solid waste in Pompano Beach, Florida. Currently beginning operation, the site has two digesters with a total capacity of 700,000 gallons and is capable of handling 50 to $100 \mathrm{TPD}$, according to the conceptual design. The digesters are equipped with mechanical agitators for mixing. Startup is scheduled for late 1977 to early 1978.

\section{Cost--}

A recent economic analysis and conceptual design of biogasification of municipal solid waste indicates that the concept may be economically feasible. Using a computer model, preliminary cost estimates have been derived which indicate that large plants in metropolitan areas can produce methane from solid waste at a base-line cost of $\$ 2$ per thousand cubic feet which is equivalent to $\$ 25.51$ per ton of MSW. The process consumes 37.5 percent of the gas produced; the rest is available as a fuel product. The conceptual design flow diagram is shown in Figure 65. SYSTECH's estimates are from $\$ 1.99$ to $\$ 7.57$. per million Btu based on results from the large-scale mixing study.

Reșearch Needs--

1. Full-scale, long-term demonstration of technology including actuai operating economics.

2. Lab-scale and full-scale demonstrations of various process optimization possibilities in combination: acid and enzyme hydrolysis or other pretreatments with one- and two-stage digestion.

3. Lab-scale testing of new concepts such as plug flow digestion or other minimal cost designs.

\section{Annelidic (Earthworms) Processing of MSW}

\section{Process Description--}

Earthworms ingest organic materials and soil, break down the biodegradable matter for food, and excrete the remains as castings. The castings are 


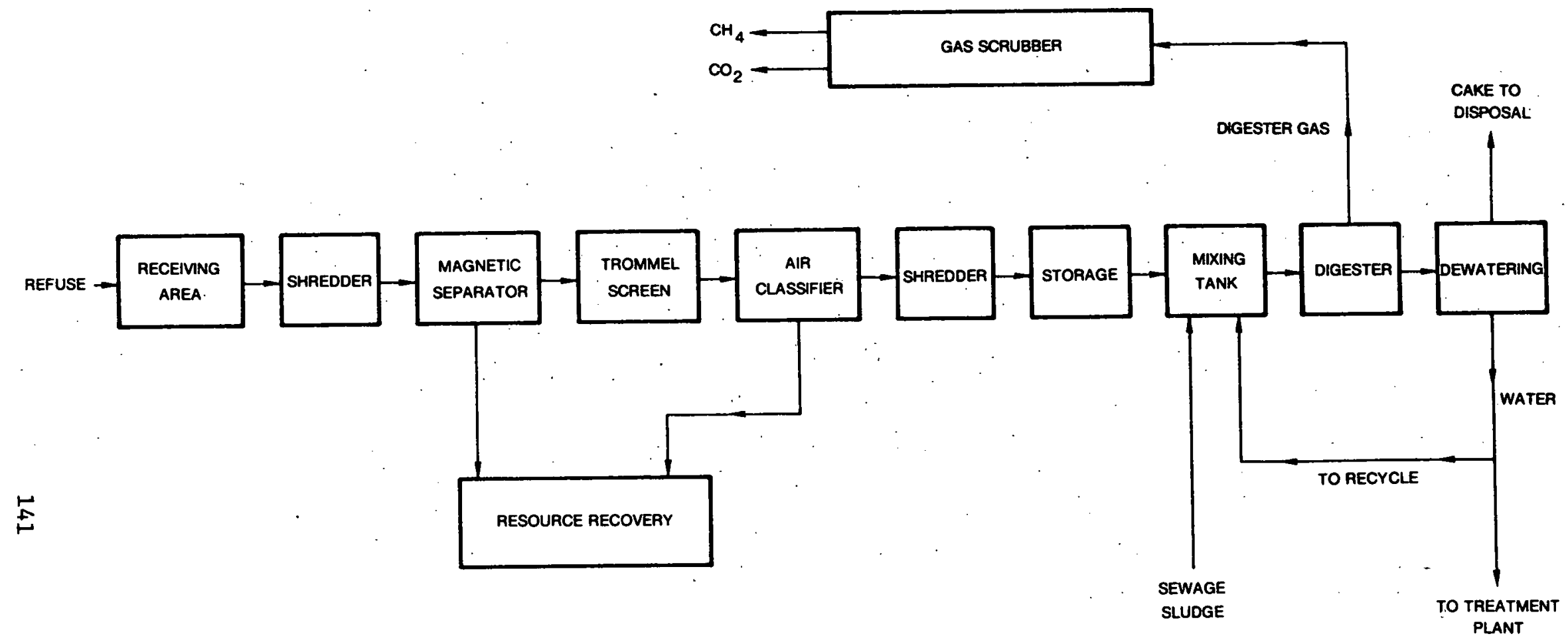

200 TPD

a. Process Capaćity

$8.33 \mathrm{TPH}$

$0.32 \mathrm{MH} /$ ton

c. Labor Rate-Maintenance $0.24 \mathrm{MH} /$ ton

d. Capital Cost $\$ 3,361,000$

e. Supplies

f. Power Usage $430 \mathrm{kw}-\mathrm{hr} / \mathrm{ton}$

$\$ 3.93 /$ ton

g. Energy Efficiency

$31 \%$

Figure 65. Anaerobic digestion process flow diagram. 
an excellent soil supplement with a desirable ratio of nitrogen, phosphate, and potash and are high in soluble minerals such as copper, iron, and zinc. They are a valuable end product with an established market as top soil, potting soil, and a fertilizer additive. Their use on crops increases yields by 40 percent or more.

Two species of earthworms are particularly suited for refuse decomposition: Helodrilus foetidus, commonly found in refuse and manure, and Lumbricus rubellus, a worm of ten found in decaying matter. These worms are raised commercially by many growers and are readily available.

An earthworm can consume up to its own body weight in organic wastes and soil in 24 hours, 8 to 30 percent of which is organic material. At a consumption rate of 10 percent and a doubling time of 60 to 90 days, a worm population at 2000 pounds $(909 \mathrm{~kg}$ ) doubling to 4000 pounds $(1818 \mathrm{~kg})$ in 60 days will consume 17,413 pounds $(7,915 \mathrm{~kg}$ ) of biodegradable substrate. At a doubling time of 90 days, 26,068 pounds $(11,849 \mathrm{~kg})$ of material would be consumed.

- The casting production expected from worm processing of municipal solid waste is approxmately 25 to 30 percent of the weight of the incoming biodegradable matter. Worm digestion of dried sewage sludge (20 percent solids) produces a castings yield of about 35 percent of the weight of the dried sludge. The castings are worth $\$ 25$ per ton sold in bulk or $\$ .05$ per pound sold in smaller quantities.

\section{Experience--}

The practice of using earthworms to degrade wastes is a relatively recent one, particularly as applied to MSW. Several firms grow worms for this purpose, and many more have grown them for years for bait and garden use. One firm has completed a 4-year study documenting test results using municipal refuse, with an equipment study, cost-benefit ratios, and a market survey. However, the report will not be available until mid 1978. A largescale demonstration facility processing MSW does not yet exist in the United States.

\section{Cost--}

The economics presented are based on numbers supplied by a worm digestion service to municipalities. They were calculated for a community generating 200 TPD of MSW for 260 days per year, 80 TPD of which is considered biodegradable substrate for the earthworms. The earthworm processing plant is allowed 1.5 years to bring an initial population of 9 tons of earthworms to the population of 540 tons required to process all the biodegradable matter on a continuing basis. The project requires 75 acres but can be conducted over a closed landfill site if desired. Their data indicate a gross operating cost of $\$ 16.94$ per ton of refuse and a net cost after sale of castings, etc., of \$9. per ton of refuse. 
Research Needs--

1. Identify preprocessing needs and their effect on worm population growth rate.

2. Determine effect of metals and other toxins in refuse on worm survival and reproduction.

3. Determine methods of separating worm protein and castings from undigested refuse.

4. Conduct pilot-scale operation to identify process costs. 
AENCO, Inc., Coinpany Brochure. New Castle, Delaware.

Aluminum Company of America. Company Brochure. Pittsburgh; Pennsylvania.

Andco, Inc., Company Brochure. Buffälo, New York.

Anon., Earthworms and Electrons. Sludge Magazine, Vol. 1, No. 1, JanFeb., 1978,

Anon., Earthworms to Aid Sludge Disposal. Chemical Engineering, Dec. 5, 1977.

Anon., Advanced System Experimental Facility Solid Waste to Methane Gas. Title 1. Preliminary Engineering, Jan., 1976. Prepared for DOE.

Arthur Young \& Company, Interim Progress Report. Contract No. 68-01-3889.

Blanchett, M. J., et al, Treatment and Utilization of Landfill Gas Mountain View Project Feastbility Study. EPA/SW-583, U.S. Environmental Protection Agency, 1977.

Brenner, W.; Rugg, B.; Rogers, C. Utilization of Waste Cellulose for Production of Chemical Feedstocks Via Acid Hydrolysis. In: Symposium Papers from Clean Fuels from Biomass and Wastes, Jan. 25-28, 1977, Orlando, Florida.

Callihan, C. D., Proteins From Waste Cellulose. In: Proceedings of the Eighth Cellulose Conference. I. Wood Chemicals - A Future Challenge. John Wiley and Sons, New York, 1975:.

Carlson, John A, Recovery of Landfill Gas at Mountainview Engineering Site Study. EPA/530/SW-587d. U.S. Environmental Protection Agency, May, 1977.

Century Research, Inc., Company Brochure. Gardena, California.

Combustion Equipment Associates, Company Brochure. New York, New York.

Converse, A. O, et al, Acid Hydrolysis of Cellulose in Refuse to Sugar, and its Fermentation to Alcohol... U.S. Environmental Protection Agency, Grant No. EP-00279. June, 1973.

Diaz, L. F., Trézek, G. J., Biogasification of a Selected Fraction of Municipal Solid Wastes.: Compost Science, March-April, 1977. 
Ecologenics Corp., Company Brochure. Red Lion, Pennsylvania.

Enterprise Company, Company Brochure. Santa Ana, California.

Envirotech Corp., Company Brochure. Belmont, California.

Feldmann, H. F., Syngas Process Converts Waste to SNG. Hydrocarbon Processing, November, 1976, p. 201-205.

Gaden, E1mer L., Jr., et al, Enzymatic Conversion of Cellulosic Materials:

Technology and Applications. John Wiley and Sons, 1976.

Ghosh, S., Klass, D., Two-Phase Anaerobic Digestion. Paper presented at Symposium on Clean Fuels from Biomass and Wastes, Institute of Gas Technology, Orlando, Florida, Jan. 25-28, 1977.

Gossett, J. M., McCarty, P. L., Heat Treatment of Refuse for Increasing Biodegradability. NSF Grant GI-43504. Department of Civil Engineering, Stanford University, 1974.

GRA, Inc., Company Brochure. Wilmington, Delaware.

Healy, J., et al, Heat Treatment of Organics for Increasing Anaerobic Biodegradibility. Quarterly Progress Report, March-May, 1977. U.S. Department of Energy, Washington, D.C.

Ingham County, Michigan and Wheeler Industries, Inc. Proposal to U.S. Department of Energy, Redker-Young Process. Mason, Michigan.

Jarvis, C. E., Swartzbaugh, J. T., Ph.D., Walter, D. K., Wiles, C. C., Evaluation of an Operating, Full-Scale Municipal Solid Waste Blogasification System. Presented at ASME Solid Waste Processing Conference, Chicago, Illinois, May, 1978.

Kemp Reduction Company, Company Brochure. Santa Barbara, California.

Kispert, R. G., et al, Fuel Gas Production from Solid Waste Semi-Annual Report. Dynatech R/D Company, July 31, 1974.

Lawrence, A. W., and McCarty, P. L., Kinetics of Methane Fermentation in Anaerobic Waste Treatment. Department of Civil Engineering, Stanford University, 1967.

Langer, Bernhardt W., Jr., The Earthworm and Resource Recovery. GTA, Inc., Wilmington, Delaware 19801.

Leas Brothers Development Corp., Company Brochure. Columbus, Ohito. Lehigh Forming Company, Inc., Company Brochure. Easton, Pennsylvania. North American Bait Farmis, Inc., Company Brochure. Ontaria, California. 
Pan American Resources, Inc., Company Brochure. Upland, California.

Pfeffer, John T., and Liebman, Jon C., Energy from Refuse by Bioconversion, Fermentation, and Residue Disposal Processes. Presented at Energy Recovery from Solid Waste Symposium, March 13-14, 1975.

Pfeffer, J. T., Increased Loadings on Digesters with Recycle of Digested Solids. Journal of Water Pollution Control Federation, 70, 1920-1933, No. 1968.

Pfeffer, J. T., Reclamation of Energy from Organic Waste. EPA-670/2-74-016. U.S. Environmental Protection Agency, March, 1974.

Pyro Sol, Inc., Company Brochure. Redwood City, California.

Resource Recovery Corp., Company Brochure. Raleigh, North Carolina.

Ross Hofmann Assoc., Evaluation of Small Modular Incinerators. U.S.

Environmental Protection Agency, Washington, D.C., 1976.

Seglin, L. and Combustion Processes, Inc., Preliminary Evaluation of the Simplex

Process. New York, New York, March 31, 1978.

Scientific Energy and Recycling Group, Inc., Company Brochure. Butler New Jersey.

Solid Waste Resources, Ltd., Company Brochure. Eugene, Oregon.

Stanford University, et al, Proposal for A Solid Waste Demonstration Program. Phase I - Preliminary Development Program and System Study. Stanford, California.

Swartzbaugh, Joseph T., Miller, J. W., and Wiles, C. C., Operating Experience with Large Scale Digestion of Urban Refuse with Sewage Sludge. Clean Fuels from Biomass and Waste Symposium, Jan. 25-28, 1977.

Tech Air Corp., Company Brochure. Atlanta, Georgia.

Teknekron, Company Brochure. Berkley, California.

Thermal Processes, Inc., Company Brochure. La Grange, Illinois. $\checkmark$

Titan Environmental Service, Company Brochure. Paramus, New Jersey.

Vista Chemical \& Fiber Corp., Company Brochure. Los Gatos, California.

Wallace Atkins 011 Corp., Company Brochure. Houston, Texas.

Waste Control Service, Company Brochure. Santa Rosa, California.

Watson Energy Systems, Company Brochure. Los Angeles, California. 